\title{
Epidemiologische Untersuchungen zur \\ Toxoplasmose und Identifizierung immunogener parasitärer Antigene
}

\author{
Dissertation \\ zur Erlangung des mathematisch-naturwissenschaftlichen Doktorgrades \\ „Doctor rerum naturalium“ \\ der Georg-August-Universität zu Göttingen
}

vorgelegt von

Andrea Hotop, geb. Hruzik

aus Salzgitter 
Mitglieder des Betreuungsausschusses:

Referent: Prof. Dr. Uwe Groß

Korreferent: Prof. Dr. Gerhard Braus

Tag der mündlichen Prüfung: 07.07.2011 


\section{Inhaltsverzeichnis}

INHALTSVERZEICHNIS

ABBILDUNGSVERZEICHNIS. . V

TABELLENVERZEICHNIS. VII

ABKÜRZUNGSVERZEICHNIS VIII

1

1.1 Der Parasit Toxoplasma gondii.. .1

1.2 Der Lebenszyklus von Toxoplasma gondii ............................................................

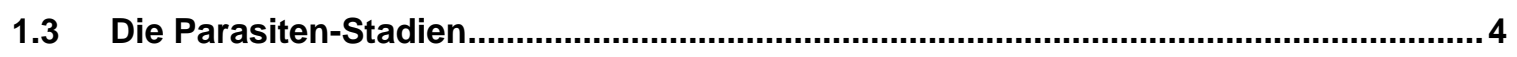

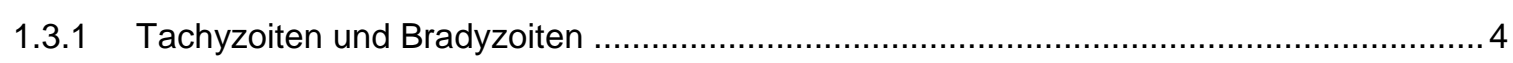

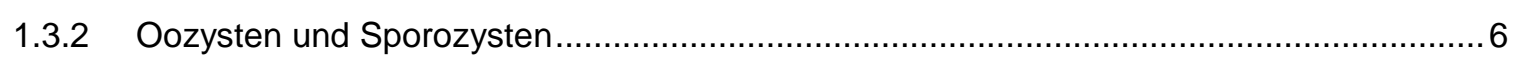

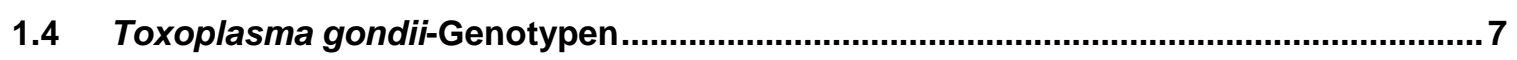

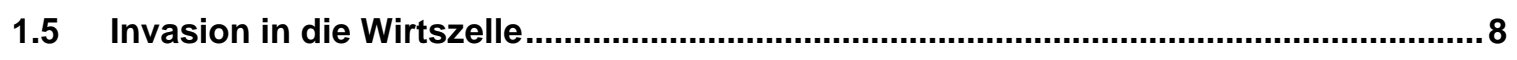

1.6 Die Bedeutung von Nutztieren für die Übertragung von T. gondii auf den

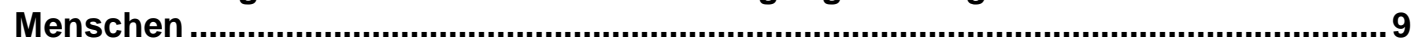

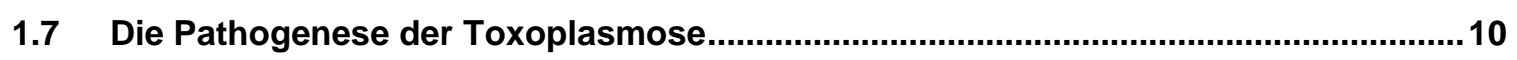

1.8 Die humorale Immunantwort des Wirtes............................................................11

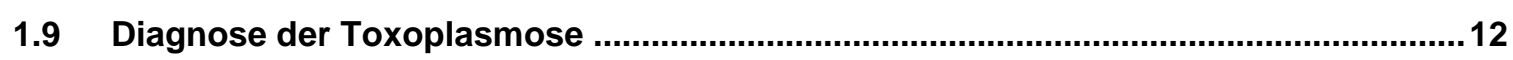

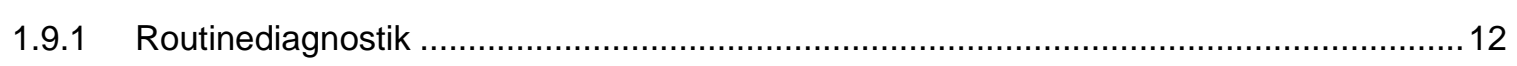

1.9.2 Rekombinante Antigene für die Serodiagnostik ................................................... 14

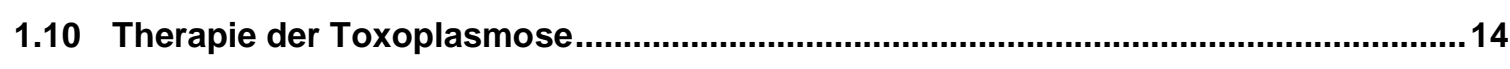

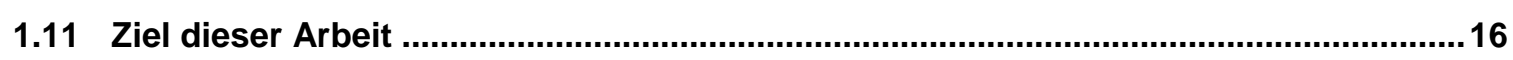

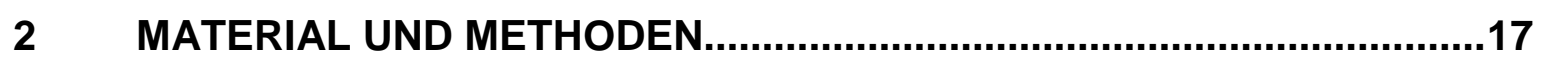

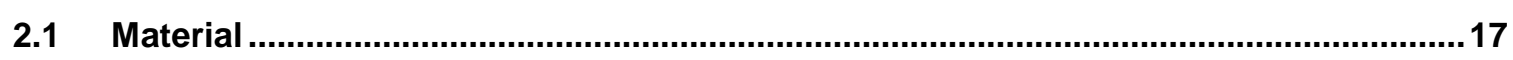

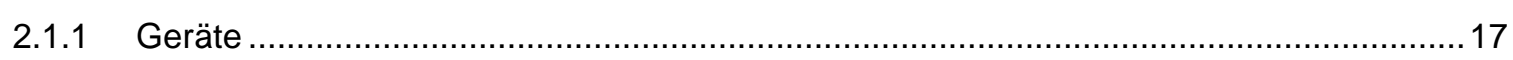

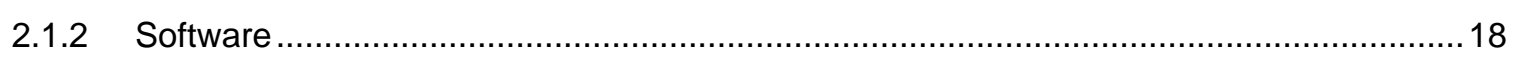

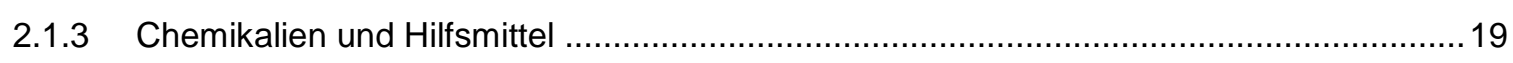

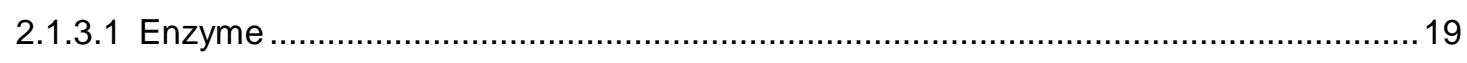

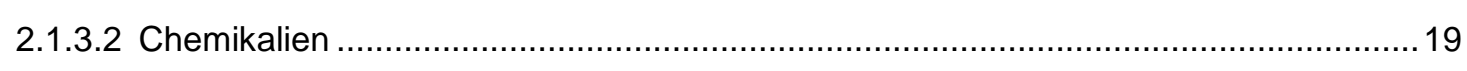

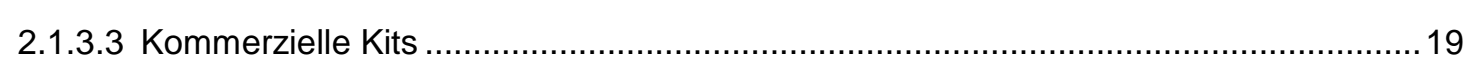

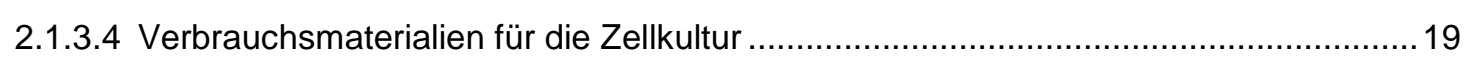




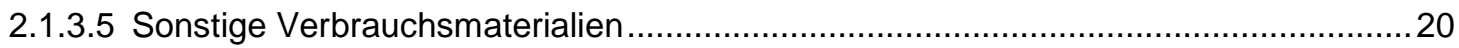

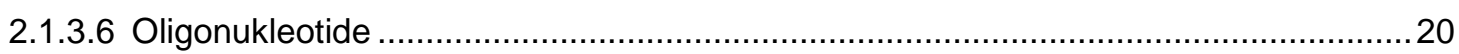

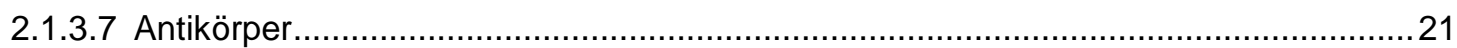

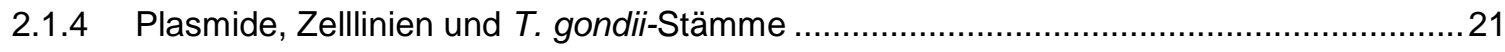

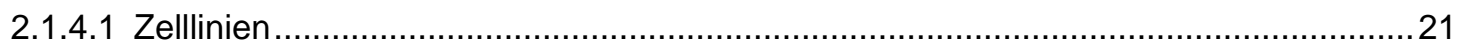

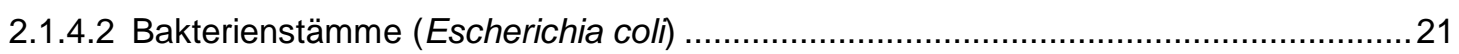

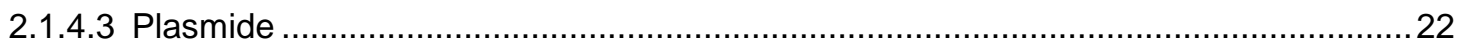

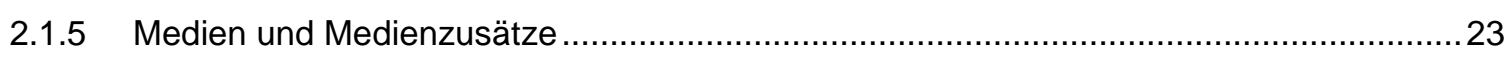

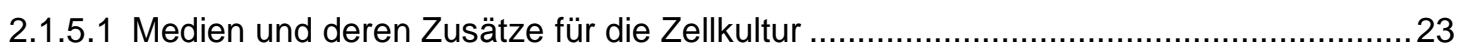

2.1.5.2 Medien und deren Zusätze für die Bakterienkultur ..................................................23

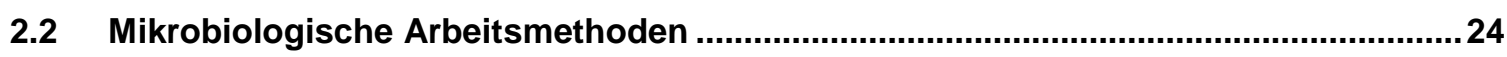

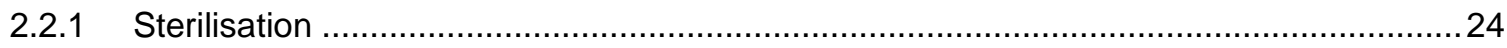

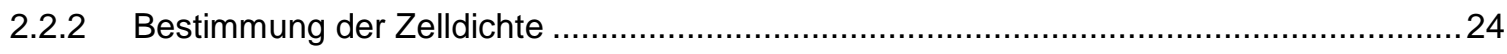

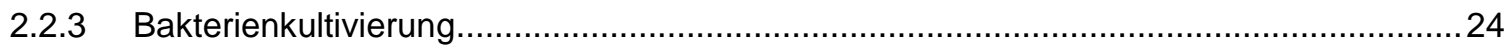

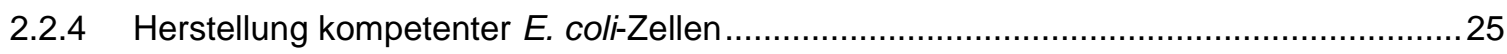

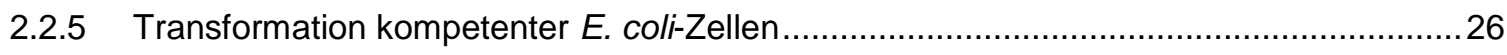

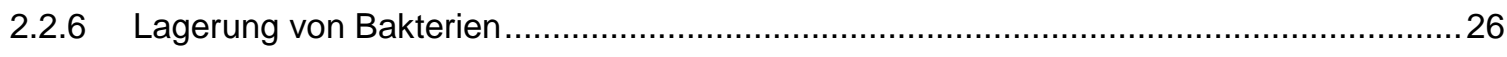

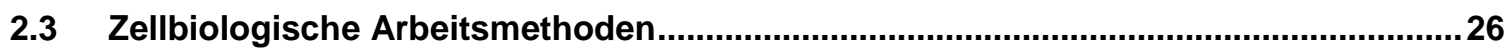

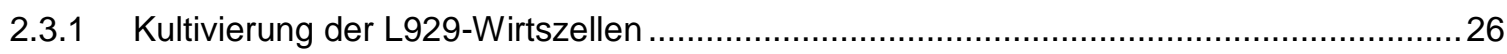

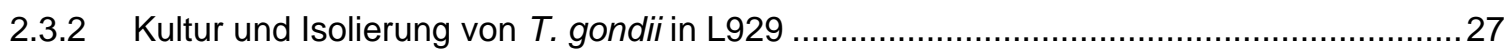

2.3.3 Kultur und Passagierung der humanen Vorhaut-Fibroblasten (HFF) .............................27

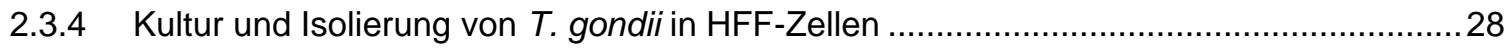

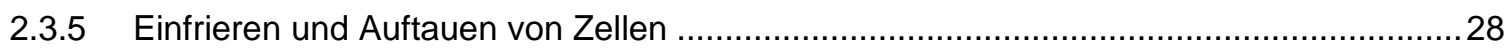

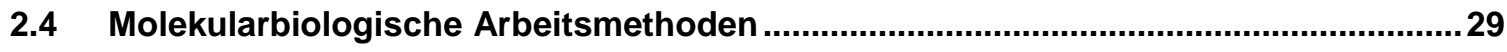

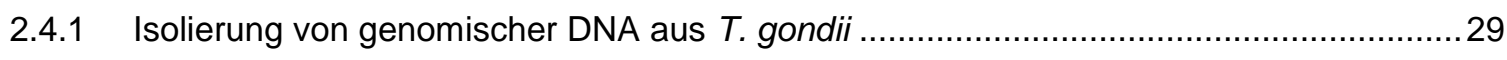

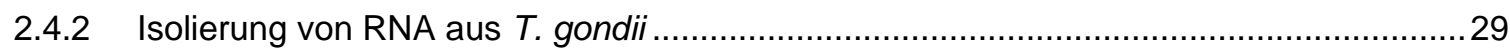

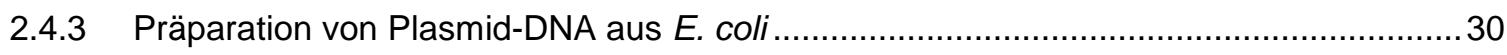

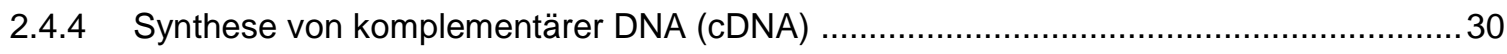

2.4.5 Bestimmung der Nukleinsäurekonzentration ............................................................ 31

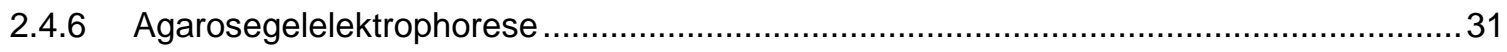

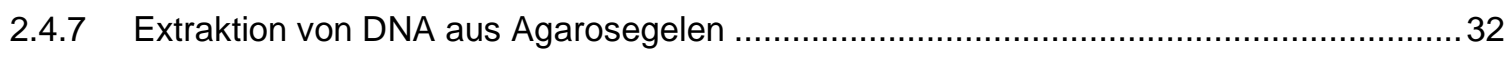

2.4.8 DNA-Amplifikation mittels Polymerase-Kettenreaktion (PCR) …................................... 32

2.4.9 Spalten von DNA mittels Restriktionsendonukleasen ..................................................... 33

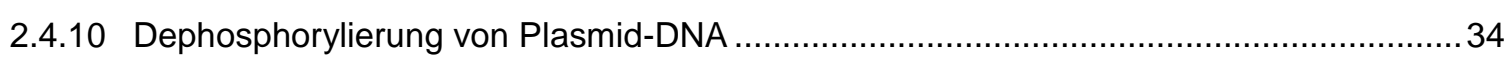

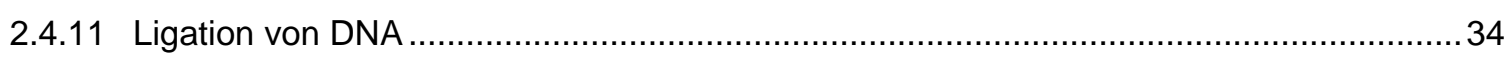

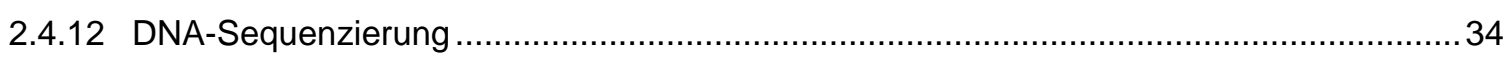

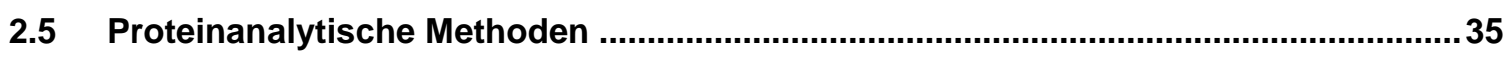




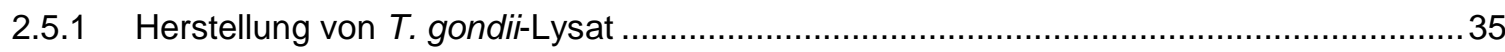

2.5.2 Denaturierende Reinigung von His-Tag fusionierten Proteinen ......................................36

2.5.3 BCA-Assay zur Bestimmung der Proteinkonzentration ................................................. 36

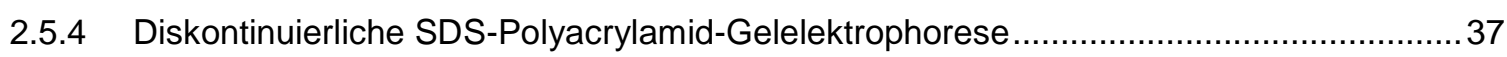

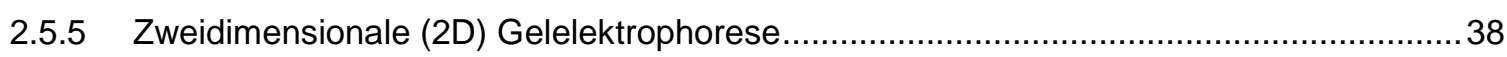

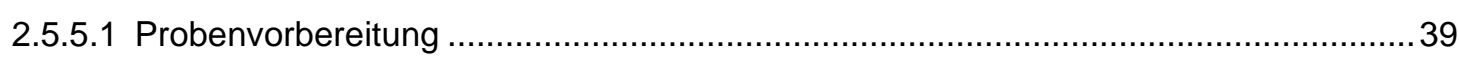

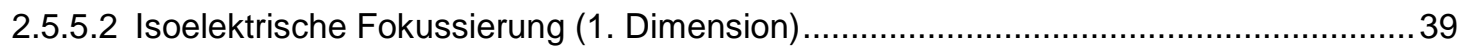

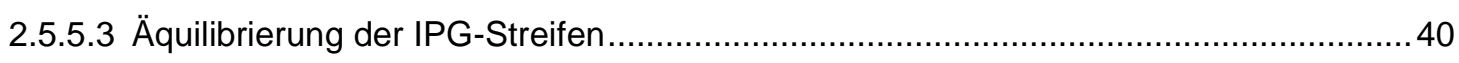

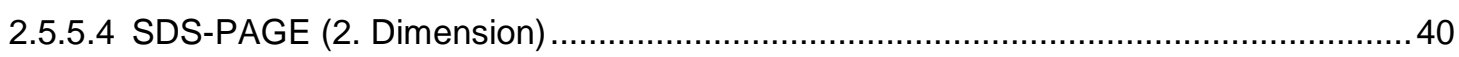

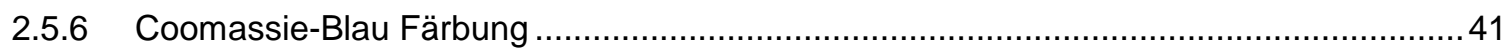

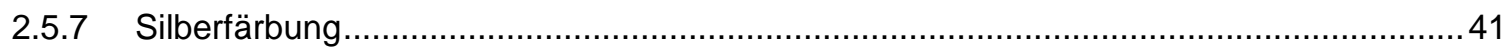

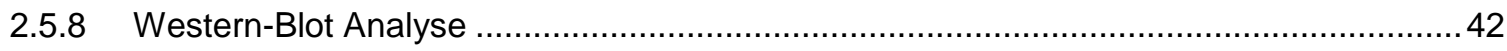

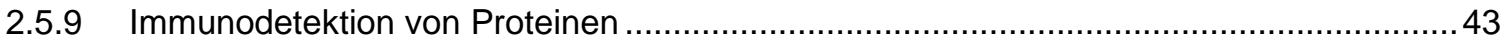

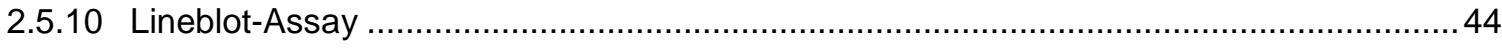

2.5.11 In-Gel Verdau von Silber-gefärbten Proteinen ........................................................ 45

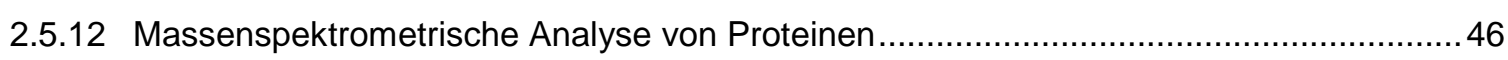

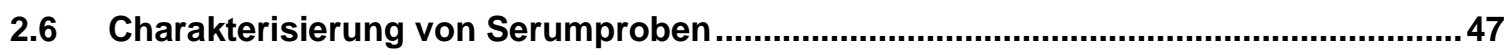

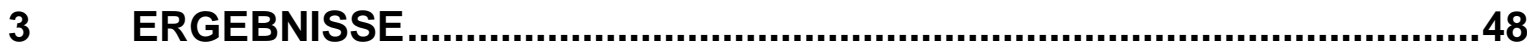

3.1 Epidemiologische Untersuchung zur konnatalen Toxoplasmose .............................48

3.1.1 Ermittlung der Transmission von T. gondii von der infizierten Mutter auf den Fötus .......49

3.1.2 Ermittlung zur Häufigkeit von klinisch-manifesten Erkrankungen bei pränatal

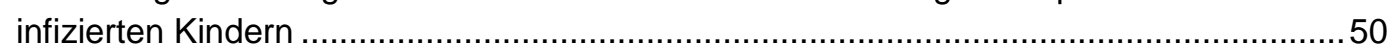

3.1.3 Untersuchung der Toxoplasmose-Therapie in der Schwangerschaft bei Frauen mit

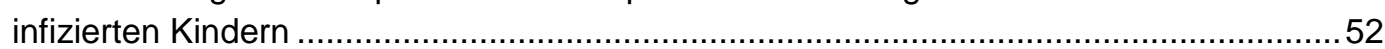

3.2 Identifizierung von parasitären Antigenen, die eine serologische Identifizierung einer akuten Toxoplasmose ermöglichen .............................................53

3.2.1 Isolierung von T. gondii-Antigenen mittels 2D-Gelelektrophorese ..................................53

3.2.2 Identifizierung IgA-immunogener Proteine durch Q-TOF Massenspektrometrie ..............55

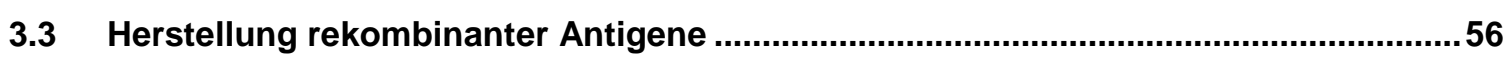

3.4 Evaluierung rekombinanter T. gondii-Antigene als diagnostische Marker für Humanseren

3.4.1 Evaluation der rekombinanten T. gondii-Antigene durch Quantifizierung mit dem Multi Gauge-Programm mit vordefinierten Cut-off Werten ..............................................62

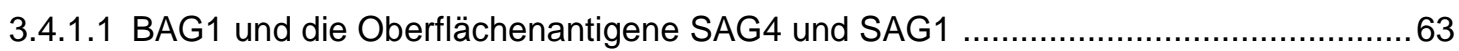

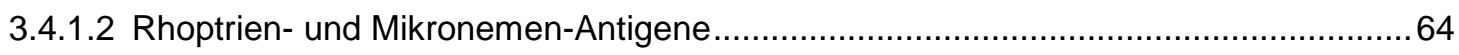

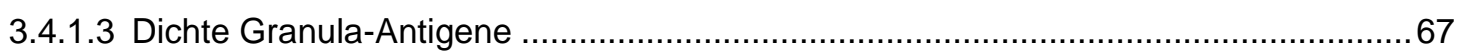

3.4.2 Vergleichende Evaluierung der rekombinanten Antigene durch eine zeitunabhängige Quantifizierung mit dem Multi Gauge- und ImageJ-Programm..............70

3.4.2.1 BAG1 und die Oberflächenantigene SAG4 und SAG1 .........................................73 
3.4.2.2 Rhoptrien- und Mikronemen-Antigene ............................................................ 74

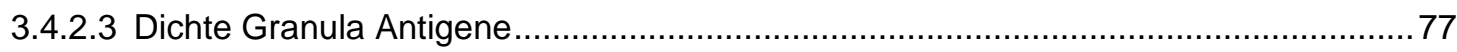

3.5 Evaluierung rekombinanter Antigene für die Diagnose einer Retinochorioiditis bei Toxoplasma-infizierten Patienten.

3.6 Untersuchung der Immunantwort von Nutztieren gegen rekombinante $T$. gondii-Antigene in einem Lineblot-Assay.

3.6.1 Untersuchung der Immunantwort von experimentell mit $T$. gondii-infizierten Puten .........86

3.6.2 Lineblot-Analyse der Immunantwort bei mit Oozysten infizierten Hühnern ....................... 89

3.6.2.1 Reproduzierbarkeit der Lineblot-Assay Ergebnisse ...............................................93

3.6.3 Untersuchung der Immunantwort von Schweinen im Lineblot ......................................94

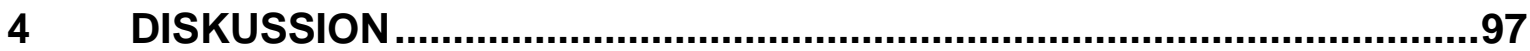

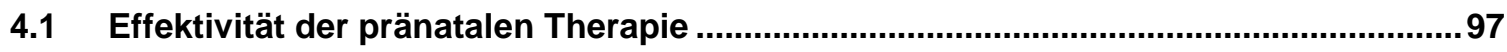

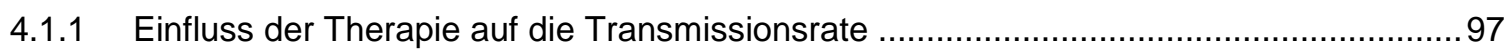

4.1.2 Eine frühzeitig eingeleitete Therapie führt zur Reduzierung von klinischen Symptomen bei einer pränatalen Infektion mit $T$. gondii

4.2 Serodiagnostik der humanen $T$. gondii-Infektion mit Hilfe von rekombinanten Antigenen in einem Lineblot-Assay ....................................................101

4.2.1 Die Auswahl der richtigen Evaluierungsstrategie ................................................... 103

4.2.2 Dichte Granula-Antigene sind nützliche Hilfsmittel für die Diagnose einer

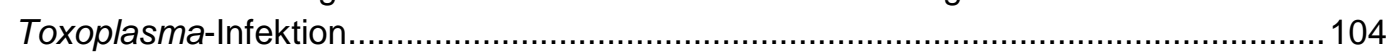

4.2.3 Rekombinante Antigene für den Nachweis einer akuten Infektion ................................107

4.3 Die Anwendung des Lineblot-Assays zur Identifizierung einer Retinochorioiditis.

4.4 Serodiagnostik von Nutztieren mit Hilfe von rekombinanten Antigenen von T. gondii. 


\section{Abbildungsverzeichnis}

Abb. 1.1: Lebenszyklus von Toxoplasma gondii..................................................... 3

Abb. 1.2: Toxoplasma gondii Tachyzoiten und Bradyzoiten ..................................... 5

Abb. 1.3: Toxoplasma gondii Oozyste ...................................................................... 7

Abb. 1.4: Fleischverzehr pro Kopf der Bevölkerung in Deutschland ......................... 10

Abb. 3.1: Übertragung von T. gondii von der infizierten Mutter auf den Fötus. ............50 50

Abb. 3.2: Anzahl infizierter Kinder und infizierter Kinder mit klinischen Symptomen.............................................................................. 51

Abb. 3.3: Immunoblot nach 2D-Gelelektrophorese ................................................ 54

Abb. 3.4: Zweidimensionale Darstellung von T. gondii Tachyzoiten-Proteinen ............ 55

Abb. 3.5: Antigenindex von T. gondii-Antigenen für die Expression in E. coli ............. 58

Abb. 3.6: Reinigung rekombinanter Antigene nach Expression in E. coli über den PQE-30-Vektor

Abb. 3.7: Anteil falsch-positiver Seren unter Verwendung von E. coli/pQE-30 Proteinen im Lineblot-Assay in einer zeitabhängigen Auswertung 63

Abb. 3.8: Emission der Seren bei Verwendung der Antigene rSUB1 und ROP1 ........66

Abb. 3.9: Emission der Seren bei Verwendung der Antigene rGRA1, rGRA2 und rGRA6(RH)

Abb. 3.10: Prozentuale Menge an falsch-positiven Seren unter Verwendung von E. coli-Proteinen im Lineblot-Assay und einem Antigen-spezifischen Cut-off

Abb. 3.11: Emission der Seren bei Verwendung der Antigene rSUB1 und rROP1 .......76

Abb. 3.12: Emission der Seren bei Verwendung der Antigene rGRA1, rGRA2 und rGRA6

Abb. 3.13: Lineblot-Assay mit Seren von Patienten mit und ohne Retinochorioiditis.

Abb. 3.14: Vergleich der Patienten mit und ohne Retinochorioiditis. 83

Abb. 3.15: Antikörperreaktionen gegen rekombinante Antigene, die signifikante Unterschiede zwischen Patienten mit und ohne Retinochorioiditis

Abb. 3.16: Lineblot-Assay mit Seren von experimentell infizierten Puten .... 87

Abb. 3.17: Vergleichende quantitative Auswertung der IgG-Immunantwort von mit Tachyzoiten oder Oozysten infizierten Puten 
Abb. 3.18: Lineblot-Analyse mit Seren von experimentell infizierten Hühnern ...............90

Abb. 3.19: Infektionsdosis-abhängige Immunantwort von Hühnern ............................ 91

Abb. 3.20: Dreidimensionale Darstellung der humoralen Immunantwort von Hühnern gegen definierte Toxoplasma-Antigene .................................... 92

Abb. 3.21: Dreifach-Untersuchung von Hühnerseren im Lineblot ...............................93

Abb. 3.22: IgG-Immunantwort von Schweinen im Lineblot-Assay ............................... 94

Abb. 3.23: Quantitative Auswertung der Antikörperantwort experimentell infizierter Schweine. 95

Abb. 4.1: Aminosäuresequenz des T. gondii GRA6 105

Abb. 4.2: Hypothese zum Anstieg der IgY-Immunantwort des Huhns nach Infektion mit Oozysten 


\section{Tabellenverzeichnis}

Tab. 2.1: Auflistung der verwendeten Geräte mit Modell und Hersteller 17

Tab. 2.2: Auflistung der verwendeten Oligonukleotide. Die Restriktionsschnittstellen sind unterstrichen.

Tab. 2.3: Auflistung der verwendeten E. coli-Stämme. 21

Tab. 2.4: Auflistung der verwendeten Plasmide 22

Tab. 2.5: PCR-Programm zur Amplifikation von DNA-Fragmenten mit TaqPolymerase....

Tab. 2.6: PCR-Programm zur Amplifikation von DNA-Fragmenten mit PfuPolymerase

Tab. 3.1: Auflistung der klinischen Symptome bei pränatal infizierten Kindern 51

Tab. 3.2: Abschätzung des Zeitintervalls vom wahrscheinlichen Infektionszeitpunkt der Mutter bis zum Therapiebeginn ( $N=33)$ 53

Tab. 3.3: Quantifizierung der Immunantwort gegen die rekombinanten $T$. gondii-Antigene BAG1, SAG4 und SAG1 in einem Lineblot-Assay

Tab. 3.4: Quantifizierung der Immunantwort gegen die rekombinanten $T$. gondii-Antigene ROP1, ROP9, MIC5 und SUB1 im Lineblot-Assay

Tab. 3.5: Quantifizierung der Immunantwort gegen die rekombinanten T. gondii GRA-Antigene im Lineblot-Assay....

Tab. 3.6: Quantifizierung der Immunantwort gegen die rekombinanten $T$. gondii-Antigene BAG1, SAG4 und SAG1 über definierte Zeitpunkte.

Tab. 3.7: Quantifizierung der Antikörperreaktivität gegen die rekombinanten $T$. gondii-Antigene ROP1, ROP9 und SUB1 über definierte Zeitpunkte.

Tab. 3.8: Quantifizierung der Immunantwort gegen die rekombinanten T. gondii GRA-Antigene zu definierten Zeitpunkten

Tab. 4.1: Kombination von Antigenen im Lineblot zur Identifizierung einer Toxoplasma-Infektion

Tab. 4.2: Kombination von Antigenen im Lineblot zur Identifizierung einer akuten Infektion 


\section{Abkürzungsverzeichnis}

\begin{tabular}{|c|c|}
\hline${ }^{\circ} \mathrm{C}$ & Grad Celsius \\
\hline A & Ampere \\
\hline AAP & Antarktische Alkalische Phosphatase (Antarctic Phosphatase) \\
\hline Abb. & Abbildung \\
\hline Amp & Ampicillin \\
\hline APS & Ammoniumperoxosulfat \\
\hline AS & Aminosäure \\
\hline$A U$ & willkürliche Einheit (arbitrary unit) \\
\hline BAG & Bradyzoiten-spezifisches Antigen \\
\hline bp & Basenpaare \\
\hline bzw. & beziehungsweise \\
\hline ca. & circa \\
\hline $\mathrm{Cm}$ & Chloramphenicol \\
\hline d & Tag \\
\hline $\mathrm{Da}$ & Dalton \\
\hline DMEM & Dulbecco's Modiefied Eagle Medium \\
\hline DMSO & Dimethylsulfoxid \\
\hline DNA & Desoxyribonukleinsäure (desoxyribonucleic acid) \\
\hline dNTP & Desoxyribonukleotid \\
\hline dpi & Tage nach Infektion (days post infection) \\
\hline DTT & 1,4-Dithio-D,L-threitol \\
\hline EDTA & Ethylendiamintetraacidic acid \\
\hline ELISA & Enzyme-linked Immunosorbent Assay \\
\hline FCS & Fötales Kälberserum (fetal calf serum) \\
\hline g & Ortsfaktor $\left(9.81 \mathrm{~m} / \mathrm{sec}^{2}\right)$ \\
\hline GRA & Dichte Granula Antigen (dense granules antigen) \\
\hline h & Stunde (hour) \\
\hline $\mathrm{HCl}$ & Salzsäure \\
\hline HRP & Meerrettichperoxidase (Horseradish Peroxidase) \\
\hline HSP & Hitzeschockprotein (heat shock protein) \\
\hline $\lg A$ & Immunoglobulin Isotyp A \\
\hline $\lg G$ & Immunoglobulin Isotyp G \\
\hline $\lg \mathrm{M}$ & Immunoglobulin Isotyp M \\
\hline IPG & immobilisierter pH-Gradient \\
\hline IPTG & Isopropyl-D-thiogalaktopyranosid \\
\hline ISAGA & Immunosorbent-Agglutinations Assay \\
\hline $\mathrm{kb}$ & Kilobasen \\
\hline L & Liter \\
\hline LAT & Latex-Agglutinationstest \\
\hline LB & Luria Bertani \\
\hline M & Molar \\
\hline
\end{tabular}




\begin{tabular}{|c|c|}
\hline MAT & modifizierter Agglutinationstest \\
\hline MIC & Mikronemen Antigen \\
\hline $\min$ & Minute \\
\hline $\mathrm{NaCl}$ & Natriumchlorid \\
\hline $\mathrm{NaOH}$ & Natriumhydroxid \\
\hline NBT & Nitroblau Tetrazoliumchlorid \\
\hline NPV & negativer Vorhersagewert (negative predictive value) \\
\hline $\mathrm{OD}_{\lambda}$ & Optische Dichte bei einer Wellenlänge von $\lambda \mathrm{nm}$ \\
\hline PAGE & Polyacrylamidgelelektrophorese \\
\hline PBS & Phosphatgepufferte Salzlösung (phosphate buffered saline) \\
\hline PCR & Polymerasekettenreaktion (polymerase chain reaction) \\
\hline Pfu & Pyrococcus furiosus \\
\hline $\mathrm{pH}$ & negativer dekadischer Logarithmus der Wasserstoffionenkonzentration \\
\hline pl & isoelektrischer Punkt \\
\hline PPV & positiver Vorhersagewert (positive predictive value) \\
\hline PSF & Pyrimethamin-Sulfadiazin-Folinsäure \\
\hline PV & parasitophore Vakuole \\
\hline PVDF & Polyvinylidenfluorid \\
\hline PVM & parasitophore Vakuolenmembran \\
\hline RNA & Ribonukleinsäure (ribonucleic acid) \\
\hline RNAse & Ribonuklease \\
\hline ROP & Rhoptrien Antigen \\
\hline rpm & Umdrehung pro Minute (rounds per minute) \\
\hline RPMI & Roswell Park Memorial Institute \\
\hline $\mathrm{RT}$ & Raumtemperatur \\
\hline SAG & Oberflächenantigen (surface antigen) \\
\hline SDS & Sodiumdodecylsulfat \\
\hline $\sec$ & Sekunde \\
\hline SSW & Schwangerschaftswoche \\
\hline Tab. & Tabelle \\
\hline TAE & Tris-Acetat-EDTA \\
\hline Taq & Thermus aquaticus \\
\hline TEMED & N, N, N', N'-Tetramethylethylendiamin \\
\hline Tris & Tris(hydroxylmethyl)-aminomethan \\
\hline Tween & Polyoxyethylensorbitanmonolaurat \\
\hline U & Unit \\
\hline UV & Ultraviolett \\
\hline $\mathrm{v} / \mathrm{v}$ & Volumenanteil pro Volumen (volume per volume) \\
\hline$w / v$ & Gewichtsanteil pro Volumen (weight per volume) \\
\hline ZNS & Zentralnervensystem \\
\hline
\end{tabular}




\section{Einleitung}

\subsection{Der Parasit Toxoplasma gondii}

Toxoplasma gondii, der Erreger der Toxoplasmose, ist ein obligat intrazellulär lebender Parasit, der erstmalig 1908 von C. Nicolle und L. Manceaux beschrieben wurde (Nicolle und Manceaux, 1908). Bei ihrer Forschungsarbeit auf dem Gebiet der Leishmaniose in Nordafrika wurde der Parasit zufällig aus dem Nagetier Ctenodactylus gundi isoliert. Sie haben inm später, aufgrund seiner gebogenen Form (griechisch: toxon = Bogen; plasma = Form) und seines Fundortes, den Namen Toxoplasma gondii gegeben. Im selben Jahr wie Nicolle und Manceaux konnte auch der Brasilianer A. Splendore den Parasiten in Kaninchen nachweisen (Splendore, 1908).

Taxonomisch gehört T. gondii zu den Protozoen (Einzeller) und gliedert sich im Stamm der Apikomplexa (Sporozoen) ein. Apikomplexa sind eukaryotische Parasiten, bei denen ein charakteristischer Generationswechsel mit einem geschlechtlichen und ungeschlechtlichen Vermehrungszyklus vollzogen wird. Allen Apikomplexa gemein ist der charakteristisch strukturierte Vorderpol, der Apikalkomplex, von dem der Name herrührt. Dieser Komplex besteht aus spezialisierten Organellen wie Rhoptrien und Mikronemen, sowie komplexen zytoskelettalen Elementen (Conoid), die zum Eindringen in die Wirtszelle benötigt werden (Dubey et al., 1998). Außerdem besitzen sie neben den üblichen Zellorganellen noch ein spezielles Plastid-ähnliches Organell, den Apikoplast (Fichera und Roos, 1997; Marechal und Cesbron-Delauw, 2001; Seeber, 2003). Neben T. gondii gehören noch andere humanpathogene Parasiten, wie Plasmodium falciparum (Erreger der Malaria) und Cryptosporidium parvum (Verursacher von Diarrhoe), sowie die tierpathogenen Erreger Neospora, Sarcozystis und Eimeria zum Stamm der Apikomplexa.

Aufgrund seines breiten Wirtsspektrums gehört $T$. gondii zu einem der weltweit erfolgreichsten Parasiten. In Abhängigkeit vom Alter, Ernährungsgewohnheiten und geografischer Lage wird davon ausgegangen, dass ca. ein Drittel der Weltbevölkerung mit T. gondii infiziert ist (Tenter et al., 2000).

\subsection{Der Lebenszyklus von Toxoplasma gondii}

Der vollständige Lebenszyklus von T. gondii wurde erstmalig 1970 beschrieben, nachdem nach der asexuellen-, auch die sexuelle Phase des Lebenszyklus bekannt wurde (Frenkel et al., 1970; Hutchison et al., 1970). 
Toxoplasma gondii kann während seines Vermehrungszykluses in drei verschiedenen Stadien vorkommen: als Tachyzoiten, Bradyzoiten oder als Sporozoiten. Tachy- und Bradyzoiten kommen sowohl im Zwischen- als auch im Endwirt vor und stellen die asexuelle Vermehrungsform dar. Als Zwischenwirte dienen alle warmblütigen Vertebraten, einschließlich des Menschen. Die geschlechtliche Vermehrung findet ausschließlich im Dünndarmepithel des Endwirtes statt (Lindsay et al., 1991; Dubey et al., 1998). Der Endwirt des Parasiten sind Katzen und andere Mitglieder der Familie der Felidae.

Während der asexuellen Vermehrung innerhalb der akuten Infektionsphase treten Tachyzoiten auf, die sich durch eine schnelle Replikation auszeichnen (griechisch: tachos = schnell). Die durchschnittliche Replikationsrate beträgt in vitro ungefähr sechs bis neun Stunden. Während der Infektion vermehren sich die Tachyzoiten innerhalb einer Membran begrenzten parasitophoren Vakuole zu bis zu 128 Parasiten pro Zelle (Radke und White, 1998). Nach Ruptur der Wirtszelle werden die Tachyzoiten freigesetzt, die sofort neue Zellen durch aktives Eindringen infizieren (Dobrowolski und Sibley, 1996). Während der akuten Infektionsphase kommt es so zu einer rasanten Vermehrung der Toxoplasmen in vielen Organen. Die einsetzende wirtsspezifische Immunantwort induziert die Differenzierung der Tachyzoiten in ein langsam wachsendes Bradyzoiten-Stadium (griechisch: brady = langsam). Dabei wandelt sich die parasitophore Vakuole in eine Zystenhülle um (Ferguson und Hutchison, 1987; Dubey et al., 1998). Die Bradyzoiten zeichnen sich durch eine verlangsamte Replikationsrate und verminderten Metabolismus aus (Bohne et al., 1999). Etwa sieben bis zehn Tage nach der Infektion können Bradyzoiten-enthaltende Zysten im Gewebe nachgewiesen werden. In diesem Ruhestadium kann der Parasit lebenslang persistieren, ohne dass im immunkompetenten Wirt klinische Symptome auftreten (Bohne et al., 1999). Abhängig vom Zwischenwirt häufen sich die Zysten bevorzugt in den Neuronen des Zentralen Nervensystems (ZNS), im Muskelgewebe, in der Retina und nur zu einem geringen Teil in anderen Geweben an (Israelski und Remington, 1993; Dubey et al., 1998).

Durch die Aufnahme von zystenhaltigem Fleisch können sowohl weitere Zwischenwirte, als auch der Endwirt mit T. gondii infiziert werden (Abb. 1.1). Im Zwischenwirt werden nach der Magenpassage der säureresistenten Zysten, die Epithelzellen des Dünndarms von Bradyzoiten infiziert, aus denen sich wiederum schnell replizierende Tachyzoiten bilden (Jacobs et al., 1960; Pettersen, 1979) und so eine akute Infektion hervorrufen. 


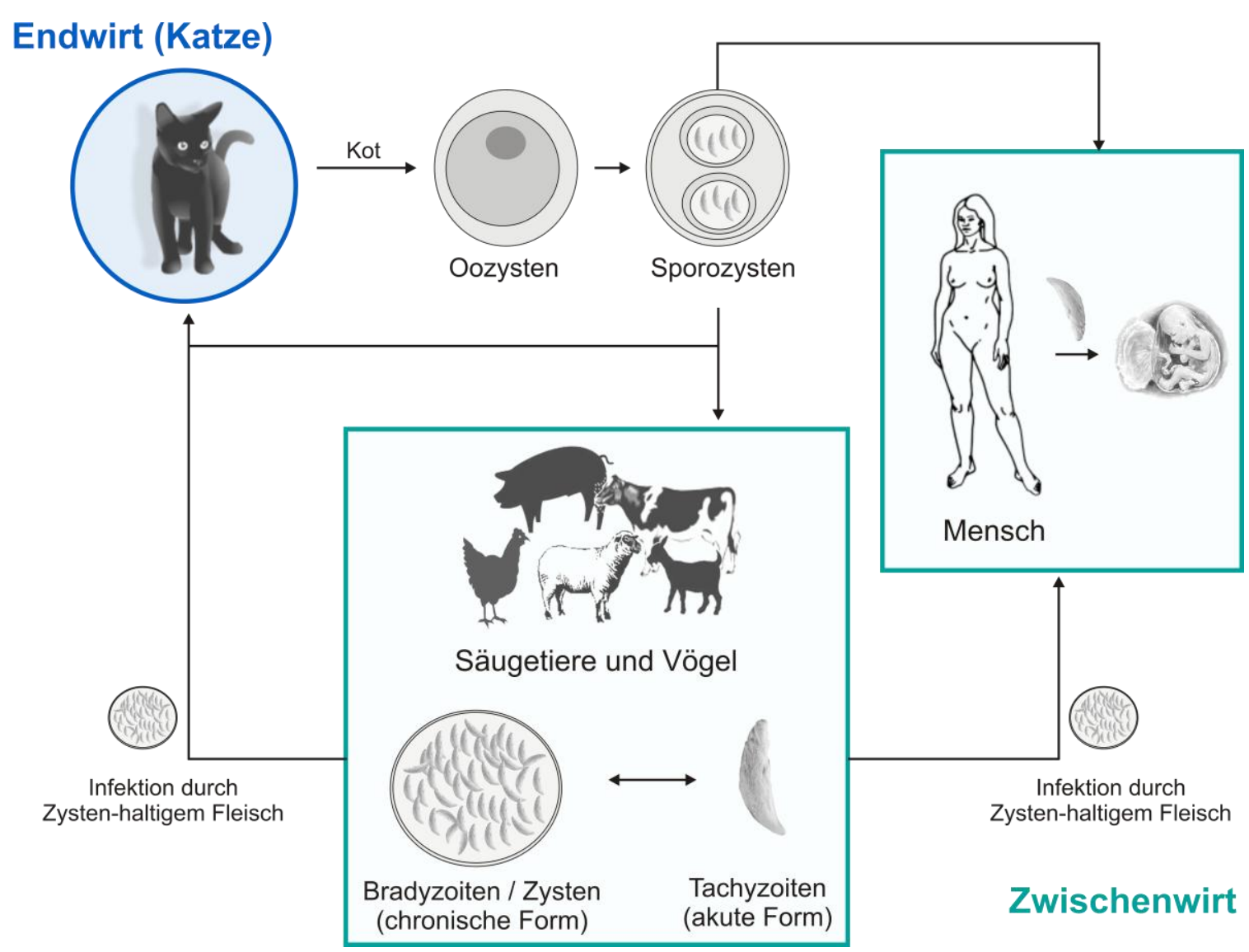

Abb. 1.1: Lebenszyklus von Toxoplasma gondii

Der Endwirt (Katze) scheidet unsporulierte Oozysten aus, die außerhalb des Wirtes sporulieren und somit infektiös werden. Über verschiedene Wege können diese vom Menschen, anderen Zwischenwirten und dem Endwirt aufgenommen werden. Im Zwischenwirt vermehrt sich der Parasit in der akuten Phase asexuell in Form von zunächst sich schnell vermehrenden Tachyzoiten, die sich bei Einsetzen der Immunantwort des Wirtes zu stoffwechselinaktiven Bradyzoiten differenzieren und in Form von Zysten im Gewebe und Gehirn verbleiben. Sie repräsentieren die chronische Infektion. Durch Aufnahme von Zysten-haltigem Fleisch kann sich wiederum sowohl der Endwirt als auch andere Zwischenwirte infizieren. In der Schwangerschaft kann T. gondii über die Plazenta auf den Fötus übertragen werden und dort zu dessen Schädigung oder zu einer Fehlgeburt führen.

Nach oraler Aufnahme von Zysten-haltigem Fleisch durch den Endwirt (Katze) wird die Zystenwand im Magen der Katze aufgelöst und der haploide Parasit dringt in die Zellen des Dünndarmepithels ein. In den Darmzellen durchläuft der Parasit mehrere asexuelle Teilungsschritte, bevor er sich zur sexuellen Vermehrung in männliche und weibliche Gametozysten, die Mikro- und Makrozysten ausdifferenziert, die nach Verschmelzung eine diploide Oozyste ausbilden (Freyre et al., 1989). Die Epithelzellen zerplatzen und entlassen die Oozysten ins Darmlumen. Diese werden mit dem Kot ausgeschieden und sporulieren außerhalb des Wirtes innerhalb von ein bis fünf Tagen zu infektiösen Sporozysten (Ferguson et al., 1979; Dubey et al., 1998). Jede Oozyste enthält zwei Sporozysten, von denen jede wiederum vier Sporozoiten besitzt (Ferguson et al., 1979). Aufgrund ihrer außerordentlichen Widerstandsfähigkeit in feuchter Umgebung bleibt die 
Infektiosität der Oozysten über Monate bis Jahre erhalten. Über kontaminiertes Wasser, Erde oder Nahrung können die sporulierten Oozysten oral aufgenommen und die Sporozoiten im Darmepithel des neuen Wirtes freigesetzt werden, wo sie dann zu Tachyzoiten differenzieren.

\subsection{Die Parasiten-Stadien}

\subsubsection{Tachyzoiten und Bradyzoiten}

Die im End- als auch im Zwischenwirt auftretenden Tachy- und Bradyzoiten sind lichtmikroskopisch an Hand ihrer Morphologie kaum zu unterscheiden. Beide sind ca. $5 \mu \mathrm{m}$ lang und $2 \mu \mathrm{m}$ breit (Weiss und Kim, 2000). Unterschiede lassen sich im Elektronenmikroskop durch verschiedene Organellen erkennen. Bei den sich schnell replizierenden Tachyzoiten, welche vorwiegend bei einer akuten Infektion vorliegen, liegt der Zellkern zentral in der Zelle, während er bei den langsam vermehrenden Bradyzoiten zum posteriolen Pol verlagert ist. Außerdem findet eine Anhäufung Amylopektin-haltiger Granula in den Bradyzoiten statt, die nicht oder nur selten in den Tachyzoiten vorzufinden sind (Dubey et al., 1998; Guerardel et al., 2005). Diese Amylopektin-haltigen Granula spielen in den Bradyzoiten vermutlich eine Rolle bei der Energieversorgung des Dauerstadiums (Weiss und Kim, 2000). Einhergehend mit der Umstellung des Energiestoffwechsels ist die Wachstumsrate in Bradyzoiten deutlich reduziert (Jerome et al., 1998) und der Citratzyklus inaktiviert. Zudem fehlt eine funktionelle Atmungskette (Denton et al., 1996), so dass die benötigte Energie über alternative Wege gewonnen werden muss.

Am apikalen Pol von T. gondii befindet sich der bei Apikomplexa typische Apikalkomplex, der aus dem Conoid, dem Polringkomplex, subpellikulären Mikrotubuli sowie zwei sekretorischen Organellen, den Rhoptrien und den Mikronemen besteht (Carruthers und Sibley, 1997; Dubey et al., 1998; Black und Boothroyd, 2000). Eine dritte Gruppe von sekretorischen Organellen, die Dichte Granula, ist im gesamten Zytoplasma der Tachyzoiten und Bradyzoiten verteilt (Carruthers, 1999). Der Apikalkomplex dient dem Eindringen des Parasiten in die Wirtszelle (Morrissette und Sibley, 2002).

Des Weiteren gelten Bradyzoiten, im Gegensatz zu Tachyzoiten, als säure- und magensaftresistent und überleben die Magenpassage ohne Verlust ihrer Infektiosität (Jacobs et al., 1960). Tachyzoiten jedoch werden unter gleichen Bedingungen innerhalb kürzester Zeit abgetötet und sind nicht mehr in der Lage eine Infektion hervorzurufen. 

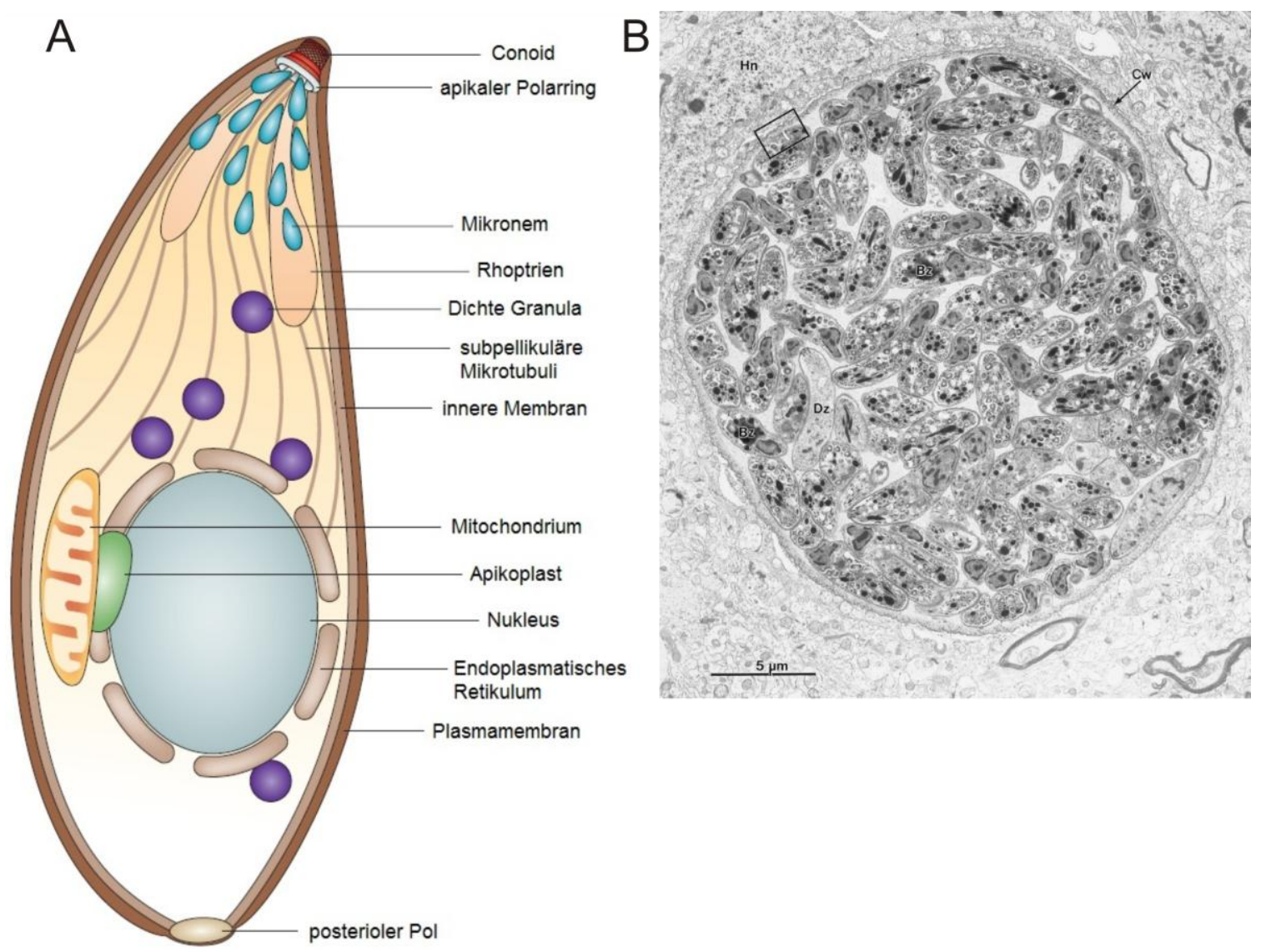

Abb. 1.2: Toxoplasma gondii Tachyzoiten und Bradyzoiten

(A) Schematische Darstellung eines T. gondii-Tachyzoiten. Er ist ca. $5 \mu \mathrm{m}$ lang und ca. $2 \mu \mathrm{m}$ breit. Der für Apikomplexa typische Apikalkomplex bestehend aus dem Conoid, den sekretorischen Organellen Mikronemen und Rhoptrien, sowie den subpellikulären Mikrotubuli. Der Apikalkomplex dient als Penetrationsapparat zum Eindringen in die Wirtszelle. Darüber hinaus besitzen alle Apikomplexa eine dritte Art an sekretorischen Organellen, die Dichte Granula und einen Apikoplasten. (Quelle: (Baum et al., 2006), modifiziert). (B) Elektronenmikroskopische Aufnahme einer Gewebezyste isoliert aus dem Gehirn einer Maus. Die Gewebezyste enthält etwa 100 Bradyzoiten (BZ) und ist von einer Zystenwand umgeben (CW) (Quelle: (Dubey et al., 1998)).

Eine Gewebezyste beinhaltet etwa 500 bis 2000 Bradyzoiten und ist von einer elastischen Zystenwand, bestehend aus Lektinen und Chinin, umgeben. Durch Pepsin und Trypsin wird die Zystenwand im Verdauungstrakt aufgelöst und die Bradyzoiten freigesetzt (Weiss und Kim, 2000). Die Bradyzoiten können Zellen direkt infizieren und müssen nicht erst in Tachyzoiten differenzieren. Ein weiteres Unterscheidungskriterium besteht in der Antigenexpression von Tachy- und Bradyzoiten (Kasper, 1989). So exprimieren Tachyzoiten auf ihrer Oberfläche sogenannte „surface antigens“. Bislang konnten die Antigene SAG1 und SAG2 identifiziert werden (Burg et al., 1988; Mineo et al., 1993). Außerdem wurde das Rhoptrienprotein ROP9 als sekretiertes Protein nur in Tachyzoiten nachgewiesen (Reichmann et al., 2002), und es konnte gezeigt werden, dass die Genexpression des rop1-Gens ist in Bradyzoiten herabgesetzt ist (Cleary et al., 
2002). In Folge der Differenzierung vom Tachyzoiten- ins Bradyzoiten-Stadium findet eine Veränderung in der Antigenexpression statt und die TachyzoitenOberflächenproteine SAG1 und SAG2 werden durch SAG4 und BSR4 ersetzt (Bohne et al., 1999; Lekutis et al., 2000). Als Bradyzoiten-spezifische Proteine gelten das zytoplasmatische „Bradyzoiten-Antigen“ BAG1 und das Protein p34, welches sich auf der Oberfläche von Bradyzoiten befindet (Tomavo et al., 1991; Bohne et al., 1995; Parmley et al., 1995).

Die Differenzierung von Tachyzoiten in Bradyzoiten kann in vitro und in vivo als Reaktion auf eine "Stressreaktion“ induziert werden. Hierbei spielen eine Temperaturerhöhung oder pH-Änderung (Weiss und Kim, 2000), aber auch Chemikalien wie Natriumarsenit oder Pyrimethamin, eine wesentliche Rolle (Gross et al., 1996; Soete und Dubremetz, 1996). In vivo wird eine Stadienkonversion als natürliche Reaktion beim Einsetzten der Immunantwort hervorgerufen. Bei Immunsupprimierten kann eine chronische Toxoplasma-Infektion reaktivieren und die Bradyzoiten wandeln sich wieder in infektiöse Tachyzoiten um (Gross et al., 1996).

\subsubsection{Oozysten und Sporozysten}

Durch eine sexuelle Replikation von T. gondii im Endwirt Katze entstehen in deren Dünndarmepithel Oozysten, die mit dem Kot ausgeschieden werden. Oozysten sind umweltresistente Dauerformen, die ebenso wie die Bradyzoiten-enthaltenen Zysten, eine Magenpassage überleben können. Unsporulierte Oozysten besitzen annähernd eine sphärische Form mit einem Durchmesser von 10-12 um (Dubey et al., 1998). Sie sind von einer einschichtigen, mit wenigen Mikroporen versetzten Membran, sowie einer zweischichtigen Oozystenwand umgeben. Außerhalb der Katze sporulieren Oozysten, abhängig von den klimatischen Bedingungen, innerhalb von ein bis fünf Tagen zu infektiösen Sporozysten (Jackson und Hutchison, 1989). Dabei teilt sich der vergrößerte Nukleus zunächst zwei Mal. Durch Kompartimentierung entstehen zwei etwa 6-8 $\mu \mathrm{m}$ große Sporozysten, die jeweils zwei Nuklei enthalten und von einer Sporozystenwand umgeben sind. Durch weitere Teilung der Nuklei entstehen in jeder Sporozyste vier Sporozoiten, die von einer einschichtigen Membran umschlossen sind.

Kasper et al. konnten zeigen, dass Sporozoiten, wie Tachy- und Bradyzoiten, Stadienspezifische Antigene präsentieren (Kasper et al., 1984; Kasper, 1989). Die OberflächenAntigene SAG1 (30 kDa), SRS3 (35 kDa) und SAG3 (43 kDa) sind in Tachyzoiten wie auch in Sporozoiten vertreten. Das SAG2 A/B jedoch konnte nur in Tachyzoiten nachgewiesen werden (Radke et al., 2004). Des Weiteren scheint ein etwa 25 kDa 
großes Protein nur in den Sporozoiten vorzukommen (Kasper et al., 1984; Radke et al., 2004) und ein 18,3 kDa großes Protein, mit dem Namen DGP5p+, ein Oozystenspezifisches Antigen zu sein (Hill et al., 2010).
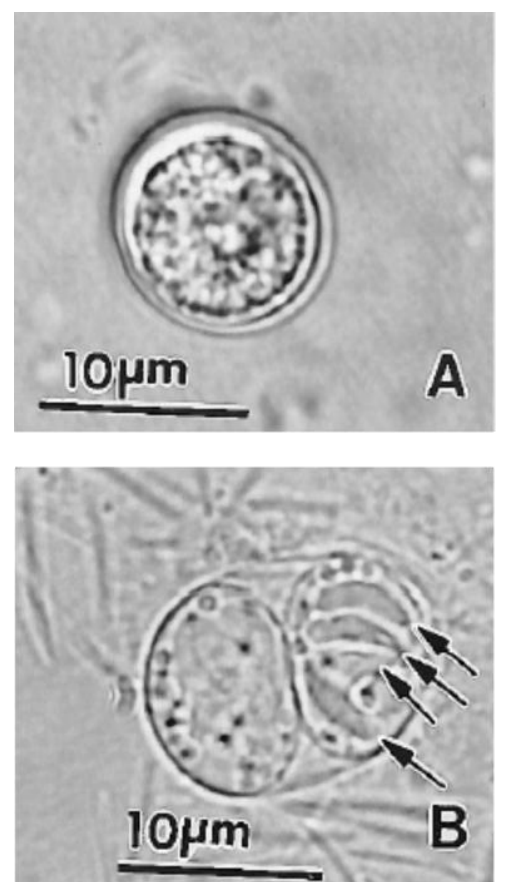

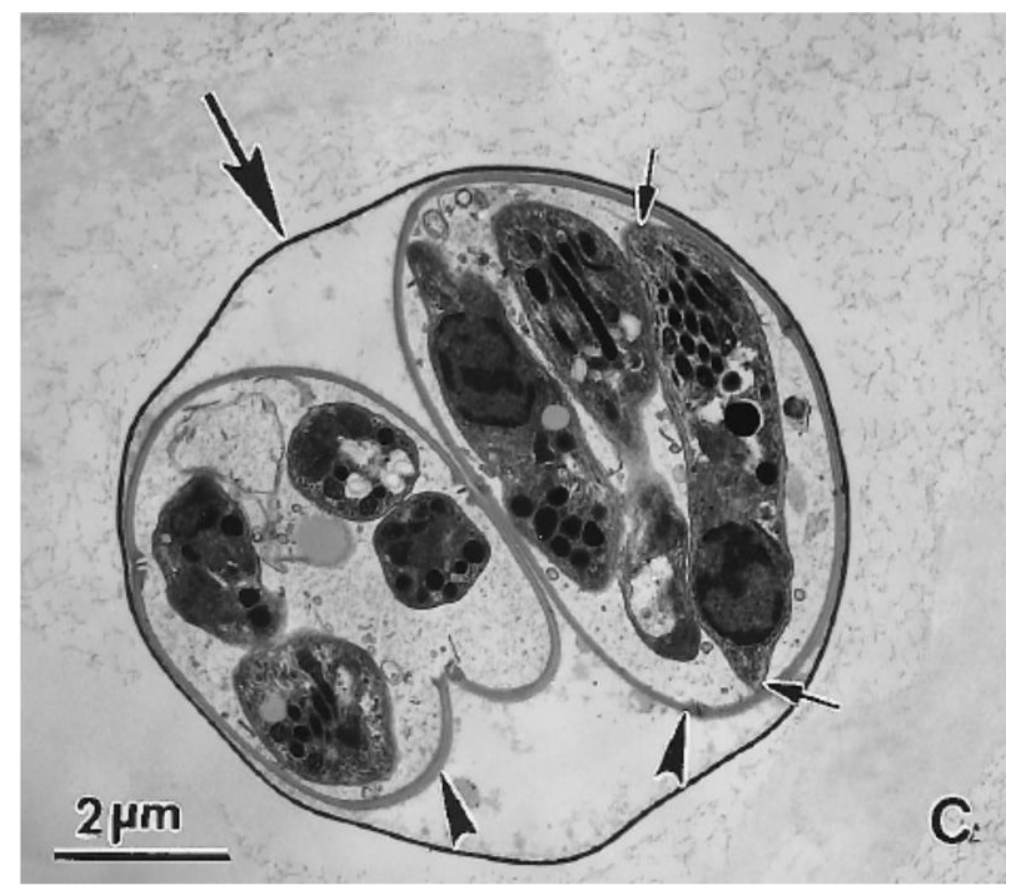

C.

\section{Abb. 1.3: Toxoplasma gondii Oozyste}

(A) Unsporulierte Oozyste. (B) Sporulierte Oozyste mit zwei Sporozysten und vier Sporozoiten (Pfeile). (C) Elektronenmikroskopische Betrachtung einer sporulierten Oozyste. Die sporulierte Oozyste ist von einer dünnen Oozystenwand umgeben und enthält zwei Sporozysten mit jeweils vier Sporozoiten (Quelle: (Dubey et al., 1998)).

\subsection{Toxoplasma gondii-Genotypen}

Isolate von $T$. gondii werden an Hand von Restriktionsfragment-Längenpolymorphismen (RFLP) in drei Subtypen (Typ I, II und III) klassifiziert (Darde et al., 1992; Sibley und Boothroyd, 1992). Die Subtypen entwickelten sich wahrscheinlich vor ca. 10.000 Jahren aus einem gemeinsamen Vorfahren ( $\mathrm{Su}$ et al., 2003) und sind zu $98 \%$ genetisch identisch (Grigg et al., 2001). Die geringen genetischen Unterschiede bestimmen über die Virulenz des Parasiten. Im Falle von T. gondii wird die Virulenz über den Verlauf einer experimentellen Infektion in Mäusen definiert. Typ-I Isolate (RH, GT1, BK) sind hoch virulent in Mäusen. Nur eine einzige Tachyzoite reicht hier aus, um eine letale Infektion innerhalb von 14 Tagen $\left(\operatorname{LD}_{100}=1\right)$ hervorzurufen (Howe et al., 1996). Im Gegensatz dazu gelten Typ-II (ME49, DX, NTE) und Typ-III (VEG) Isolate als Mausavirulente Stämme. Die Infektionsdosis, bei der $50 \%$ der infizierten Mäuse innerhalb 
von 14 Tagen sterben, liegt hier bei $10^{3}-10^{5}$ Tachyzoiten $\left(\operatorname{LD}_{50}>10^{3}\right)$ (Sibley et al., 2002). In Zellkultur vermehren sich Typ-II und -III deutlich langsamer als Typ-I Isolate. In vivo jedoch verbreiten sich virulente und avirulente gleich schnell. Die Parasitenzahl im Gewebe ist jedoch bei einer Infektion mit virulenten Toxoplasma-Stämmen deutlich höher und steht in Verbindung mit der Ausprägung einer okulären Toxoplasmose (Switaj et al., 2006).

In Europa sind vorwiegend Typ-II und -III Isolate zu finden. Dabei werden aus Menschen und Nutztieren am häufigsten Typ-II Toxoplasmen isoliert. Typ-III Isolate sind bei Menschen eher selten zu finden. Sie werden häufiger aus Tieren isoliert, die nicht als Nahrung des Menschen dienen, wie z. B. Vögel, Katzen und Nagetiere.

\subsection{Invasion in die Wirtszelle}

Die Invasion von T. gondii in die Wirtszelle läuft nicht über eine Phagozytose, sondern ist ein aktiver Prozess des Parasiten (Dobrowolski und Sibley, 1996; Dubremetz et al., 1998), der innerhalb von 15 Sekunden stattfindet (Smith, 1995).

Der erste Schritt ist die Adhäsion des Parasiten an die Wirtszelle. Die Kontaktaufnahme wird über spezifische Rezeptoren und Liganden gesteuert, die wahrscheinlich sowohl vom Parasiten als auch vom Wirt stammen. Nach der Adhäsion folgt eine Reorientierung des Tachyzoiten, so dass der Apikalkomplex und die Wirtszellmembran einander direkt gegenüber liegen. Diese Umorientierung wird vermutlich von Mikronemenproteinen (MIC) gesteuert, die Calcium-abhängig während der Ausrichtungsphase vom apikalen Ende des Parasiten sekretiert werden (Lourenco et al., 2001; Lovett et al., 2002). Nach erfolgreicher Anlagerung des Parasiten wird an der Kontaktstelle eine feste Verbindung zwischen Parasit und Wirtszelle, eine sogenannte „tight junction" ausgebildet (Michel et al., 1980). In diesem Bereich sind die Zytoskelettstrukturen von Wirt und Parasit eng miteinander verbunden, sowie die Zellmembran der Wirtszelle zur Invasion durchbrochen (Soldati et al., 2001). Kurz vor dem Eintritt des Parasiten in die Wirtszelle werden aus den Rhoptrien Organellspezifische Proteine (ROP) und andere Membrankomponenten in die Wirtszelle sezerniert. In Folge dessen stülpt der Parasit an der Kontaktstelle die Wirtsmembran ins Wirtszellzytoplasma ein und es entsteht beiderseitig eine sog. „moving junction“, die den Parasiten vom apikalen bis zum posterioren Pol kreisförmig umgibt. Dabei werden Wirtzellproteine aus der Wirtszellmembran aktiv eliminiert (Pfefferkorn, 1990). Nach Abschluss dieses Prozesses schließt sich die Wirtszellmembran wieder und der Parasit befindet sich in einer intrazellulären parasitophoren Vakuole (PV) (Lingelbach und 
Joiner, 1998). Die Membran der PV besteht zu $85 \%$ aus der ursprünglichen Wirtszellmembran. Aus dieser werden Transmembran- und Membran-assoziierte Proteine sehr schnell entfernt und unter anderem durch ROP-Proteine ersetzt (Joiner und Roos, 2002). Die Modifikation der PV-Membran durch T. gondii verhindert, dass die Vakuole mit endozytotischen Kompartimenten des Wirtes fusioniert und ihr Inhalt in Lysosomen degradiert wird (Hakansson et al., 2001). In dieser PV kann sich der Parasit ungehindert replizieren. Die Versorgung des Parasiten mit Nährstoffen ermöglichen in der PV enthaltene Poren, die Moleküle bis zu einer Größe von 1.300 Da durchlassen (Schwab et al., 1994).

Innerhalb von zehn bis zwanzig Minuten nach der Invasion bildet sich in der PV ein stabilisierendes tubulovesikuläres Netzwerk aus (Mercier et al., 2002), welches mit Dichte Granula (GRA)-Proteinen ausgekleidet ist.

\subsection{Die Bedeutung von Nutztieren für die Übertragung von T. gondii auf den Menschen}

In Zwischenwirten, wie Säugetieren und Vögeln, vermehrt T. gondii sich ausschließlich asexuell und führt letztendlich zur Persistenz von Zysten in Muskelgewebe und Gehirn. Durch den Verzehr von Zysten-haltigem Fleisch und Fleischprodukten kann T. gondii auf den Menschen übertragen werden. In verschiedenen Kulturen spielen dabei Fleischprodukte von unterschiedlichen Tierarten eine Rolle. Die Abbildung 1.5 zeigt den unterschiedlichen Fleischverzehr pro Kopf in Deutschland. Dabei ist zu erkennen, dass ca. vier Mal so viel Schweinefleisch pro Kopf und Jahr verzehrt wird, wie Geflügel- oder Rind/Kalbsfleisch. Im Vergleich dazu werden Schaf- und Ziegenfleisch hierzulande eher selten verzehrt. Tenter et al. konnten zeigen, das Toxoplasma-Zysten häufig in Geweben von Schweinen, Schafen und Ziegen vorkommen, weniger jedoch in Geflügel und Kaninchen. Dabei wurden nur sehr wenige Gewebezysten in Rindern gefunden (Tenter et al., 2000). Somit stellt wahrscheinlich der Verzehr von Schweinefleisch in Deutschland eine bedeutende Rolle in der Übertragung des Parasiten auf den Menschen dar.

Eine Übersicht zur Seroprävalenz T. gondii-spezifischer Antikörper bei Schweinen wurde 2009 von J. P. Dubey verfasst (Dubey, 2009). Dabei sank die Seroprävalenz in Deutschland von 20,5\% (2003) auf 4,1\% (2008). Im Vergleich dazu betrug die Seroprävalenz bei Schafen und Ziegen in den Jahren 1993 bis 1997 zwischen 21-33\% bzw. 19-42\% (Tenter et al., 2000). 
Die Änderung hin zur ökologischen Haltung von Nutztieren zeigt jetzt jedoch wieder eine steigende Tendenz der Seroprävalenz in Tierbeständen (Tenter et al., 2000; Ludewig et al., 2007).

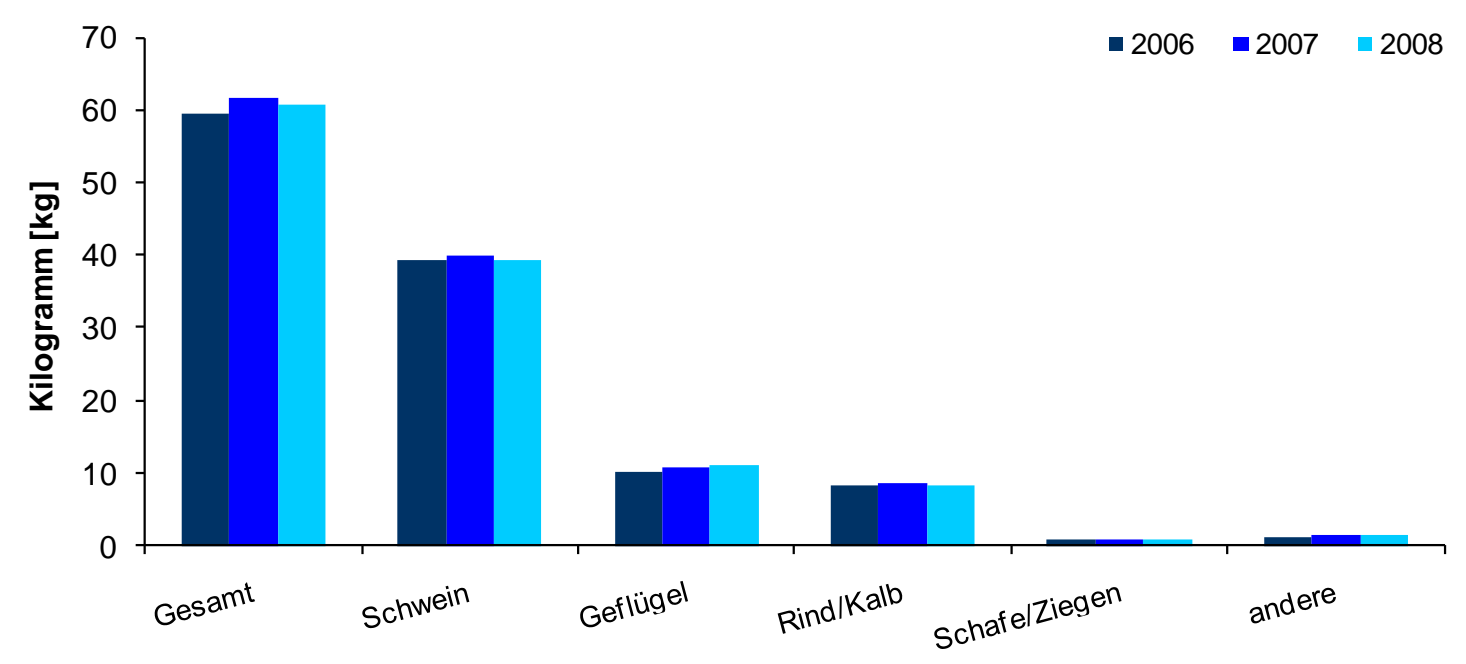

Abb. 1.4: Fleischverzehr pro Kopf der Bevölkerung in Deutschland

Dargestellt ist der Fleischverzehr in Kilogramm $(\mathrm{kg})$ pro Kopf der Bevölkerung in Deutschland für die Jahre 2006-2008. Der Fleischverzehr wurde nach Tierart unterteilt. Unter den anderen Tierarten sind vor allem Wild und Kaninchen vertreten. (Quelle: Bundesverband der Deutschen Fleischwarenindustrie e. V.)

\subsection{Die Pathogenese der Toxoplasmose}

Eine Infektion des Menschen mit T. gondii erfolgt entweder durch den Verzehr von Zysten-haltigem rohem bzw. unzureichend erhitztem Fleisch oder durch Kontakt mit im Katzenkot befindlichen sporulierten Oozysten.

Abhängig vom Infektionszeitpunkt wird zwischen einer postnatalen und einer pränatal erworbenen Toxoplasmose unterschieden.

Die Pathogenität von Toxoplasma bei einer postnatal erworbenen Infektion ist abhängig vom Immunstatus des Wirtes. Dabei verläuft eine Infektion im immunkompetenten Wirt häufig asymptomatisch. Nur bei etwa 1-5\% der Infizierten äußert sich die Infektion in Form eines leicht grippalen Infektes mit Lymphadenitis, Müdigkeit, Kopfschmerzen und selten mit Fieber.

Während der akuten Infektionsphase wird die Vermehrung des Parasiten durch die rasch einsetzende zelluläre Immunantwort des Wirtes eingedämmt. In Folge dessen bildet der Parasit Zysten aus, die sich bevorzugt in den Neuronen des 
Zentralnervensystems (ZNS), im Auge und im Muskelgewebe ansiedeln. Durch die Ausbildung dieses Dauerstadiums entwickelt sich eine chronisch/latente Infektion.

Bei immunsupprimierten Personen, wie z. B. AIDS-Patienten, Transplantatempfängern oder Tumorpatienten können Komplikationen durch eine nicht ausreichende Immunantwort und eine dadurch bedingte Reaktivierung des latenten Parasitenstadiums entstehen (Israelski und Remington, 1993; Weiss und Dubey, 2009). Bei einer Reaktivierung platzen die Bradyzoiten-enthaltenen Zysten auf und diese differenzieren sich zu Tachyzoiten, die sich ohne Immunantwort ungehindert vermehren können. Dieses kann zu multiplen zerebralen Läsionen und einer toxoplasmatischen Enzephalitis führen (Ambroise-Thomas und Pelloux, 1993; Luft et al., 1993), welche unbehandelt innerhalb weniger Wochen zum Tod führt (Luft und Remington, 1992).

Die pränatale (kongenitale) Toxoplasmose findet bei einer Primärinfektion der werdenden Mutter durch eine diaplazentare Übertragung des Parasiten auf den Fötus statt. Aufgrund des unreifen Immunsystems des Föten kann es hierbei zu schweren Schädigung dessen oder zu einer Fehlgeburt kommen. Die klinischen Symptome können sehr unterschiedlich sein, wobei aber häufig ein Hydrozephalus, intrakraniale Läsionen und eine Retinochorioiditis beobachtet werden (Martin, 2001). Die Übertragung des Parasiten in der Schwangerschaft, sowie die Schwere der Schädigung sind abhängig vom Infektionszeitpunkt der Mutter in der Schwangerschaft. Dabei steigt mit Fortschritt der Schwangerschaft das Risiko einer pränatalen Infektion des Föten, gleichzeitig sinkt jedoch das Risiko und die Schwere klinischer Symptome des Föten (Gross et al., 2001).

\subsection{Die humorale Immunantwort des Wirtes}

Immunoglobuline (Antikörper) sind Proteinmoleküle, die spezifisch mit einem Epitop eines Antigens reagieren. Sie werden in fünf Klassen eingeteilt: $\lg A, \lg M, \lg D, \lg E$ und $\lg G$.

Immunoglobulin $\mathrm{G}(\lg G)$ ist das häufigste zirkulierende Antigen und unterteilt sich in vier Untergruppen: $\lg _{1}, \lg G_{2}, \lg _{3}$ und $\lg _{4}$. Es besitzt ein relatives Molekularmasse von $150 \mathrm{kDa}$ und besteht aus zwei leichten und zwei schweren Ketten. IgG kommt in extrazellulären Flüssigkeiten, im Blut und Lymphflüssigkeit vor und wird ca. drei Wochen nach der Infektion gebildet. In der Schwangerschaft kann IgG aufgrund seiner geringen Größe die Plazenta überwinden und somit auf den Fötus übergehen.

Immunoglobulin M (IgM) ist der erste Antikörper, der ca. 3-10 Tagen nach einer Infektion mit $T$. gondii in Erscheinung tritt. Aufgrund der teilweise monate- bis jahrelangen 
Präsenz von IgM im Serum ist dieser Antikörper nicht immer repräsentativ für eine akute Infektion (Correa et al., 2007). IgM besitzt zudem eine geringe Affinität zu Antigenen (Madigan et al., 2003). IgM kommt häufig als Pentamer in Blut und Lymphflüssigkeiten vor und hat in dieser Form eine Molekularmasse von 970 kDa.

Immunoglobulin A (IgA) liegt im Serum als Monomer mit einer Molekülmasse von 150 $\mathrm{kDa}$ vor. In Zell- und Blutflüssigkeiten kommt $\lg A$ jedoch als Dimer mit einem Molekularmasse von 385 kDa vor. Nach IgM ist IgA einer der nächsten Antikörper, die nach einer Infektion gebildet werden und ist dann etwa sechs bis sieben Monate nachweisbar (Correa et al., 2007).

Immunoglobulin E ( $\mathrm{IgE}$ ) kommt nur in geringen Mengen im Blut und Lymphflüssigkeiten vor und hat eine Molekularmasse von $190 \mathrm{kDa}$. Wie $\lg \mathrm{A}$ ist auch $\lg \mathrm{E}$ nur während einer akuten T. gondii-Infektion vorhanden und ist nach ca. vier Monaten nicht mehr nachweisbar (Pinon et al., 1990).

Immunoglobulin D ( $\operatorname{gD}$ ) ist ebenfalls nur in geringer Konzentration im Blut und Lymphflüssigkeiten vorhanden und hat als zirkulierender Antikörper nur eine geringe Bedeutung.

Bei Hühnern stellt IgY das funktionelle Äquivalent zu IgG mit zwei leichten und zwei schweren Ketten dar. Mit einer Molekularmasse von 167 kDa ist IgY jedoch etwas größer als IgG. Aufgrund seiner geringen Kreuzreaktivität mit Säugetierproteinen werden daher zum Nachweis einer Toxoplasma-Infektion beim Huhn spezifische IgYAntikörper nachgewiesen.

\subsection{Diagnose der Toxoplasmose}

Die Diagnose einer T. gondii-Infektion erfolgt in erster Linie serologisch in Form einer Stufendiagnostik, da es derzeit mit einem einzelnen Test nicht möglich ist, zwischen einer frischen, akuten Infektion und einer chronischen Infektion zu unterscheiden (Roberts et al., 2001). Der Nachweis Toxoplasma-spezifischer Antikörper ist abhängig von der Untersuchungsmethode. So sind nach ca. ein bis zwei Wochen spezifische IgMund ca. vier Wochen nach der Infektion IgG-Antikörper im Serum nachweisbar.

\subsubsection{Routinediagnostik}

Den ersten serologischen Test für die Toxoplasma-Diagnostik entwickelten 1948 Albert Sabin und Harry Feldman (Sabin und Feldman, 1948). Mit Hilfe dieses Testes konnte erstmalig eine epidemiologische Studie zur Inzidenz der Toxoplasmose durchgeführt werden, die zeigte, dass der Parasit weltweit im Menschen verbreitet ist. 
Der Sabin-Feldman-Test (SFT) oder auch Dye-Test genannt, galt lange Zeit als "Goldener Standard“ zum Nachweis von T. gondii. Der SFT beruht darauf, dass sich lebende Toxoplasmen nicht mit Methylenblau anfärben lassen wenn im Patientenserum in Gegenwart eines Komplements spezifische Antikörper gegen Toxoplasmen vorhanden sind. Ebenso veraltete Nachweismethoden wie der SFT sind die Komplementbindungsreaktion (KBR) und der direkte Agglutinationstest (DA).

Des Weiteren dienen der Latexagglutinationstest (LAT), wie auch der modifizierte Agglutinationstest (MAT), als qualitative Nachweismethoden, werden aber hauptsächlich in der Veterinärmedizin eingesetzt.

In der Routinediagnostik der Humanmedizin wird heutzutage z. B. der indirekte Immunofluoreszenz-Test (IIFT) durchgeführt. Er dient dem Nachweis von IgG-, IgModer IgA-Antikörpern und besitzt eine hohe Spezifität und Sensitivität. Für den IIFT werden abgetötete Tachyzoiten auf einem Objektträger fixiert und mit verschiedenen Verdünnungen des Patientenserums inkubiert. Über Fluoreszin-beladene anti-Human Immunoglobuline und Evans-Blau kann die Anwesenheit spezifischer Antikörper im Fluoreszenzmikroskop durch gelb-grün fluoreszierende Tachyzoiten sichtbar gemacht werden.

Weit verbreitete Methoden, wie u. a. der Enzym-linked-Immunosorbent-Assay (ELISA), erlauben ebenfalls den Nachweis von IgG-, IgM- und IgA Antikörpern und können so zwischen einer akuten und chronischen Infektion unterscheiden (Carvalho et al., 2008; Araujo und Ferreira, 2010).

Für die Diskriminierung einer akuten von einer chronischen T. gondii-Infektion kann auch die Immunoblot-Technik durch Nachweis spezifischer IgG-, IgM- oder $\lg \mathrm{A}$ Antikörper hilfreich sein (Lu et al., 2006). Außerdem ermöglicht der Immunoblot den Vergleich von mütterlichen und kindlichen IgG-Antikörper durch direkten Abgleich der Reaktivität mit T. gondii-Antigenen (Nielsen et al., 2005; Di Carlo et al., 2007). Für den Immunoblot werden die T. gondii-Proteine elektrophoretisch aufgetrennt und auf eine Nitrozellulose-Membran transferiert. Nach Inkubation mit Patientenserum und einem anti-Human IgG-, IgM- oder IgA-Antiserum, können Immunoglobulin-spezifische Antikörper durch eine Farbreaktion nachgewiesen werden.

Einen direkten Nachweis des Parasiten in Gewebe und Körperflüssigkeiten bietet die Polymerase-Kettenreaktion (PCR). Guy et al. etablierten für die Routinediagnostik den Nachweis des B1-Gens (Guy et al., 1996). Dieses ist eine 2.214 bp lange, repetitive Sequenz, die mit ca. 35 Kopien im Genom von T. gondii vorkommt. In Abhängigkeit vom Untersuchungsmaterial ist dies eine sensitive Nachweismethode von Toxoplasma (Filisetti et al., 2003; Mason et al., 2010). Zum Nachweis von T. gondii im Fruchtwasser 
ist jedoch der Nachweis einer 529 bp-Repeat-Region geeigneter. Hierbei handelt es sich ebenfalls um eine repetitive Region, die mit etwa 200-300 Kopien im Genom von T. gondii vertreten ist. Die PCR zum Nachweis des 529 bp-Fragmentes ist etwa zehn Mal sensitiver als der Nachweis des B1-Genes (Homan et al., 2000).

\subsubsection{Rekombinante Antigene für die Serodiagnostik}

In den letzten 20 Jahren wurden zahlreiche $T$. gondii-Proteine rekombinant in Escherichia coli als potenzielle diagnostische Marker für die Identifizierung einer Toxoplasma-Infektion sowohl in Menschen als auch in Tieren hergestellt. Dabei sind überwiegend sekretierte Proteine der Organellen - Dichte Granula, Rhoptrien und Mikronemen - von großer Bedeutung (Kotresha und Noordin, 2010). Eingesetzt wurden die rekombinanten Antigene vor allem im ELISA zum Nachweis spezifischer IgG- und IgM- Antikörper (Nigro et al., 2003; Pfrepper et al., 2005; Altcheh et al., 2006).

Ebenso wurden Oberflächen-Antigene von Toxoplasma für die Serodiagnostik eingesetzt. Eines der am häufigsten eingesetzten Antigene ist das Tachyzoitenspezifische SAG1 (Chen et al., 2001; Pietkiewicz et al., 2004; Wu et al., 2009). Als Bradyzoiten-spezifischer Marker diente vor allem das MAG1-Antigen (Pfrepper et al., 2005; Holec et al., 2007). Die bisher mit diesen Antigenen erzeilten Ergebnisse sind jedoch kontrovers.

Es wurde gezeigt, dass einige rekombinante GRA-Antigene, wie GRA2 (Golkar et al., 2007), GRA6 (Aubert et al., 2000; Hiszczynska-Sawicka et al., 2005) oder GRA7 (Pfrepper et al., 2005; Pietkiewicz et al., 2007) für die Diagnose einer akuten Infektion geeignet scheinen. GRA1 hingegen für die Diagnose der chronischen Infektionsphase in Frage kommt (Ferrandiz et al., 2004; Pietkiewicz et al., 2004).

\subsection{Therapie der Toxoplasmose}

Die Therapie der T. gondii-Infektion soll die Vermehrung des Parasiten in der akuten Infektionsphase verhindern, führt aber nicht zu dessen Abtötung. Vielmehr führt die Therapie zur Induktion der Stadienkonversion in das Bradyzoiten-Stadium. Dabei wird aber nicht jede Toxoplasma-Infektion medikamentös behandelt. Eine Therapieindikation wird hauptsächlich bei immundefizienten Patienten, bei einer Retinochorioiditis, einer Primärinfektion in der Schwangerschaft und bei einer kongenital erworbenen Infektion des Neugeborenen durchgeführt.

Bei einer Serokonversion oder bei Verdacht auf eine Infektion mit $T$. gondii in der Schwangerschaft wird hierzulande bis zur 16. Schwangerschaftswoche eine 
Monotherapie mit Spiramycin in einer Tagesdosis von 9 Mio. I. E. durchgeführt. Spiramycin ist ein Makrolid-Antibiotikum, welches die Hemmung der Proteinbiosynthese bewirkt (Ruf und Pohle, 1995). Während der Schwangerschaft verhindert es vor allem die Übertragung des Parasiten auf den Fötus. Da Spiramycin nur eine geringe Plazentagängigkeit aufweist (Couvreur et al., 1988), ist eine Monotherapie mit diesem Antibiotikum in der Schwangerschaft jedoch nicht ausreichend. Daher wird empfohlen, ab der 16. Schwangerschaftswoche eine Kombinationstherapie, bestehend aus Pyrimethamin (50 mg/1. Tag; $25 \mathrm{mg} / \mathrm{Tag}$ ab den 2. Tag), Sulfadiazin (50 mg/kg Körpergewicht (KG) pro Tag bis 4 g/Tag) und Folinsäure (10-15 mg/Tag), durchzuführen. Aufgrund von möglichen teratogenen Eigenschaften des Pyrimethamins sollte die Kombinationstherapie nicht vor der 16. Schwangerschaftswoche durchgeführt werden.

Die Kombination von Sulfadiazin und Pyrimethamin ist eine plazentagängige Therapie und kann somit eine fetale Infektion im Uterus behandeln. Sulfadiazin führt zu einer Blockierung der Dehydrofolatsynthase, während Pyrimethamin die Dehydrofolatreduktase hemmt (Ruf und Pohle, 1995), wodurch keine Umwandlung von Folsäure zu Folinsäure stattfinden kann. In Kombination erreichen diese beiden Medikamente einen synergistischen Effekt mit einem hohen Wirkungsgrad. Wegen einer möglichen hämatologischen Toxizität des Pyrimethamins wird, um Störungen des Folsäurestoffwechsels $\mathrm{zu}$ vermeiden, zu der Kombinationstherapie Folinsäure verabreicht.

Neugeborene mit einer pränatal erworbenen Toxoplasmose werden, abhängig von der Ausprägung einer klinischen Manifestation, bis zum 12. Lebensmonat mit der Kombinationstherapie - bestehend aus Pyrimethamin $(2 \mathrm{mg} / \mathrm{kg} \mathrm{KG}$ an den ersten beiden Tagen, danach $1 \mathrm{mg} / \mathrm{kg} \mathrm{KG}$ pro Tag), Sulfadiazin (50-100 mg/kg KG pro Tag) und Folinsäure (2 $\times 5 \mathrm{mg}$ pro Woche) - therapiert. 


\subsection{Ziel dieser Arbeit}

Die Primärinfektion mit T. gondii in der Schwangerschaft gehört zu den bedeutendsten Infektionen mit dem Parasiten. Hervorgerufen wird diese entweder durch den Verzehr von Zysten-haltigem Fleisch oder durch Kontakt mit im Erdboden enthaltenen Oozysten. Einhergehend mit der Infektion der Frau, kann der Parasit diaplazentar auf den Fötus übertragen werden und dort unter anderem zu schweren Erkrankungen des Zentralnervensystems führen.

Im Zuge dieser Arbeit soll an Hand einer epidemiologischen Untersuchung geklärt werden, wie häufig der Parasit in der Schwangerschaft auf den Föten übertragen wird und welche Auswirkungen eine kongenitale Infektion auf die Ausprägung von klinischen Symptomen des Kindes hat. Einhergehend damit soll untersucht werden, welchen Einfluss dabei die in Deutschland durchgeführte pränatale Toxoplasmose-Therapie auf die Transmissionsrate und auf die Ausprägung von klinischen Symptomen beim Kind hat.

Um eine Infektion mit T. gondii in der Schwangerschaft früh erkennen zu können ist eine zuverlässige Diagnostik notwendig. Daher sollen Toxoplasma-Antigene identifiziert werden, mit deren Hilfe eine Differenzierung zwischen einer akuten und einer chronischen Infektion ermöglicht wird. Als rekombinante Antigene sollen diese dann in einem Immunoblot-Verfahren an Humanseren getestet und ihre diagnostischen Eigenschaften evaluiert werden.

Des Weiteren soll mit Hilfe der rekombinanten Antigene untersucht werden, ob die häufigste klinisch-manifeste Erkrankung, die Toxoplasma-bedingte Retinochorioiditis, erkannt werden kann.

Ferner soll überprüft werden ob der Einsatz eines Immunoblots mit rekombinanten Antigenen geeignet ist, um eine Toxoplasma-Infektion in Nutztieren nachzuweisen. Ein Nachweis Toxoplasma-spezifischer Antikörper in Tieren könnte den Verzehr von kontaminiertem Fleisch einschränken und so das Risiko für eine Infektion in der Schwangerschaft herabsetzen. 


\section{Material und Methoden}

\section{$2.1 \quad$ Material}

\subsubsection{Geräte}

Tab. 2.1: Auflistung der verwendeten Geräte mit Modell und Hersteller

\begin{tabular}{|c|c|c|}
\hline Gerät & 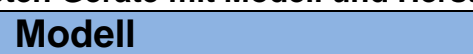 & Hersteller \\
\hline Acrylamid Gel-Caster & Mini Protean II & Bio-Rad, München \\
\hline Agarosegelelektrophorese & & $\begin{array}{l}\text { Keutz Labortechnik, } \\
\text { Reiskirchen }\end{array}$ \\
\hline Blotapparatur & $\begin{array}{l}\text { Trans-Blot }{ }^{(B)} \text { SD Semi-Dry } \\
\text { Electrophoretic Transfer Cell }\end{array}$ & Bio-Rad, München \\
\hline Brutschränke & & Heraeus, Hanau \\
\hline Elektrophoresekammer für 2D & DALT vertical system & Hoefer, Holliston, MA, USA \\
\hline Geldokumentationsanlage & BioDoc II & Biometra, Göttingen \\
\hline Gradientenmischer und Pumpe & Ettan DALT II System & $\begin{array}{l}\text { Amersham Pharmacia } \\
\text { Biotech, Freiburg }\end{array}$ \\
\hline IPG Strip-Holder & & $\begin{array}{l}\text { Amersham Pharmacia } \\
\text { Biotech, Freiburg }\end{array}$ \\
\hline Isoelektrische Fokussierung & $\begin{array}{l}\text { IPGphor Isoelectric Focusing } \\
\text { System }\end{array}$ & $\begin{array}{l}\text { Amersham Pharmacia } \\
\text { Biotech, Freiburg }\end{array}$ \\
\hline Kühlungssystem & Multitemp III & Pharmacia Biotech, Freiburg \\
\hline Lineblot Apparatur & & Eigenbau \\
\hline Lumineszenz Image Reader & LAS-4000 & Fujifilm, Düsseldorf \\
\hline Magnetrührer & RCT basic & IKA Labortechnik, Staufen \\
\hline Mikrotiterschüttelplatte & MTS 4 & IKA Labortechnik, Staufen \\
\hline Nano-Drop & 1000 & Thermo Scientific, Schwerte \\
\hline pH-Meter & 766 Calimatic & Knick, Berlin \\
\hline Photometer & Ultraspec 1000 & Pharmacia Biotech, Freiburg \\
\hline Pipetten & $\begin{array}{l}\text { Reference } 10 \mu \mathrm{l} \\
\text { Reference } 100 \mu \mathrm{l} \\
\text { Research } 200 \mu \mathrm{l} \\
\text { Reference } 1000 \mu \mathrm{l}\end{array}$ & $\begin{array}{l}\text { Eppendorf, Hamburg } \\
\text { Eppendorf, Hamburg } \\
\text { Eppendorf, Hamburg } \\
\text { Eppendorf, Hamburg }\end{array}$ \\
\hline Pipettierhilfen & $\begin{array}{l}\text { Pipetus Akku } \\
\text { Pipetboy acu }\end{array}$ & $\begin{array}{l}\text { Hirschmann, Eberstadt } \\
\text { IBS, Zizers, Schweiz }\end{array}$ \\
\hline
\end{tabular}


Tab. 2.1 Fortsetzung

\begin{tabular}{|c|c|c|}
\hline Gerät & Modell & Hersteller \\
\hline Plattenphotometer & LP 400 & $\begin{array}{l}\text { Sanofi Diagnostic Pasteur, } \\
\text { Wien }(A)\end{array}$ \\
\hline Schüttelinkubator & $\begin{array}{l}\text { SM-30 Control } \\
3020\end{array}$ & $\begin{array}{l}\text { Johanna Otto GmbH, } \\
\text { Hechingen } \\
\text { GFL, Burgwedel }\end{array}$ \\
\hline SDS-PAGE & MiniProtean TetraCell & Bio-Rad, München \\
\hline Spannungsgeräte & $\begin{array}{l}\text { Power-Pac HC } \\
\text { EPS 2A200 }\end{array}$ & $\begin{array}{l}\text { Bio-Rad, München } \\
\text { Hoefer, Holliston, MA, USA }\end{array}$ \\
\hline Sterilbank & BDK-S 1800 & $\begin{array}{l}\text { Luft- und Reinraum Technik, } \\
\text { Sonnenbühl }\end{array}$ \\
\hline Thermocycler & T3 & Biometra, Göttingen \\
\hline Thermomixer & Thermomixer Compact & Eppendorf, Hamburg \\
\hline Überkopfschüttler & & Renner GmbH, Dannstadt \\
\hline Ultraschallgerät & Cell Disrupter B15 & $\begin{array}{l}\text { Branson Sonifier, } \\
\text { Dietzenbach }\end{array}$ \\
\hline Vortexer & Reax Top & Heidolph, Kelheim \\
\hline Waagen & $\begin{array}{l}\text { BP } 221 \mathrm{~S} \\
\text { LP } 6200 \mathrm{~S}\end{array}$ & $\begin{array}{l}\text { Sartorius, Göttingen } \\
\text { Sartorius, Göttingen }\end{array}$ \\
\hline Wasserbad & & GFL, Burgwedel \\
\hline Zellkulturmikroskop & DM IL & Leica, Heidelberg \\
\hline Zentrifugen & $\begin{array}{l}\text { Multifuge 3-SR } \\
\text { Megafuge 2.0 RS } \\
\text { Megafuge } 2.0 \\
5417 \mathrm{R} \\
5417 \mathrm{C} \\
\text { Avanti }^{\mathrm{TM}} \text { J-25 }\end{array}$ & $\begin{array}{l}\text { Heraeus, Hanau } \\
\text { Heraeus, Hanau } \\
\text { Heraeus, Hanau } \\
\text { Eppendorf, Hamburg } \\
\text { Eppendorf, Hamburg } \\
\text { Beckman, Krefeld }\end{array}$ \\
\hline
\end{tabular}

\subsubsection{Software}

Lasergene $^{\circledR} \quad$ DNASTAR, Madison, WI, USA

Multi Gauge Fujifilm, Düsseldorf

ImageJ W. Rasband, National Institutes of Health, USA (http://rsbweb.nih.gov/ij) 


\subsubsection{Chemikalien und Hilfsmittel}

\subsubsection{Enzyme}

Restriktionsendonukleasen

Taq-Polymerase

New England Biolabs, Frankfurt

Pfu-Polymerase

Roche, Mannheim

Fermentas, St. Leon-Rot

Antarctic Phosphatase

T4 DNA Quick Ligase

Trypsin Gold, Mass Spectrometry Grade

New England Biolabs, Frankfurt

New England Biolabs, Frankfurt

Promega, Mannheim

RNase A

Sigma-Aldrich, München

DNase I

Sigma-Aldrich, München

\subsubsection{Chemikalien}

GeneRuler 100 bp / 1 kb Ladder

Prestained Protein Marker, Broad Range

Prestained peqGOLD Protein-Marker IV

Nukleotide (dNTPs)

IPG Cover Fluid

Repel Silane ES

IPG-Puffer pH 3-10 NL

Protease-Inhibitor, EDTA frei

Strip-Holder Cleaning Solution

ECL-Reaktionslösung

Fermentas, St. Leon-Rot

New England Biolabs, Frankfurt

Peqlab, Erlangen

Roche, Mannheim

GE Healthcare, München

GE Healthcare, München

GE Healthcare, München

Roche, Mannheim

GE Healthcare, München

GE Healthcare, München

\subsubsection{Kommerzielle Kits}

QIAquick ${ }^{\circledR}$ PCR Purification Kit

Qiagen, Hilden

QIAEX $\|^{\circledR}$ Gel Extraction Kit

Qiagen, Hilden

GeneElute ${ }^{\text {TM }}$ Plasmid Mini-Prep Kit

Sigma-Aldrich, München

peqGOLD Tissue DNA Mini Kit

Pierce ${ }^{\circledR}$ BCA Protein Assay Kit

GeneElute $^{\mathrm{TM}}$ Mammalian Total RNA Kit

PeqLab, Erlangen

Thermo Scientific, Rockford, IL, USA

Sigma-Aldrich, München

Transcriptor High Fidelity cDNA Synthesis Kit

Roche, Mannheim

\subsubsection{Verbrauchsmaterialien für die Zellkultur}

Verbrauchsmaterialien für die Zellkultur wurden von folgenden Firmen bezogen: Nunc, Roskilde, Dänemark; Falcon, Becton-Dickinson, Heidelberg; Corning/Costar, Bodenheim; Greiner, Frickenhausen; Braun, Melsungen. 


\subsubsection{Sonstige Verbrauchsmaterialien}

Hybond-P PVDF Blotmembran

Whatmanpapier

$18 \mathrm{~cm}$ IPG Immobiline Dry Strips pH 3-10 NL Ni-NTA Agarose

PD-10 Säulen

Halbmikro-Einmalküvetten

Vivaspin2 Säulen
GE Healthcare, München

Rettberg, Göttingen

GE Healthcare, München

Qiagen, Hilden

GE Healthcare, München

Brand, Wertheim

Sartorius Stedim Biotech, Göttingen

\subsubsection{Oligonukleotide}

Alle Oligonukleotide wurden, wenn nicht anders angegeben, von Sigma-Genosys (Darmstadt) bezogen.

Tab. 2.2: Auflistung der verwendeten Oligonukleotide. Die Restriktionsschnittstellen sind unterstrichen.

\begin{tabular}{|c|c|}
\hline Name des Primers: & Sequenz 5' - 3' \\
\hline TgSAG1AS49-322f & GTA TTA GCA TGC GAT CCC CCT CTT GTT G \\
\hline TgSAG1AS49-322r & 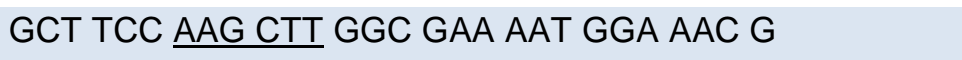 \\
\hline TgGRA7AS19-226f & NNN NNN GCA TGC GCT TTG CCC CAG TTC GCT ACC G \\
\hline TgGRA7AS19-226r & 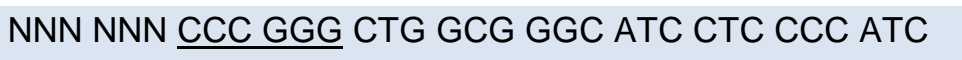 \\
\hline TgSUB1AS 552-772f & GAT ATT GCA TGC GCA GAA GGT CGG CAC AAG \\
\hline TgSUB1 AS552-772r & 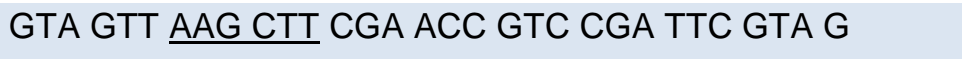 \\
\hline TgSAG4AS24-139f & GTA AAA GCA TGC CGA GTG CGG GCA AAG AGC \\
\hline TgSAG4AS24-139r & 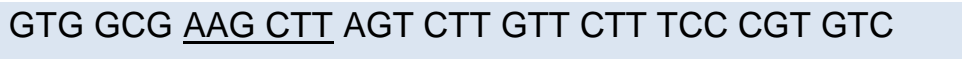 \\
\hline TgROP9AS66-348f & GAT TTA GCA TGC GGA AAA CCC CAA GGA TCG \\
\hline TgROP9AS66-348r & GCT CAG AAG CTT ATC AAA GCC TTC ATG GCC \\
\hline TgGRA1AS26-190f & GTA AAA GGA TCC GAA GGC GGC GAC AAC CAG \\
\hline TgGRA1AS26-190r & GGC ACT GTC GAC CTC TCT CTC TCC TGT TAG \\
\hline TgGRA2AS37-185f & GAT TTT GCA TGC GTG CCT TTC AGC GGT AAA CC \\
\hline TgGRA2AS37-185f & 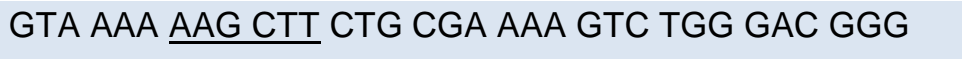 \\
\hline TgROP1AS41-396f & GAA TAA GCA TGC CTC TCT TCC AAC GGC GAG \\
\hline TgROP1AS41-396r & 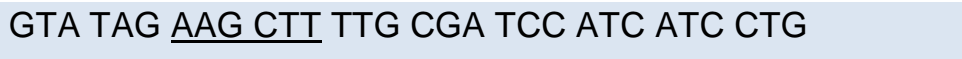 \\
\hline TgGRA6AS1-221f & GTA TTC GCA TGC GAC AGC GGT GGT GTT AGG \\
\hline TgGRA6AS1-221f & GTT CCT AAG CTT CTC ATT CAC ACT TCC CGG GTG \\
\hline pQE Promotor Region & CCC GAA AAG TGC CAC CTG \\
\hline pQE reverse Sequencing & GTT CTG AGG TCA TTA CTG G \\
\hline
\end{tabular}




\subsubsection{Antikörper}

Alle Antikörper, wenn nicht anders angegeben, von Dianova (Hamburg) bezogen.

\section{Primärantikörper}

Maus anti-(His) $)_{5}$ BSA frei

(Qiagen, Hilden)

Sekundärantikörper

AP-konjugiertes Ziege-anti-Maus IgG $(\mathrm{H}+\mathrm{L})$

HRP-konjugiertes Ziege anti-Maus IgG $(\mathrm{H}+\mathrm{L})$

HRP-konjugiertes Ziege anti-Human IgM, $\mathrm{Fc}_{5 \mu}$ Fragment spezifisch

HRP-konjugiertes Kaninchen anti-Human $\lg \mathrm{G}(\mathrm{H}+\mathrm{L})$

HRP-konjugiertes Kaninchen anti-Human Serum IgA, $\alpha$-Kette spezifisch

HRP-konjugiertes Ziege anti-Pute IgG $(\mathrm{H}+\mathrm{L})$

(Medac, Wedel)

HRP-konjugiertes Ziege anti-Schwein IgG $(\mathrm{H}+\mathrm{L})$

HRP-konjugiertes Kaninchen anti-Huhn $\lg Y(\lg G)(H+L)$

\subsubsection{Plasmide, Zelllinien und T. gondii-Stämme}

\subsubsection{Zelllinien}

Wirtszellen HFF (Humane Vorhaut-Fibroblasten (human foreskin fibroblasts)) L929 (Mausfibroblasten)

T. gondii-Stämme $\quad \mathrm{RH}$ (Genotyp I)

NTE (Genotyp II)

\subsubsection{Bakterienstämme (Escherichia coli)}

Tab. 2.3: Auflistung der verwendeten E. coli-Stämme

\begin{tabular}{|c|c|c|}
\hline Stamm & Genotyp & Quelle \\
\hline $\mathrm{DH} 5 \alpha$ & $\begin{array}{l}\mathrm{F}^{-} \text {p80lacZDM15 } \Delta(\text { lacZYA-argF }) \cup 169 \\
\left.\text { recA1 endA1 hsdR17( } \mathrm{r}_{\mathrm{k}}^{-}, \mathrm{m}_{\mathrm{k}}^{+}\right) \text {phoA } \\
\text { supE44 thi-1 gyrA96 relA1 } \lambda^{-}\end{array}$ & Invitrogen, Karlsruhe \\
\hline $\begin{array}{l}\text { BL21 CodonPlus } \\
\text { (DE3)-RIL }\end{array}$ & $\begin{array}{l}\text { B F ompT hsdS }\left(r_{B}^{-} m_{B}^{-}\right) \text {dcm }^{+} \text {Tet }^{r} \text { gal } \lambda \\
\left.\text { (DE3) endA Hte[argU ileY leuW Cam }{ }^{r}\right]\end{array}$ & $\begin{array}{l}\text { Stratagene, La Jolla, } \\
\text { CA (USA) }\end{array}$ \\
\hline Rosetta $^{\text {TM }} 2$ (DE3) & $\begin{array}{l}\mathrm{F}^{-} \text {ompT } h s d S_{\mathrm{B}}\left(\mathrm{r}_{\mathrm{B}}^{-} \mathrm{m}_{\mathrm{B}}^{-}\right) \text {gal dcm (DE3) } \\
\text { pRARE2 }\left(\mathrm{Cam}^{\mathrm{R}}\right)\end{array}$ & $\begin{array}{l}\text { Merck KGaA, } \\
\text { Darmstadt }\end{array}$ \\
\hline
\end{tabular}




\subsubsection{Plasmide}

Tab. 2.4: Auflistung der verwendeten Plasmide

\begin{tabular}{|c|c|c|}
\hline Plasmid & Beschreibung & Quelle \\
\hline pQE-30 & $\begin{array}{l}3.461 \text { bp Expressionsvektor; codiert für } \\
\text { N-terminalen } 6 x \text { His-Tag, Amp }{ }^{R}\end{array}$ & Qiagen, Hilden \\
\hline pQETgBAG1 & $\begin{array}{l}\text { bag1 aus Toxoplasma gondii (NTE) in } \\
\text { pQE-31 kloniert, 5'-His-bag1 Fusion, } \\
\text { Amp }^{R}\end{array}$ & (Bohne et al., 1995) \\
\hline pQETgSAG1 & $\begin{array}{l}822 \text { bp Hind III Sph/ sag1-Fragment aus } \\
\text { Toxoplasma gondii (RH) in pQE-30 } \\
\text { kloniert, 5'-His-sag1 Fusion, Amp }\end{array}$ & diese Arbeit \\
\hline pQETgSAG4 & $\begin{array}{l}348 \text { bp Sph/ Hind/II sag4-Fragment aus } \\
\text { Toxoplasma gondii (NTE) in pQE-30 } \\
\text { kloniert; 5'-His-sag4 Fusion, Amp }{ }^{\mathrm{R}}\end{array}$ & diese Arbeit \\
\hline pQETgGRA1 & $\begin{array}{l}494 \text { bp BamH/ Sal/ gra1-Fragment aus } \\
\text { Toxoplasma gondii (NTE) in pQE-30 } \\
\text { kloniert; 5'-His-gra1 Fusion, Amp }\end{array}$ & diese Arbeit \\
\hline pQETgGRA2 & $\begin{array}{l}446 \text { bp Sph/ Hind/II gra2-Fragment aus } \\
\text { Toxoplasma gondii (NTE) in pQE-30 } \\
\text { kloniert; 5'-His-gra2 Fusion, Amp }{ }^{R}\end{array}$ & diese Arbeit \\
\hline pQETgGRA6 & $\begin{array}{l}530 \mathrm{bp} \text { Sph/ Hind III aus Toxoplasma } \\
\text { gondii (NTE) in } \mathrm{pQE}-30 \text { kloniert; 5'-His- } \\
\text { gra6 Fusion, Amp }{ }^{R}\end{array}$ & diese Arbeit \\
\hline pQETgGRA7 & $\begin{array}{l}654 \text { bp Sph/ Xmal gra7-Fragment aus } \\
\text { Toxoplasma gondii (RH) in pQE-30 } \\
\text { kloniert, 5'-His-gra7Fusion, Amp }{ }^{R}\end{array}$ & diese Arbeit \\
\hline pQETgROP1 & $\begin{array}{l}1.134 \mathrm{bp} \mathrm{Sph/} \mathrm{Hind/II} \mathrm{rop1-Fragment} \\
\text { aus Toxoplasma gondii (NTE) in pQE- } \\
30 \text { kloniert; } 5 \text { '-His-rop1 Fusion, Amp }{ }^{\mathrm{R}}\end{array}$ & diese Arbeit \\
\hline pQETgROP9 & $\begin{array}{l}848 \text { bp Sph/ Hind/II rop9-Fragment aus } \\
\text { Toxoplasma gondii (NTE) in pQE-30 } \\
\text { kloniert; 5'-His-rop9 Fusion, Amp }{ }^{R}\end{array}$ & diese Arbeit \\
\hline pQETgSUB1 & $\begin{array}{l}660 \text { bp Sph/ Hind III sub1 C-Terminus } \\
\text { Region aus Toxoplasma gondii (NTE) in } \\
\text { pQE-30 kloniert; 5'-His-sub1 Fusion, } \\
\text { Amp }^{R}\end{array}$ & diese Arbeit \\
\hline
\end{tabular}




\subsubsection{Medien und Medienzusätze}

\subsubsection{Medien und deren Zusätze für die Zellkultur}

Medien

Roswell Park Memorial Institute (RPMI) 1640 Medium mit 300 mg/l L-Glutamin und 2 g/l $\mathrm{NaHCO}_{3}, \mathrm{pH} 7,2$

Dulbecco's Modifiziertes Eaggle Medium (DMEM) mit 4,5 g/l Glucose, $580 \mathrm{mg} / \mathrm{l}$ L-Glutamin, HEPES und 3,7 g/l $\mathrm{NaHCO}_{3}, \mathrm{pH} 7,2$

\section{Medienzusätze}

Penicillin / Streptomycin (Pen-Strep), $10.000 \mathrm{U} / 10.000 \mu \mathrm{g} / \mathrm{ml}$

Fötales Kälberserum (FCS); inaktiviert durch 45 min Inkubation bei $56{ }^{\circ} \mathrm{C}$

EDTA (Versen) $1 \%$ in PBS ohne $\mathrm{Ca}^{2+}, \mathrm{Mg}^{2+}$

Trypsin (1:250) $0,25 \%$ in PBS ohne $\mathrm{Ca}^{2+}, \mathrm{Mg}^{2+}$

L-Glutamin, $200 \mathrm{mM}$

$\mathrm{NaHCO}_{3} 7,5 \%$ in PBS

Alle Medien und Zusätze wurden von Biochrom, Berlin bezogen.

\subsubsection{Medien und deren Zusätze für die Bakterienkultur}

\section{Medien}

\section{LB-Medium}

$1 \%(w / v)$ Bacto-Trypton

$0,5 \%(w / v)$ Bacto-Hefeextrakt

$0,5 \%(w / v) ~ N a C l$

\section{LB-Agar}

$1 \%(w / v)$ Bacto-Trypton

$0,5 \%(w / v)$ Bacto-Hefeextrakt

$0,5 \%(w / v) ~ N a C l$

$1,5 \%(w / v)$ Bacto-Agar

\section{SOC-Medium}

$2 \%$ Trypton

$0,5 \%$ Hefeextrakt $\quad 10 \mathrm{mM} \mathrm{MgCl}_{2}$

$10 \mathrm{mM} \mathrm{NaCl} \quad 10 \mathrm{mM} \mathrm{MgSO}_{4}$

$2,5 \mathrm{mM} \mathrm{KCl} \quad 20 \mathrm{mM}$ Glucose

\section{Antibiotikazusätze}

Die Antibiotika wurden als Konzentrat angesetzt und steril filtriert. Sie wurden dem autoklavierten Medium unter sterilen Bedingungen zugesetzt. Dabei wurden folgende Endkonzentrationen verwendet: 


$\begin{array}{lrrr}\text { Ampicillin } & 100 \mu \mathrm{g} / \mathrm{ml} & \text { Stammlösung } & 100 \mathrm{mg} / \mathrm{ml} \text { in } 50 \% \text { Ethanol } \\ \text { Chloramphenicol } & 34 \mu \mathrm{g} / \mathrm{ml} & \text { Stammlösung } & 34 \mathrm{mg} / \mathrm{ml} \text { in } 100 \% \text { Ethanol }\end{array}$

Die Stammlösungen wurden bei $-20^{\circ} \mathrm{C}$ gelagert.

\section{Sonstige Medienzusätze}

Zur Kultivierung von Bakterien wurden zusätzliche Medienzusätze verwendet. Die Endkonzentrationen waren folgende:

IPTG $\quad 0,1-1 \mathrm{mM} \quad$ Stammlösung $1 \mathrm{M}$ in $\mathrm{ddH}_{2} 0$

Die Stammlösungen wurden bei $-20^{\circ} \mathrm{C}$ gelagert.

\subsection{Mikrobiologische Arbeitsmethoden}

\subsubsection{Sterilisation}

Wenn nicht anders angegeben wurden alle Medien, Puffer, Glas- und Plastikgefäße für $20 \mathrm{~min}$ bei $121^{\circ} \mathrm{C}$ und 1 bar dampfsterilisiert. Temperaturempfindliche Substanzen wurden mit Hilfe eines Sterilfilters mit einer Porengröße von 0,2 $\mu \mathrm{m}$ steril filtriert.

\subsubsection{Bestimmung der Zelldichte}

Die Zelldichte der Bakterien- und Hefekulturen wurde durch Messung der OD bei $600 \mathrm{~nm}$ im Photometer (Ultraspec 1000) bestimmt. Bei einer $\mathrm{OD}_{600}>0.6$ wurde eine Verdünnung von 1:10 vermessen. Eine $\mathrm{OD}_{600}$ von 1 entspricht hierbei einer Zellzahl von ca. $1 \times 10^{9}$ Zellen pro ml Kultur.

\subsubsection{Bakterienkultivierung}

Für die Expression rekombinanter Proteine T. gondii-Antigene wurden die E. coliStämme BL21CodonPlus ${ }^{\circledR}$ (DE3)-RIL bzw. Rosetta ${ }^{\text {TM }} 2$ (DE3) verwendet. Beide Stämme verwenden ein T7-Expressionssystem und stellen tRNAs für die in Eukaryoten häufiger verwendeten Codons AGA, AGG, AUA und CUA zu Verfügung. Der Rosetta ${ }^{\mathrm{TM}}$ 
2 (DE3)-Stamm besitzt zu dem drei weitere tRNAs für die Codons GGA, CCC und CGG und ist somit besonders geeignet für die Expression eukaryotischer Proteine.

Für Vorkulturen wurden entweder $5 \mathrm{ml}$ in einem Reagenzglas oder 10-30 ml LB-Medium in einem 100 ml-Schüttelkolben mit entsprechenden Antibiotikazusätzen angesetzt. Angeimpft wurde entweder aus einer Glycerinkultur oder von einer Einzelkolonie einer LB-Agar-Platte mit einer sterilen Pipettenspitze. Die Kultur wurde über Nacht bei $37^{\circ} \mathrm{C}$ und $200 \mathrm{rpm}$ auf einem Schüttler inkubiert. Ausgehend von der Vorkultur wurde eine Hauptkultur im Verhältnis 1:100 in einem 2 L-Schikanekolben mit entsprechenden Antibiotikazusätzen angeimpft und bei $37^{\circ} \mathrm{C}$ und $200 \mathrm{rpm}$ bis zur gewünschten optischen Dichte (OD) inkubiert.

Für die Induktion der Proteinexpression wurde dem Medium bei einer ${ } D_{600}$ von 0,5 Isopropyl- $\beta-D$-thiogalactopyranosid (IPTG) in einer Endkonzentration von 0,5-1 $\mu \mathrm{M}$ zugegeben.

\subsubsection{Herstellung kompetenter E. coli-Zellen}

Zur Herstellung kompetenter E. coli-Zellen wurde eine $100 \mathrm{ml}$-Flüssigkultur mit $2 \mathrm{ml}$ einer über Nacht Vorkultur angeimpft und bis $\mathrm{OD}_{600}$ von $0,5-0,6$ inkubiert. Nach Zentrifugation $\left(4.000 \times \mathrm{g}, 10 \mathrm{~min}, 4^{\circ} \mathrm{C}\right)$ wurde das Sediment ein Mal in $30 \mathrm{ml}$ eiskalter, steriler TFB I-Lösung resuspendiert und dann für 30 min auf Eis inkubiert. Danach wurden die Zellen wieder sedimentiert $\left(4.000 \times \mathrm{g}, 10 \mathrm{~min}, 4^{\circ} \mathrm{C}\right)$. Anschließend wurde das Sediment in $4 \mathrm{ml}$ TFB II-Lösung resuspendiert und erneut für $30 \mathrm{~min}$ auf Eis inkubiert. Die Zellen wurden entweder sofort für die Transformation verwendet oder in $100 \mu \mathrm{l}$-Aliquots bei $-80^{\circ} \mathrm{C}$ gelagert.

Lösungen zur Präparation von chemisch kompetenten E. coli-Zellen

$\begin{array}{lll}\text { TFB I } & \text { Rubidiumchlorid }\left(\mathrm{RbCl}^{2}\right) & 100 \mathrm{mM} \\ & \text { Manganchlorid }\left(\mathrm{MnCl}_{2}\right) & 50 \mathrm{mM} \\ & \text { Kaliumacetat } & 30 \mathrm{mM} \\ & \text { Calciumchlorid }\left(\mathrm{CaCl}_{2}\right) & 10 \mathrm{mM} \\ & \text { Glycerin } & 15 \%(\mathrm{v} / \mathrm{v}) \\ & \text { pH 5,8 } & \\ \text { TFB II } & \text { MOPS } & 10 \mathrm{mM} \\ & \text { Rubidiumchlorid }\left(\mathrm{RbCl}^{2}\right) & 10 \mathrm{mM} \\ & \text { Calciumchlorid }\left(\mathrm{CaCl}_{2}\right) & 75 \mathrm{mM} \\ & \text { Glycerin } & 15 \%(\mathrm{v} / \mathrm{v}) \\ & \text { pH 7,0 } & \end{array}$




\subsubsection{Transformation kompetenter E. coli-Zellen}

Für die Transformation wurden $100 \mu \mathrm{l}$ kompetente E. coli-Zellen auf Eis aufgetaut und mit der entsprechenden Menge Plasmid (10-100 pg Plasmid-DNA) versetzt. Es folgte eine 30 min Inkubation auf Eis mit anschließendem Hitzeschock für 1 min bei $42^{\circ} \mathrm{C} \mathrm{im}$ Thermoblock. Der Transformationsansatz wurde anschließend für $5 \mathrm{~min}$ auf Eis inkubiert. Zur Regeneration der Zellen wurde der Transformationsansatz mit $1 \mathrm{ml}$ LBMedium bzw. $500 \mu \mathrm{l}$ SOC-Medium versetzt und für $1 \mathrm{~h}$ bei $37^{\circ} \mathrm{C}$ inkubiert. Von den Ansätzen wurden 25-100 $\mu \mathrm{l}$ abgenommen und auf LB-Agar-Platten mit entsprechenden Antibiotikazusätzen ausplattiert. Die Platten wurden über Nacht bei $37^{\circ} \mathrm{C}$ inkubiert.

Bei Ligationsansätzen wurde der Transformationsansatz nach Inkubation bei $37^{\circ} \mathrm{C} 2 \mathrm{~min}$ bei 6.000 rpm sedimentiert. Anschließend wurde vom Überstand $500 \mu \mathrm{l}$ abgenommen. Das Pellet wurde in den verbleibenden $100 \mu \mathrm{l}$ resuspendiert und vollständig auf LBAgar-Platten mit entsprechenden Antibiotikazusätzen ausplattiert.

\subsubsection{Lagerung von Bakterien}

Zur längerfristigen Lagerung von Bakterien wurden 50\%ige (v/v) Glycerinkulturen angelegt. Dazu wurden in einem äquivalenten Verhältnis einer über Nacht Vorkultur mit $87 \%$ igem (v/v) Glycerin gründlich vermischt und bei $-80^{\circ} \mathrm{C}$ gelagert.

Eine kurzfristige Lagerung von bis zu 2 Wochen erfolgte bei $4^{\circ} \mathrm{C}$ auf LB-Agar-Platten.

\subsection{Zellbiologische Arbeitsmethoden}

Alle Arbeiten mit Zellkulturen wurden unter Laminar-Flow-Sicherheitswerkbänken unter sterilen Bedingungen durchgeführt. Die Kultivierung der eukaryotischen Wirtszellen sowie von $T$. gondii fand bei $37^{\circ} \mathrm{C}, 5 \% \mathrm{CO}_{2}$ und wasserdampfgesättigter Luftfeuchtigkeit in einem Brutschrank statt.

\subsubsection{Kultivierung der L929-Wirtszellen}

Die Mausfibroblasten dienten als Wirtszellen für die Passagierung der Toxoplasmen. L929-Zellen wurden in 6-Lochplatten mit $3 \mathrm{ml}$ DMEM-Medium mit 1\% FCS, $100 \mathrm{U} / \mathrm{ml}$ Penicillin, $100 \mathrm{mg} / \mathrm{ml}$ Streptomycin, $1 \mathrm{mM}$ Natriumpyruvat und $1 \mathrm{x}$ nicht-essenzielle Aminosäuren kultiviert. 
Zweimal pro Woche wurden die Zellen mit einem Zellkulturspatel vom Boden der Lochplatte gelöst und in Medium resuspendiert. In jeder Vertiefung der 6-Lochplatten wurden 250-350 $\mu \mathrm{l}$ der Zellsuspension mit frischem Medium gemischt. Die übrige Zellsuspension wurde für die Kokultur mit Toxoplasmen verwendet.

\subsubsection{Kultur und Isolierung von T. gondii in L929}

Für die meisten Versuche wurde der Maus-avirulente T. gondii-Stamm NTE verwendet. Die Toxoplasmen wurden als Tachyzoiten kultiviert, als Nährmedium diente RPMI 1640Medium mit 1\% FCS, $100 \mathrm{U} / \mathrm{ml}$ Penicillin und $100 \mathrm{mg} / \mathrm{ml}$ Streptomycin. Die Kultur erfolgte in 12-Lochplatten, in die in unterschiedlichen Verhältnissen eine L929Zellsuspension $\left(5 \times 10^{4}-1,3 \times 10^{5}\right.$ Zellen) und eine Toxoplasmen-Suspension $\left(8 \times 10^{5}\right.$ $2,5 \times 10^{6}$ Toxoplasmen) angesetzt wurden. Die Vertiefungen der Platte wurden mit 1,5 ml Medium aufgefüllt. Die Wirtszellen und Toxoplasmen wurden so lange inkubiert, bis die Mehrzahl der L929-Zellen durch die Parasitenvermehrung ruptiert waren. Dann wurden die Toxoplasmen isoliert. Für Infektionsversuche wurden in der Regel Toxoplasmen verwendet, die für zehn Tage mit frischen L929-Zellen kokultiviert worden waren. Zur Isolierung der Toxoplasmen wurden die L929-Zellen durch Zentrifugation bei $400 \mathrm{x} \mathrm{g}$ für 5 min sedimentiert und der Toxoplasmen-haltige Überstand in ein neues Röhrchen überführt. Die Toxoplasmen wurden danach zweimal bei $2.500 \times \mathrm{g}$ für $10 \mathrm{~min}$ zentrifugiert und in Nährmedium gewaschen.

\subsubsection{Kultur und Passagierung der humanen Vorhaut-Fibroblasten (HFF)}

Als Wirtszellinie zur Kultivierung von T. gondii wurden humane Vorhaut-Fibroblasten (human foreskin fibroblasts, HFF) verwendet. Diese wurden in $25 \mathrm{~cm}^{2}$ bis $175 \mathrm{~cm}^{2}$ Zellkulturflaschen in DMEM mit 10\% FCS, $100 \mathrm{U} / \mathrm{ml}$ Penicillin und $100 \mu \mathrm{g} / \mathrm{ml}$ Streptomycin (Pen-Strep) kultiviert. Nach spätestens 4 Wochen wurden sie zur Passagierung mit 4-8 $\mathrm{ml}$ 1\% EDTA in PBS gespült und dann mit 4-8 $\mathrm{ml}$ 0,25\% Trypsin in PBS inkubiert, bis sie vollständig vom Untergrund abgelöst waren. Anschließend wurde $10 \mathrm{ml} \mathrm{HFF-Medium} \mathrm{hinzu} \mathrm{gegeben} \mathrm{und} \mathrm{die} \mathrm{HFF-Zellen} \mathrm{bei} 400 \times \mathrm{g}$ pelletiert. Nach einmaligem Waschen mit 1x PBS wurden die Zellen in HFF-Medium aufgenommen und auf neue Zellkulturflaschen verteilt. Die Inkubation fand unter den Standardbedingungen von eukaryotischen Zellen statt. 


\subsubsection{Kultur und Isolierung von T. gondii in HFF-Zellen}

Für die Kultivierung von T. gondii wurden zunächst die HFF-Zellen in einer $175 \mathrm{~cm}^{2}$ Zellkulturflasche bis zur Konfluenz herangezogen. Anschließend wurden die Wirtszellen mit Toxoplasmen infiziert und für 3-5 Tage unter den Standardbedingungen für eukaryotische Zellen inkubiert. Nach vollständiger Ruptur der Wirtszellen durch die sich vermehrenden T. gondii wurde der Inhalt einer Zellkulturflasche resuspendiert und die Toxoplasmen über eine Filtrationsanlage mit einem 0,2 $\mu \mathrm{m}$ Sterilfilter (Millipore) filtriert. Dabei passieren die Toxoplasmen den Filter und verbliebene Verunreinigungen durch Wirtszellen wurden zurückgehalten. Das Filtrat wurde anschließend in ein $50 \mathrm{ml}$ Falkonröhrchen überführt, bei $2.500 \mathrm{rpm}$ für $10 \mathrm{~min}$ bei RT zentrifugiert und der Überstand verworfen. Das Pellet wurde ein Mal in $10 \mathrm{ml}$ 1x PBS gewaschen, gefolgt von einer weiteren Zentrifugation bei $2.500 \mathrm{rpm}$ für $10 \mathrm{~min}$ bei RT. Nach Abnahme des Überstandes wurde das Pellet in 1,5 ml 1x PBS resuspendiert und die Zellzahl mit einer Neubauer-Zählkammer mikroskopisch bestimmt. Die Menge der isolierten Parasiten wurde durch Multiplikation der durchschnittlichen Zellzahl pro Großquadrat mit dem Suspensionsvolumen, dem Verdünnungsfaktor und der Konstanten $10^{4}$ berechnet. Die Toxoplasmen-Suspension wurde in ein Eppendorf-Reaktionsgefäß überführt, bei 4.000 rpm für 10 min zentrifugiert und der Überstand verworfen. Das Pellet wurde bis zur weiteren Verwendung bei $-80^{\circ} \mathrm{C}$ gelagert.

\subsubsection{Einfrieren und Auftauen von Zellen}

Zur längeren Lagerung von Zellen wurden diese in flüssigem Stickstoff eingefroren. Dazu wurden Zellsuspensionen des entsprechenden Zellkulturmediums mit demselben Volumen 2x Einfriermedium gemischt und in Kryoröhrchen aliquotiert. Die Zellen wurden einige Tage in einem Styroporblock auf $-80^{\circ} \mathrm{C}$ herunter gekühlt und später in flüssigen Stickstoff überführt.

Zum Auftauen wurden die Zellen aus dem flüssigen Stickstoff in einem $37^{\circ} \mathrm{C}$ warmen Wasserbad angetaut, zügig in warmes Zellkulturmedium gegeben, gleichmäßig verteilt und bei $37{ }^{\circ} \mathrm{C}$ und $5 \% \mathrm{CO}_{2}$ inkubiert. Am folgenden Tag wurde ein Medienwechsel durchgeführt, da das restliche DMSO des Einfriermediums das Wachstum der Zellen beeinflusste.

2x Einfriermedium:

$40 \%(v / v)$ DMEM

$40 \%(\mathrm{v} / \mathrm{v}) \mathrm{FCS}$

$20 \%(v / v)$ Dimethylsulfoxid (DMSO) 


\subsection{Molekularbiologische Arbeitsmethoden}

\subsubsection{Isolierung von genomischer DNA aus T. gondii}

Für die Gewinnung von genomischer DNA (gDNA) aus $T$. gondii wurde das peqGOLD Tissue DNA Mini Kit (PeqLab) verwendet. Zunächst wurden von einer $25 \mathrm{~cm}^{2}$ Gewebekulturflasche die Toxoplasmen aus HFF-Zellen isoliert. Hierfür wurde der Inhalt einer Flasche bei $400 \mathrm{rpm}$ für $5 \mathrm{~min}$ zentrifugiert, der Überstand in ein neues Falkonröhrchen überführt und die Toxoplasmen bei $2.500 \mathrm{rpm}$ für $10 \mathrm{~min}$ sedimentiert. Anschließend wurde das Pellet in $400 \mu \mathrm{l}$ TL-Puffer vorsichtig resuspendiert und in ein $1,5 \mathrm{ml}$ Eppendorf-Reaktionsgefäß überführt. Des Weiteren wurde der Suspension $25 \mu \mathrm{l}$ $\mathrm{OB}^{\mathrm{Tm}}$-Protease hinzugefügt und bei $55^{\circ} \mathrm{C}$ im Thermoblock bei $400 \mathrm{rpm}$ für $1 \mathrm{~h}$ inkubiert. Nach der Inkubation wurden $500 \mu \mathrm{g}$ RNase A zugegeben und für 2 min bei RT inkubiert. Anschließend wurde $440 \mu \mathrm{l} \mathrm{BL-Puffer} \mathrm{zugefügt,} \mathrm{gemischt} \mathrm{und} \mathrm{für} 10 \mathrm{~min}$ bei $70^{\circ} \mathrm{C}$ inkubiert. Außerdem wurde $440 \mu \mathrm{l} 100 \%$ iges Ethanol zugegeben und gemischt. Von dem Ansatz wurden in $650 \mu \mathrm{l}$ auf eine HiBind DNA-Säule und für 1 min bei $8.000 \times \mathrm{g}$ zentrifugiert. Der Vorgang wurde so lange wiederholt bis der komplette Ansatz in der Säule war. Die Säule wurde anschließend in ein neues Eppendorf-Reaktionsgefäß überführt und zwei Mal mit $750 \mu \mathrm{l}$ DNA-Waschpuffer gewaschen. Zwischendurch wurde für $1 \mathrm{~min}$ bei $8.000 \times \mathrm{g}$ zentrifugiert. Nachdem der Durchfluss verworfen wurde, wurde erneut für 2 min bei $10.000 \times g$ zentrifugiert. Anschließend wurde die Säule in ein neues Eppendorf-Reaktionsgefäß überführt und $200 \mu \mathrm{l}$ auf $70^{\circ} \mathrm{C}$ vorgewärmter Elutionspuffer auf die Säule gegeben. Die Säule wurde für $5 \mathrm{~min}$ bei RT stehen gelassen und dann bei $8.000 \times \mathrm{g}$ für $1 \mathrm{~min}$ zentrifugiert. Das Eluat wurde nochmals auf die Säule gegeben und der Elutionsvorgang wurde wiederholt. Die gDNA wurde bis zur weiteren Verwendung bei $-20^{\circ} \mathrm{C}$ gelagert.

\subsubsection{Isolierung von RNA aus $T$. gondii}

Für die Isolierung von RNA aus $T$. gondii wurde das GenElute ${ }^{\text {TM }}$ Mammalian Total RNA Miniprep Kit (Sigma-Aldrich) verwendet.

Ausgehend von isolierten Toxoplasmen aus L929 wurden ca. $2 \times 10^{8}$ Zellen mit $350 \mu \mathrm{l}$ Lysispuffer mit $10 \mu \mathrm{l} / \mathrm{ml}$ 2-Mercaptoethanol versetzt und resuspendiert. Anschließend wurde das Lysat in eine blaue Filtrationsäule überführt und für 2 min bei $14.000 \times \mathrm{g}$ zentrifugiert. Zum Durchfluss wurden $350 \mu \mathrm{l} 70$ \%iger Ethanol gegeben und vorsichtig vermischt. Anschließend wurde das Lysat/Ethanol-Gemisch auf eine farblose Bindesäule gegeben, für $1 \mathrm{~min}$ bei $14.000 \times \mathrm{g}$ zentrifugiert und der Durchfluss 
verworfen. Dann wurde $500 \mu \mathrm{l}$ Waschpuffer 1 auf die Säule gegeben und für 1 min bei $14.000 \times \mathrm{g}$ zentrifugiert. Nach dem ersten Waschschritt wurde die Säule in ein neues Eppendorf-Reaktionsgefäß gestellt und $500 \mu \mathrm{l}$ Waschlösung 2 auf die Säule gegeben. Nach einer 1-minütigen Zentrifugation bei $14.000 \times \mathrm{g}$ wurde der Durchfluss verworfen und der Zentrifugationsschritt wiederholt. Anschließend wurde die Säule in ein neues Eppendorf-Reaktionsgefäß überführt und die RNA mit $50 \mu$ Elutionspuffer eluiert. Nach der Elution der RNA folgte ein DNase-Verdau, in dem der RNA $5 \mu$ 10x DNase I Reaktionspuffer (Sigma-Aldrich) und $5 \mu$ l DNase I (Sigma-Aldrich) zugesetzt wurden. Nach einer 30minütigen Inkubation bei RT wurde $5 \mu$ l Stopplösung (Sigma-Aldrich) zugegeben und $10 \mathrm{~min}$ bei $70^{\circ} \mathrm{C}$ inkubiert.

Anschließend wurde die RNA-Konzentration am Nano-Drop (Nano-Drop 1000) gegen den Elutionspuffer bestimmt. Bis zur weiteren Verwendung wurde die RNA bei $-80^{\circ} \mathrm{C}$ gelagert.

\subsubsection{Präparation von Plasmid-DNA aus E. coli}

Die Präparation von Plasmid-DNA aus E. coli wurde mit dem GenElute ${ }^{\text {TM }}$ Plasmid Minioder Maxi-Prep Kit (Sigma-Aldrich) nach Angaben des Herstellers durchgeführt. Dabei wurden die Bakterien in Gegenwart von RNase A nach dem Prinzip der alkalischen Lyse lysiert und die Lysate durch Zentrifugation von Proteinen und genomischer DNA befreit. Die klaren Lysate wurden anschließend auf Säulen gegeben und die Plasmid-DNA an die Säule gebunden. Weitere Verunreinigungen wurden durch Waschschritte entfernt und die reine Plasmid-DNA in einem kleinen Volumen Wasser aufgenommen.

\subsubsection{Synthese von komplementärer DNA (cDNA)}

Für die Synthese von komplementärer DNA (cDNA) wurde das Transcriptor High Fidelity cDNA Synthesis Kit (Roche) verwendet.

Hierfür wurde zunächst in einem $500 \mu$ l Eppendorf-Reaktionsgefäß auf Eis 0,75-1 $\mu \mathrm{g}$ RNA mit 2,5 $\mu \mathrm{M}$ Anchored-oligo(dT) ${ }_{18}$ Primer versetzt und bis zu einem Volumen von $11,4 \mu \mathrm{l}$ mit $\mathrm{H}_{2} \mathrm{O}$ (PCR Grade) aufgefüllt. Der Ansatz wurde für 10 min bei $65^{\circ} \mathrm{C}$ inkubiert und anschließend sofort wieder auf Eis gestellt. Als nächstes wurde $4 \mu \mathrm{l} 5 \mathrm{x}$ Transcriptor High Fidelity Reverse Transkriptase Reaktionspuffer, 20 U Protector RNase Inhibitor, je $1 \mathrm{mM}$ Deoxynukleotide, $5 \mathrm{mM}$ DTT sowie $10 \mathrm{U}$ Transcriptor High Fidelity Reverse Transkriptase hinzugefügt und vorsichtig vermischt. Anschließend wurde der Ansatz zunächst für $30 \mathrm{~min}$ bei $55^{\circ} \mathrm{C}$ und dann für $5 \mathrm{~min}$ bei $85^{\circ} \mathrm{C}$ inkubiert. 
Für die weitere Verwendung der cDNA wurde diese mit Hilfe des PCR Purification Kit (Qiagen) gereinigt.

\subsubsection{Bestimmung der Nukleinsäurekonzentration}

Die Konzentration der DNA wurde durch Messung der Absorption bei $260 \mathrm{~nm}$ am Photometer (Ultraspec 1000) bestimmt. Zur Kontrolle der Reinheit der DNA wurde parallel die Absorption bei $280 \mathrm{~nm}$ gemessen. Dabei wurde davon ausgegangen, dass eine $A_{260}$ von 1 einer dsDNA-Konzentration von ungefähr $50 \mu \mathrm{g} / \mathrm{ml}$ entspricht. Die Reinheit der DNA ergab sich aus dem Quotienten zwischen $A_{260}$ und $A_{280}$, wobei ein Quotient von 1,8 einer reinen dsDNA-Lösung entspricht.

Alternativ wurde die DNA-Konzentration am Nano-Drop (Nano-Drop 1000) bestimmt.

\subsubsection{Agarosegelelektrophorese}

Bei der Agarosegelelektrophorese werden DNA-Fragmente in einem elektrischen Feld proportional zum negativen Logarithmus ihres relativen Molekulargewichtes aufgetrennt. Die Agarose wurde in TAE-Puffer in einer Mikrowelle aufgekocht und nach dem Abkühlen auf etwa $60{ }^{\circ} \mathrm{C}$ wurde $0,1 \mu \mathrm{g} / \mathrm{ml}$ Ethidiumbromid zugegeben und das Gel zum Abkühlen in eine mit einem Kamm bestückte Flachgelapparatur gegossen. Nach Erstarren der Lösung wurde das Gel in einer Gelkammer mit TAE-Puffer überschichtet und der Kamm entfernt. Die DNA-Proben wurden mit 10x DNA-Probenpuffer versetzt und zusammen mit einem DNA-Molekulargewichtsstandard auf das Gel aufgetragen. Die Elektrophorese erfolgte in einem 1 \%igen Agarosegel für ungefähr 30 min bei einer konstanten Spannung von 120 V. Die DNA-Banden wurden bei einer Wellenlänge von $312 \mathrm{~nm}$ durch Fluoreszenz des interkalierenden Ethidiumbromids sichtbar gemacht. Die Größenbestimmung der DNA erfolgte mittels des Längenstandards „GeneRuler ${ }^{\text {TM }}$ DNA Ladder Mix“.

\section{Lösungen zur Agarosegelelektrophorese}

$\begin{array}{llr}\text { TAE-Puffer } & \text { Tris-Acetat }(\mathrm{pH} 8,0) & 40 \mathrm{mM}\end{array}$

EDTA $1 \mathrm{mM}$




\subsubsection{Extraktion von DNA aus Agarosegelen}

DNA wurde durch Agarosegelelektrophorese aufgetrennt. Die entsprechende DNABande wurde auf einem Transilluminator unter UV-Licht (70\% der normalen Intensität, um DNA-Schäden zu vermeiden) identifiziert, mit einem Skalpell ausgeschnitten und mit Hilfe des QiaExII-Kits der Firma Qiagen isoliert. Das Kit arbeitet mit einer Silika-Matrix, an die selektiv und quantitativ DNA gebunden wird, nachdem die Agarose aufgelöst ist. Dazu wurde das ausgeschnittene Agarosegelfragment in einem Puffer bei $50{ }^{\circ} \mathrm{C}$ gelöst, die gelöste Agarose und der restliche Puffer durch Waschen entfernt und die DNA aus der Silika-Matrix in $\mathrm{H}_{2} \mathrm{O}$ eluiert.

\subsubsection{DNA-Amplifikation mittels Polymerase-Kettenreaktion (PCR)}

Die PCR nach (Saiki et al., 1988) wurde zur Amplifikation von DNA-Fragmenten zur Analyse oder Klonierung verwendet. Die Methode beruht im Prinzip auf zyklischen Wiederholungen von Denaturierung der template-DNA, Anlagerung sequenzspezifischer Oligonukleotide (Primer), und der Synthese einer komplementären DNA-Kopie durch eine thermostabile DNA-Polymerase. Aufgrund des Durchlaufens mehrerer Zyklen kommt es zu einer exponentiellen Vermehrung der durch die Primer flankierten DNASequenz. Zur Amplifizierung von DNA-Fragmenten wurden folgende Bedingungen gewählt:

\section{Taq-Polymerase:}

Template-DNA

Desoxyribonukleotide (dNTPs, $25 \mathrm{mM}$ )

Primer I (10 mM)

Primer II (10 mM)

10x Taq-Puffer $+\mathrm{MgCl}_{2}$

Taq DNA-Polymerase

$$
\begin{array}{r}
10-100 \mathrm{ng} \\
\text { je } 2,5 \mathrm{mM} \\
1 \mu \mathrm{M} \\
1 \mu \mathrm{M} \\
5 \mu \mathrm{l} \\
0,3-0,5 \mathrm{U} \\
\hline \text { ad } 50 \mu \mathrm{H}_{2} \mathrm{O}
\end{array}
$$

Tab. 2.5: PCR-Programm zur Amplifikation von DNA-Fragmenten mit Taq-Polymerase

\begin{tabular}{|l|l|l|}
\hline Temperatur & Zeit & Funktion \\
\hline $95^{\circ} \mathrm{C}$ & $5 \mathrm{~min}$ & Denaturierung \\
$95^{\circ} \mathrm{C}$ & $1 \mathrm{~min}$ \\
spez. ${ }^{*}$ & $1 \mathrm{~min}$ \\
$72^{\circ} \mathrm{C}$ & $1 \mathrm{~min}$ \\
$72^{\circ} \mathrm{C}$ & $7 \mathrm{~min}$ & Denaturierung \\
& & Primer-Anlagerung \\
& & Synthese \\
Syntheseabschluss
\end{tabular}




\section{Pfu-Polymerase:}

Template-DNA

Desoxyribonukleotide (dNTPs, $25 \mathrm{mM}$ )

Primer I $(10 \mu \mathrm{M})$

Primer II (10 mM)

10x Pfu-Puffer $+\mathrm{MgSO}_{4}$

Pfu DNA-Polymerase

$$
\begin{array}{r}
10-100 \mathrm{ng} \\
\text { je } 2,5 \mathrm{mM} \\
1 \mu \mathrm{M} \\
1 \mu \mathrm{M} \\
5 \mu \mathrm{l} \\
0,3-0,5 \mathrm{U} \\
\hline \text { ad } 50 \mu \mathrm{l} \mathrm{H}_{2} \mathrm{O}
\end{array}
$$

Tab. 2.6: PCR-Programm zur Amplifikation von DNA-Fragmenten mit Pfu-Polymerase

\begin{tabular}{|l|l|l|}
\hline Temperatur & Zeit & Funktion \\
\hline $95^{\circ} \mathrm{C}$ & $5 \mathrm{~min}$ & Denaturierung \\
$95^{\circ} \mathrm{C}$ & $1 \mathrm{~min}$ & Denaturierung \\
spez. & & $1 \mathrm{~min}$ \\
$72^{\circ} \mathrm{C}$ & $2 \mathrm{~min}$ \\
$72^{\circ} \mathrm{C}$ & $7 \mathrm{~min}$ & Primer-Anlagerung \\
& & Synthese \\
Syntheseabschluss
\end{tabular}

Der Nachweis von PCR-Produkten erfolgte mittels Agarosegelelektrophorese. Zur Reinigung der PCR-Produkte wurde das QIAquick $^{\circledR}$ PCR-Purification Kit (Qiagen) verwendet.

* Primer-Anlagerungstemperaturen

$\begin{array}{lllllllll}\text { sag1 } & \text { sag4 } & \text { gra1 } & \text { gra2 } & \text { gra6 } & \text { gra7 } & \text { rop1 } & \text { rop9 } & \text { sub1 } \\ 60^{\circ} \mathrm{C} & 65^{\circ} \mathrm{C} & 65^{\circ} \mathrm{C} & 65^{\circ} \mathrm{C} & 65^{\circ} \mathrm{C} & 60^{\circ} \mathrm{C} & 65^{\circ} \mathrm{C} & 65^{\circ} \mathrm{C} & 65^{\circ} \mathrm{C}\end{array}$

\subsubsection{Spalten von DNA mittels Restriktionsendonukleasen}

Durch das Spalten von DNA-Doppelsträngen von Vektor und PCR-Fragment mit den entsprechenden Restriktionsendonukleasen wurden komplementäre „sticky ends“ erzeugt, um die Insertion des Fragments in den Vektor zu ermöglichen. Die Restriktion erfolgte jeweils in den entsprechenden Restriktionspuffern nach Angabe des Herstellers. Die Restriktion von Plasmid-DNA und PCR-Fragmenten wurde in $50 \mu \mathrm{l}$ Ansätzen durchgeführt. Es wurden $10 \mathrm{U}$ der beiden Restriktionsendonukleasen pro $\mu \mathrm{g}$ DNA eingesetzt. Zur Kontrolle der einzelnen Restriktionsansätze erfolgte jeweils auch eine Restriktion des Vektors ohne Insert. Die Restriktion erfolgte für $3-4 \mathrm{~h}$ bei $37^{\circ} \mathrm{C}$. Anschließend wurden die Restriktionsendonukleasen durch 20-minütiges Erhitzen bei $65^{\circ} \mathrm{C}$ im Thermomixer inaktiviert. Zur Entfernung der Restriktionsendonukleasen aus dem Restriktionsansatz wurde anschließend eine Reinigung des Inserts über das 
QIAquick $^{\circledR}$ PCR Purification Kit (Qiagen) durchgeführt. Abweichend von dem Herstellerprotokoll wurde dabei in $30 \mu \mathrm{ld} \mathrm{H}_{2} \mathrm{O}$ eluiert. Der Elution ging eine Inkubation von 10 min bei RT voraus.

Die Größe der geschnittenen Vektoren und Inserts wurden auf einem 1\%igem Agarosegel durch Vergleich mit einem DNA-Standard (GeneRuler ${ }^{\mathrm{TM}}$ DNA Ladder Mix) abgeschätzt.

\subsubsection{Dephosphorylierung von Plasmid-DNA}

Die Dephosphorylierung der 5'-Phosphatenden der geschnittenen Plasmid-DNA erfolgte, um eine mögliche Religation des Vektors zu verhindern. Die PCR-Fragmente wurden nicht dephosphoryliert, so dass eine spätere Ligation mit dem Vektor stattfinden konnte.

Zur Dephosphorylierung wurde die Antarktisch Alkalische Phosphatase (AAP) verwendet. Hierzu wurde der geschnittene Restriktionsansatz mit $10 \cup$ AAP für $1 \mathrm{~h}$ bei $37^{\circ} \mathrm{C}$ inkubiert und anschließend die AAP durch Erhitzen (Thermomixer, $5 \mathrm{~min}, 65^{\circ} \mathrm{C}$ ) inaktiviert. Die dephosphorylierte Plasmid-DNA wurde anschließend mit dem QIAquick $^{\circledR}$ PCR-Purification Kit (Qiagen) gereinigt.

\subsubsection{Ligation von DNA}

Die Ligation von dephosphoryliertem Vektor und Insert erfolgte mittels T4-DNA-Quick Ligase (NEB). In einem $20 \mu \mathrm{l}$ Ansatz wurde dabei etwa ein molares Vektor-Insert Verhältnis von 1:2, 1:4 und 1:6 verwendet. Die eingesetzten DNA-Mengen lagen ca. zwischen 50 und $300 \mathrm{ng}$. Um die eingesetzten DNA-Mengen abzuschätzen, wurden der Vektor und das PCR-Fragment auf einem 1\%igen Agarosegel analysiert. Anhand der Bandenstärke wurde dann die DNA-Konzentration abgeschätzt. Zudem wurde eine Kontrollreaktion ohne Insert angesetzt. Die Ligation wurde in einem Thermoblock durchgeführt. Hierfür wurden die Ligationsansätze zunächst für 20 min bei $25^{\circ} \mathrm{C}$ inkubiert. Anschließend wurde in 20minütigen Inkubationsschritten die Temperatur um jeweils $2^{\circ} \mathrm{C}$ herabgesetzt und dann über Nacht bei $17^{\circ} \mathrm{C}$ inkubiert.

\subsubsection{DNA-Sequenzierung}

Zur Überprüfung der DNA-Sequenz klonierter Fragmente wurde eine Sequenzierung durchgeführt. Die Sequenzierung erfolgte mittels Didesoxy-Verfahren nach Sanger 
(Sanger et al., 1977). Ausgehend von einer bekannten Startsequenz wird durch Zugabe eines spezifischen Sequenzierprimers, eines Nukleotid (dNTP)-Gemisches und einer DNA-Polymerase, die Synthese eines komplementären Stranges initiiert. Das verwendete dNTP-Gemisch enthält neben den natürlicherweise vorkommenden 2'-Desoxynukleotiden A, T, G und C auch einen Anteil der jeweiligen 2',3'-Didesoxynukleotide, welche mit unterschiedlichen Fluoreszenzfarbstoffen markiert sind. Diese so genannten Terminatoren werden während der Strangsynthese an unterschiedlichen Positionen eingebaut und sorgen für den Basen-spezifischen Kettenabbruch. Die Reaktionsprodukte werden anschließend elektrophoretisch entsprechend ihrer Größe getrennt. Die unterschiedliche Fluoreszenz der Basenspezifischen Terminatoren ermöglicht eine direkte Bestimmung der Basenfolge durch den Sequenzierer.

Die Sequenzierung wurde von der Firma SeqLab (Göttingen) durchgeführt. Dabei wurde in einem Volumen von $7 \mu$ 500-700 ng Plasmid-DNA mit 20 pmol Sequenzierprimer versetzt. Die Analyse der Sequenzen erfolgte unter Verwendung der Programme Chromas Lite (Technelysium, Australien) und Seqman (DNASTAR, USA).

\subsection{Proteinanalytische Methoden}

\subsubsection{Herstellung von T. gondii-Lysat}

Für die Herstellung von $T$. gondii-Lysat wurden ca. $4 \times 10^{8}$ Toxoplasmen in $1 \mathrm{ml} 1 \times$ PBS resuspendiert. Die Suspension wurde in drei Zyklen abwechselnd in flüssigem Stickstoff eingefroren und einem $37^{\circ} \mathrm{C}-$ Wasserbad wieder aufgetaut. Anschließend erfolgte eine Ultraschallbehandlung auf Eis für $10 \mathrm{~min}$ auf Output Stufe 2 bei einem Unterbrechungszyklus von 30\% (Ultraschallgerät Cell Disruptor B15, Branson Sonifier). Die Suspension wurde dann für $20 \mathrm{~min}$ auf Eis ruhen gelassen. Darauf folgte die Wiederholung der Ultraschallbehandlung. Anschließend wurde die Suspension bei $20.800 \times \mathrm{g}$ für $20 \mathrm{~min}$ bei $4^{\circ} \mathrm{C}$ zentrifugiert, der Überstand abgenommen und dieser steril filtriert $(0,2 \mu \mathrm{m}$ Spritzenfilter, Millipore). Das filtrierte Lysat wurde einer Proteinbestimmung mit dem BCA Protein Assay (Thermo Scientific) unterzogen und dann bei $-80^{\circ} \mathrm{C}$ aufbewahrt. 


\subsubsection{Denaturierende Reinigung von His-Tag fusionierten Proteinen}

Über das Plasmid pQE-30 in E. coli exprimierte Proteine lagen als His ${ }_{6}$-Fusionsproteine vor. Dieser N-terminale Tag ermöglichte eine Reinigung über eine NickelNitrilotriessigsäure (Ni-NTA) Metall-Affinitätschromatographie.

Nach der Expression in 2 L LB-Medium mit entsprechenden Antibiotikazusätzen wurden die Zellen bei $5.000 \mathrm{rpm}$ für $10 \mathrm{~min}$ bei $4^{\circ} \mathrm{C}$ (Avanti ${ }^{\mathrm{TM}} \mathrm{J}-25$, Beckman) sedimentiert. Vom Zellpellet wurde das Nassgewicht bestimmt und entweder direkt weiter verarbeitet oder bei $-20^{\circ} \mathrm{C}$ gelagert.

Pro Gramm Nassgewicht wurde $5 \mathrm{ml}$ Puffer B zu dem Zellpellet hinzugegeben, die Zellen resuspendiert und für $6 \mathrm{~h}$ bei RT unter leichtem Schwenken lysiert. Anschließend wurde die Zellsuspension bei 14.000 rpm für 30 min (Avanti ${ }^{\mathrm{TM}} \mathrm{J}-25$, Beckman) pelletiert und der klare Überstand abgenommen. Zu dem Lysat wurde $10 \mu \mathrm{g} / \mathrm{ml}$ RNAse A, $5 \mu \mathrm{g} / \mathrm{ml}$ DNAse I, 1x Protease-Inhibitormix (Roche), sowie $2 \mathrm{ml} 50$ \%ige Ni-NTA gegeben und über Nacht in einem Überkopfschüttler bei RT inkubiert. Anschließend wurde der LysatResin-Mix in eine leere Chromatographie-Säule gegeben und der Durchfluss für eine SDS-PAGE Analyse aufbewahrt. Die Säule wurde drei Mal mit $5 \mathrm{ml}$ Puffer $\mathrm{C}$ gewaschen und die Waschfraktionen ebenfalls für eine SDS-PAGE Analyse aufbewahrt. Das rekombinante Protein wurde durch Zugabe von drei Mal $1 \mathrm{ml}$ Puffer D, drei Mal $1 \mathrm{ml}$ Puffer $E$ und drei Mal $1 \mathrm{ml}$ Puffer $F$ von der Säule eluiert und die Elutionen durch eine SDS-PAGE analysiert.

Puffer für die denaturierende Proteinreinigung von His-Fusionsproteinen Puffer B (Lysispuffer) Puffer C (Waschpuffer)

Natriumhydrogenphosphat $100 \mathrm{mM}$ Puffer B Tris- $\mathrm{HCl}$ Harnstoff $10 \mathrm{mM}$ Ethanol $8 \mathrm{M}$ $\mathrm{pH} 6,3$

$\mathrm{pH} 8,0$

\section{Puffer D (Elutionspuffer)}

Puffer B pH 5,9

\section{Puffer D (Elutionspuffer)}

Puffer B pH 4,5
Puffer D (Elutionspuffer)

Puffer B pH 3,0

\subsubsection{BCA-Assay zur Bestimmung der Proteinkonzentration}

Für die Bestimmung der Proteinkonzentration wurde das Pierce ${ }^{\circledR}$ BCA Protein Assay Kit (Thermo Scientific) nach Angaben des Herstellers verwendet. 
Das Prinzip beruht auf der Reduktion von $\mathrm{Cu}^{2+}$-Ionen $\mathrm{zu} \mathrm{Cu}^{+}$durch Proteine in alkalischer Lösung unter Bildung eines violetten Komplexes mit Bicinchoninsäure (BCA), welcher photometrisch bei $562 \mathrm{~nm}$ bestimmt werden kann.

Der BCA-Assay wurde auf einer 96-Loch-Mikrotiterplatte als Doppelbestimmungen durchgeführt. Dabei wurden je $25 \mu \mathrm{l}$ Proteinlösung mit $200 \mu \mathrm{l}$ BCA-Reagenz versetzt, auf einer Mikrotitermischplatte gemischt und für $30 \mathrm{~min}$ bei $37^{\circ} \mathrm{C}$ inkubiert. Anschließend wurde die OD bei $550 \mathrm{~nm}$ an einem Plattenphotometer (LP 400, Sanofi Diagnostics Pasteur) bestimmt. Der Proteingehalt der Probe wurde anhand einer Kalibriergeraden mit Rinderserumalbumin (BSA) ermittelt.

\subsubsection{Diskontinuierliche SDS-Polyacrylamid-Gelelektrophorese}

Bei der SDS-PAGE werden Proteine unter denaturierenden Bedingungen unabhängig von ihrer ursprünglichen Oberflächenladung nur aufgrund ihrer Molekularmasse getrennt (Laemmli, 1970). Durch Vergleich mit einem Proteingrößenstandard kann die Molekularmasse abgeschätzt werden.

Bei der diskontinuierlichen SDS-PAGE werden die Proteine zunächst in einem großporigen Sammelgel bei pH 6,8 konzentriert und anschließend in einem kleinporigen Trenngel mit pH 8,8 aufgetrennt, wodurch eine große Bandenschärfe und eine hohe Trennleistung erreicht wird (Righetti et al., 1990).

Polyacrylamidgele sind inert und entstehen durch Polymerisation von Acrylamid, das über Methylenbisacrylamid quervernetzt wird. Die Polymerisation wird von Sulfatradikalen des Ammoniumperoxosulfats (APS) ausgelöst. N,N,N',N'-Tetramethylethylendiamin (TEMED) dient als basischer Katalysator bei der Polymerisation.

Es wurden jeweils 4\%ige Sammelgele und 10-15\%ige Trenngele verwendet. Die Proteinproben wurden mit SDS-Probenpuffer versetzt und anschließend für 10 min bei $95^{\circ} \mathrm{C}$ im Thermomixer denaturiert. Nach einer Zentrifugation von 5 min bei $13.400 \mathrm{rpm}$ (Eppendorf) wurden die Proben auf das SDS-Gel aufgetragen und bei einer Stromstärke von $25 \mathrm{~mA}$ pro Gel für ca. $1 \mathrm{~h}$ aufgetrennt. Anschließend wurde das Gel in einem Western Blot eingesetzt oder gefärbt. 
Lösungen zur SDS-PAGE

Acrylamid-Stammlösung

Acrylamid

$30 \%(w / v)$

Bisacrylamid

$0.8 \%(w / v)$

Trenngel (12\%)

Acrylamid-Stammlösung

$2 \mathrm{ml}$

$1.5 \mathrm{M}$ Tris- $\mathrm{HCl}(\mathrm{pH} 8,8)$

$1,25 \mathrm{ml}$

$10 \%$ SDS

$100 \mu \mathrm{l}$

dest. $\mathrm{H}_{2} \mathrm{O}$

$1,75 \mathrm{ml}$

APS (10\%)

$50 \mu \mathrm{l}$

TEMED

$5 \mu \mathrm{l}$

Sammelgel (4\%)

Acrylamid-Stammlösung

$0,5 \mathrm{ml}$

500 mM Tris- $\mathrm{HCl}(\mathrm{pH} \mathrm{6,8)}$

$625 \mu \mathrm{l}$

$10 \%$ SDS

$100 \mu \mathrm{l}$

$\mathrm{dH}_{2} \mathrm{O}$

$1,375 \mathrm{ml}$

APS (10\%)

$25 \mu \mathrm{l}$

TEMED

$2,5 \mu \mathrm{l}$

Elektrophoresepuffer

Tris- $\mathrm{HCl}(\mathrm{pH} 8,8)$

$50 \mathrm{mM}$

Glycin

$380 \mathrm{mM}$

SDS

$0,1 \%(w / v)$

SDS-Probenpuffer

Tris- $\mathrm{HCl}(\mathrm{pH} 8,0)$

$250 \mathrm{mM}$

Glycerin

$25 \%(\mathrm{v} / \mathrm{v})$

SDS

$7,5 \%(w / v)$

$\beta$-Mercaptoethanol

$12,5 \%(\mathrm{v} / \mathrm{v})$

Bromphenolblau

$0,2 \%(w / v)$

\subsubsection{Zweidimensionale (2D) Gelelektrophorese}

Bei der 2D-Gelelektrophorese werden Proteine zunächst durch eine isoelektrische Fokussierung (erste Dimension) an Hand ihres spezifischen isoelektrischen Punktes ( $p /$ ) getrennt. Hierbei wird ein immobilisierter pH-Gradient (IPG) eingesetzt, der auf einem Polyacrylamidgel fixiert ist. Durch die Eigenladung von Proteinen wandern diese in einem elektrischen Feld entlang des pH-Gradienten. An einem definierten pH-Wert heben sich jedoch die basischen und sauren Ladungen der Aminosäuren eines Proteinmoleküls auf, so dass dieses nach außen ladungsneutral ist. Dieser Zustand wird als isoelektrischer Punkt $(\mathrm{p} /$ ) bezeichnet. An diesem Punkt verbleiben die Proteine auf dem IPG-Gel. In der zweiten Dimension werden dann die Proteine an Hand ihres Molekulargewichtes in einer SDS-PAGE getrennt. 


\subsubsection{Probenvorbereitung}

Für die 2D-Gelelektrophorese wurden ausschließlich aus HFF-Zellen isolierte Toxoplasmen verwendet. Für die Herstellung von Toxoplasma-Lysat wurde das Protokoll, wie unter Kapitel 2.5.1 beschrieben, verwendet. Jedoch wurden hierbei die Toxoplasmen in $1 \mathrm{ml}$ Lysispuffer resuspendiert. Nach erfolgter Lyse wurde das Lysat über eine Vivaspin2-Säule mit PES-Membran (Sartorius) entsalzt und konzentriert.

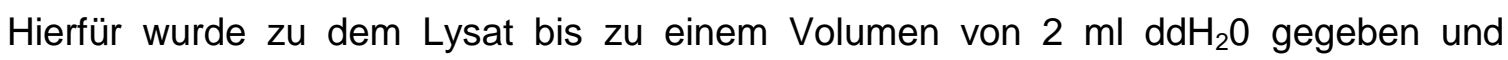
anschließend bei $4.000 \times \mathrm{g}$ (Eppendorf) für $30 \mathrm{~min}$ bei RT zentrifugiert. Nach der Entfernung des Durchflusses wurde der Vorgang wiederholt, das entsalzte Lysat gewonnen und die Proteinmenge mit dem BCA-Assay (Thermo Scientific) bestimmt.

Da für die 2D-Gelelektrophorese zwei Ansätze parallel verwendet wurden, wurde jeweils 100-500 $\mu \mathrm{g}$ Proteinlösung mit der entsprechenden Menge Rehydrationspuffer bis zu einem Endvolumen von $360 \mu \mathrm{l}$ versetzt und für $2 \mathrm{~h}$ bei RT unter leichtem Schütteln inkubiert. Anschließend wurden die Ansätze bei $14.000 \mathrm{rpm}$ für $5 \mathrm{~min}$ bei RT zentrifugiert, die Überstände abgenommen und diese für die isoelektrische Fokussierung verwendet.

\section{Lösungen für die Probenvorbereitung}

\section{Lysispuffer}

7 M Harnstoff

$2 \mathrm{M}$ Thioharnstoff

$4 \%(w / v)$ CHAPS

\author{
Rehydrationspuffer \\ $7 \mathrm{M}$ Harnstoff \\ $2 \mathrm{M}$ Thioharnstoff \\ $4 \%(w / v)$ CHAPS \\ $2 \%(v / v)$ IPG Puffer \\ $40 \mathrm{mM}$ DTT \\ $0,01 \%(w / v)$ Bromphenolblau
}

\subsubsection{Isoelektrische Fokussierung (1. Dimension)}

Für die isoelektrische Fokussierung wurde zunächst pro Ansatz ein $18 \mathrm{~cm}$ IPG-StripHolder gründlich mit der Strip-Holder Cleaning Solution (Pharmacia) gereinigt, mit je ca. $800 \mu \mathrm{l}$ Repel-Silane ES (Pharmacia) beschichtet und für $30 \mathrm{~min}$ getrocknet. Die aufgearbeitete Bromphenolblau-gefärbte Proteinprobe wurde tröpfchenweise in den Strip-Holder pipettiert, wobei jedoch die Elektroden ausgelassen wurden. Anschließend wurde pro Probe ein IPG-Streifen mit der Gelseite nach unten in die Strip-Holder gegeben, so dass sich die Proteinprobe gleichmäßig darunter verteilen konnte und die mit einem Plus-markierte Seite auf der Kathode lag. Die IPG-Streifen wurden vor Austrocknung geschützt und über Nacht bei RT inkubiert. 
Am folgenden Tag wurden unter dem IPG-Streifen auf den Elektroden mit AmpuwaWasser benetzte Filterpapiere gelegt und der Streifen so platziert, dass das Gel sowohl die Anode als auch die Kathode berührte. Anschließend wurde der IPG-Streifen mit Cover-Fluid (Pharmacia) bedeckt und die benötigte Anzahl an Proben in den IPG-StripHolder auf das IPGphor (Amersham Pharmacia) gegeben.

Die isoelektrische Fokussierung wurde in einem mehrstufigen Protokoll über das IPGphor durchgeführt: 200 V, 1 h; 500 V, 1 h; 1.000 V, 1 h; 8.000 V, 12 h. Nach erfolgter Fokussierung wurden die IPG-Streifen entweder direkt weiter verwendet oder bei $-80^{\circ} \mathrm{C}$ gelagert.

\subsubsection{3 Äquilibrierung der IPG-Streifen}

Nach der isoelektrischen Fokussierung wurden die Proteine auf den IPG-Streifen zunächst für 25 min mit Äquilibrierungspuffer I reduziert. Dabei werden die Disulfidbrücken der Proteine entfernt. Um eine Reoxidation zu verhindern, wurden anschließend die IPG-Streifen für 25 min mit Äquilibrierungspuffer II alkyliert. Letztendlich werden die Proteine mit SDS beladen, was zu einer Entfaltung der Proteinmoleküle führt.

Lösungen für die Äquilibrierung

\section{Äquilibrierungspuffer I}

$50 \mathrm{mM}$ Tris- $\mathrm{HCl} \mathrm{pH} 8,8$

$6 \mathrm{M}$ Harnstoff

$30 \%$ Glycerol (v/v)

$2 \%$ SDS (w/v)

$62,5 \mathrm{mM}$ DTT

\section{Äquilibrierungspuffer II}

$50 \mathrm{mM}$ Tris- $\mathrm{HCl} \mathrm{pH} \mathrm{8,8}$

$6 \mathrm{M}$ Harnstoff

$30 \%$ Glycerol (v/v)

$2 \%$ SDS (w/v)

$2,5 \%$ lodacetamid

\subsubsection{SDS-PAGE (2. Dimension)}

Für die SDS-PAGE wurden 12,5 \%ige Trenngele verwendet. Die äquilibrierten IPGStreifen wurden zunächst kurz in SDS-Laufpuffer gewaschen und mit der Gelseite nach vorne auf das SDS-Gel gelegt, so dass der Gelstreifen das SDS-Gel berührte. Anschließend wurde der IPG-Streifen mit einer Agaroselösung überschichtet und die SDS-PAGE in einer DALT-Elektrophoreskammer unter Kühlung auf $14^{\circ} \mathrm{C}$ durchgeführt. Der Gellauf fand zunächst bei 2,5 W pro Gel für $1 \mathrm{~h}$ und dann für ca. $8 \mathrm{~h}$ bei $19 \mathrm{~W}$ pro Gel statt. 
Lösungen für die 2D SDS-PAGE

Trenngel (12,5\%)

Acrylamid-Stammlösung

$57,7 \mathrm{ml}$

1,5 M Tris- $\mathrm{HCl}(\mathrm{pH} 8,8)$

$34,6 \mathrm{ml}$

$10 \%$ SDS

$1,4 \mathrm{ml}$

dest. $\mathrm{H}_{2} \mathrm{O}$

$44 \mathrm{ml}$

APS (10\%)

$700 \mu \mathrm{l}$

TEMED

$45,7 \mu \mathrm{l}$

Elektrophoresepuffer

Tris- $\mathrm{HCl}(\mathrm{pH} \mathrm{8,8)}$

$25 \mathrm{mM}$

Glycin

$192 \mathrm{mM}$

SDS

$0,1 \%(w / v)$

Agaroselösung

SDS-Laufpuffer

Agarose

$0,5 \%(w / v)$

Bromphenolblau

$0,01 \%(w / v)$

\subsubsection{Coomassie-Blau Färbung}

Nach der Auftrennung von Proteinen in einer SDS-PAGE können diese mit Hilfe des Coomassie-Brilliant-Blau Farbstoffes im Gel angefärbt werden. Hierfür wurde das Gel für ca. $2 \mathrm{~h}$ bei RT mit der Färbelösung geschwenkt. Anschließend wurde das Gel mit einer Entfärberlösung wieder entfärbt, bis blaue Banden zu erkennen waren.

Lösungen für die Coomassie-Färbung

\section{Coomassie-Blau Färbelösung}

Ethanol

Essigsäure

Coomassie-Brilliant-Blau

$$
\begin{array}{r}
30 \%(\mathrm{v} / \mathrm{v}) \\
10 \%(\mathrm{v} / \mathrm{v}) \\
0,25 \%(\mathrm{w} / \mathrm{v})
\end{array}
$$

\section{Entfärber}

Ethanol

$30 \%(\mathrm{v} / \mathrm{v})$

Essigsäure

\subsubsection{Silberfärbung}

Für das Anfärben von Proteinen nach der 2D-Gelelektrophorese im SDS-Gel wurde die Silberfärbung verwendet. Hierfür wurde das Gel zunächst für $1 \mathrm{~h}$ in Fixierlösung I und dann über Nacht in Fixierlösung II fixiert. Anschließend wurde das Gel drei Mal für 30 min in $\mathrm{ddH}_{2} \mathrm{O}$ gewaschen und für 60 min in der Silberlösung gefärbt. Im Folgenden wurde das Gel für 2 min in $d_{d H_{2}} \mathrm{O}$ gewaschen und für 12 min in der Entwicklungslösung entwickelt. Die Farbreaktion wurde durch Inkubation für 12 min in Stopplösung beendet. Das Gel wurde bis zur weiteren Verwendung in $5 \%(\mathrm{v} / \mathrm{v})$ Essigsäure bei $4^{\circ} \mathrm{C}$ gelagert. 


\section{Lösungen für die Silberfärbung}

Fixierlösung I

Isopropanol

Essigsäure

$30 \%(\mathrm{v} / \mathrm{v})$

$10 \%(\mathrm{v} / \mathrm{v})$

\section{Fixierlösung II}

Natriumacetat

Natriumthiosulfat

Ethanol

$0,2 \%(w / v)$

$30 \%(\mathrm{v} / \mathrm{v})$

\section{Entwicklerlösung}

Natriumcarbonat

$2,5 \%(w / v)$

Formaldehyd

\section{Stopplösung}

Methanol

Essigsäure

$$
\begin{array}{r}
0,1 \%(w / v) \\
0,02 \%(v / v)
\end{array}
$$

\subsubsection{Western-Blot Analyse}

Bei der Western-Blot Analyse werden gelelektrophoretisch aufgetrennte Proteine über eine Semi-dry Blotapparatur (Semi-Dry Blotter, BioRad) elektrophoretisch auf eine PVDF-Membran übertragen.

Für den Transfer wurden sechs 3 MM'-Whatman-Filterpapiere, die der Größe des Gel entsprachen, in Anodenpuffer I getränkt und auf die Anodenplatte gelegt. Des Weiteren wurden drei Whatman-Filterpapiere in Anodenpuffer II getränkt und auf die ersten Filterpapiere gelegt. Anschließend wurde die in $100 \%$ Methanol aktivierte PVDFMembran auf die Filterpapiere gegeben und das Proteingel luftblasenfrei auf die Membran gebracht. Der Ansatz wurde mit neun in Kathodenpuffer getränkten Filterpapieren abgedeckt und die Semi-Dry Apparatur verschlossen.

Der Transfer erfolgte bei einer konstanten Stromstärke von $0,8 \mathrm{~mA}$ pro $\mathrm{cm}^{2}$ Gelfläche für 90 min. Anschließend konnten die auf die PVDF-Membran übertragenen Proteine immunologisch durch spezifische Antikörper analysiert werden.

Bei der Western-Blot Analyse der 2D-Gele wurde die Anzahl der Whatman-Filterpapiere jeweils verdoppelt und der Transfer mit einer Stromstärke von $0,1 \mathrm{~mA}$ pro $\mathrm{cm}^{2}$ Gelfläche für $12 \mathrm{~h}$ durchgeführt. 
Lösungen für den Western-Blot

\section{Anodenpuffer I}

Tris- $\mathrm{HCl} \mathrm{pH} \mathrm{10,4}$

Methanol

Kathodenpuffer

6-Aminohexansäure $\mathrm{pH} \mathrm{7,6}$

Methanol

\section{Anodenpuffer II}

Tris- $\mathrm{HCl} \mathrm{pH} \mathrm{10,4}$ Methanol
$25 \mathrm{mM}$

$20 \%(v / v)$
$40 \mathrm{mM}$
$20 \%(\mathrm{v} / \mathrm{v})$

\subsubsection{Immunodetektion von Proteinen}

Die auf die PVDF-Membran aufgebrachten Proteine können durch immuno-chemische Nachweisreaktionen durch spezifische Primär- und Enzym-gekoppelte Sekundärantikörper nachgewiesen werden. Nach dem Elektrotransfer der Proteine wurde die PVDF-Membran zur Sättigung unspezifischer Antikörper-Bindestellen für $1 \mathrm{~h}$ bei RT in Blockierlösung unter leichtem Schütteln blockiert. Anschließend wurde der in Blockierlösung verdünnte Primärantiköper zugegeben und über Nacht bei $4^{\circ} \mathrm{C}$ inkubiert. Nach der Entfernung der Antikörperlösung wurde die Membran drei Mal für 20 min mit Waschpuffer gewaschen und dann für 90 min mit dem in Blockierlösung verdünnten Alkalische Phosphatase (AP)-gekoppelten Sekundärantikörper inkubiert. Nach erneutem Waschen wurde die Detektion über die am Sekundärantikörper gebundene AP durchgeführt. Hierfür wurde die Membran für 5 min in $37^{\circ} \mathrm{C}$ vorgewärmten Substratpuffer gewaschen und dann mit Reaktionspuffer inkubiert, bis Banden sichtbar wurden. Die AP-Reaktion wurde durch Waschen mit $\mathrm{H}_{2} \mathrm{O}$ gestoppt und die Membran im Dunkeln getrocknet.

\section{Lösungen für die Immunodetektion}

\section{Blockierlösung}

Magermilchpulver in PBS

\section{Substratpuffer}

Diäthanolamin pH 9,6 Magnesiumchlorid in physiol. $\mathrm{NaCl}$

\section{Waschpuffer}

$$
5 \%(w / v)
$$

Tween-20 In PBS

\section{Reaktionspuffer}

$$
\begin{array}{r}
2 \%(\mathrm{v} / \mathrm{v}) \\
50 \mu \mathrm{M}
\end{array}
$$

Substratpuffer $9 \mathrm{ml}$ $\operatorname{NBT}(1 \%(w / v))$ $1 \mathrm{ml}$ $\operatorname{BCIP}(5 \%(w / v))$ 


\subsubsection{Lineblot-Assay}

Der Lineblot Assay ermöglicht das Aufbringen von mehreren Proteinen auf eine PVDFMembran ohne elektronischen Transfer.

Für den Lineblot wurden entsprechende Mengen an gereinigten Proteinen bis zu einem Endvolumen von $150 \mu \mathrm{l}$ in PBS verdünnt, mit Hilfe einer eigens dafür entwickelten Lineblot-Apparatur auf einer Fläche von ca. 6,5 x 0,2 cm $\left(1,3 \mathrm{~cm}^{2}\right)$ auf eine PVDFMembran aufgebracht und über Nacht unter leichtem Schwenken bei RT getrocknet. Anschließend wurde die Membran bei $-20^{\circ} \mathrm{C}$ gelagert oder direkt für die Immunodetektion verwendet.

Für die Immunodetektion wurde die Membran in ca. $2 \mathrm{~mm}$ breite Streifen geschnitten und diese einzeln für $1 \mathrm{~h}$ bei RT in Blockierlösung (5\% Magermilchpulver in PBS) blockiert. Der in Blockierlösung verdünnte Primärantiköper oder Serum wurde über Nacht bei $4^{\circ} \mathrm{C}$ inkubiert und anschließend drei Mal für $20 \mathrm{~min}$ in Waschpuffer gewaschen. Der Meerrettichperoxidase-gekoppelter Sekundärantikörper wurde ebenfalls in Blockierlösung verdünnt und jeweils $1 \mathrm{ml}$ davon für $90 \mathrm{~min}$ zu einem BlotStreifen gegeben.

Die Detektion erfolgte über das am Sekundärantikörper gebundene Enzym Peroxidase, welches das verwendete Chemilumineszenz-Substrat umwandelt und die daraus resultierende Lichtemission mit Hilfe einer Lumineszenz-Apparatur (LAS-4000, Fujifilm) nachweisen kann. Mit dieser Apparatur ist es möglich in definierten Zeitintervallen Bilder aufzunehmen, wobei die Expositionszeit sich nach dem verwendeten Sekundärantikörper richtete.

Die Quantifizierung des Lineblot-Assays wurde mit Hilfe des Multi Gaue (Fujifilm)- bzw. ImageJ (http://rsbweb.nih.gov/ij/index.html)-Programmes durchgeführt.

Ausgehend von den Ergebnissen wurde der prozentuale Anteil an korrekt negativ reagierenden Seren (Spezifität) und der prozentuale Anteil an korrekt positiv reagierenden Seren (Sensitivität) berechnet. Des Weiteren wurde, bei einem positiven Ergebnis, der positive Vorhersagewert PPV (positive predictive value) berechnet, der die Wahrscheinlichkeit für eine akute bzw. chronische Infektion angibt. Die Wahrscheinlichkeit für ein richtig negatives Ergebnis wurde über den negativen Vorhersagewert NPV (negative predictive value) bestimmt. 
Formeln zur Beurteilung der Lineblot-Ergebnisse

Spezifität $=\frac{\text { Anzahl richtig-negative }}{(\text { Anzahl richtig-negative }+ \text { Anzahl falsch-positive })}$

Sensitivität (akute Infektion) $=\frac{\text { Anzahl richtig-positve akute }}{\text { (Anzahl richtig-positive akute }+ \text { Anzahl falsch-negative akute) }}$

Sensitivität (chron. Infektion) $=\frac{\text { Anzahl richtig-positve chron. }}{\text { (Anzahl richtig-positive chron. }+ \text { Anzahl falsch-negative chron.) }}$

$\boldsymbol{P P V}$ (akute Infektion) $=\frac{\% \text { richtig-positive akute }}{(\% \text { richtig-positive akute }+\% \text { richtig-positive chron. }+\% \text { falsch-positive })}$

$P P V($ chron. Infektion $)=\frac{\% \text { richtig-positive chron. }}{(\% \text { richtig-positive chron. }+\% \text { richtig-positive akute }+\% \text { falsch-positive })}$

NPV $=\frac{\% \text { richtig-negative }}{\text { (\% richtig-negative }+\% \text { falsch-negative akute }+ \text { chron. })}$

\subsubsection{In-Gel Verdau von Silber-gefärbten Proteinen}

Für die Analyse der aus der 2D-Gelelektrophorese erhaltenen Proteinspots mittels Massenspektrometrie mussten diese zunächst aus dem Gel isoliert werden.

Hierfür wurde der zu analysierende Protein-Spot aus dem Silber-gefärbten Gel herausgeschnitten und in ein $0,5 \mathrm{ml}$ Eppendorf-Reaktionsgefäß überführt. $\mathrm{Zu}$ dem

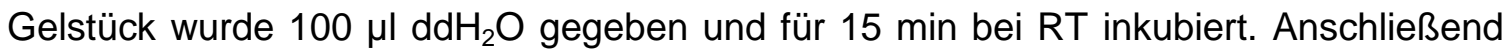
wurde das Gelstück drei Mal mit $100 \mu \mathrm{lddH_{2 }} O$ gewaschen und dann mit $50 \mu l$ einer 1:1 Lösung aus $30 \mathrm{mM}$ Kaliumferricyanid und $100 \mathrm{mM}$ Natriumthiosulfat versetzt, bis das Gel komplett entfärbt war. Nach kurzem Waschen mit ddH $\mathrm{H}_{2} \mathrm{O}$ wurde das Gel mit $40 \mu \mathrm{l}$ 50 \%igem Acetonitril (ACN) versetzt und für 15 min bei RT inkubiert. Nach der Entfernung des Überstandes wurde zu dem Gel $40 \mu \mathrm{l} 100 \%$ ACN gegeben, bis dieses sich weiß verfärbte. Anschließend wurde der Überstand entfernt und durch $50 \mu 100$ $\mathrm{mM}$ Ammoniumbicarbonat ersetzt und für 5 min inkubiert. Des Weiteren wurden $50 \mu \mathrm{l}$ $100 \%$ ACN zugegeben und für weitere 15 min inkubiert. Danach wurden die Überstände entfernt und die Proben im Vakuum getrocknet.

Zu den getrockneten Proben wurde $10 \mu$ Trypsinlösung gegeben und für 45 min auf Eis gestellt. Nach der Entfernung des Überstandes wurde $40 \mu \mathrm{l}$ Digestionspuffer hinzugegeben und der Ansatz bei $37^{\circ} \mathrm{C}$ über Nacht inkubiert. 
Am folgenden Tag wurde der Überstand in ein neues Eppendorf-Cup überführt und unter Vakuum getrocknet. Zu dem im Gel befindlichen Protein wurden $50 \mu$ einer 0,1 \%igen Trifluoressigsäurelösung (TFA) gegeben und für 30 min in ein gekühltes Ultraschallbad gestellt. Anschließend wurden der Überstand zu dem bereits getrockneten Überstand gegeben und ebenfalls getrocknet. Zu dem im Gel befindlichen Proteinen wurde im Folgenden eine Lösung aus $30 \%$ ACN und $70 \%$ 0,1 \% TFA, $60 \%$ ACN und $40 \%$ 0,1\% TFA, und $100 \%$ ACN gegeben und der Vorgang wiederholt. Die getrocknete Probe wurde bis zu deren Analyse bei $-20^{\circ} \mathrm{C}$ gelagert.

\section{Lösungen für den tryptischen Verdau}

\section{Digestionpuffer}

Kaliumchlorid $\quad 5 \mathrm{mM}$

Ammoniumbicarbonat $25 \mathrm{mM}$

\section{Trypsinlösung}

Trypsin Gold $\quad 0,1 \mu \mathrm{g} / \mu \mathrm{l}$

\subsubsection{Massenspektrometrische Analyse von Proteinen}

Die massenspektrometrische Analyse der aus der 2D-Gelelektrophorese erhaltenen Proteinspots wurde in der Abteilung der Klinischen Chemie der Universitätsmedizin Göttingen von Dr. A. R. Asif und seinen Mitarbeitern durchgeführt.

Bei der Massenspektrometrie werden die zu analysierenden Substanzen in die Gasphase überführt, ionisiert und in einem elektrischen Feld beschleunigt. Über einen Detektor wird die Zeit für das Zurücklegen der Strecke des elektrischen Feldes festgehalten, die abhängig von der Masse der zu analysierenden Substanz ist.

Die aufgearbeiteten, getrockneten Proteine wurden hierfür in einer wässrigen 0,1\%igen (v/v) Formaldehydlösung resuspendiert und über einen ESI-QTOF-MS/MS Spektrometer (Waters) analysiert. Über die MassLynx Software (V 4.0) (Waters) wurden die zeitabhängigen Flugmuster jedes Proteins festgehalten und die erhaltenen Muster über die MASCOT (http://www.matrixscience.com), Swiss-Prot (http://expasy.org/sprot) und NCBI (http://www.ncbi.nlm.nih.gov/protein) Proteindatenbanken analysiert. 


\subsection{Charakterisierung von Serumproben}

Die verwendeten humanen Serumproben wurden in der Routinediagnostik in Hinblick auf eine Toxoplasma-Infektion durch folgende Testverfahren als (i) nicht mit T. gondii infiziert, (ii) akute Toxoplasmose und (iii) chronische Toxoplasma-Infektion charakterisiert:

Toxo-Spot IF (bioMèrieux, Marcy-l‘Etoile, Frankreich)

negativ: $\leq 1: 4 \quad$ grenzwertig: $>1: 4-<1: 16$

positiv: $\geq 1: 16$

VIDAS $^{\circledR}$ Toxo IgG II (TXG) (bioMèrieux)

negativ: $<4 \mathrm{IU} / \mathrm{ml} \quad$ grenzwertig: $4-8 \mathrm{IU} / \mathrm{ml} \quad$ positiv: $>8 \mathrm{IU} / \mathrm{ml}$

VIDAS $^{\circledR}$ Toxo IgM (TXM) (bioMèrieux)

negativ: $<0,55$ (Index) grenzwertig: 0,55-0,65 (Index) positiv: >0,65 (Index)

VIDAS $^{\circledR}$ Toxo lgG Avidität (TXGA) (bioMèrieux)

gering $<0,2 \quad$ intermediär $\geq 0,2-<0,3 \quad$ hoch: $\geq 0,3$

Platelia $^{\text {TM }}$ Toxo IgA TMB (Bio-Rad, Marnes-la-Coquette, Frankreich)

negativ: <0,0 (Index) grenzwertig: 0,0-2,0 (Index) positiv: >2,0 (Index)

Die als negativ-deklarierte Seren zeigten in keinem Test ein positives Ergebnis. Seren von Patienten mit einer akuten Toxoplasmose hatten einen IFT-Titer von $\geq 1: 256$, einen positiven IgM- und/oder IgA-Index. Dabei zeigte eine hoch-akute Infektion einen IFTTiter $\geq 1: 1.1024-16.384$ und eine subakute Infektion einen IFT-Titer $\geq 1: 256-1.1024$. Chronisch-infizierte Patienten zeichneten sich durch einen IFT-Titer von 1:64-1:256, einem positiven IgG-Titer, einer hohen Avidität und durch das Fehlen von IgM- und IgAAntikörpern aus. 


\section{Ergebnisse}

\subsection{Epidemiologische Untersuchung zur konnatalen Toxoplasmose}

Eine Infektion mit $T$. gondii verläuft in den meisten immunkompetenten Menschen asymptomatisch. Eine besondere Gefährdung entsteht allerdings, wenn eine Erstinfektion während einer Schwangerschaft stattfindet. Dabei kann es diaplazentar zu einer Übertragung des Parasiten auf den Fötus kommen. Besonders in der ersten Hälfte einer Schwangerschaft ist eine Infektion des Föten gefährlich, weil eine Fehlgeburt oder schwere Erkrankungen $u$. a. des Zentralnervensystems die Folge sein können.

Nach langjähriger und allgemein akzeptierter Auffassung wird in Deutschland die in der Schwangerschaft erworbene Toxoplasmose nach der RKI-Richtlinie von 2007 bis zur 16. Schwangerschaftswoche (SSW) mit Spiramycin, und anschließend mit einer vierwöchigen Kombination aus Pyrimethamin, Sulfadiazin und Folinsäure, therapiert. In schwerwiegenden Fällen kann diese Zeit jedoch länger betragen.

Um die Effektivität dieser Therapie beurteilen zu können, wurde in dieser Arbeit in Kooperation mit Dr. H. Hlobil von der Laborärztlichen Gemeinschaftspraxis in Sindelfingen, eine retrospektive Untersuchung an 685 Frauen durchgeführt, deren serologische Konstellation für eine Primärinfektion in der Schwangerschaft sprach. Dabei wurde die Transmissionsrate auf die Föten, sowie die Anzahl der infizierten, klinisch-auffälligen Kinder in utero bzw. neonatal bestimmt.

In der Laborärztlichen Gemeinschaftspraxis in Sindelfingen, die als Beratungslabor für Toxoplasmose fungiert, wurden zwischen Juli 1995 und Februar 2008 Daten von 808 Frauen mit einer schwangerschaftsrelevanten Toxoplasmose festgehalten. Die Informationen basierten auf medizinischen Daten, die im Rahmen der Routinediagnostik aufgezeichnet wurden und einem für diesen Zweck etabliertem „Follow-up“-Programm. Dieses „Follow-up“-Programm diente zur Informationsbereitstellung für die werdenden Eltern und den behandelnden Ärzten, sowie die Rückmeldung von Informationen an das Labor in Sindelfingen.

Von der Studie ausgeschlossen wurden zwei Frauen, sie sich zu einem Abbruch der Schwangerschaft entschieden. Eine der Frauen litt an Depressionen, die andere hatte ein Mammakarzinom und unterzog sich einer Chemotherapie. Eine weitere Frau wurde ebenso ausgeschlossen, da der weitere Verlauf dieses Falles unklar war. Bei dieser Frau ergab die Fruchtwasseruntersuchung in der 20. SSW ein positives PCR-Ergebnis für Toxoplasma. Außerdem zeigte der Fötus im Ultraschall Anzeichen für eine Seitenventrikelerweiterung. Des Weiteren erlitten sieben Frauen eine Fehlgeburt. Sie 
wurden ebenfalls aus der Studie ausgeschlossen, da unklar war, ob die Fehlgeburt durch eine T. gondii-Infektion hervorgerufen wurde. Ebenso wurden 113 Frauen ausgeschlossen, die sich an Hand der serologischen Befunde kurz vor der Schwangerschaft infiziert haben mussten. Da nicht klar war, ob diese Infektionen schwangerschaftsrelevant waren, wurden diese Fälle bei der Auswertung nicht berücksichtigt.

Die schwangeren Frauen, sowie deren Kinder, wurden - ausgehend vom wahrscheinlichsten Infektionszeitpunkt der Mutter - in drei Gruppen eingeteilt: (1) 1.-12. SSW, (2) 13.-24. SSW und (3) 25. SSW bis Geburt.

Das Risiko für die Übertragung des Parasiten, sowie das Risiko einer klinischen Manifestation wurde an Hand der drei Gruppen untersucht.

\subsubsection{Ermittlung der Transmission von T. gondii von der infizierten Mutter auf den Fötus}

In der Schwangerschaft kann T. gondii über die Plazenta auf den Fötus übertragen werden. An Hand der 685 Schwangeren wurde untersucht, wie häufig dieses Ereignis stattfand.

Von den 685 Frauen mit einer schwangerschaftsrelevanten Toxoplasmose hatten sich 479 Frauen $(69,9 \%)$ im 1., 160 Frauen $(23,4 \%)$ im 2. und 46 Frauen (6,7 \%) im 3. Trimester infiziert (Abb. 3.1). Jedes Neugeborene wurde in dieselbe Gruppe eingeordnet wie dessen Mutter und wurde neonatal serologisch auf eine Toxoplasma-Infektion untersucht. Die serologische Untersuchung erfolgte vorwiegend in der Routinediagnostik der Laborärztlichen Gemeinschaftspraxis in Sindelfingen in Form eines IgG- und IgMEnzym-Immunoassays (Liaison $^{\circledR}$, DiaSorin, Saluggia, Italien), IgM- und $\lg \mathrm{A}$ Immunosorbent-Agglutinationstest (ISAGA), einem vergleichenden Immunoblot unter Verwendung von T. gondii-Volllysat zum Vergleich der IgG-Bandenmuster, sowie dem Nachweis von Toxoplasma in Plazenta- und Nabelschnurgewebe mittels PCR. Es konnte gezeigt werden, dass 1,3\% (6/479) der Kinder aus der Gruppe (1) mit einer Toxoplasma-Infektion geboren wurden. Mit fortschreiten der Schwangerschaft stieg der Anteil auf 10,6 \% (17/160 Kinder) bei Infektion der Mutter im 2. Trimester (Gruppe 2) und auf $21,7 \%$ (10/46 Kinder) bei Infektion der Mutter im 3. Trimester (Gruppe 3) an (Abb. 3.1). Die durchschnittliche Transmissionsrate lag bei 4,8 \% (33/685 Kinder). Unter den 33 mit einer T. gondii-Infektion geborenen Kindern, waren fünfzehn Mädchen, siebzehn Jungen und ein Kind dessen Geschlecht nicht dokumentiert wurde. 


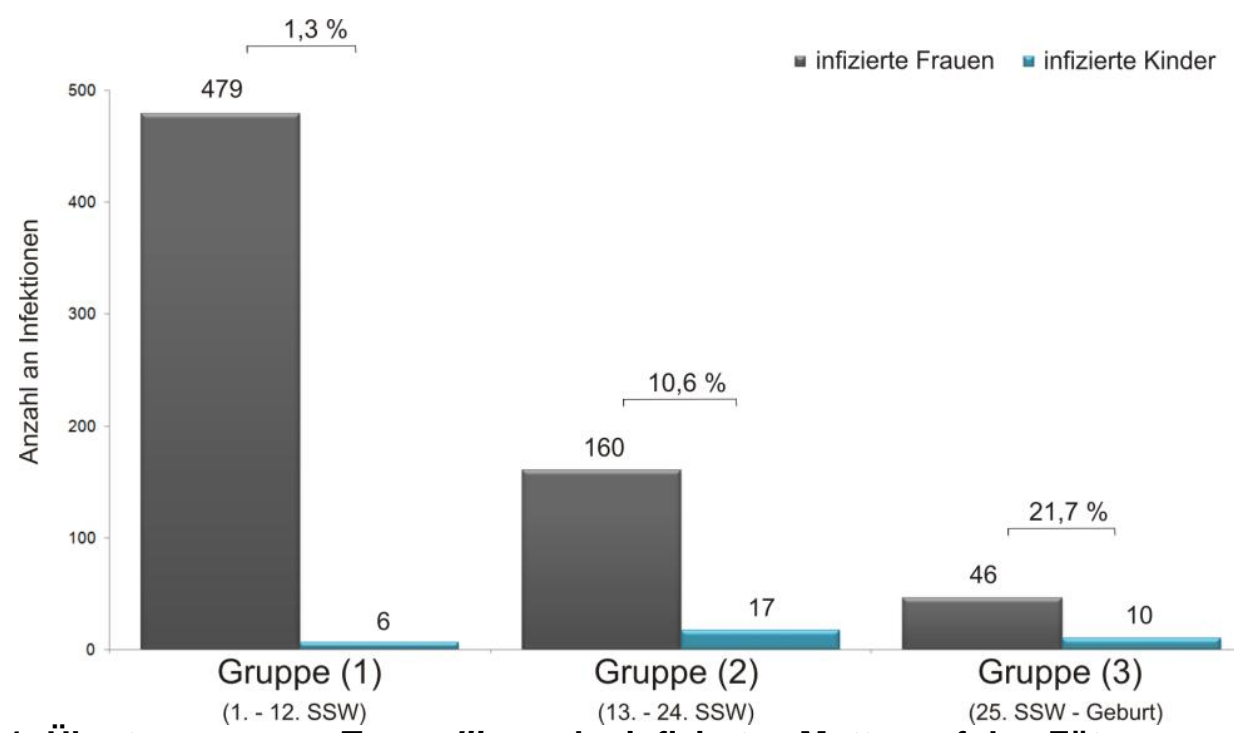

Abb. 3.1: Übertragung von T. gondii von der infizierten Mutter auf den Fötus.

Untersuchung von 685 Mutter-Kind Paarungen hinsichtlich der Transmissionsrate von der infizierten Mutter auf den Fötus. Abhängig von der Schwangerschaftswoche (SSW) bei Infektion wurden diese in drei Gruppen (1) - (3) eingeteilt.

\subsubsection{Ermittlung zur Häufigkeit von klinisch-manifesten Erkrankungen bei pränatal infizierten Kindern}

Die Übertragung des Parasiten auf den Fötus kann zu Schädigungen u. a. des Zentralnervensystems führen. Dabei sind die häufigsten beobachteten klinischen Manifestationen, die sowohl in utero als auch neonatal festgestellt werden können: Hydrozephalus, Ventrikelerweiterung und intrakraniale Läsionen. Andere Symptome, wie z. B. eine Retinochorioiditis lassen sich erst nach der Geburt feststellen oder treten sogar erst in späteren Lebensjahren auf.

Zur Feststellung von klinischen Symptomen wurden sowohl bereits in der Schwangerschaft, als auch nach der Geburt bei den mit T. gondii-infizierten Kindern sonografische Untersuchungen durchgeführt. Außerdem wurden in den meisten Fällen innerhalb des ersten Lebensjahres eine Computertomographie des Schädels (CT) und eine ophthalmologische Untersuchung durchgeführt.

Bei der Feststellung von klinischen Manifestationen wurden infizierte Kinder in dieselbe Gruppe wie deren Mütter eingeordnet. Von den sechs in Gruppe (1) infizierten Kindern, waren zwei Kinder zum Zeitpunkt der Geburt bzw. innerhalb des ersten Lebensjahres klinisch auffällig (33,3\%). In Gruppe (2) zeigten 41,2 \% (7/17) und in Gruppe (3) nur noch $10 \%$ (1/10) der Kinder eine klinische Symptomatik (Abb. 3.2). Somit hatten 30,3\% (10/33) der infizierten Kinder klinische Symptome. Insgesamt führte eine Erstinfektion der Schwangeren mit Toxoplasma in 1,5 \% (10/685) der Fälle zu klinisch auffälligen Kindern. 


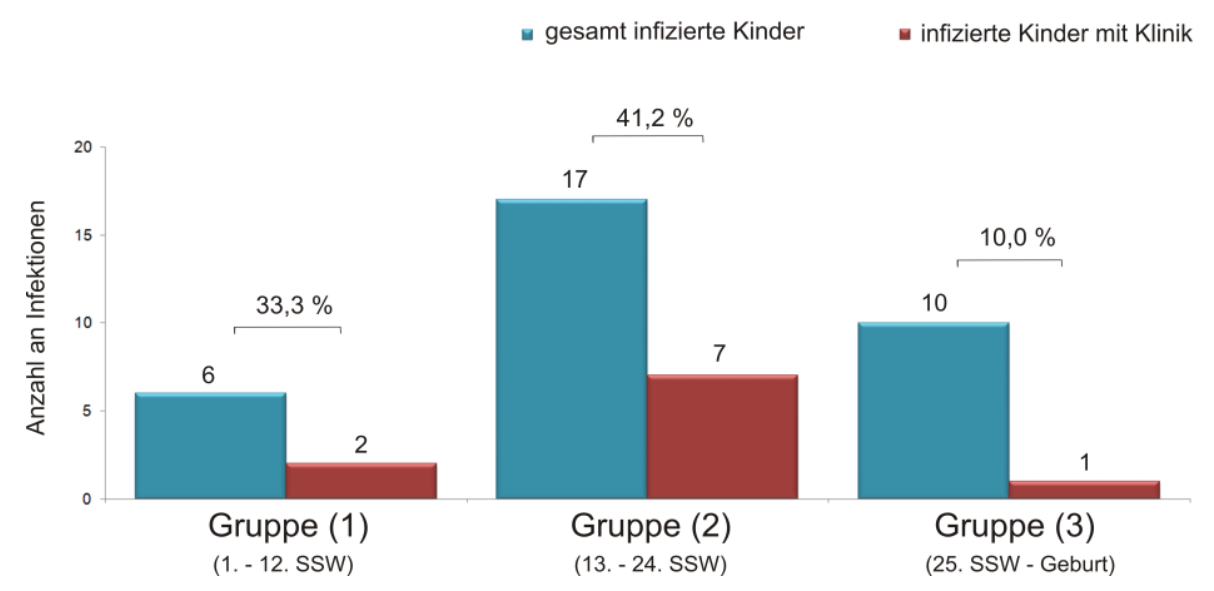

Abb. 3.2: Anzahl infizierter Kinder und infizierter Kinder mit klinischen Symptomen Untersuchung der 33 pränatal mit $T$. gondii infizierten Kindern auf klinische Manifestationen in utero und/oder neonatal. Ausgehend von der Schwangerschaftswoche (SSW) der Mutter bei Infektion wurden diese in drei Gruppen (1) - (3) eingeteilt.

In Tabelle 3.1 sind die klinischen Symptome der zehn symptomatisch infizierten Kinder aufgelistet. Dabei zeigten 60 \% (6/10) der Kinder intrakraniale Läsionen, 30 \% (3/10) eine Ventrikelerweiterung und $20 \%$ (2/10) einen Hydrozephalus, eine Retinochorioiditis oder einen Perikarderguss. Weniger häufig wurden ein Aszites oder eine Blut-Liquor Schrankenstörung beobachtet. Bei den meisten Kindern war die Ausprägung der Klinik jedoch nur relativ gering. Bei drei Kindern waren, unter dem Einfluss einer Therapie, die in utero festgestellten klinischen Symptome rückläufig und bis zur Geburt gänzlich abgeklungen.

Tab. 3.1: Auflistung der klinischen Symptome bei pränatal infizierten Kindern

Fälle

\begin{tabular}{|c|c|c|c|c|c|c|c|c|c|c|}
\hline & & & & & & & & & & \\
\hline & 1 & 2 & 3 & 4 & 5 & 6 & 7 & 8 & 9 & 10 \\
\hline SSW bei Diagnose & 26 & 28 & 32 & 22 & 24 & 25 & 25 & 27 & 30 & 30 \\
\hline Wahrscheinliches Trimester bei Infektion & 2 & 2 & 3 & 1 & 2 & 1 & 2 & 2 & 2 & 2 \\
\hline Wochen bis Therapiebeginn nach Infektion & & $<4$ & & & & & $>8$ & & & \\
\hline
\end{tabular}

\begin{tabular}{|c|c|c|c|c|c|c|c|c|c|c|c|}
\hline \multirow{8}{*}{ 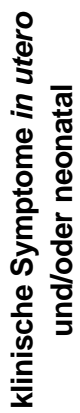 } & \multirow{3}{*}{$\begin{array}{l}\text { Hydrozephalus } \\
\text { intrakraniale Verkalkungen } \\
\text { Ventrikelerweiterung }\end{array}$} & \multirow[b]{2}{*}{+} & & & & \multicolumn{3}{|c|}{$+/-^{*}$} & \multicolumn{3}{|c|}{$+/(+)^{*}$} \\
\hline & & & & & & $(+)$ & & + & + & + & + \\
\hline & & & & & & & $+/-^{*}$ & & $(+)^{*}$ & $+*$ & \\
\hline & Retinochorioiditis & & + & & + & & & & & & \\
\hline & Fleckblutung am Auge & & & + & & & & & & & \\
\hline & Perikarderguss & & & & & & & & & $(+)^{*}$ & + \\
\hline & Aszites & & & & & & & & & & + \\
\hline & Blut-Liquor Schrankenstörung & & & & & & & + & & & \\
\hline
\end{tabular}

* Reduktion der klinischen Symptome unter Therapie (neonatal klinisch unauffällig) 


\subsubsection{Untersuchung der Toxoplasmose-Therapie in der Schwangerschaft bei Frauen mit infizierten Kindern}

Eine Infektion mit T. gondii in der Schwangerschaft wird in Deutschland in der Regel nach der Leitlinie des Robert-Koch-Institutes (RKI) therapiert (RKI, 2007). Diese sieht bis zum Ende der 15. Schwangerschaftswoche (SSW) eine Monotherapie mit Spiramycin und ab der 16. SSW eine Kombinationstherapie, bestehend aus Pyrimethamin (P), Sulfadiazin (S) und Folinsäure (F), vor. Die Dauer der Kombinationstherapie beträgt im Allgemeinen vier Wochen. In schwerwiegenden Fällen wird die Kombinationstherapie über diesen Zeitraum hinaus fortgesetzt.

Um die Effizienz der Therapie beurteilen zu können, wurde die Dauer von der Infektion der Mutter bis zur Einleitung der Therapie untersucht. In Abhängigkeit von der SSW bei Diagnosestellung, konnten die Frauen mit einem pränatal infizierten Kind in zwei Gruppen unterteilt werden. Die eine Gruppe bestand aus vier Frauen, die eine Therapie mit Spiramycin, gefolgt von der PSF-Kombinationstherapie verabreicht bekamen. Die andere Gruppe bestand aus 29 Frauen, die ausschließlich die PSFKombinationstherapie erhielten. In Tabelle 3.2 sind die beiden Gruppen separat aufgelistet. Die Dauer vom wahrscheinlichen Infektionszeitpunkt bis zur Einleitung der Therapie wurde in vierwöchigen Intervallen mit weniger als vier- bis länger als acht Wochen an Hand der serologischen Befunde abgeschätzt. Von den vier Frauen mit einer Spiramycin Monotherapie, gefolgt von einer PSF-Kombinationstherapie gebar keine ein infiziertes Kind mit klinischen Symptomen.

Bei den Frauen, die eine alleinige Kombinationstherapie erhielten, erfolgte diese bei $58,6 \%$ (17/29) der Frauen innerhalb der ersten vier Wochen nach der Infektion. Drei der 17 Kinder (17,6 \%) dieser Gruppe zeigten klinische Manifestationen. Insgesamt zeigten $14,3 \%$ der Kinder eine klinische Symptomatik, wenn das Zeitintervall bis zur Therapie unter vier Wochen lag (Tabelle 3.2). Wurde die Therapie erst 8 Wochen oder noch später nach der Infektion begonnen, stieg der Anteil der klinisch-manifesten erkrankten Kinder auf $70 \%$ an (Tabelle 3.2).

Da die Nachuntersuchung bei einigen Kindern weniger als ein Jahr betrug, besteht die Möglichkeit, dass einige klinische Symptome, wie z. B. eine Retinochorioiditis, erst zu einem späteren Zeitpunkt auftraten und somit zu einer unvollständigen Anzahl an klinisch-manifest erkrankten Kindern führte.

Diese Untersuchungen zeigten jedoch eindrucksvoll, dass ein Zeitintervall von mehr als acht Wochen von der Infektion in der Schwangerschaft bis zur Therapieeinleitung einen negativen Einfluss auf die Ausprägung einer klinischen Manifestation beim Kind hat. 
Tab. 3.2: Abschätzung des Zeitintervalls vom wahrscheinlichen Infektionszeitpunkt der Mutter bis zum Therapiebeginn $(\mathrm{N}=33)$

\begin{tabular}{|c|c|c|c|}
\hline \multirow[t]{2}{*}{ 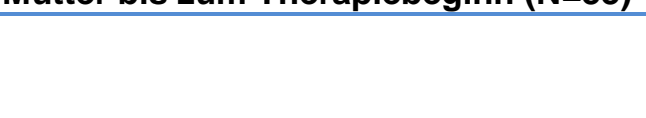 } & \multicolumn{3}{|c|}{ Wochen bis Therapiebeginn } \\
\hline & $<4$ & $4-8$ & $>8$ \\
\hline \multicolumn{4}{|c|}{ Spiramycin $\rightarrow$ PSF (Pyrimethamin + Sulfadiazin + Folinsäure) } \\
\hline Pränatale Infektionen: & $\begin{array}{c}4 \\
(2 / 2)\end{array}$ & 0 & 0 \\
\hline Kinder mit klinischen Symptomen: & 0 & 0 & 0 \\
\hline \multicolumn{4}{|l|}{ nur PSF } \\
\hline Pränatale Infektionen: & $\begin{array}{c}17 \\
(6 / 11)\end{array}$ & $\begin{array}{c}2 \\
(1 / 1)\end{array}$ & $\begin{array}{c}10 \\
(5 / 5)\end{array}$ \\
\hline Kinder mit klinischen Symptomen: & $\begin{array}{c}3 \\
(0 / 3)\end{array}$ & 0 & $\begin{array}{c}7 \\
(4 / 3)\end{array}$ \\
\hline $\begin{array}{l}\text { Risiko für ein infiziertes Kind mit } \\
\text { klinischen Symptomen: }\end{array}$ & $14,3 \%$ & & $70,0 \%$ \\
\hline
\end{tabular}

\subsection{Identifizierung von parasitären Antigenen, die eine serologische Identifizierung einer akuten Toxoplasmose ermöglichen}

Um eine Übertragung von T. gondii in der Schwangerschaft auf den Fötus zu verhindern, sollte eine Infektion möglichst frühzeitig in der Schwangerschaft erkannt werden. Wie die Ergebnisse in 3.1 belegen, kann durch eine frühzeitig eingeleitete antiparasitäre Therapie (i) die Infektion oder (ii) die Ausprägung von klinisch-manifesten Erscheinungen des Kindes möglicherweise vermindert werden.

Daher sollten im 2. Teil dieser Arbeit T. gondii-Antigene identifiziert werden, welche sich für die serologische Diagnose der akuten Infektionsphase eignen könnten.

Um dieses Ziel zu erreichen, wurden die Proteine eines Gesamtzelllysates von T. gondii durch 2D-Gelelektrophoresen aufgetrennt, mit definierten Patientenseren inkubiert und immunogene Antigene anschließend in der Massenspektrometrie analysiert.

\subsubsection{Isolierung von $T$. gondii-Antigenen mittels 2D-Gelelektrophorese}

Für die 2D-Gelelektrophorese wurden zunächst die Gesamtproteine aus T. gondii gewonnen. Hierfür wurden Tachyzoiten des NTE-Stammes (Typ II) verwendet und die 
Proteine isoliert. Die Gesamtproteinkonzentration wurde mit dem BCA-Protein Assay bestimmt. In zwei parallelen Ansätzen wurden je 100 bis $500 \mu \mathrm{g}$ Protein in der ersten Dimension auf einem nicht-linearen, immobilisierten $\mathrm{pH}$-Gradienten (IPG) nach ihrem isoelektrischen Punkt $(p /)$ isoliert. Anschließend wurden die Proteine in der zweiten Dimension in einer SDS-PAGE nach ihrer Molekularmasse getrennt. Nach erfolgtem Gellauf wurde ein Gel einer Silberfärbung unterzogen. Das andere Gel wurde in einem Immunoblot eingesetzt. Hierfür wurden die Proteine zunächst durch einen Western-Blot auf eine Membran transferiert und diese anschließend mit einem Serumpool von akutinfizierten Patienten inkubiert. Anschließend wurden die IgA-reaktiven Proteine mit einem HRP-konjugierten anti-Human IgA-Sekundärantikörper detektiert (Abb. 3.3). Nach erfolgter Detektion wurden die Antikörper entfernt und als Kontrolle die Membran mit einem Serumpool von nicht-infizierten Patienten inkubiert. Im Folgenden wurden erneut die IgA-immunogenen Proteine detektiert.

Die beiden Immunoblot-Ergebnisse wurden miteinander verglichen und die Proteine, die nur mit Antikörpern von akut T. gondii-infizierten Patienten reagierten, isoliert. Diese Proteine wurden auf dem Silber-gefärbten Gel identifiziert und für eine Massenspektrometrie-Analyse ausgeschnitten.

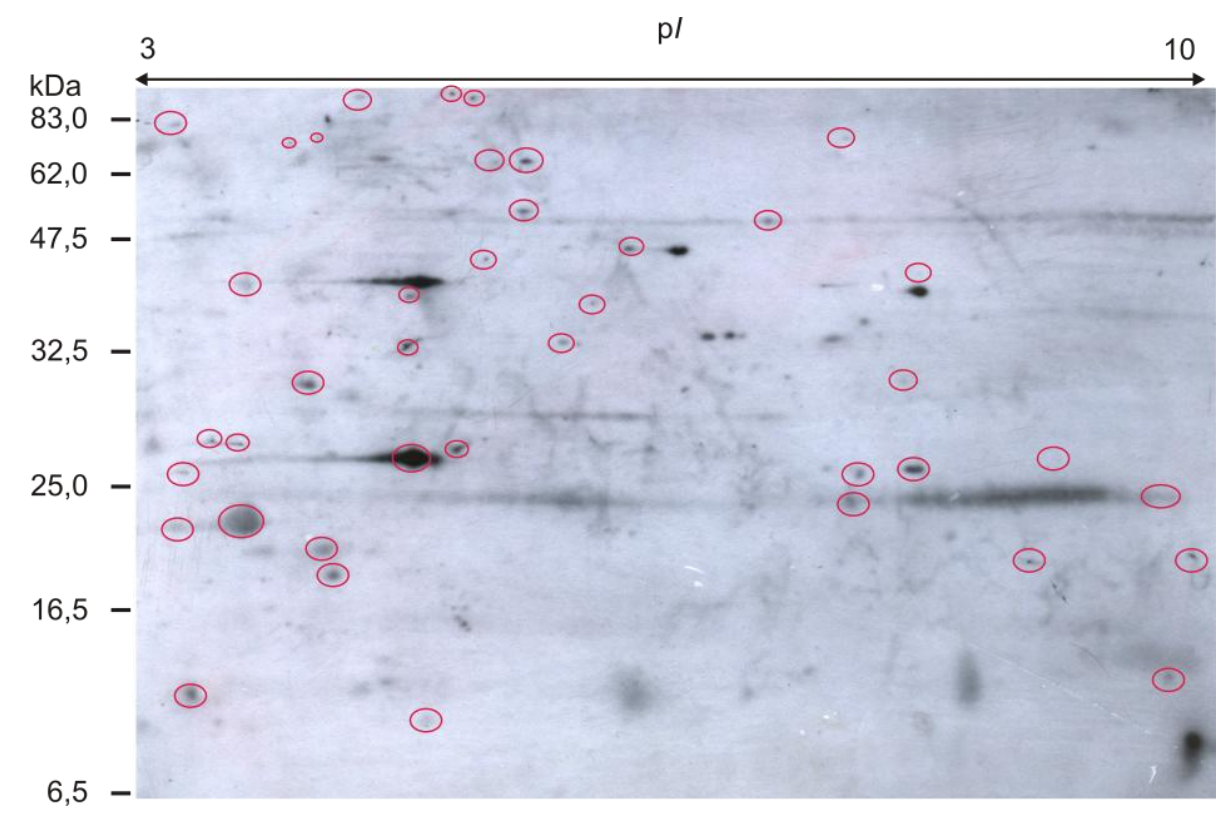

Abb. 3.3: Immunoblot nach 2D-Gelelektrophorese

Auftrennung von $100 \mu \mathrm{g}$ Tachyzoiten-Gesamtprotein in einem nicht-linearen $\mathrm{pH}$-Gradienten zwischen pH 3-10 und anschließender SDS-PAGE unter Verwendung eines 12,5\%igen Polyacrylamidgels. Marker: Prestained Protein Marker (New England Biolabs). Immunoblot mit einem humanen Serumpool von elf akut-infizierten Patienten. Als Kontrolle wurde ein Immunoblot mit einem humanen Serumpool von zwölf Patienten ohne T. gondii-Infektion durchgeführt. In beiden Fällen wurde die Detektion spezifischer IgA-Antikörper mit einem 1:2.500 verdünnten HRP-konjugierten anti-Human IgA-Sekundärantikörper ( $\alpha$-Kette) durchgeführt. Die markierten Proteine reagierten nicht mit Immunoglobulin der Seren der Kontrollgruppe. 


\subsubsection{Identifizierung IgA-immunogener Proteine durch Q-TOF Massenspektrometrie}

Nach der Identifizierung von IgA-immunogenen Proteinen im Immunoblot wurden diese auf dem Silber-gefärbten Polyacrylamidgel ausgemacht und aus dem Gel isoliert. Durch einen tryptischen Verdau wurden die Proteine aus dem Gel gelöst und für die massenspektrometrische Analyse aufgearbeitet. Die massenspektrometrische Analyse wurde mit einem ESI-Q-TOF Massenspektrometer (Waters, Eschborn) von PD Dr. Asif in der Abteilung Klinische Chemie der Universitätsmedizin Göttingen durchgeführt.

Mit der MassLynx Software (V 4.0) wurden die zeitabhängigen Flugmuster jedes Proteins festgehalten und die erhaltenen Muster über die MASCOT(http://www.matrixscience.com), Swiss-Prot- (http://expasy.org/sprot) und NCBIProteindatenbanken (http://www.ncbi.nlm.nih.gov/protein) ausgewertet. Wegen möglicher Modifikationen von Cysteinresten durch Carboamidmethylation oder Metheoninoxidation war dabei eine 0,5 Dalton (Da) Toleranzgrenze angegeben.

Die Proteine wurden durch zwei oder mehr Peptide mit einer Wahrscheinlichkeit von mehr als $\mathrm{P}>0,05$ und einem Konfidenzniveau von $95 \%$ identifiziert.

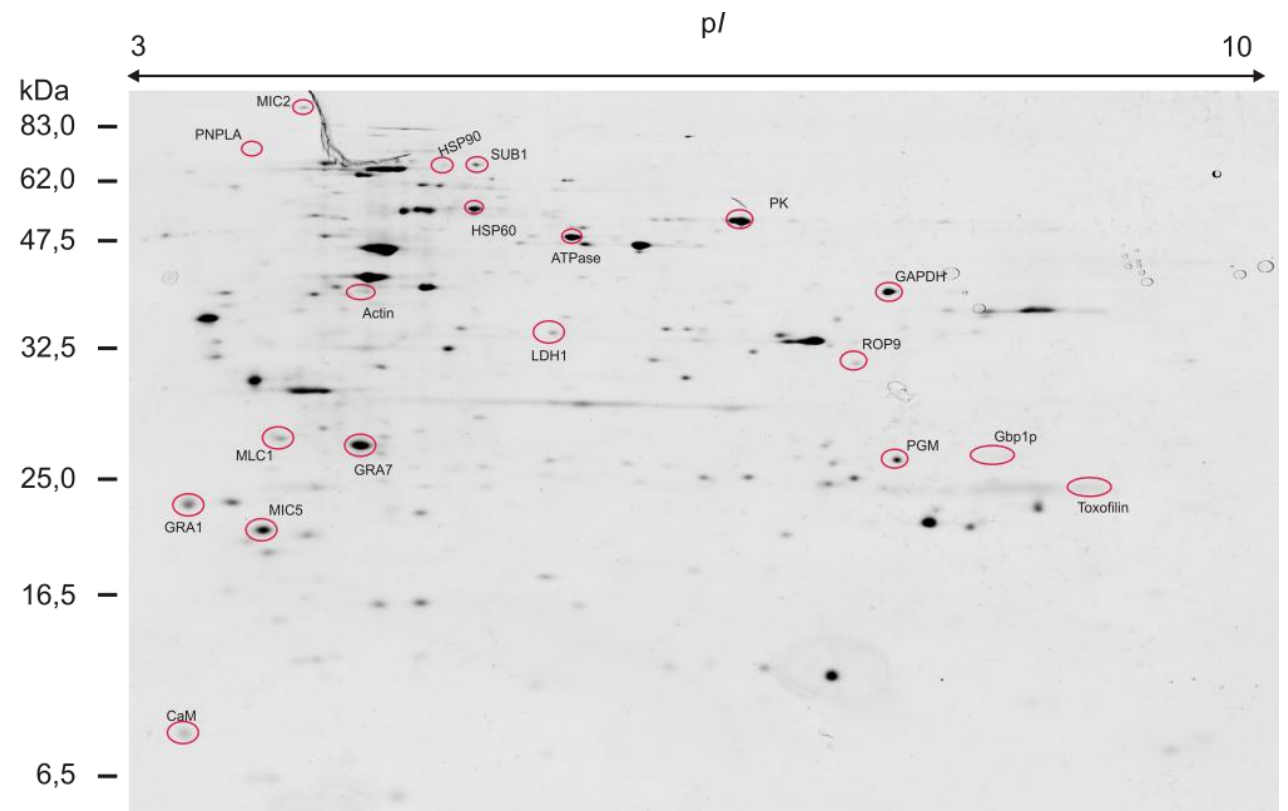

Abb. 3.4: Zweidimensionale Darstellung von T. gondii Tachyzoiten-Proteinen

Auftrennung von $100 \mu \mathrm{g}$ Tachyzoiten-Gesamtprotein in einem nicht-linearen $\mathrm{pH}$-Gradienten zwischen pH 3-10 und anschließender SDS-PAGE unter Verwendung eines 12,5\%igen Polyacrylamidgels. Marker: Prestained Protein Marker (New England Biolabs, Frankfurt). IgAimmunogene Proteine: Mikronemen-Protein 2 (MIC2), Patatin-ähnliche Phospholipase Domäne enthaltenes Protein (PNPLA), Hitzeschockprotein 90 (HSP90), Subtilisin-ähnliches Protein 1 (SUB1), Hitzeschockprotein 60 (HSP60), ATP-Synthase $\beta$-Kette (ATPase), Pyruvatkinase (PK), Actin, Apoform der Lactatdehydrogenase (LDH1), Fragment der Glycerinaldehyd-3-phosphat Dehydrogenase (GAPDH), Rhoptrien Protein 9 (ROP9), leichte Kette des Myosins (MLC1), Dichte Granula Protein 7 (GRA7), Dichte Granula Protein 1 (GRA1), Mikronemen Protein 5 (MIC5), Calciummodulin (CaM), Phosoplycerat Mutase 2 (PGM), Gbp1p Protein (Gbp1p), Toxofilin. 
Insgesamt wurden in der Massenspektrometrie 47 Proteinproben untersucht. Von diesen konnten zwanzig als Toxoplasma-Proteine identifiziert werden. Bei acht der untersuchten Proteine handelte es sich vorwiegend um das humane Keratin, welches wahrscheinlich bei der Präparation des Parasiten aus den humanen HFF-Zellen mit isoliert wurde.

Bei neunzehn Proben führte die massenspektrometrische Analyse zu keinem Ergebnis, da entweder die Proteinkonzentration zu gering, oder nur das bei der Probenaufbereitung verwendete Trypsin nachgewiesen werden konnte. Unter den zwanzig T. gondii-Proteinen wurde, auf Grund der Präparation aus verschiedenen Ansätzen, zwei Mal das Protein Phosphoglycerat Mutase 2 (PGM) identifiziert. Bei den anderen $T$. gondii-Proteinen handelte es sich vor allem um sogenannte sekretierte und bereits für die Diagnostik eingesetzte Antigene wie z. B. die Mikronemen-Antigene (MIC) MIC2 und MIC5, die Dichte Granula Antigene (GRA) GRA1 und GRA7, sowie das Rhoptrien Antigen (ROP) ROP9. Damit konnte eine funktionelle Richtigkeit für unseren experimentellen Ansatz gezeigt werden („Proof of Principle“). Zusätzlich konnte ein bisher für die Diagnostik unbekanntes Protein, das Subtilisin-ähnliche Protein 1 (SUB1), nachgewiesen werden. Des Weiteren konnten einige dem Metabolismus zugehörige Proteine identifiziert werden. Dies waren unter anderem ein Fragment der Glycerataldehyd-3-phosphat Dehydrogenase (GAPDH), die Pyruvat Kinase (PK), die aKette der Lactatdehydrogenase (LDH1), die Phosphoglycerat Mutase 2 (PGM), sowie ein Patatin-ähnliche Phospholipase Domäne enthaltenes Protein (PNPLA), welches an dem Lipidstoffwechsel beteiligt ist.

\subsection{Herstellung rekombinanter Antigene}

Die Genexpression in Prokaryoten ermöglicht die standardisierte Expression parasitärer Antigene. Außerdem entfällt das Arbeiten mit dem infektiösen Parasiten und trägt somit zu einer sichereren Labortätigkeit bei.

Daher wurden vier der über die 2D-Gelektrophorese und Massenspektrometrie identifizierten Toxoplasma-Proteine, sowie sechs aus der Literatur bekannte Antigene, rekombinant in Escherichia coli hergestellt. Zudem wurden über die Arbeitsgruppe von Prof. Dr. W. Däubener vom Institut für Medizinische Mikrobiologie und Krankenhaushygiene der Universität Düsseldorf drei weitere rekombinante $T$. gondii Proteine bezogen. 
Das gram-negative Enterobakterium Escherichia coli ist wegen seiner einfachen Handhabung und kurzen Generationszeit der am häufigsten eingesetzte prokaryotische Mikroorganismus für die Produktion von rekombinanten Proteinen.

Für die Klonierung der Gene sag1, sag4, gra1, gra2, gra6, gra7, rop1, rop9 und sub1 aus T. gondii wurde zunächst mit Hilfe der Lasergene Protean Software der Antigenindex des Proteins untersucht. Der Antigenindex berechnet sich aus einem nach Jameson und Wolf entwickelten, Computer basierten Algorithmus (Jameson und Wolf, 1988) und repräsentiert die antigenen Eigenschaften eines Proteins. Da die meisten Proteine ihre Antigenbindungsstellen innerhalb ihrer oberflächenpräsentierenden Bereiche besitzen kann das Programm an Hand der primären Aminosäuresequenz Werte zur Oberflächenbeschaffenheit eines Proteins generieren und kombiniert diese mit der Flexibilität der Sekundärstruktur. Das Ergebnis dieses Algorithmus ist der sogenannte Antigenindex, der ein lineares Oberflächenprofil eines Proteins erschafft. Für die Klonierung der T. gondii-Antigene wurden daher die Primer so gewählt, dass möglichst die antigenpräsentierenden Bereiche vertreten waren. Es wurde versucht eventuelle hydrophobe Bereiche oder Membranbindungsstellen nicht zu verwenden.

Ausgehend von dem zuvor festgelegten Proteinbereich (Abb. 3.5) wurden für die Klonierung der T. gondii-Gene entsprechende Primer verwendet.

Zu Beginn dieser Arbeit wurde zunächst der Toxoplasma RH-Stamm (Typ I) verwendet. Auf der Basis der genomischen DNA dieses Genotypes wurden die Gene sag1 und gra7 amplifiziert. Da jedoch die meisten humanen Infektionen in West-Europa durch einen Genotyp II hervorgerufen werden (Ajzenberg et al., 2002), wurde für die Klonierung weiterer Antigene der NTE-Stamm (Typ II) als geeigneter erachtet. Hierfür wurde aufgrund möglicher Introns die Gesamt-RNA isoliert und anschließend durch eine reverse Transkription in komplementäre DNA (cDNA) umgeschrieben. Über eine Polymerase-Kettenreaktion (PCR), unter Verwendung Gen-spezifischer Primer und der Pfu-DNA-Polymerase, wurde der gewünschte DNA-Bereich vervielfältigt. Mit Hilfe der Primer wurden den PCR-Fragmenten am 5'- und 3'-Ende Schnittstellen für Restriktionsendonukleasen angefügt, mit welchen diese in die ,Multiple Cloning Site (MCS) des E. coli-Expressionsvektors pQE-30 eingefügt werden konnten.

Nach der Insertion wurden die Klone auf mögliche Mutationen mit Hilfe einer Sequenzierung mit entsprechenden Sequenzierungsprimern überprüft.

Für die rekombinante Proteinexpression wurden nur Klone ohne Mutationen verwendet. 
T. gondii SAG1 Protein

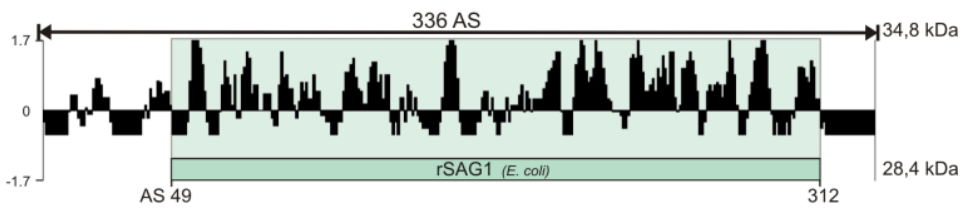

T. gondii SAG4 Protein

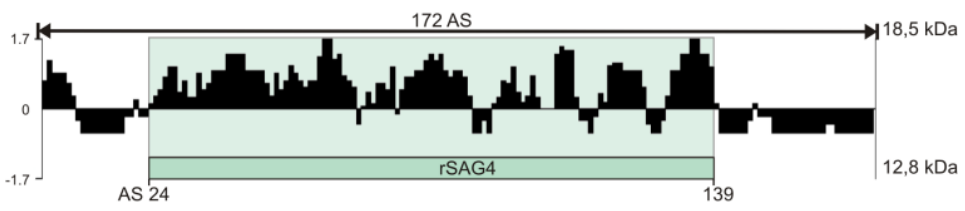

T. gondii GRA1 Protein

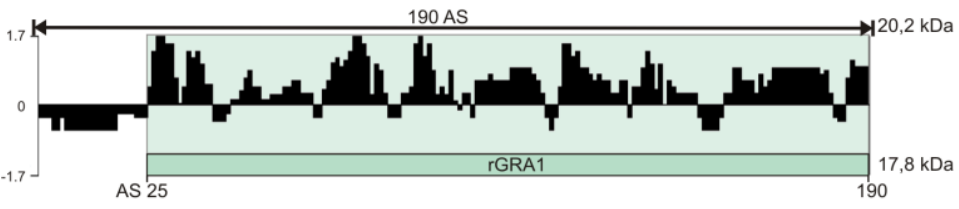

T. gondii GRA2 Protein

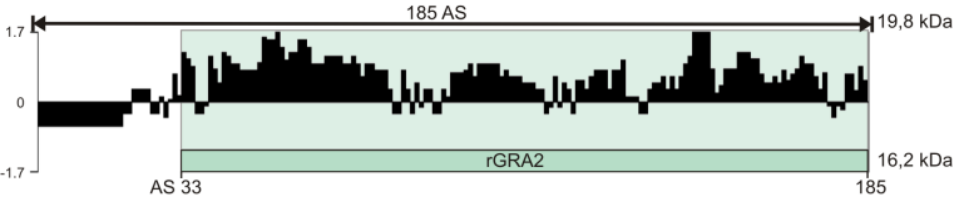

T. gondii GRA6 Protein

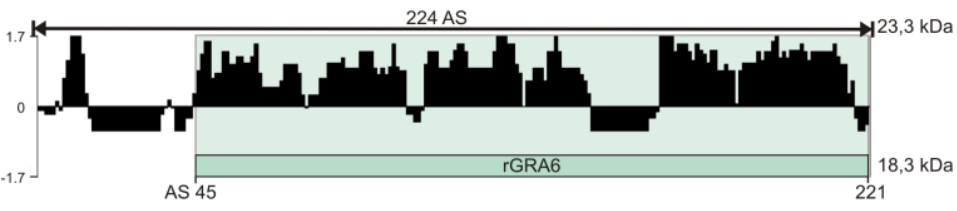

T. gondii GRA7 Protein

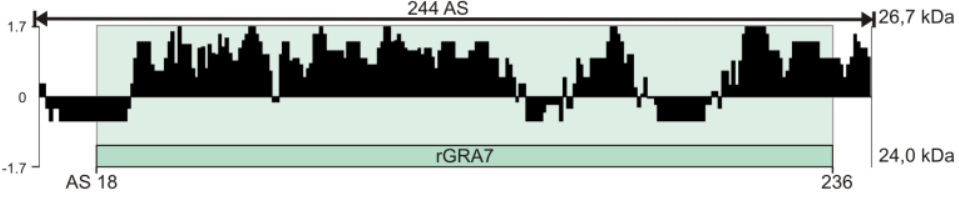

T. gondii ROP1 Protein

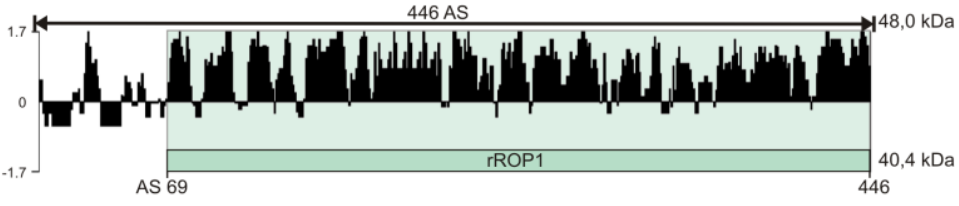

T. gondii ROP9 Protein

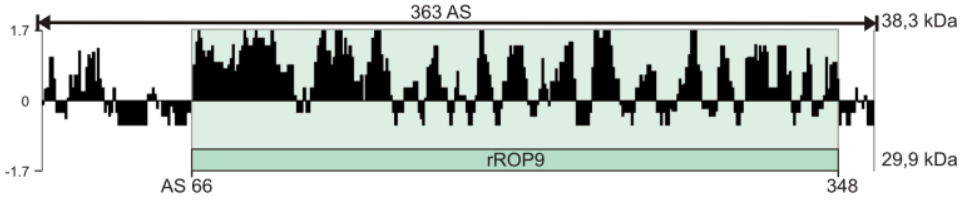

T. gondii SUB1 Protein

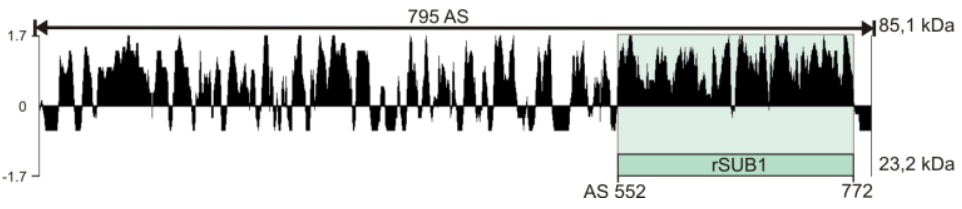

Abb. 3.5: Antigenindex von T. gondii-Antigenen für die Expression in E. coli

Gezeigt sind die Jameson und Wolf-Antigenindices der T. gondii-Proteine SAG1, SAG4, GRA1, GRA2, GRA6 und GRA7, ROP1 und ROP9, sowie SUB1. Der farbig unterlegte Bereich stellt den klonierten Bereich dar. 
Nach Expression in E. coli BL21CodonPlus ${ }^{\circledR}$ (DE3)-RIL bzw. Rosetta ${ }^{\mathrm{TM}} 2$ (DE3) und Reinigung unter denaturierenden Bedingungen wurden die Elutionsfraktionen durch eine SDS-PAGE und einem Western-Blot analysiert (Abb. 3.6).

Der pQETgBAG1-Vektor wurde von der Arbeitsgruppe Bohne (Institut für Medizinische Mikrobiologie, UMG Göttingen) bezogen und bestand aus dem Plasmid pQE-31 und dem Toxoplasma Bradyzoiten-spezifischen bag1-Gen. Die Produktion des rekombinanten BAG1-Proteins wurde mit Hilfe des E. coli BL21CodonPlus ${ }^{\circledR}$ (DE3)-RIL Stammes durchgeführt. Die Analyse der Elutionsfraktionen zeigte in den Elutionen 5 bis 7 die Anreicherung des rBAG1-Antigens mit einer relativen molaren Masse von ca. $30 \mathrm{kDa}$. Dieser Wert stimmte mit dem aus T. gondii berechneten theoretischen Molekulargewicht des BAG1-Proteins von 25 kDa überein.

Ebenfalls im E. coli BL21CodonPlus ${ }^{\circledR}$ (DE3)-RIL Stamm wurden die Antigene SAG1, GRA7 und GRA6 exprimiert. Während die Reinigung des rekombinanten SAG1Antigens zu einer hohen Ausbeute, mit bis zu 1,1 mg/ml in Elution 6, führte, konnte bei der Reinigung des rGRA6-Proteins nur eine geringe Menge Antigen isoliert werden. Die Proteinkonzentration lag hier in der Elution 5 bei $158 \mu \mathrm{g} / \mathrm{ml}$ und in der Elution 6 sogar bei nur $86 \mu \mathrm{g} / \mathrm{ml}$.

Die Antigene SAG4, ROP1, ROP9, GRA1, GRA2 und die C-terminale Domäne von SUB1 wurden mit Hilfe des E. coli Rosetta ${ }^{\mathrm{TM}} 2$ (DE3) Stammes rekombinant hergestellt. Die erhaltenen Proteinbanden für rSAG4, rROP9, rGRA1 und rGRA2 stimmten mit den erwarteten molaren Massen von ca. 14,7; 31,8; 20,1 bzw. 18,1 kDa überein.

Durch die Reinigung des rSUB1-Proteins konnte bei der Immunoblot-Analyse ein Protein mit einem Molekulargewicht von etwa $24 \mathrm{kDa}$ nachgewiesen werden, welches übereinstimmend mit dem theoretisch errechneten Molekulargewicht von 24,7 kDa für das His-SUB1-Fusionsprotein ist. Ferner konnte ein deutliches Signal bei ca. 50 kDa beobachtet werden. Dies könnte auf eine mögliche Dimerisierung des rekombinanten Proteins unter denaturierenden Bedingungen hindeuten. Ein ähnliches Ergebnis wurde bei der Analyse der ROP1-Elutionsfraktionen im Immunoblot erhalten. Auch hier war in den Elutionen 5 bis 7 eine deutliche Proteinbande bei etwa $80 \mathrm{kDa}$ zu sehen, welches mit einem Dimer des rekombinanten ROP1-Proteins mit einem theoretischen Molekulargewicht von 42,4 kDa vereinbar wäre. 


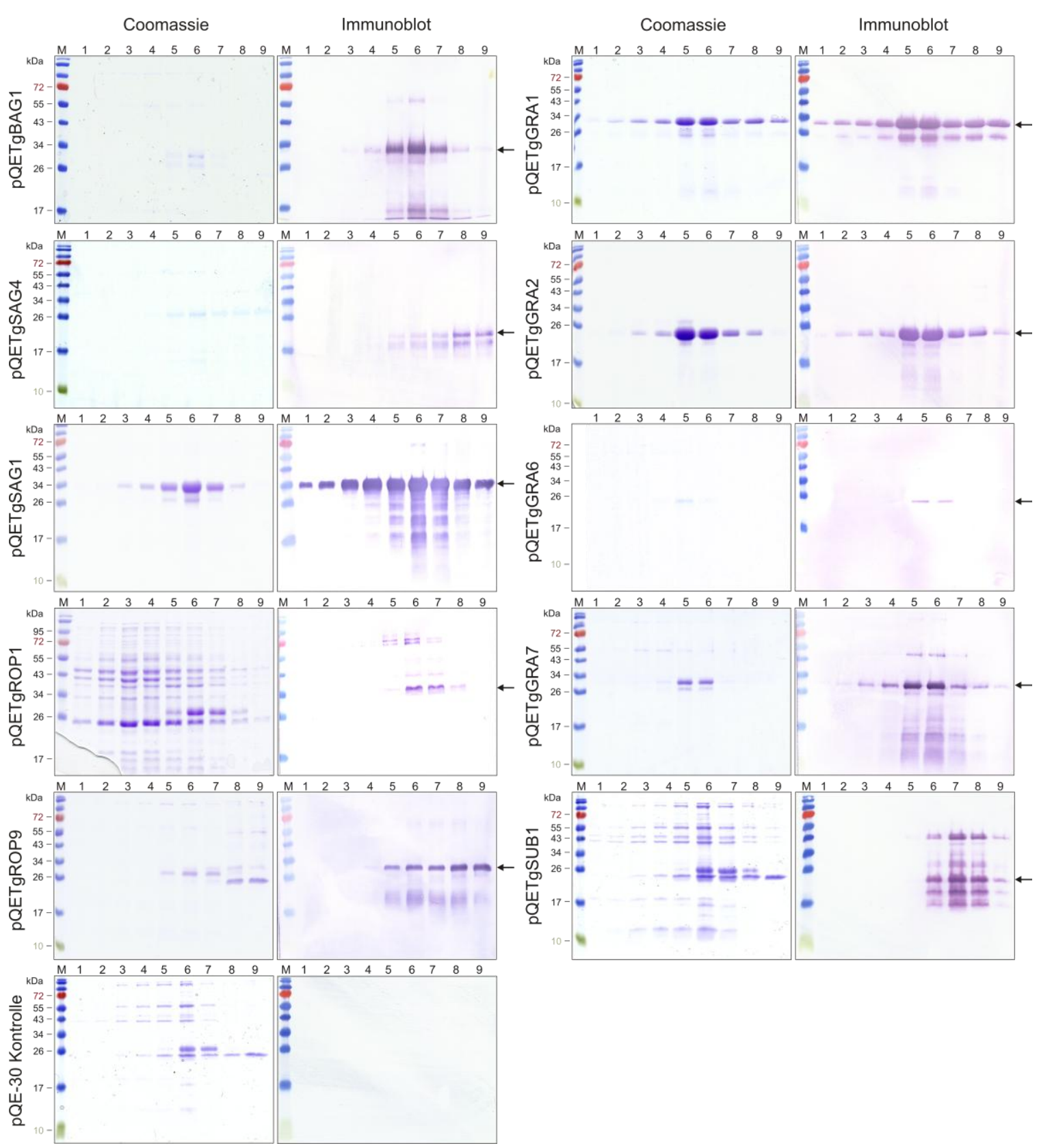

Abb. 3.6: Reinigung rekombinanter Antigene nach Expression in E. coli über den pQE-30Vektor

In einer SDS-PAGE unter Verwendung eines 12-15\%igen Polyacrylamidgel wurden je $10 \mu \mathrm{l}$ Elutionsfraktion (1-9) aufgetrennt. Gezeigt sind die Coomassie Brillant Blau gefärbten Gele und Immunoblot-Analysen der T. gondii-Antigene BAG1, SAG1, SAG4, GRA1, GRA2, GRA6 und GRA7, ROP1 und ROP9, sowie die C-terminale Domäne des SUB1-Proteins. Die Position des rekombinanten Antigens ist durch einen Pfeil angegeben. Als Kontrolle wurde eine Expression und Reinigung mit dem Ausgangsvektor pQE-30 durchgeführt. Die Detektion der rekombinanten Antigene im Immunoblot erfolgte durch einem 1:3.000 verdünnten Maus anti-His (Qiagen) und einem 1:1.000 verdünnten AP-konjugierten Ziege anti-Maus lgG $(H+L)$ Sekundärantikörper. (M) PeqGold Prestained Protein-Marker IV.

Die über die Kooperation mit Prof. W. Däubener bezogenen Proteine GRA6, GRA9 und MIC5 wurden aus dem Toxoplasma RH-Stamm kloniert und über den Expressionsvektor pET32a $(+)$ (Novagen, Merck, Darmstadt) in dem E. coli BL21 (DE3)-Stamm 
rekombinant hergestellt. Die Reinigung erfolgte ebenfalls unter denaturierenden Bedingungen. Die Analyse der Protein-Reinigungen erfolgte über eine SDS-PAGE und einen Western-Blot mit Hilfe eines anti-His Antikörpers

\subsection{Evaluierung rekombinanter T. gondii-Antigene als diagnostische Marker für Humanseren}

Die in $E$. coli rekombinant hergestellten $T$. gondii-Proteine wurden auf ihre diagnostischen Eigenschaften an Humanseren untersucht.

Da viele der rekombinanten Proteine ein ähnliches Molekulargewicht aufwiesen und nur wenig Humanserum zu Verfügung stand, wurde ein Lineblot-Assay entwickelt. Unter der Verwendung einer eigens hierfür entwickelten Lineblot-Apparatur konnten acht Proteine separat in einer Proteinmenge von 1 bis $2 \mu \mathrm{g}$ auf einer Fläche von $6,5 \times 0,2 \mathrm{~cm}$ $\left(1,3 \mathrm{~cm}^{2}\right)$ direkt auf eine Polyvinylidenfluorid (PVDF)-Membran aufgetragen werden. Auf Grund der hydrophoben Eigenschaften der Membran wurde die aufgetragene Proteinlösung nicht aufgesaugt und verblieb auf der Oberfläche, wo sie dann trocknete. Anschließend wurde die Membran in ca. $0,2 \mathrm{~cm}$ breite Streifen geschnitten und für die Immundetektion Toxoplasma-spezifischer Antikörper verwendet.

Die verwendeten Humanseren wurden größtenteils aus dem Serologielabor der Abteilung Medizinische Mikrobiologie der Universitätsmedizin Göttingen bezogen, wo sie routinemäßig auf $T$. gondii-spezifische Antikörper überprüft wurden. Die dort verwendeten Untersuchungen bestanden vorwiegend aus kommerziell bezogenen TestKits der Firmen bioMérieux und Bio-Rad (vgl. 2.6). Ausgehend vom Untersuchungsergebnis in der Routinediagnostik wurden die Seren in drei Gruppen eingeteilt: (i) Seren von Patienten ohne Toxoplasma-Infektion, (ii) Seren von Patienten mit einer akuten Toxoplasmose und (iii) Seren von Patienten mit einer chronischen/latenten Toxoplasma-Infektion.

Für die Evaluation der rekombinanten Proteine wurden 23 Seren von Patienten mit einer akuten und 28 Seren von Patienten mit einer chronischen/latenten Toxoplasma-Infektion untersucht. Als Kontrollgruppe wurden 29 Seren von Patienten ohne eine T. gondiiInfektion verwendet. In drei unabhängigen Experimenten wurden die Seren auf Toxoplasma-spezifische IgG-, IgA- und IgM-Antikörper unter Verwendung der rekombinanten Antigene untersucht. Dafür wurden die Lineblot-Streifen mit einem Serum inkubiert und die Immunreaktion durch Zugabe von HRP-konjugierten antiHuman IgG- $(H+L)$, IgM- ( $\mu$-Kette) bzw. IgA- ( $\alpha$-Kette) Sekundärantikörpern in einer Chemilumineszenz-Reaktion nachgewiesen. Mit Hilfe des Lumineszenz Image Reader 
LAS-4000 wurden bei der Detektion spezifischer IgG- und IgM-Antikörper alle $20 \mathrm{sec}$ bzw. alle $60 \mathrm{sec}$ bei der Detektion von IgA-Antikörpern Bilder aufgenommen. Anschließend wurden die Bilder mit Hilfe der ImageJ- und Multi Gauge-Software quantitativ ausgewertet.

\subsubsection{Evaluation der rekombinanten T. gondii-Antigene durch Quantifizierung mit dem Multi Gauge-Programm mit vordefinierten Cut-off Werten}

Die Quantifizierung mit dem Multi Gauge-Programm basierte auf den durch den LAS4000 erzeugten *.img-Dateien und führte zu einer Bestimmung der Emissionsrate pro $\mathrm{mm}^{2}\left(\mathrm{AU} / \mathrm{mm}^{2}\right)$. In einer zunächst zeitabhängigen Untersuchung wurde die Emissionsrate der Kontrollgruppe ohne Toxoplasma-Infektion alle $20 \mathrm{sec}(\operatorname{lgM} / \lg \mathrm{G})$ bzw. $60 \mathrm{sec}(\lg \mathrm{A})$ bestimmt. Bei einem Überschreiten des Wertes von $10.000 \mathrm{AU} / \mathrm{mm}^{2}$, wurde die Quantifizierung zu diesem Zeitpunkt beendet. Zum selben Zeitpunkt wurde die Emission der Seren von Patienten mit einer akuten bzw. chronischen Infektion ermittelt. Alle Seren die zu diesem Zeitpunkt eine Emissionsrate von mehr als $20.000 \mathrm{AU} / \mathrm{mm}^{2}$ besaßen, wurden als positiv gewertet. Ausgehend von diesen Ergebnissen wurde die Spezifität, die Sensitivität, sowie der positive (PPV)- und negative (NPV)Vorhersagewert bestimmt (vgl. 2.5.10).

Diagnostisch relevante Antigene zeichneten sich durch eine Spezifität von mehr als $90 \%$ und einer Sensitivität von mindestens $45 \%$ aus. Als Stadium-spezifischer Marker wurde ein Antigen gewertet, wenn der PPV-Wert $\geq 70 \%$ für eine akute bzw. chronische Infektion vorlag und der NPV einen Wert von $75 \%$ oder mehr aufwies.

Als Kontrolle auf mögliche Kreuzreaktionen der Seren mit E. coli-Proteinen wurden 1-2 $\mu$ g E. coli/pQE-30 Proteine pro Membran nach einer denaturierenden Reinigung im Lineblot eingesetzt. $\mathrm{Zu}$ den in Abb. 3.7 angegeben Entwicklungszeiten wurde die prozentuale Menge an positiven Seren bestimmt. Die Untersuchung der Seren mit einer Emission von mehr als $20.000 \mathrm{AU} / \mathrm{mm}^{2}$ zeigte, dass weniger als $3 \%$ der untersuchten Seren bei Verwendung von anti-Human IgA- und IgM-Sekundärantikörpern falschpositiv reagierten. Keine falsch-positiven Ergebnisse zeigte dagegen die Verwendung des anti-Human IgG-Sekundärantikörpers bis zu einer Entwicklungszeit von $60 \mathrm{sec}$ (Abb. 3.7). 

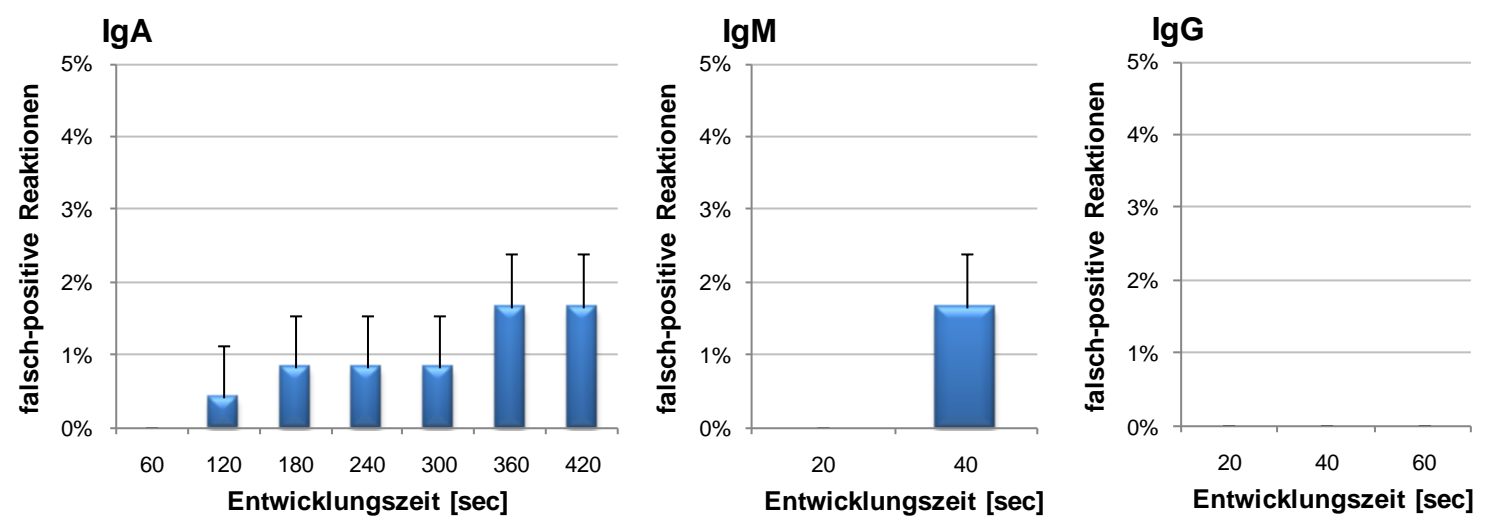

Abb. 3.7: Anteil falsch-positiver Seren unter Verwendung von E. coli/pQE-30 Proteinen im Lineblot-Assay in einer zeitabhängigen Auswertung

In einem Lineblot wurden 1-2 $\mu \mathrm{g}$ E. coli/pQE-30 Proteine/Membran nach einer denaturierenden Reinigung mit 1:100 verdünnten Humanseren getestet. Die Detektion erfolgte mit Hilfe von 1:1.000 verdünnten HRP-konjugierten anti-Human IgA-, IgM- bzw. IgG-Sekundärantikörpern zu den angegebenen Zeitpunkten. Die Quantifizierung erfolgte mit dem Multi Gauge-Programm mit einem Cut-off von $\geq 20.000 \mathrm{AU} / \mathrm{mm}^{2}$.

\subsubsection{BAG1 und die Oberflächenantigene SAG4 und SAG1}

Die Antigene BAG1, SAG4 und SAG1 wurden unter denaturierenden Bedingungen über eine Ni-NTA Affinitätschromatographie gereinigt und in einem Lineblot-Assay mit folgenden Konzentrationen eingesetzt: $2 \mu \mathrm{g}$ rBAG1/Membran, 1 g rSAG4/Membran, $2 \mu \mathrm{g}$ rSAG1/Membran.

In Tabelle 3.3 ist eine Übersicht der Spezifität und Sensitivität, sowie der PPV-Wert für eine akute bzw. chronische Infektion und der NPV-Wert für den Nachweis spezifischer Antikörper gegen die rekombinanten Antigene BAG1, SAG4 und SAG1 gezeigt. Ausgewertet wurden die Seren, die eine Emission von mehr als $20.000 \mathrm{AU} / \mathrm{mm}^{2}$ aufwiesen. In Abhängigkeit davon, wann ein oder mehrere Seren von nicht-Infizierten (Kontrollgruppe) den Wert von $10.000 \mathrm{AU} / \mathrm{mm}^{2}$ erreichten, ergaben sich für jedes Antigen und jede Immunoglobulin-Klasse unterschiedliche Auswertungszeitpunkte. 
Tab. 3.3: Quantifizierung der Immunantwort gegen die rekombinanten $T$. gondii-Antigene BAG1, SAG4 und SAG1 in einem Lineblot-Assay

In einem Lineblot wurden 1-2 $\mu \mathrm{g} T$. gondii-Antigen/Membran aufgetragen. Die Quantifizierung der Immunantwort erfolgte über das Multi Gauge-Programm. Die Berechnungen beruhten auf den positiv-reagierenden Seren mit einer Emission von $\geq 20.000 \mathrm{AU} / \mathrm{mm}^{2}$. Angaben in Prozent [\%].

\begin{tabular}{|c|c|c|c|c|c|c|c|c|c|c|c|c|c|c|c|c|c|c|c|c|}
\hline \multirow{5}{*}{ 으 } & \multirow[b]{3}{*}{ rBAG1 } & \multirow{3}{*}{$\frac{\mathrm{sec}}{360}$} & \multirow{2}{*}{\multicolumn{3}{|c|}{ Spezifität }} & \multicolumn{6}{|c|}{ Sensitivität } & \multicolumn{6}{|c|}{ PPV } & \multicolumn{3}{|c|}{ NPV } \\
\hline & & & & & & \multicolumn{3}{|c|}{$\begin{array}{c}\text { akute } \\
\text { Infektion }\end{array}$} & \multicolumn{3}{|c|}{$\begin{array}{l}\text { chronische } \\
\text { Infektion }\end{array}$} & \multicolumn{3}{|c|}{$\begin{array}{c}\text { akute } \\
\text { Infektion }\end{array}$} & \multicolumn{3}{|c|}{$\begin{array}{l}\text { chronische } \\
\text { Infektion }\end{array}$} & \multirow{2}{*}{\multicolumn{2}{|c|}{$51 \pm$}} & \multirow[b]{2}{*}{ \pm} \\
\hline & & & 99 & \pm & & 3 & \pm & 5 & 6 & \pm & 2 & 21 & & $\overline{36}$ & 85 & & 25 & & & \\
\hline & rSAG4 & 300 & 100 & \pm & 0 & 1 & \pm & 3 & 4 & \pm & 4 & 33 & & 58 & 67 & \pm 5 & & 51 & \pm & 0 \\
\hline & rSAG1 & 60 & 98 & \pm & 2 & 0 & \pm & 0 & 0 & \pm & 0 & 0 & \pm & 0 & 0 & \pm & 0 & 49 & \pm & 1 \\
\hline \multirow{3}{*}{ 흐 } & rBAG1 & 20 & 100 & \pm & 0 & 0 & \pm & 0 & 0 & \pm & 0 & 0 & \pm & 0 & 0 & \pm & 0 & 50 & \pm & 0 \\
\hline & rSAG4 & 40 & 98 & \pm & 4 & 1 & \pm & 3 & 2 & \pm & 4 & 13 & \pm 2 & 22 & 18 & \pm 3 & 32 & 50 & \pm & 0 \\
\hline & rSAG1 & 20 & 100 & \pm & 0 & 0 & \pm & 0 & 2 & \pm & 4 & 0 & \pm & 0 & 33 & \pm 5 & 58 & 50 & \pm & 1 \\
\hline \multirow{3}{*}{ 밈 } & rBAG1 & 60 & 100 & \pm & 0 & 30 & \pm & 4 & 25 & \pm & 4 & 71 & \pm & 5 & 65 & \pm & 6 & 58 & \pm & 1 \\
\hline & rSAG4 & 40 & 99 & \pm & 2 & 0 & \pm & 0 & 0 & \pm & 0 & 0 & \pm & 0 & 0 & \pm & 0 & 50 & \pm & 1 \\
\hline & rSAG1 & 20 & 99 & \pm & 2 & 10 & \pm & 7 & 5 & \pm & 2 & 75 & \pm & 15 & 51 & \pm & 17 & 52 & \pm & 1 \\
\hline
\end{tabular}

Der Nachweis von Antikörpern gegen das rekombinante BAG1-Antigen, wie auch gegen die rekombinanten Oberflächenantigene SAG1 und SAG4 zeigte eine Spezifität von 98$100 \%$ mit nur geringen Sensitivitäten (Tab. 3.3). Dabei zeigte der Nachweis BAG1- und SAG4-spezifischer IgA-Antikörper eher eine Reaktion in der chronischen Infektionsphase. SAG1-spezifische IgG-Antikörper ließen sich dagegen eher bei einer akuten Infektion nachweisen.

Aufgrund der geringen Sensitivitäten der Antigene, war die Wahrscheinlichkeit für ein richtig-negatives Ergebnis in nur etwa 50 \% (NPV) gegeben. Daher zeigte keines dieser Antigene ein Potenzial als diagnostischer Marker.

\subsubsection{Rhoptrien- und Mikronemen-Antigene}

Die von Rhoptrien sekretierten Antigene ROP1 und ROP9, sowie die von den Mikronemen sekretierten Antigene MIC5 und SUB1 wurden ebenfalls unter denaturierenden Bedingungen über eine Ni-NTA Affinitätschromatographie gereinigt. Im Lineblot wurden die Antigene mit folgenden Konzentrationen eingesetzt: 0,5 $\mathrm{gg}$ rROP1/Membran, $2 \mu \mathrm{g}$ rROP9/Membran und 1,5 $\mu \mathrm{g}$ rSUB1/Membran. Die Auswertung fand analog zu den zuvor getesteten Antigenen statt. 
Tab. 3.4: Quantifizierung der Immunantwort gegen die rekombinanten T. gondii-Antigene ROP1, ROP9, MIC5 und SUB1 im Lineblot-Assay

In einem Lineblot wurden 0,5-2 $\mu \mathrm{g} T$. gondii-Antigen/Membran aufgetragen. Die Quantifizierung der Antikörper-Reaktivität erfolgte über das Multi Gauge-Programm. Die Berechnungen beruhen auf den positiv-reagierenden Seren mit einer Emission von $\geq 20.000 \mathrm{AU} / \mathrm{mm}^{2}$. Angaben in Prozent [\%].

\begin{tabular}{|c|c|c|c|c|c|c|c|c|c|c|c|c|c|c|c|c|c|c|c|c|}
\hline \multirow{6}{*}{ 흐 } & \multirow{2}{*}{\multicolumn{2}{|c|}{$\mathrm{sec}$}} & \multirow{2}{*}{\multicolumn{3}{|c|}{ Spezifität }} & & & & & & & \multicolumn{6}{|c|}{ PPV } & \multicolumn{3}{|c|}{ NPV } \\
\hline & & & & & & \multicolumn{3}{|c|}{$\begin{array}{c}\text { akute } \\
\text { Infektion }\end{array}$} & \multicolumn{3}{|c|}{$\begin{array}{l}\text { chronische } \\
\text { Infektion }\end{array}$} & \multicolumn{3}{|c|}{$\begin{array}{c}\text { akute } \\
\text { Infektion }\end{array}$} & \multicolumn{3}{|c|}{$\begin{array}{l}\text { chronische } \\
\text { Infektion }\end{array}$} & \multirow[b]{2}{*}{57} & \multirow[b]{2}{*}{ \pm} & \multirow[b]{2}{*}{2} \\
\hline & rROP1 & 300 & 100 & \pm & 0 & 22 & \pm & 8 & 24 & \pm & 8 & 47 & & 11 & 53 & \pm 1 & & & & \\
\hline & rROP9 & 300 & 99 & \pm & 2 & 3 & \pm & 3 & 7 & \pm & 4 & 26 & \pm & 22 & 64 & \pm 3 & & 51 & \pm & 1 \\
\hline & rMIC5 & 60 & 99 & \pm & 2 & 1 & \pm & 3 & 2 & \pm & 4 & 29 & \pm & 17 & 48 & & & 50 & \pm & 0 \\
\hline & rSUB1 & 300 & 99 & \pm & 2 & 12 & \pm & 3 & 18 & \pm & 4 & 38 & \pm & 5 & 59 & \pm & 5 & 54 & \pm & 1 \\
\hline \multirow{4}{*}{ 흥 } & rROP1 & 20 & 95 & \pm & 5 & 11 & \pm & 8 & 5 & \pm & 4 & 54 & \pm & 14 & 23 & \pm 3 & & 51 & \pm & 1 \\
\hline & rROP9 & 20 & 98 & \pm & 3 & 0 & \pm & 0 & 4 & \pm & 6 & 0 & \pm & 0 & 68 & \pm 3 & & 50 & \pm & 0 \\
\hline & rMIC5 & 20 & 96 & \pm & 1 & 3 & \pm & 5 & 2 & \pm & 2 & 31 & \pm & 32 & 26 & \pm 2 & 25 & 50 & \pm & 1 \\
\hline & rSUB1 & 20 & 99 & \pm & 2 & 2 & \pm & 4 & 0 & \pm & 0 & 66 & \pm & 58 & 0 & \pm & 0 & 50 & \pm & 1 \\
\hline \multirow{4}{*}{ 멈 } & rROP1 & 20 & 98 & \pm & 2 & 28 & \pm & 7 & 8 & \pm & 2 & 72 & \pm & 6 & 22 & \pm & 6 & 54 & \pm & 0 \\
\hline & rROP9 & 40 & 98 & \pm & 4 & 4 & \pm & 0 & 1 & \pm & 2 & 55 & \pm & 41 & 15 & \pm & 14 & 50 & \pm & 1 \\
\hline & rMIC5 & 20 & 98 & \pm & 2 & 4 & \pm & 8 & 7 & \pm & 0 & 32 & \pm & 37 & 52 & \pm & 19 & 51 & \pm & 1 \\
\hline & rSUB1 & 40 & 99 & \pm & 2 & 70 & \pm & 4 & 21 & \pm & 6 & 75 & \pm & 3 & 23 & \pm & 4 & 64 & \pm & 2 \\
\hline
\end{tabular}

Aus der Tabelle 3.4 ist zu ersehen, dass die Auswertung positiver Seren mit einer Emission von mehr als $20.000 \mathrm{AU} / \mathrm{mm}^{2}$ zu einer hohen Spezifität zwischen 95-100 \% führte. Durch den Nachweis ROP9- und MIC5-spezifischer Antikörper war jedoch nur eine geringe Sensitivität nachzuweisen

Der Nachweis von IgG-Antikörpern gegen das rSUB1 dagegen zeigte eine Sensitivität von $70 \%$ unter Verwendung von Seren aus der akuten Infektionsphase. Unter Verwendung von Seren mit einer chronischen Infektion konnten hier nur bei $21 \%$ der Seren spezifische IgG-Antikörper nachgewiesen werden. Daher spricht hier eine positive Reaktion in 75 \% (PPV) für eine akute Infektion und eine negative Reaktion in $64 \%$ (NPV) für ein richtig-negatives Ergebnis.

Der PPV bei Nachweis von IgG-Antikörpern gegen das rROP1-Antigen betrug $72 \%$, wenn Seren von Patienten mit einer akuten Infektion eingesetzt wurden.

Aufgrund der Tatsache, dass rROP1 und rSUB1 ein Potenzial als Marker für das akute Infektionsstadium zeigten, wurden diese Antigene hinsichtlich ihrer Emissionsintensität mit Seren von akut- bzw. chronisch-infizierten Patienten untersucht. Dabei steht die Intensität in Zusammenhang mit der Menge an detektierbaren Antikörpern. 
Hierfür wurden die 23 Seren von akut-infizierten Patienten nochmals in neun hoch-akut und 14 subakut Infizierte unterteilt (vgl. 2.6). In einer grafischen Auswertung wurde der Mittelwert der Emission jeden Serums, basierend auf den verschiedenen Gruppen, aufgetragen (Abb. 3.8).

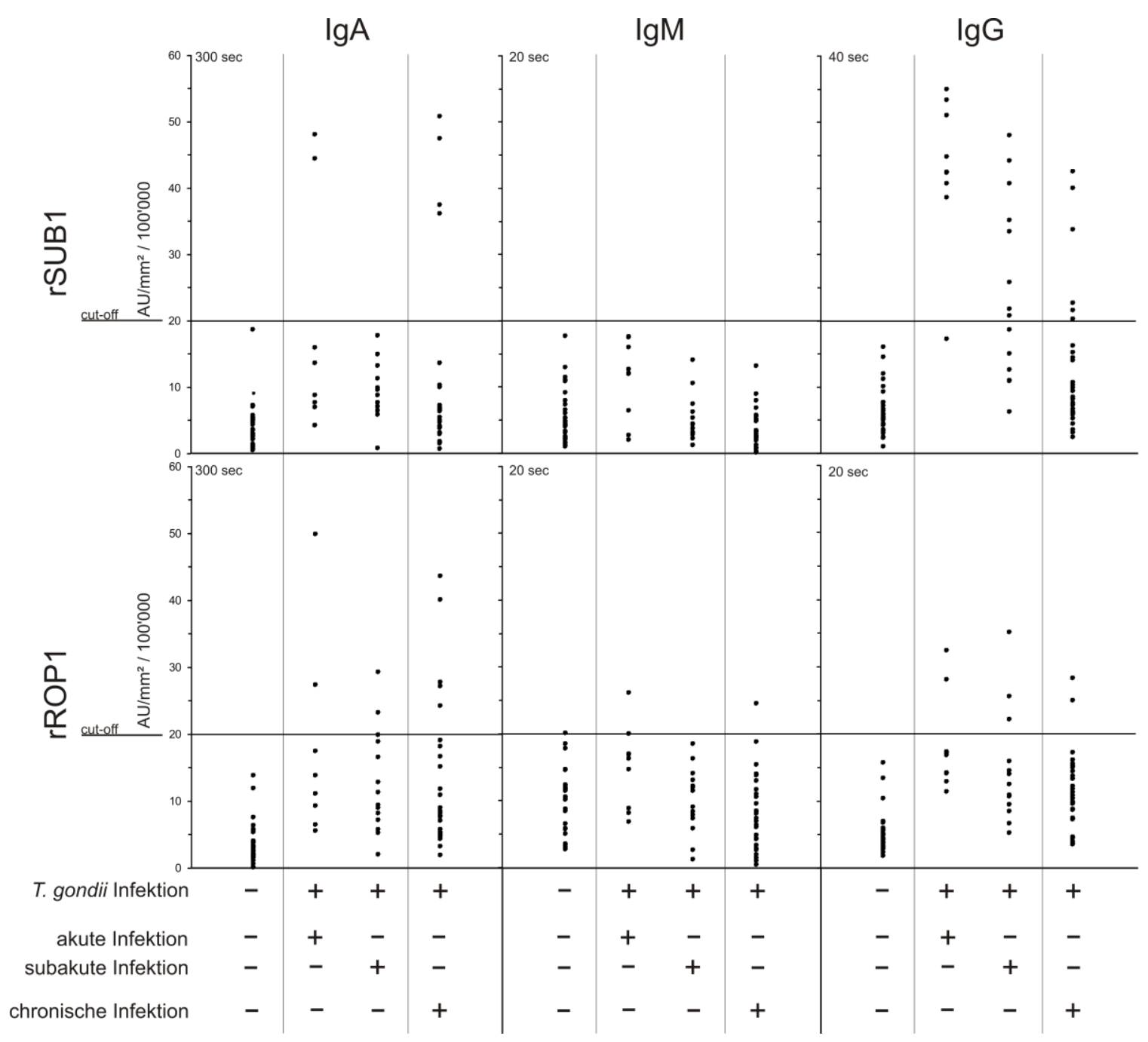

Abb. 3.8: Emission der Seren bei Verwendung der Antigene rSUB1 und ROP1

Dargestellt sind die Mittelwerte jedes Serums, welches auf SUB1- bzw. ROP1-spezifische Antikörper getestet wurde. Die Seren wurden in drei Gruppen eingeteilt: (i) Seren von Patienten ohne Toxoplasma-Infektion (N) $(n=29)$ (ii) Seren von akut-infizierten Patienten $(n=23 ; n$ (hochakut) = 9; $n$ (subakut) = 14) und (iii) Seren von chronisch-infizierten Patienten $(n=28)$. Die Entwicklungszeiten der Lineblot-Assays sind angegeben.

Bei Nachweis SUB1- bzw. ROP1-spezifischer IgM-Antikörper war kein signifikanter Unterschied der Immunreaktion von Patienten mit einer T. gondii-Infektion im Vergleich zu der Kontrollgruppe festzustellen. Geringe Unterschiede lassen sich allerdings bei dem Nachweis SUB1-spezifischer IgG-Antikörper zwischen den Seren von hoch-akut- 
und subakut- bzw. hoch-akut- und chronisch-infizierten Patienten erkennen. Mit Ausnahme eines Serums lag die Emission der Seren von hoch-akut Infizierten zwischen 40.000 und $60.000 \mathrm{AU} / \mathrm{mm}^{2}$, keines ergab jedoch eine Emission von weniger als 10.000 $\mathrm{AU} / \mathrm{mm}^{2}$. Seren von Patienten mit einer subakuten Infektion besaßen ein größeres Emissionsspektrum von etwa 5.000 bis $50.000 \mathrm{AU} / \mathrm{mm}^{2}$. Ein ähnliches Spektrum zeigten auch Seren von chronisch-Infizierten.

Bei Nachweis von IgG-Antikörpern gegen das rROP1-Antigen waren keine signifikanten Unterschiede zu erkennen. Jedoch erreichten häufiger Seren von Patienten mit einer akuten Infektion den Cut-off Wert.

\subsubsection{Dichte Granula-Antigene}

Bei der Invasion in den Wirt sekretieren die Dichte Granula Proteine in die sich bildende parasitophore Vakuole (PV). Diese GRA (dense granule antigen)-Proteine sind daher potentielle Marker für die Identifizierung einer $T$. gondii-Infektion und erlauben möglicherweise eine Differenzierung zwischen einer akuten und einer chronischen Infektion.

Die Antigene GRA1, GRA2, GRA6 (NTE) und GRA7 wurden in E. coli als HisFusionsproteine rekombinant hergestellt und anschließend mit Hilfe des His-Tags gereinigt. Des Weiteren wurden die über die Kooperation mit der Arbeitsgruppe Däubener (Düsseldorf) bezogenen rekombinanten GRA-Antigene GRA6 (RH)- und GRA9 verwendet. Die Antigene wurden ebenfalls in $E$. coli rekombinant hergestellt und unter denaturierenden Bedingungen gereinigt.

Für die Analyse der GRA-Antigene im Lineblot-Assay wurde eine Konzentration von $1 \mu \mathrm{g} /$ Membran verwendet. Die Auswertung fand wieder analog zu den zuvor getesteten Antigenen statt.

Die Evaluation der GRA-Antigene im Lineblot ergab, dass diese nur geringe unspezifische Reaktionen mit Seren von Patienten ohne eine T. gondii-Infektion zeigten und somit der Antikörper-Nachweis zu 96-100\% spezifisch war (Tab. 3.5). Der Nachweis von IgG-Antikörpern gegen die Antigene rGRA1, rGRA2, rGRA6 (RH) und rGRA9 korrelierte am häufigsten mit einer Toxoplasma-Infektion. Dabei lag die Sensitivität zwischen 49-97\% und der NPV betrug 75-86 \%. Seren von akut- und chronisch-Infizierten konnten jedoch mit diesen Antigenen nicht differenziert werden.

Bei Nachweis von spezifischen IgA-Antikörpern konnte eine akute Infektion mit Hilfe des rGRA2- etwa 1,5 Mal und unter Verwendung des rGRA6 (RH)-Antigens ca. 3,5 Mal häufiger erkannt werden als eine chronische Infektion. Dagegen zeigte der Nachweis 
von IgA-Antikörper gegen das rGRA6 (NTE), rGRA7 und rGRA9 eher eine Reaktion in der chronischen Infektionsphase. Zudem konnte bei Detektion spezifischer IgA- und IgM-Antikörper eine ähnliche Reaktivität mit den Antigenen rGRA6 (NTE) und rGRA7 beobachtet werden.

Tab. 3.5: Quantifizierung der Immunantwort gegen die rekombinanten T. gondii GRAAntigene im Lineblot-Assay

Im Lineblot wurden die GRA-Antigene in einer Konzentration von $1 \mu \mathrm{g} /$ Membran aufgetragen. Die Quantifizierung der Antikörper-Reaktivität erfolgte über das Multi Gauge-Programm. Die Berechnungen beruhten auf den positiv-reagierenden Seren mit einer Emission von $\geq 20.000$ $\mathrm{AU} / \mathrm{mm}^{2}$. Angaben in Prozent [\%].

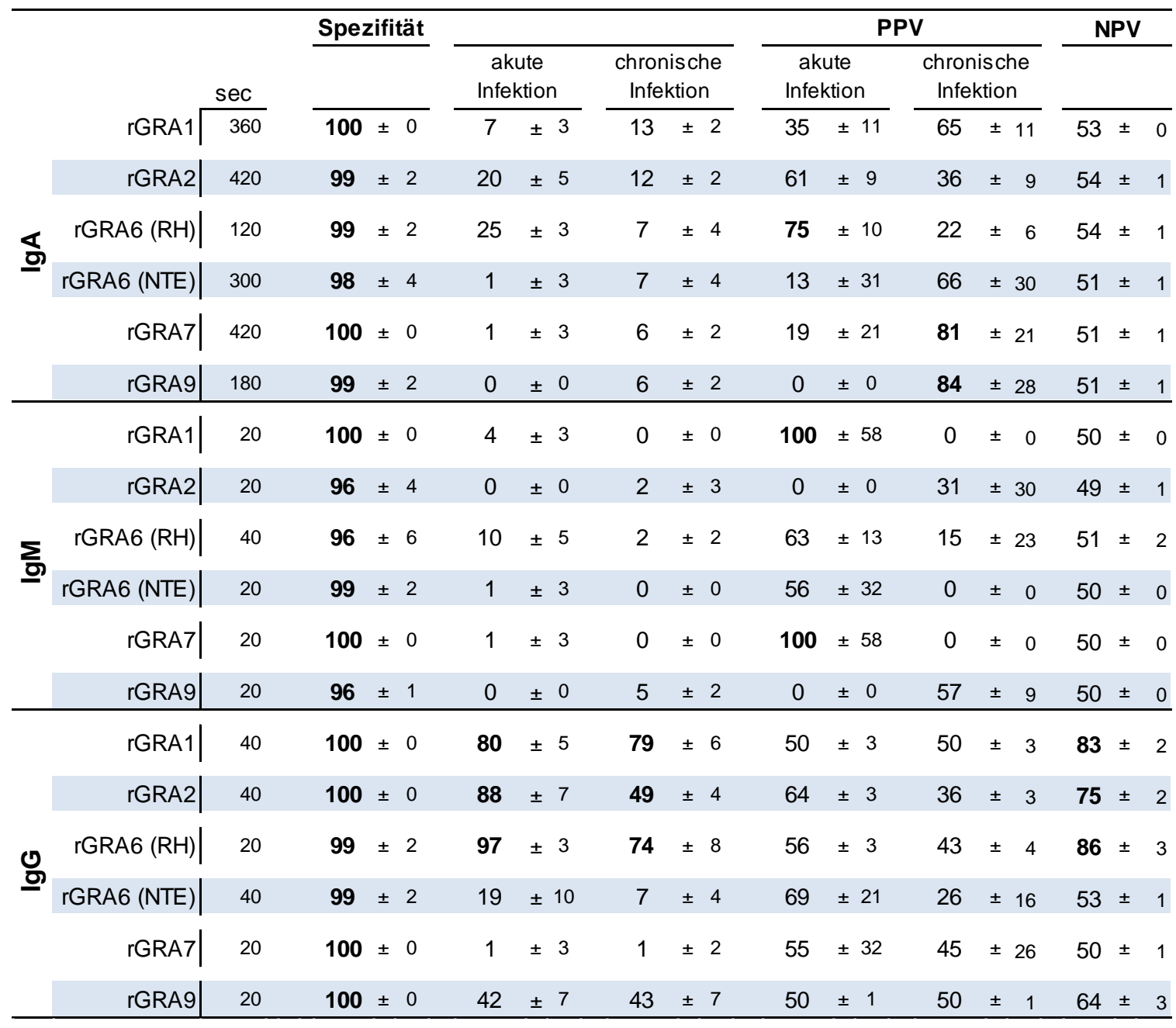

Da der Nachweis spezifischer IgG-Antikörper gegen die rekombinanten Antigene GRA1, GRA2 und GRA6 $(\mathrm{RH})$ eine hohe Sensitivität aufwiesen und das rGRA6 (RH)-Antigen bei Nachweis spezifischer IgA-Antikörper Potenzial als Marker für das akute Stadium zeigte, wurde die Immunreaktivität gegen diese Antigene, analog zu den rekombinanten Antigenen SUB1 und ROP1, ebenfalls grafisch ausgewertet. 


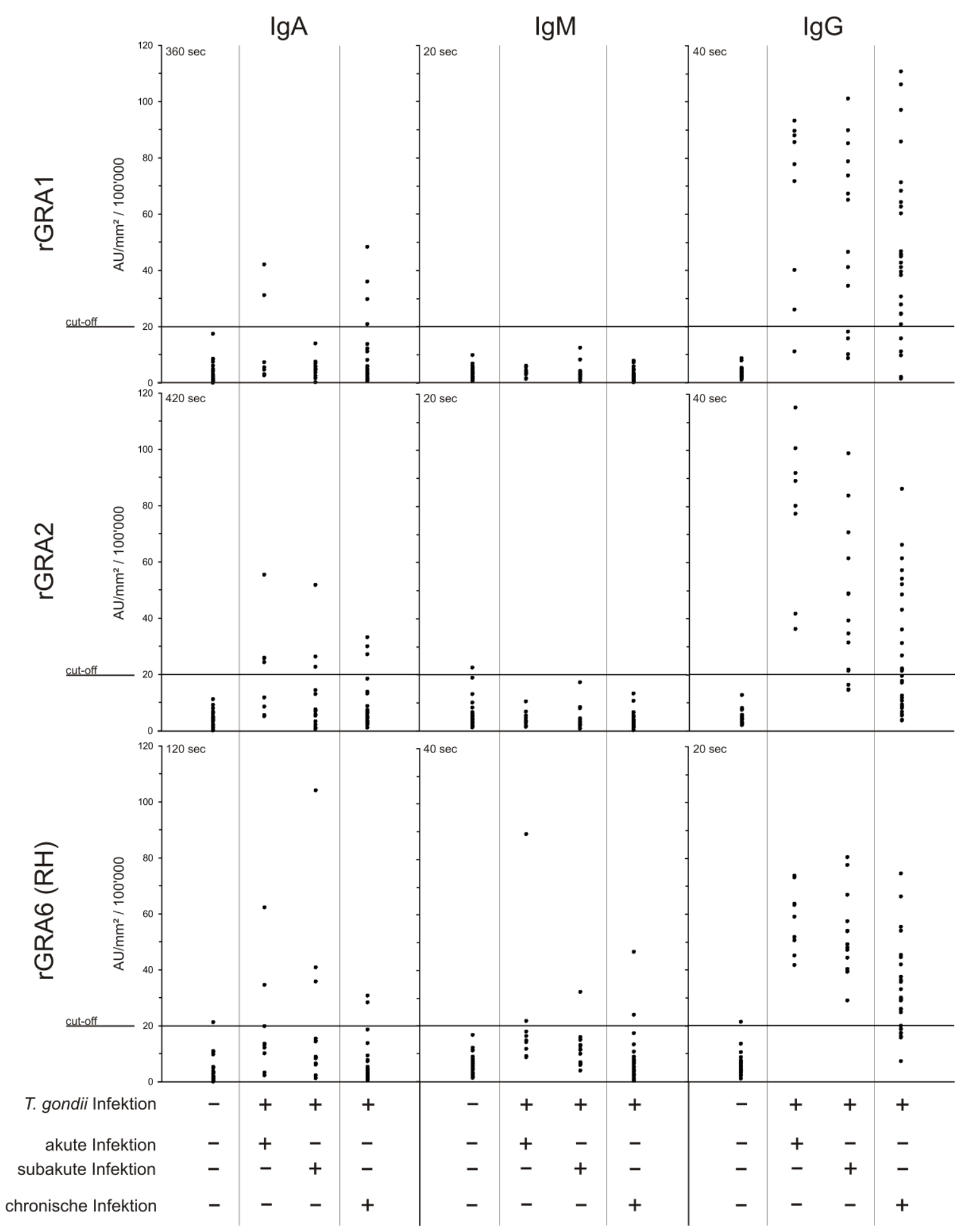

Abb. 3.9: Emission der Seren bei Verwendung der Antigene rGRA1, rGRA2 und rGRA6(RH) Dargestellt sind die Mittelwerte jedes Serums, welches auf GRA1-, GRA2- oder rGRA6 (RH)spezifische IgA-, IgM- und IgG-Antikörper getestet wurde. Die Seren wurden in drei Gruppen eingeteilt: (i) Seren von Patienten ohne Toxoplasma-Infektion $(N)(n=29)$ (ii) Seren von akutinfizierten Patienten $(n=23 ; n$ (hoch-akut) $=9 ; n$ (subakut) = 14) und (iii) Seren von chronischinfizierten Patienten $(n=28)$. Die Entwicklungszeiten der Lineblot-Assays sind angegeben. 
Bei Nachweis von GRA1-, GRA2- und GRA6 (RH)-spezifischen IgG-Antikörpern konnten keine signifikanten Unterschiede der Emission zwischen Seren von Patienten mit einer akuten und einer chronischen Infektion festgestellt werden (Abb. 3.9)

Die Berechnung der Sensitivität des Nachweises von GRA6 (RH)-spezifischen IgMAntikörpern zeigte, dass $51 \%$ der akuten Seren eine Emission von mehr als 10.000 $\mathrm{AU} / \mathrm{mm}^{2}$ besaßen. Dabei zeigten lgM-Antikörper von Patienten mit einer hoch-akuten Infektion zu 78 \% eine Reaktivität mit rGRA6 $(\mathrm{RH})$. Einen Emissionswert von mehr als 20.000 AU/mm² erreichten jedoch nur wenige Seren. Ein Vergleich der Emissionswerte der akuten und chronischen Seren erbrachte keinen signifikanten Unterschied. Ein ähnliches Ergebnis wurde auch bei der Detektion GRA6 (RH)-spezifischer $\lg A$ Antikörper beobachtet.

\subsubsection{Vergleichende Evaluierung der rekombinanten Antigene durch eine zeitunabhängige Quantifizierung mit dem Multi Gauge- und ImageJ- Programm}

Für eine weitere Untersuchung der rekombinanten Antigene wurde die Quantifizierung der Immunantwort von Patienten zu vordefinierten Zeitpunkten durchgeführt. Dies hatte zum Vorteil, dass nicht für jedes Antigen der jeweilige Quantifizierungszeitpunkt separat ermittelt werden musste und dadurch der Zeitaufwand verringert werden konnte.

Für die Bestimmung Antigen-spezifischer IgA-Antikörper wurde wegen der geringen Reaktivität des anti-Human IgA-Sekundärantikörpers eine Quantifizierung nach einer Entwicklungszeit des Lineblot-Assays von $600 \mathrm{sec}$ durchgeführt. Die anti-human IgMund IgG-Sekundärantikörper führten im Vergleich dazu schon bei kürzeren Entwicklungszeiten zu positiven Signalen. Eine längere Inkubationszeit hätte zu einer starken Hintergrundbildung und somit zu falsch-positiven Reaktionen geführt. Daher wurde hier eine Quantifizierung des Lineblot-Assays nach einer Entwicklungszeit von $180 \mathrm{sec}(\operatorname{lgM})$ bzw. $160 \mathrm{sec}(\lg \mathrm{G})$ durchgeführt.

Für die Quantifizierung wurde einmal das bereits zuvor verwendete kommerziell erhältliche Multi Gauge-Programm verwendet. Des Weiteren kam das frei verfügbare ImageJ-Programm zum Einsatz. Die Quantifizierung mit dem ImageJ-Programm basierte auf die durch den LAS-4000 Image Reader erzeugten 8-bit *.tif-Dateien und führte zu einer theoretischen Unterscheidung von 256 Graustufen. Bei der Auswertung der Lineblots zeigte sich jedoch, dass hier ein Maximalwert von nur 128 Graustufen erreicht werden konnte. Dabei stellt ein Wert von 1 weiß und ein Wert von 128 schwarz dar. Der erzielte Grauwert korreliert mit der nachweisbaren Antikörperkonzentration. 
Dabei gilt: je dunkler das Grau ist, desto höher ist die Antikörperkonzentration. Diese Korrelation wird im Folgenden als Antikörper-Index bezeichnet.

Die weitere Untersuchung der Reaktivität humaner Antikörper mit den rekombinanten Antigenen zu definierten Entwicklungszeiten basierte auf den selben Experimenten wie zuvor die Quantifizierung mit dem Multi Gauge-Programm mit festgelegten Cut-off Werten.

Die Seren von Patienten ohne Toxoplasma-Infektion wurden als Kontrollgruppe verwendet. Ausgehend von dieser Gruppe wurde für die Seren der ToxoplasmaInfizierten der Cut-off-Wert über den Mittelwert (MW) und die zweifache Standardabweichung (SD) für jedes Antigen und jede Immunoglobulinklasse berechnet. Alle Seren, die über diesem berechneten Cut-off-Wert lagen wurden als positiv gewertet.

Ausgehend von diesen Ergebnissen wurden erneut die Spezifität, die Sensitivität, sowie der PPV-Wert für eine akute bzw. chronische Infektion und der NPV-Wert bestimmt.

Diagnostisch relevante Antigene zeichneten sich durch eine Spezifität von mehr als $90 \%$ und einer Sensitivität von mindestens $45 \%$ aus. Als Stadium-spezifischer Marker wurde ein Antigen gewertet, wenn der PPV-Wert $\geq 70 \%$ für eine akute bzw. chronische Infektion vorlag und der NPV einen Wert von $75 \%$ oder mehr aufwies.

Als Kontrolle für eine mögliche Kreuzreaktionen mit E. coli-Proteinen und daraus resultierenden falsch-positiven Reaktionen wurde der pQE-30 Vektor in die E. coli Rosetta $^{\mathrm{TM}} 2$ (DE3) transformiert und die Proteinexpression durch IPTG-Zugabe induziert. Nach einer denaturierenden Reinigung wurde von den verbliebenen E. coliProteinen eine Proteinkonzentration von 1-2 $\mu \mathrm{g} /$ Membran in dem Lineblot-Assay eingesetzt. Diese wurden dann zusammen mit den rekombinanten T. gondii-Antigenen an Humanseren untersucht und ausgewertet.

In der Abbildung 3.10 ist der prozentuale Anteil falsch-positiv reagierender Seren unter der Verwendung des jeweiligen Cut-off-Wertes für jedes Antigen und jede Immunoglobulinklasse durch die Quantifizierung mit dem ImageJ- bzw. Multi GaugeProgramm gezeigt. 

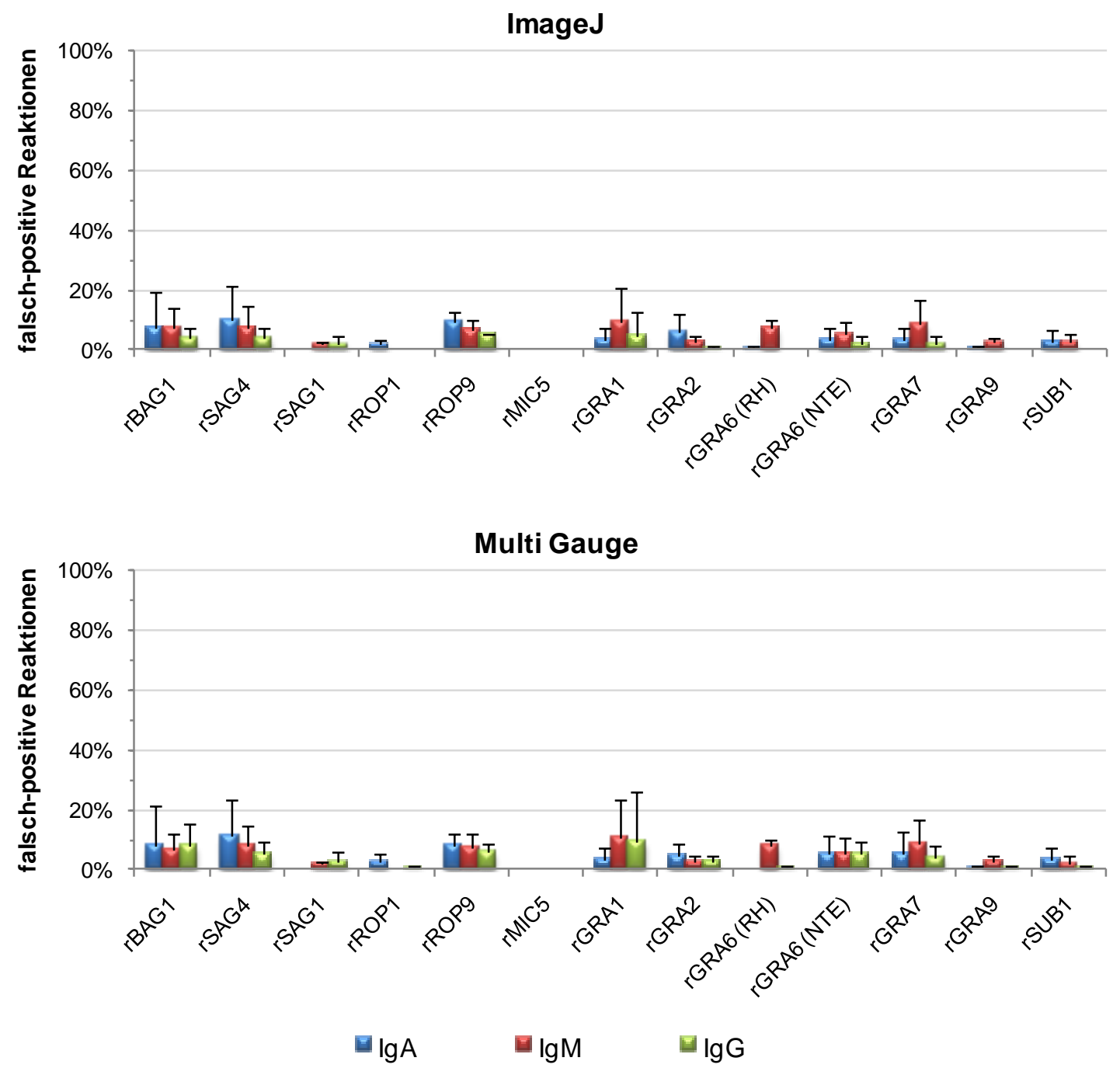

Abb. 3.10: Prozentuale Menge an falsch-positiven Seren unter Verwendung von E. coliProteinen im Lineblot-Assay und einem Antigen-spezifischen Cut-off

In einem Lineblot wurden 1-2 $\mu \mathrm{g}$ E. coli/pQE-30 Proteine/Membran nach einer denaturierenden Reinigung an 1:100 verdünnten Humanseren getestet. Die Detektion erfolgte mit Hilfe von 1:1.000 verdünnten HRP-konjugierten anti-Human IgA-, IgM- bzw. IgG-Sekundärantikörper zu den Zeitpunkten $600 \sec (\lg A), 180 \sec (\lg M)$ und $160 \sec (\lg G)$.

Unter Verwendung von E. coli/pQE-30 Proteinen im Lineblot zeigte sich, dass sich durch die Quantifizierung mit dem ImageJ- und dem Multi Gauge-Programm in den meisten Fällen nur geringfügige Unterschiede in der Menge an falsch-positiv reagierenden Humanseren ergaben. Größere prozentuale Differenzen lassen sich dadurch erklären, dass bei der Quantifizierung nicht die komplette Fläche des jeweiligen Antigens im Lineblot verwendet wurde und so wahrscheinlich zum Teil unterschiedliche Bereiche quantifiziert wurden. Deshalb ergaben sich, aufgrund der über die Kontrollgruppe berechneten Cut-off-Werte, mögliche Unterschiede. 
In den meisten Fällen zeigten in den mit dem ImageJ- und Multi Gauge-Programm durchgeführten Quantifizierungen weniger als $10 \%$ der Seren ein falsch-positives Ergebnis, was einer Anzahl von maximal acht Seren $(N=80)$ entsprach.

\subsubsection{BAG1 und die Oberflächenantigene SAG4 und SAG1}

Zunächst wurde die Quantifizierung der Immunglobulin-Reaktivität mit den Oberflächenantigenen SAG1 und SAG4, sowie dem Bradyzoiten-spezifischen Antigen BAG1 zu den Entwicklungszeiten von $600 \mathrm{sec}(\lg \mathrm{A}), 180 \mathrm{sec}(\operatorname{lgM})$ und $160 \mathrm{sec}(\lg \mathrm{G})$ durchgeführt.

Tab. 3.6: Quantifizierung der Immunantwort gegen die rekombinanten T. gondii-Antigene BAG1, SAG4 und SAG1 über definierte Zeitpunkte

In einem Lineblot wurden 1-2 $\mu \mathrm{g} T$. gondii-Antigen/Membran aufgetragen. Die Quantifizierung der Antikörper-Reaktivität erfolgte über das Multi Gauge (MG)- und ImageJ (IJ)-Programm. Die Berechnungen beruhten auf positiv-reagierenden Seren, die über den Cut-off von [MW $(N)+$ 2xSD $(N)$ ] lagen.

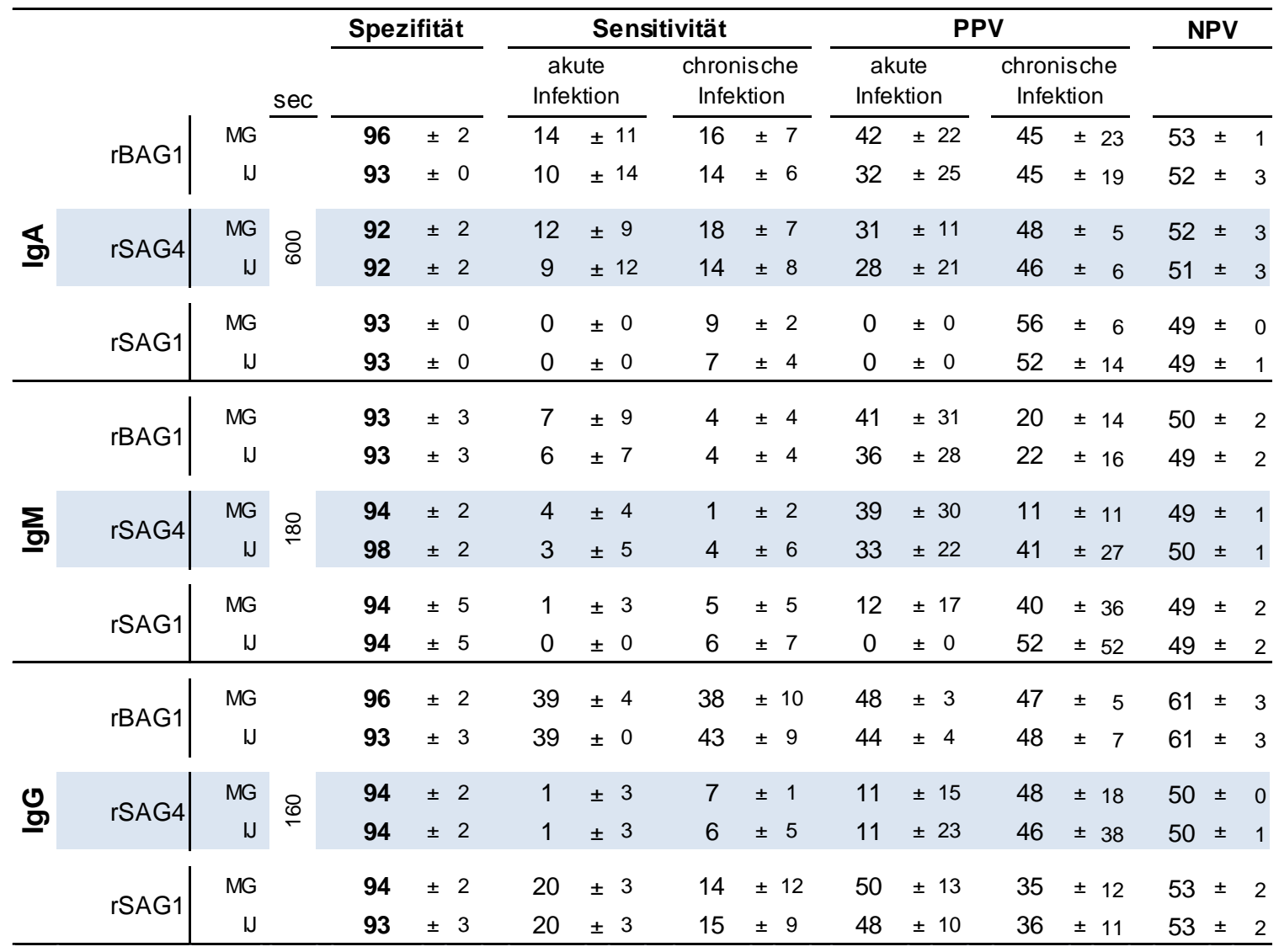


In Tabelle 3.6 sind die Spezifitäten, die Sensitivitäten, sowie der PPV-Wert für eine akute bzw. chronische Infektion und der NPV-Wert angeben. Diese zeigt außerdem eine vergleichende Auswertung der Ergebnisse, die durch die Quantifizierung mit dem ImageJ- und Multi Gauge-Programm und der sich daraus resultierenden Berechnungen ergaben. Dabei konnte in den meisten Fällen eine Übereinstimmung der mit den beiden Programmen erzielten Ergebnisse gezeigt werden. Geringe Unterschiede lassen auf einen teilweise veränderten Quantifizierungsbereich schließen.

Die Quantifizierung der Reaktivität der Antikörper gegen diese Antigene zu einem definierten Zeitpunkt und einem berechneten Cut-off-Wert zeigte eine gestiegene Sensitivität bei einer konstanten hohen Spezifität von 92-96 \% im Vergleich zu der zuvor durchgeführten Quantifizierungsmethode.

Der Nachweis SAG1-spezifischer IgA- und IgM-Antikörper zeigte eher eine Reaktion der Antikörper mit Seren aus der chronischen Infektionsphase, während eine Differenzierung zwischen einer akuten und einer chronischen Infektion mit den Antigenen rBAG1 und rSAG4 nicht möglich war. Auch der Nachweis BAG1-spezifischer IgG-Antikörper ermöglichte keine Differenzierbarkeit des Infektionsstadiums.

Die Ergebnisse der Antikörperreaktivität gegen die rekombinanten Antigene BAG1, SAG4 und SAG1 bestätigten, - wie auch in Abschnitt 3.4.1 gezeigt - dass keines der Antigene ein Potenzial als diagnostischer Marker besitzt.

\subsubsection{Rhoptrien- und Mikronemen-Antigene}

Ebenso wie die zuvor getesteten Antigene wurden auch die Rhoptrien Antigene ROP1 und ROP9, sowie die Mikronemen Antigene MIC5 und SUB1 zu den vordefinierten Zeitpunkten getestet. Die Ergebnisse sind in Tabelle 3.7 angegeben.

Die in Tabelle 3.7 gezeigten Ergebnisse weisen darauf hin, dass weder rMIC5 noch rROP9 als diagnostischer Marker für die Serologie geeignet zu seien scheinen.

Bessere Ergebnisse konnten durch den Nachweis rROP1-spezifischer IgA- und IgGAntikörper erzielt werden. Dabei konnte eine Sensitivität von ca. 58 \% $(\lg A)$ bzw. ca. $72 \%$ ( $\lg G$ ) beobachtet werden. In beiden Fällen spricht ein positives Ergebnis in ca. $58 \%$ für eine akute und in $36 \%$ für eine chronische Infektion. Gleichzeitig lag der NPVWert bei $64 \%(\lg A)$ bzw. $68 \%(\lg G)$.

Ein ähnliches Ergebnis konnte auch mit dem rSUB1-Antigen erreicht werden. Während die Wahrscheinlichkeit für eine akute Infektion durch den Nachweis SUB1-spezifischer IgA-Antikörper nur bei 58 \% (PPV) lag, konnte durch den Nachweis SUB1-spezifischer IgM-Antikörper die Wahrscheinlichkeit für eine akute Infektion auf 84-88 \% erhöht 
werden. IgG-Antikörper gegen SUB1 wurden mit einer Sensitivität von 80 \% etwa drei Mal häufiger bei einer akuten Infektion als bei einer chronischen Infektion erkannt. Daher führte der Nachweis SUB1-spezifischer IgG-Antikörper in 70 \% zur Identifizierung einer akuten Infektion. Gleichzeitig lag die Wahrscheinlichkeit für ein richtig-negatives Ergebnis bei $66 \%$.

Tab. 3.7: Quantifizierung der Antikörperreaktivität gegen die rekombinanten T. gondiiAntigene ROP1, ROP9 und SUB1 über definierte Zeitpunkte

In einem Lineblot wurden 0,5-2 $\mu \mathrm{g}$ T. gondii-Antigen/Membran aufgetragen. Die Quantifizierung der Antikörperreaktivität erfolgte über das Multi Gauge (MG)- und ImageJ (IJ)-Programm. Die Berechnungen beruhten auf positiv-reagierenden Seren, die über den Cut-off von [MW $(N)+$ 2xSD (N)] lagen.

\begin{tabular}{|c|c|c|c|c|c|c|c|c|c|c|c|c|c|c|c|c|c|c|c|c|c|}
\hline \multirow{10}{*}{ 흐 } & \multirow{4}{*}{ rROP1 } & \multirow[b]{3}{*}{ MG } & \multirow{4}{*}{ sec } & \multicolumn{3}{|c|}{ Spezifität } & \multicolumn{6}{|c|}{ Sensitivität } & \multicolumn{6}{|c|}{ PPV } & \multicolumn{3}{|c|}{ NPV } \\
\hline & & & & & & & \multicolumn{3}{|c|}{$\begin{array}{c}\text { akute } \\
\text { Infektion }\end{array}$} & \multicolumn{3}{|c|}{$\begin{array}{l}\text { chronische } \\
\text { Infektion }\end{array}$} & \multicolumn{3}{|c|}{$\begin{array}{c}\text { akute } \\
\text { Infektion }\end{array}$} & \multicolumn{3}{|c|}{$\begin{array}{l}\text { chronische } \\
\text { Infektion }\end{array}$} & \multirow[b]{2}{*}{64} & \multirow[b]{2}{*}{ \pm} & \multirow[b]{2}{*}{ \pm} \\
\hline & & & & 94 & \pm & 2 & 58 & \pm & & 36 & & 8 & 58 & & 4 & 36 & \pm & 5 & & & \\
\hline & & $\mathrm{W}$ & & 95 & \pm & 2 & 57 & \pm & 8 & 37 & \pm & 7 & 58 & \pm & 6 & 38 & \pm & 5 & 64 & \pm & 3 \\
\hline & \multirow{2}{*}{ rROP9 } & MG & \multirow{6}{*}{ ८ } & 96 & \pm & 2 & 14 & \pm & & 25 & \pm & 4 & 33 & \pm & 2 & 57 & \pm & 3 & 54 & \pm & 1 \\
\hline & & W & & 94 & \pm & 2 & 16 & \pm & & 23 & \pm & 6 & 35 & \pm & 4 & 52 & \pm & 3 & 54 & \pm & 2 \\
\hline & \multirow{2}{*}{ rMIC5 } & MG & & 90 & \pm & 0 & 4 & \pm & 0 & 5 & \pm & 2 & 23 & \pm & 2 & 26 & \pm & 8 & 49 & \pm & 0 \\
\hline & & W & & 76 & \pm 2 & 24 & 4 & \pm & & 5 & \pm & 2 & 13 & \pm & 9 & 15 & \pm & 14 & 44 & \pm & 9 \\
\hline & \multirow{2}{*}{ rSUB1 } & MG & & 97 & \pm & 3 & 33 & \pm & 21 & 23 & \pm & 11 & 55 & \pm & 12 & 39 & \pm & 6 & 58 & \pm & 5 \\
\hline & & W & & 97 & \pm & 0 & 32 & \pm & 20 & 20 & \pm & 8 & 58 & \pm & 14 & 36 & \pm & 8 & 57 & \pm & 4 \\
\hline \multirow{8}{*}{ 흐 } & \multirow{2}{*}{ rROP1 } & MG & \multirow{8}{*}{$\stackrel{\infty}{\infty}$} & 100 & \pm & 0 & 0 & \pm & 0 & 0 & \pm & 0 & 0 & \pm & 0 & 0 & \pm & 0 & & \pm & 0 \\
\hline & & W & & 100 & \pm & 0 & 0 & \pm & 0 & 0 & \pm & 0 & 0 & \pm & 0 & 0 & \pm & 0 & 50 & \pm & 0 \\
\hline & \multirow{2}{*}{ rROP9 } & MG & & 98 & \pm & 4 & 6 & \pm & & 0 & \pm & 0 & 72 & \pm & 35 & 0 & \pm & 0 & 50 & \pm & 1 \\
\hline & & W & & 99 & \pm & 2 & 4 & \pm & 0 & 0 & \pm & 0 & 80 & \pm & 25 & 0 & \pm & 0 & 50 & \pm & 0 \\
\hline & \multirow{2}{*}{ rMIC5 } & MG & & 100 & \pm & 0 & 0 & \pm & 0 & 0 & \pm & 0 & 0 & \pm & 0 & 0 & \pm & 0 & 50 & \pm & 0 \\
\hline & & $\mathrm{W}$ & & 100 & \pm & 0 & 0 & \pm & 0 & 0 & \pm & 0 & 0 & \pm & 0 & 0 & \pm & 0 & 50 & \pm & 0 \\
\hline & \multirow{2}{*}{ rSUB1 } & $M G$ & & 98 & \pm & 4 & 17 & \pm & 8 & 1 & \pm & 2 & 84 & \pm & 17 & 6 & \pm & 7 & 52 & \pm & 2 \\
\hline & & $\mathrm{W}$ & & 99 & \pm & 2 & 17 & \pm & 8 & 1 & \pm & 2 & 88 & \pm & 10 & 6 & \pm & 7 & 52 & \pm & 2 \\
\hline & $\mathrm{rROP} 1$ & MG & & 93 & \pm & 0 & 71 & \pm & 7 & 44 & \pm & 11 & 58 & \pm & 8 & 36 & \pm & 8 & 68 & \pm & 1 \\
\hline & וזרו & W & & 94 & \pm & 2 & 72 & \pm & 7 & 38 & \pm & 16 & 62 & \pm & 10 & 33 & \pm & 12 & 67 & \pm & 3 \\
\hline & $\mathrm{rR} \cap \mathrm{PQ}$ & MG & & 93 & \pm & 3 & 13 & \pm & 4 & 5 & \pm & 2 & 52 & \pm & 11 & 21 & \pm & 8 & 51 & \pm & 2 \\
\hline$\sigma$ & 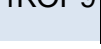 & $\mathrm{W}$ & 우 & 93 & \pm & 3 & 16 & \pm & 5 & 5 & \pm & 2 & 57 & \pm & 8 & 19 & \pm & 10 & 51 & \pm & 1 \\
\hline & $\mathrm{rMIC5}$ & MG & & 100 & \pm & 0 & 1 & \pm & 3 & 6 & \pm & 5 & 20 & \pm & 17 & 80 & \pm & 51 & 51 & \pm & 1 \\
\hline & IIVIUU & W & & 100 & \pm & 0 & 1 & \pm & 3 & 6 & \pm & 5 & 20 & \pm & 17 & 80 & \pm & 51 & 51 & \pm & 1 \\
\hline & $r$ CIR1 & MG & & 96 & \pm & 2 & 80 & \pm & 5 & 27 & \pm & 9 & 71 & \pm & 5 & 25 & \pm & 5 & 66 & \pm & 3 \\
\hline & 150 & W & & 94 & \pm & 2 & 80 & \pm & 5 & 29 & \pm & 11 & 70 & \pm & 7 & 25 & \pm & 6 & 66 & \pm & 3 \\
\hline
\end{tabular}

Da sowohl das rROP1-, als auch das rSUB1-Antigen, als Marker für das akute-Stadium der Infektion geeignet zu seien scheinen, wurden die Mittelwerte der Ergebnisse der 
Immunreaktion jedes Serums aus drei unabhängigen Experimenten grafisch ausgewertet. Das Ergebnis der Auswertung mit dem ImageJ-Programm ist in Abbildung 3.11 gezeigt. Eine Darstellung der Quantifizierungsergebnisse mit dem Multi GaugeProgramm erzeugte ähnliche Werte, so dass darauf verzichtet wurde, diese ebenfalls darzustellen.

Der Abbildung 3.11 ist zu entnehmen, dass bei dem Nachweis ROP1-spezifischer IgMAntikörper die Seren von nicht-infizierten Patienten genauso gut auf das Antigen reagierten als die Seren von infizierten Patienten. Der Nachweis rROP1- bzw. rSUB1spezifischer IgG-Antikörper dagegen zeigte, dass Seren von Patienten mit einer hochakuten T. gondii-Infektion einen Antikörper-Index von ca. 120 bewirkten. Seren von subakut- sowie chronisch-infizierten Patienten erreichten einen Antikörper-Index zwischen ca. 20 und 120 und deckten somit ein breites Spektrum ab.

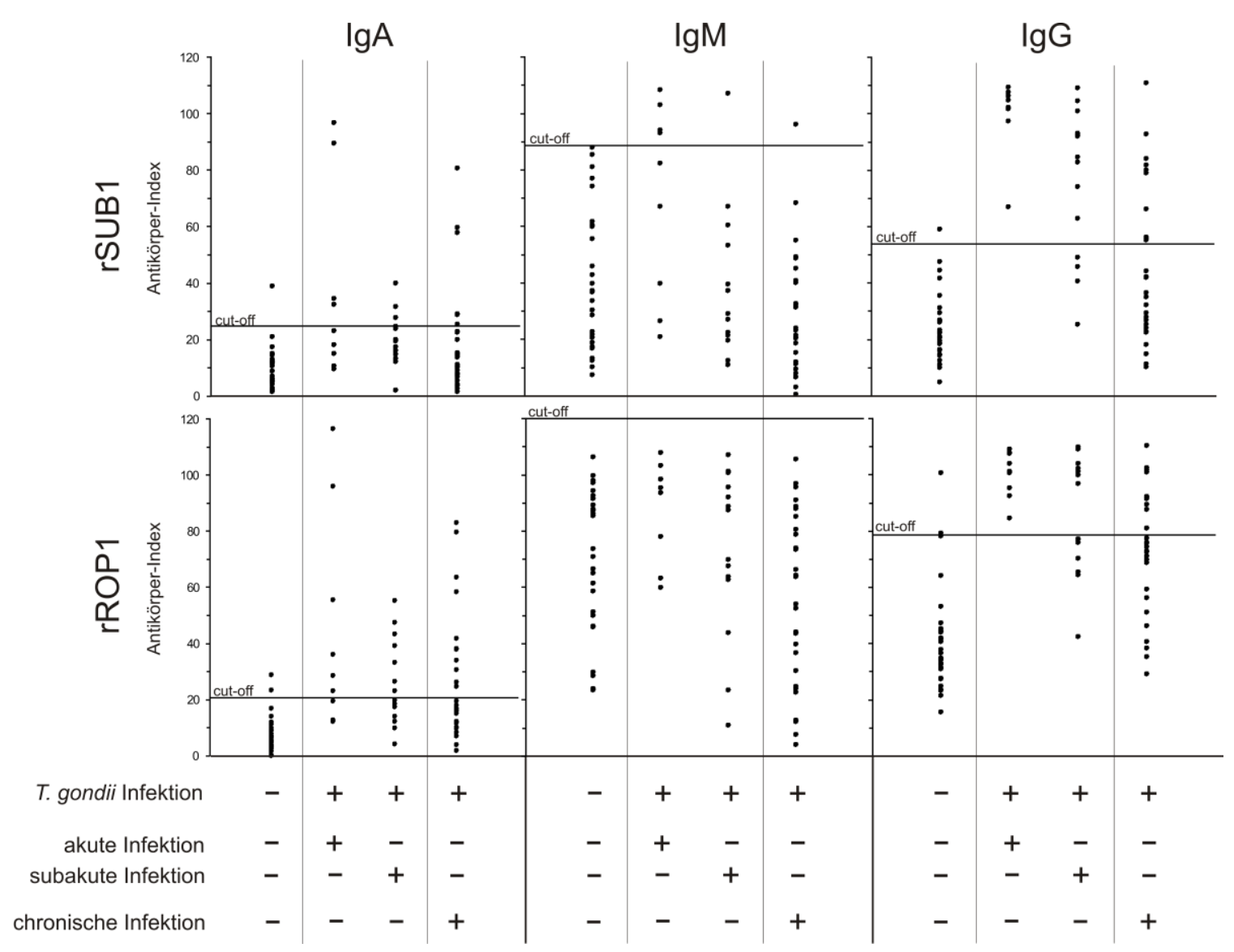

Abb. 3.11: Emission der Seren bei Verwendung der Antigene rSUB1 und rROP1

Dargestellt sind die Mittelwerte jedes Serums, welches auf die Anwesenheit von SUB1- bzw. ROP1-spezifischen Antikörpern getestet wurden. Die Seren wurden in drei Gruppen eingeteilt: (i) Seren von Patienten ohne Toxoplasma-Infektion (N) $(n=29)$ (ii) Seren von akut infizierten Patienten $(n=23 ; n$ (hoch-akut) = 9; $n$ (subakut) $=14$ ) und (iii) Seren von chronisch-infizierten Patienten $(n=28)$. Die Entwicklungszeit der Lineblot-Assays betrug $600 \sec (\lg A), 180 \sec (\lg M)$ und $160 \mathrm{sec}(\mathrm{lgG})$. Die Cut-off Werte ergaben sich aus dem MW (N) +2x SD (N). 


\subsubsection{Dichte Granula Antigene}

Unter der Verwendung des Multi Gauge- bzw. ImageJ-Programmes wurde ebenfalls eine Quantifizierung der Immunantwort gegen GRA-Antigene zu einer vordefinierten Entwicklungszeit durchgeführt. Die sich daraus ergebenen Werte für die Spezifität, die Sensitivität, sowie des PPV-Wertes für eine akute bzw. chronische Infektion und der NPV-Wert sind in Tabelle 3.8 angegeben.

Auch hierbei konnten nur geringe Unterschiede zwischen den Ergebnissen der beiden Programme festgestellt werden.

Der Nachweis von IgG-Antikörpern gegen die rekombinanten Antigene GRA1, GRA2 und GRA6 $(\mathrm{RH})$ zeigte bei einer Spezifität von 93-97 \% eine Sensitivität von 70-99 \%. Trotz dieser guten Ergebnisse war eine Unterscheidung zwischen einer akuten und einer chronischen Infektion mit diesen Antigenen jedoch nicht möglich. Der Nachweis GRA9-spezifischer IgG-Antikörper führte zu einer etwas geringeren Sensitivität von $70 \%$ bei einer Spezifität von $97 \%$ für eine Toxoplasma-Infektion. Wie auch bei den anderen GRA-Proteinen zeigte der IgG-Nachweis gegen rGRA9 keinen Hinweis auf eine Stadiumspezifität.

Durch den Nachweis von rGRA6 (RH)-spezifischen IgA-Antikörpern konnte eine akute Infektion zu etwa $50 \%$ richtig erkannt werden. Außerdem lag bei einer positiven Reaktion die Wahrscheinlichkeit für das Vorliegen einer akuten Infektion bei 69-76 \%. Bei Nachweis GRA6 (RH)-spezifischer IgM-Antikörpern konnte eine akute Infektion etwa 2,5 Mal häufiger erkannt werden als eine chronische Infektion. Dabei zeigte der PPVWert mit 64-66\% eine akute Infektion an. 
Tab. 3.8: Quantifizierung der Immunantwort gegen die rekombinanten T. gondii GRAAntigene zu definierten Zeitpunkten

In einem Lineblot wurden $1 \mu \mathrm{g} T$. gondii-Antigen/Membran aufgetragen. Die Quantifizierung der Antikörperreaktivität erfolgte über das Multi Gauge (MG)- und ImageJ (IJ)-Programm. Die Berechnungen beruhten auf positiven Seren, die über den Cut-off von [MW (N) + 2xSD (N)] lagen.

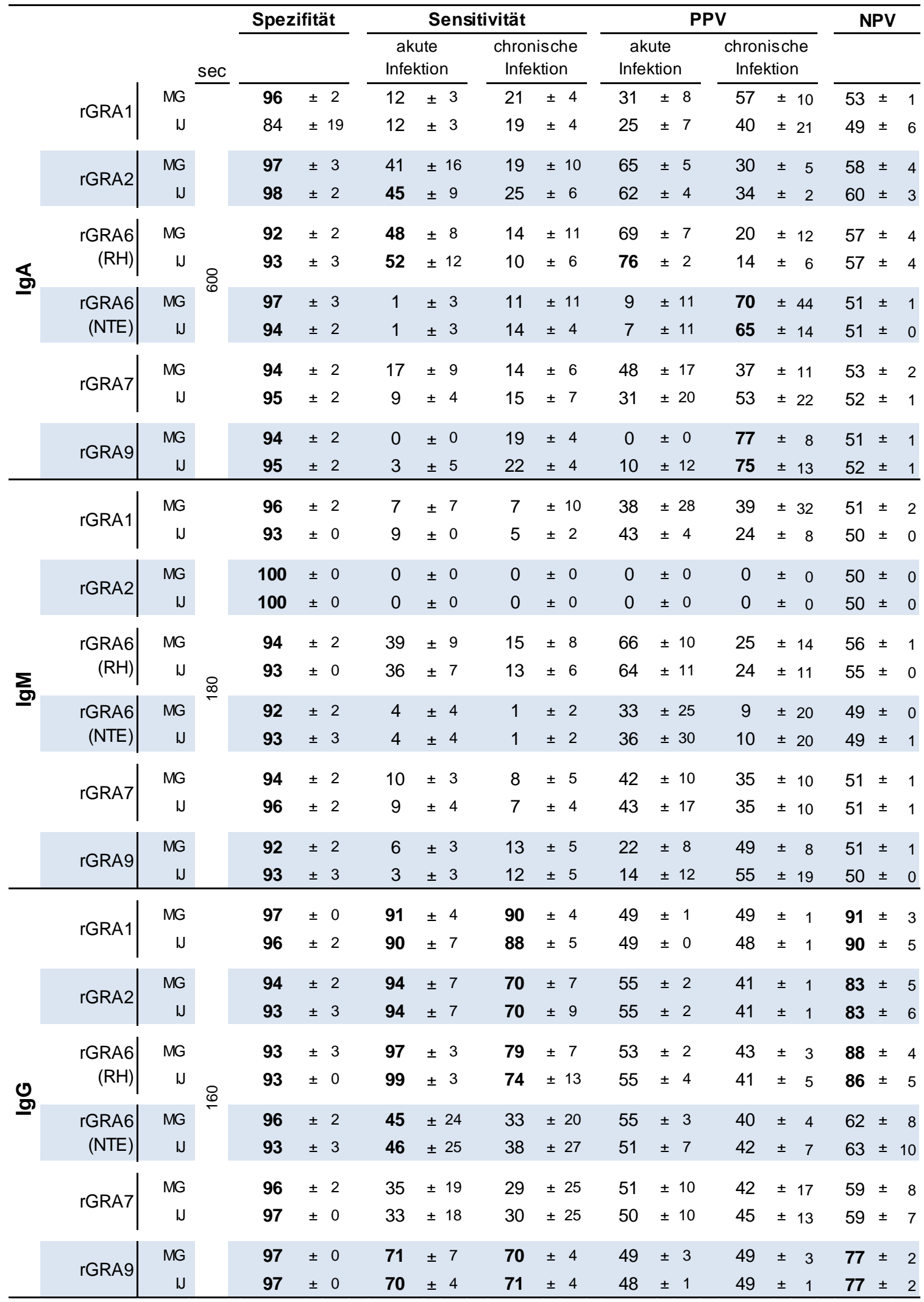


Die Abbildung 3.12 zeigt den mittleren Antikörper-Index der Immunantwort jedes Patienten gegen die rekombinanten Antigene GRA1, GRA2 und GRA6 $(\mathrm{RH})$.

Der Nachweis GRA6 (RH)-spezifischer IgM-Antikörper zeigte, dass zwischen Seren von Patienten ohne Infektion und chronisch-Infizierten kein signifikanter Unterschied bestand. Die Serumproben von Patienten mit einer akuten Infektion besaßen dagegen einen höheren Antikörper-Indices. Bei Nachweis GRA6 (RH)-spezifischer IgA-Antikörper war jedoch dieser Unterschied eindeutiger. Ein Unterschied zwischen hoch-akut- und subakuten-infizierten Patienten war allerdings nicht festzustellen. Ein ähnliches Ergebnis wurde mit dem Nachweis rGRA2-spezifischer IgA-Antikörper erzielt.

IgG-Antikörper gegen rGRA1, rGRA2 und rGRA6 $(\mathrm{RH})$ wurden bei Patienten mit einer hoch-akuten Infektion insgesamt in sehr hohen Konzentrationen nachgewiesen, während bei Patienten mit subakuten und chronischen Infektion kein Unterschied festzustellen war. 


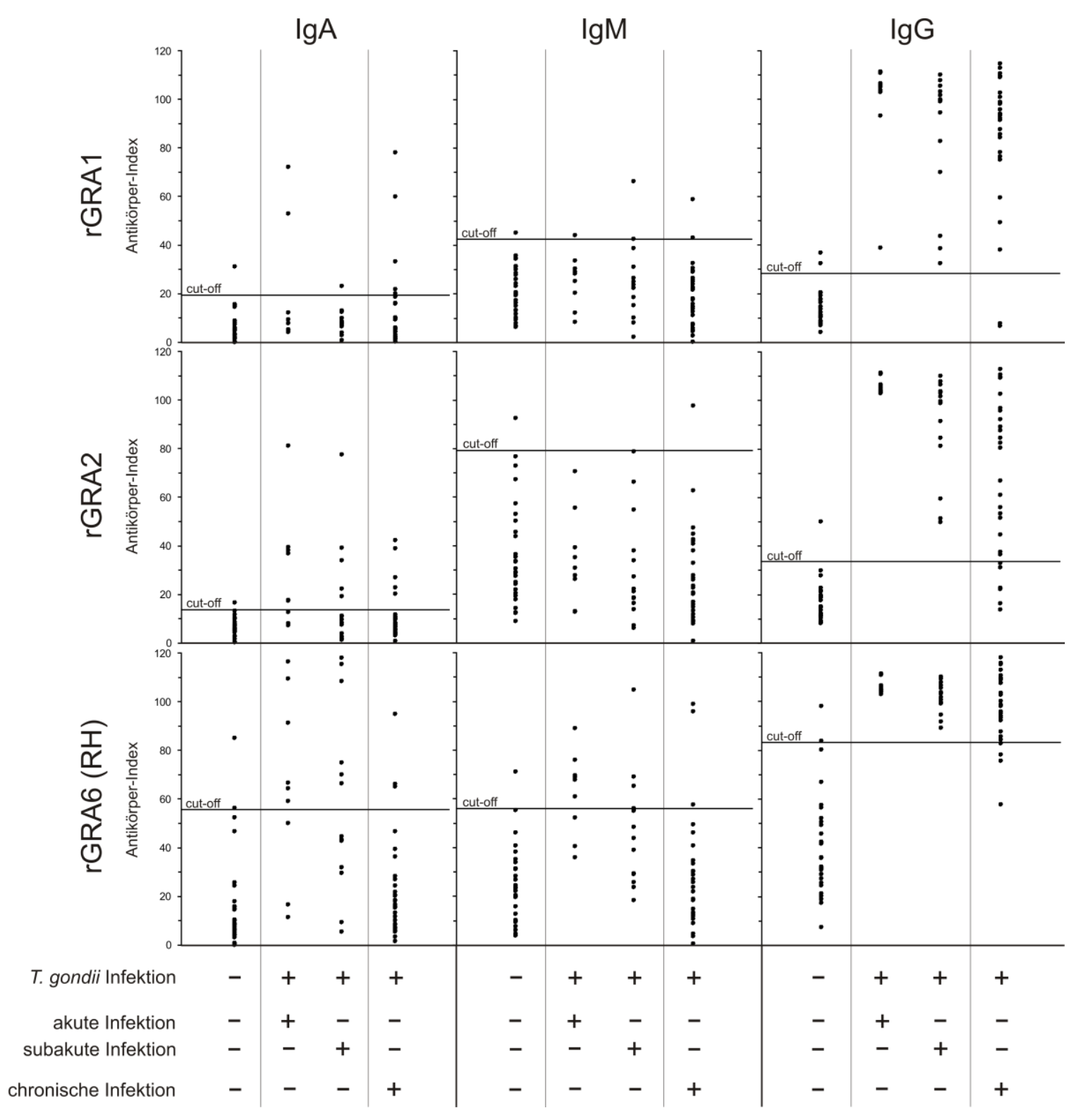

Abb. 3.12: Emission der Seren bei Verwendung der Antigene rGRA1, rGRA2 und rGRA6

Dargestellt sind die Mittelwerte jedes Serums, welches auf Antigen-spezifische Antikörper getestet wurde. Die Seren wurden in drei Gruppen eingeteilt: (i) Seren von Patienten ohne Toxoplasma-Infektion (N) $(n=29)$ (ii) Seren von akut-infizierten Patienten $(n=23 ; n$ (hoch-akut) $=9 ; \mathrm{n}$ (subakut) $=14)$ und (iii) Seren von chronisch-infizierten Patienten $(\mathrm{n}=28)$. Die Entwicklungszeit der Lineblot-Assays betrug $600 \mathrm{sec}(\lg \mathrm{A}), 180 \mathrm{sec}(\operatorname{lgM})$ und $160 \mathrm{sec}(\lg \mathrm{G})$. Die Cut-off Werte ergaben sich aus dem MW $(\mathrm{N})+2 x \operatorname{SD}(\mathrm{N})$. 


\subsection{Evaluierung rekombinanter Antigene für die Diagnose einer Retinochorioiditis bei Toxoplasma-infizierten Patienten}

Eine Infektion mit $T$. gondii verläuft bei einem immunkompetenten Menschen meist asymptomatisch. Die Toxoplasma-bedingte Retinochorioiditis ist mit etwa $30 \%$ eine der häufigsten Ursachen für eine Uveitis posterior (Entzündung der hinteren Aderhaut) (Patzelt, 2005; Augustin, 2007; Commodaro et al., 2009). Dabei zeigt sich in der Regel ein gelblich-weißer Herdbefund mit einer eventuellen Netzhautnarbe, die in schwerwiegenden Fällen bis zu einer Erblindung führen kann. Bei einer kongenitalen $T$. gondii-Infektion entwickeln etwa 20-60 \% (Freeman et al., 2008; Kodjikian, 2010; Peyron et al., 2011) der Patienten eine durch Toxoplasma hervorgerufene Retinochorioiditis. Bei einer postnatalen Infektion findet sich diese Korrelation bei 3-12 \% der Patienten wieder (Portela et al., 2004; Accorinti et al., 2009; Neves et al., 2009)

Ein sicherer Beweis einer durch T. gondii-bedingten Retinochorioiditis beruht unter anderem auf dem Nachweis von Toxoplasma-DNA im Kammerwasser mittels PCR. Die Kammerwasseruntersuchung besitzt zwar eine höhere Aussagekraft gegenüber der Serumdiagnostik (Kijlstra et al., 1989; Quentin und Reiber, 1997), setzt jedoch einen invasiven Eingriff voraus, der unter Umständen zu Komplikationen führen kann.

Daher wurde versucht, auf Basis eines serologischen Tests, eine Retinochorioiditis zu identifizieren. Hierfür wurden, über eine Kooperation mit dem Ophthalmologen Prof. Dr. U. Pleyer von der Charité in Berlin, 18 Serumproben von Patienten mit einer Toxoplasma-Infektion zur Verfügung gestellt. Bei zehn der Proben wurde zuvor an Hand einer ophthalmologischen Untersuchung und Kammerwasseruntersuchung eine okuläre Toxoplasmose (Retinochorioiditis) diagnostiziert. Bei den anderen acht Patienten konnte keine Retinochorioiditis festgestellt werden. Die Patienten mit einer okulären Toxoplasmose waren zwischen 19 und 47 Jahre alt und wiesen multiple ältere und frische Herdbefunde in der Retina auf.

Die Seren der Patienten wurden in dem Lineblot-Assay mit den rekombinanten Antigenen auf die Anwesenheit von spezifischen $\lg \mathrm{A}$-, $\lg \mathrm{M}$ - und IgG-Antikörpern untersucht. Die Abbildung 3.13 zeigt den Nachweis spezifischer IgG-Antikörper bei den untersuchten Patienten gegen die Antigene rSUB1, rGRA1, rGRA2, rGRA6 $(\mathrm{RH})$, rGRA7 und rGRA9. 
T. gondii negativ

T. gondii positiv

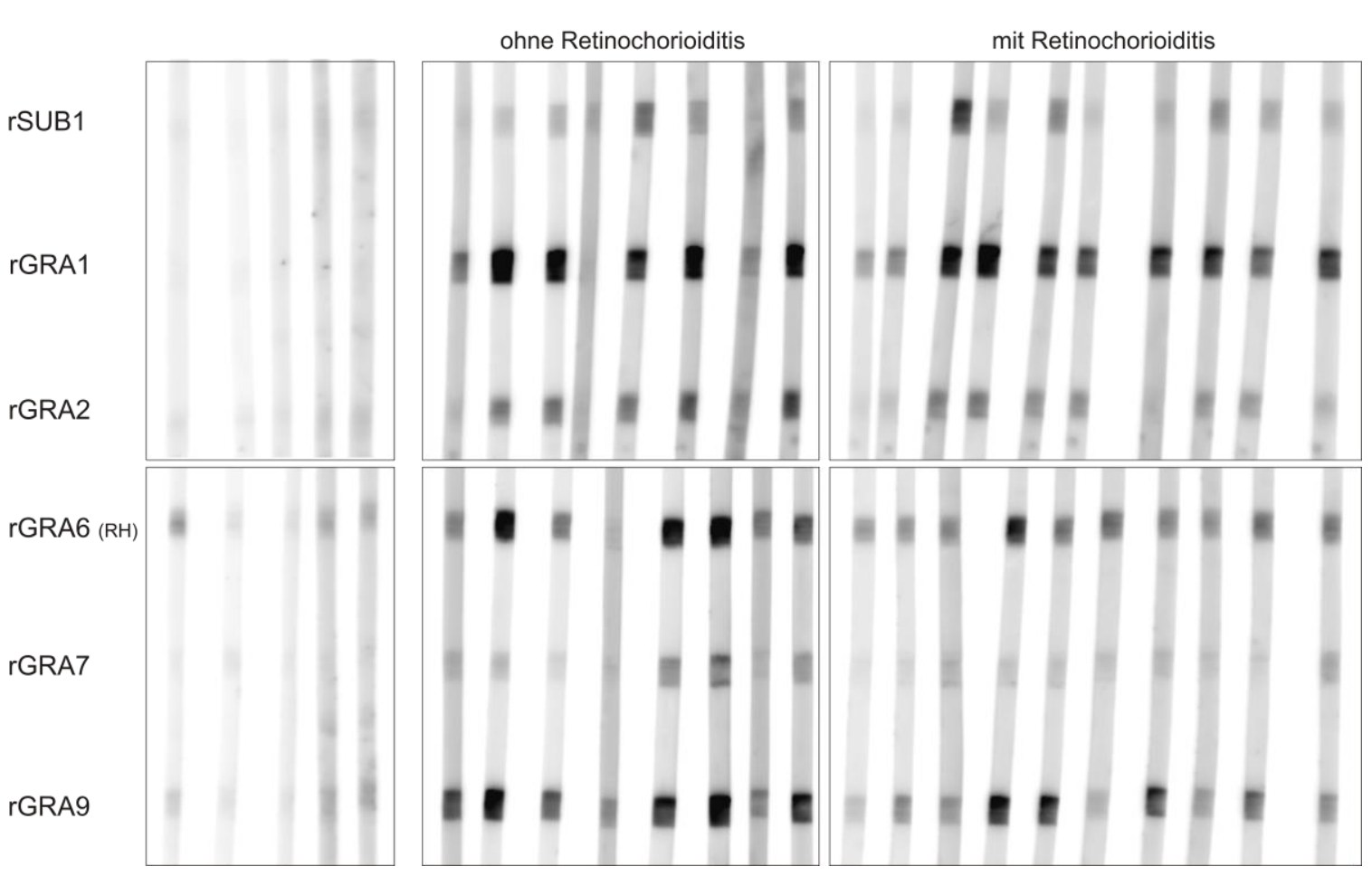

Abb. 3.13: Lineblot-Assay mit Seren von Patienten mit und ohne Retinochorioiditis

Gezeigt ist ein Lineblot-Assay mit Nachweis spezifischer IgG-Antikörper gegen die rekombinanten Antigene SUB1, GRA1, GRA2, GRA6 (RH), GRA7 und GRA9 bei Patienten mit $(\mathrm{N}=10)$ und ohne $(\mathrm{N}=8)$ okulärer Toxoplasmose. Als Kontrolle wurden Seren von Patienten ohne eine Toxoplasma-Infektion ( $\mathrm{N}=5$ ) verwendet. Die Detektion Antigen-spezifischer Antikörper fand durch Inkubation der Blotstreifen mit 1:100 verdünnten Serum und einem 1:1.000 verdünnten HRP-konjugierten anti-Human IgG $(\mathrm{H}+\mathrm{L})$-Sekundärantikörper statt. Die Entwicklungszeit der Lineblots betrug $160 \mathrm{sec}$.

Da uns keine serologischen Befunde aus Berlin zur Verfügung standen, wurden in Kooperation mit P. Maksimov vom Friedrich-Löffler-Institut (FLI) in Wusterhausen die Seren in einem Latex-Agglutinations-Test (LAT) untersucht. Anschließend wurden die Lineblots mit Hilfe des ImageJ-Programmes ausgewertet. In der Abbildung 3.14 sind die im Lineblot erzielten Ergebnisse im Vergleich zu den aus dem LAT-Test erhaltenen Titern dargestellt.

Seren von Patienten mit- und ohne eine okuläre Toxoplasmose zeigten eine ähnliche IgG-Immunantwort gegen rGRA1 und rGRA2 (Abb. 3.13/14). Mit Hilfe der rekombinanten Antigene BAG1, GRA7, GRA9 und ROP1 konnte gezeigt werden, dass Seren von Patienten mit einer Toxoplasma-Infektion aber ohne eine Augenbeteiligung häufiger IgG-Antikörper gegen diese Antigene aufwiesen (Abb. 3.13/14).

Des Weiteren zeigte ein Vergleich der LAT- und Lineblot-Ergebnisse von Patientenseren ohne eine Retinochorioiditis eine positive Korrelation zwischen einem hohen LAT-Titer und einer IgG-Immunantwort gegen die meisten der verwendeten 
rekombinanten $T$. gondii-Antigene. Bei den Seren von Patienten mit einer okulären Toxoplasmose konnte eine derartig starke Korrelation nicht festgestellt werden.

Es konnte gezeigt werden, dass der Nachweis von IgG-Antikörpern gegen die GRAAntigene GRA1, GRA2 und GRA6 (RH) eine sehr hohe Sensitivität von 70-99\% besaßen (vgl. 3.4). Der Nachweis von IgG-Antikörpern gegen das rGRA1-Antigen bei dem Patienten (-4) konnte im LAT-Test nicht bestätigt werden. Daher wurde davon ausgegangen, dass dieser Patient nicht mit Toxoplasma infiziert war.

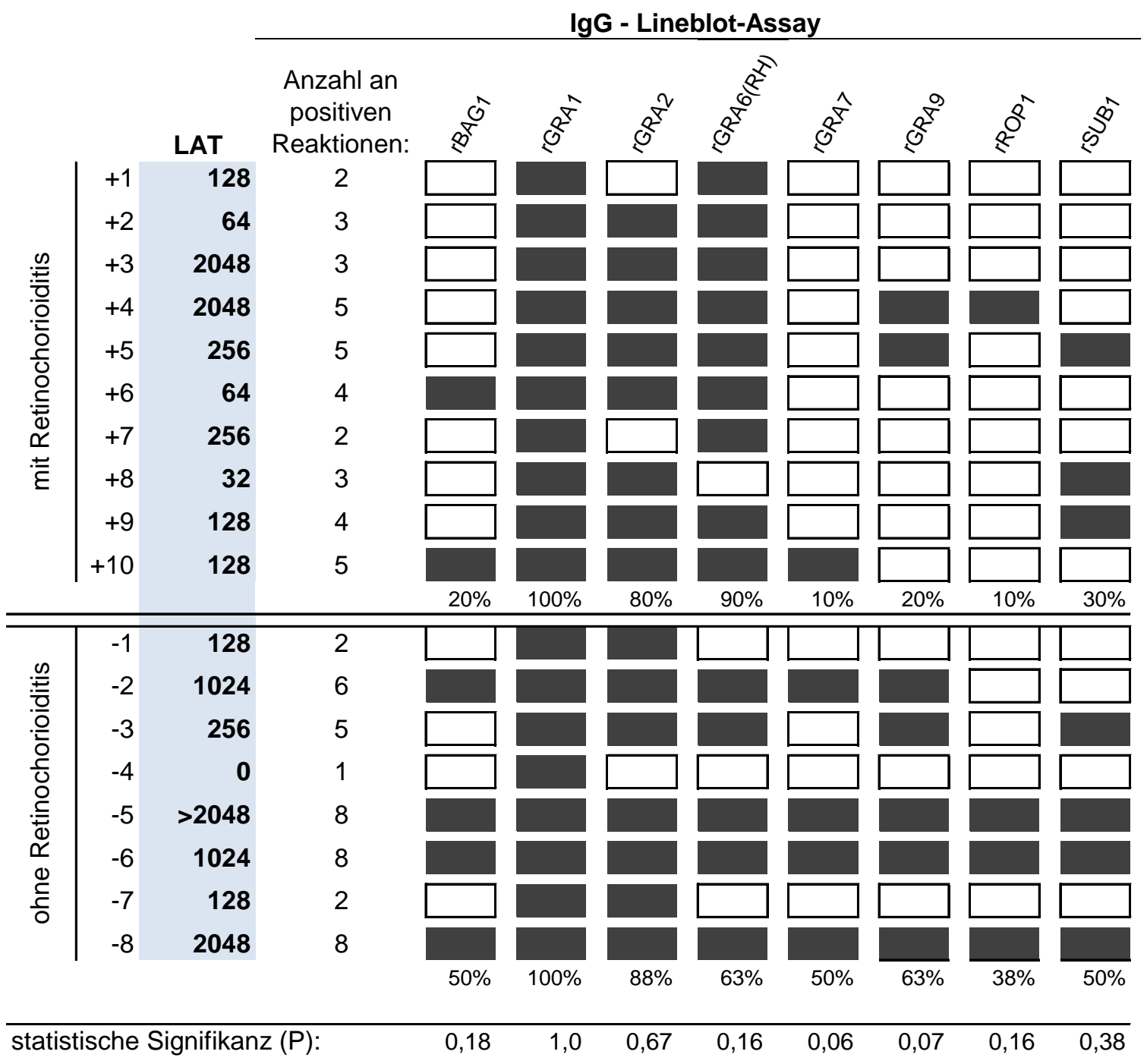

Abb. 3.14: Vergleich der Patienten mit und ohne Retinochorioiditis

In einem Latex-Agglutionations Test (LAT) und Lineblot-Assay wurden Seren in Hinblick auf ihre Antikörperantwort gegen rekombinante Antigene mit und ohne okulärer Toxoplasmose untersucht. In LAT wurde der Titer [1:X] bestimmt. Für den Lineblot-Assay wurden die Seren 1:100 verdünnt und mit einem 1:1.000 verdünnten HRP-konjugierten anti-Human $\lg G(\mathrm{H}+\mathrm{L})$ Sekundärantikörper inkubiert. Positive IgG-Immunantworten gegen die verwendeten rekombinanten Antigene sind schwarz unterlegt. 
Für eine weitere Analyse der Immunantwort der Patienten mit- und ohne okulärer Toxoplasmose wurde - nach dem Nachweis spezifischer IgA-, IgM- und IgG-Antikörper im Lineblot und einer Auswertung mit dem ImageJ-Programm - der Mittelwert und die Standardabweichung der beiden Gruppen für jedes Antigen und jede Immunoglobulinklasse gebildet. Anschließend wurde über den $t$-Test geprüft, ob mögliche signifikante Unterschiede innerhalb der beiden Gruppen bestehen. Als Kontrollgruppe wurden fünf Seren von Patienten ohne eine Toxoplasma-Infektion verwendet.

In der Abbildung 3.15 sind die Antigene gezeigt, bei denen ein signifikanter Unterschied in der Immunoglobulin-Antwort zwischen den Patienten mit okulärer und nicht-okulärer Toxoplasmose festzustellen war.

Bei Nachweis GRA2-spezifischer IgG-Antikörper konnte kein Unterschied zwischen Patienten mit einer okulären und einer nicht-okulären Toxoplasmose festgestellt werden (vgl. Abb. 3.13/14). Der Nachweis BAG1-spezifischer IgG- und GRA2-spezifischer IgAAntikörper konnte jedoch ein signifikanter Unterschied $(P<0,05)$ zwischen den beiden Gruppen festgestellt werden. Ein ebenso signifikanter Unterschied bestand für den Nachweis dieser Antikörper zwischen Patienten ohne eine okuläre Toxoplasma-Infektion im Vergleich zu der Kontrollgruppe ohne eine Infektion mit T. gondii. Während unter der Verwendung des rBAG1-Antigens auch ein signifikanter Unterschied in der IgG-Antwort zwischen Patienten mit einer okulären Toxoplasma-Infektion und der Kontrollgruppe bestand, konnte für IgA-spezifische Antikörper gegen rGRA2 kein Unterschied festgestellt werden.

Die Darstellung der Ergebnisse für jedes Einzelserum zeigte, dass jedoch nur wenige Seren den Cut-off Wert überschritten und dass diese Seren aus der Gruppe der Patienten ohne eine Retinochorioiditis stammten.

Die Antikörperantwort gegen die anderen im Lineblot getesteten Antigene zeigte keine signifikanten Unterschiede zwischen Patienten mit okulärer und nicht-okulärer Toxoplasmose. 

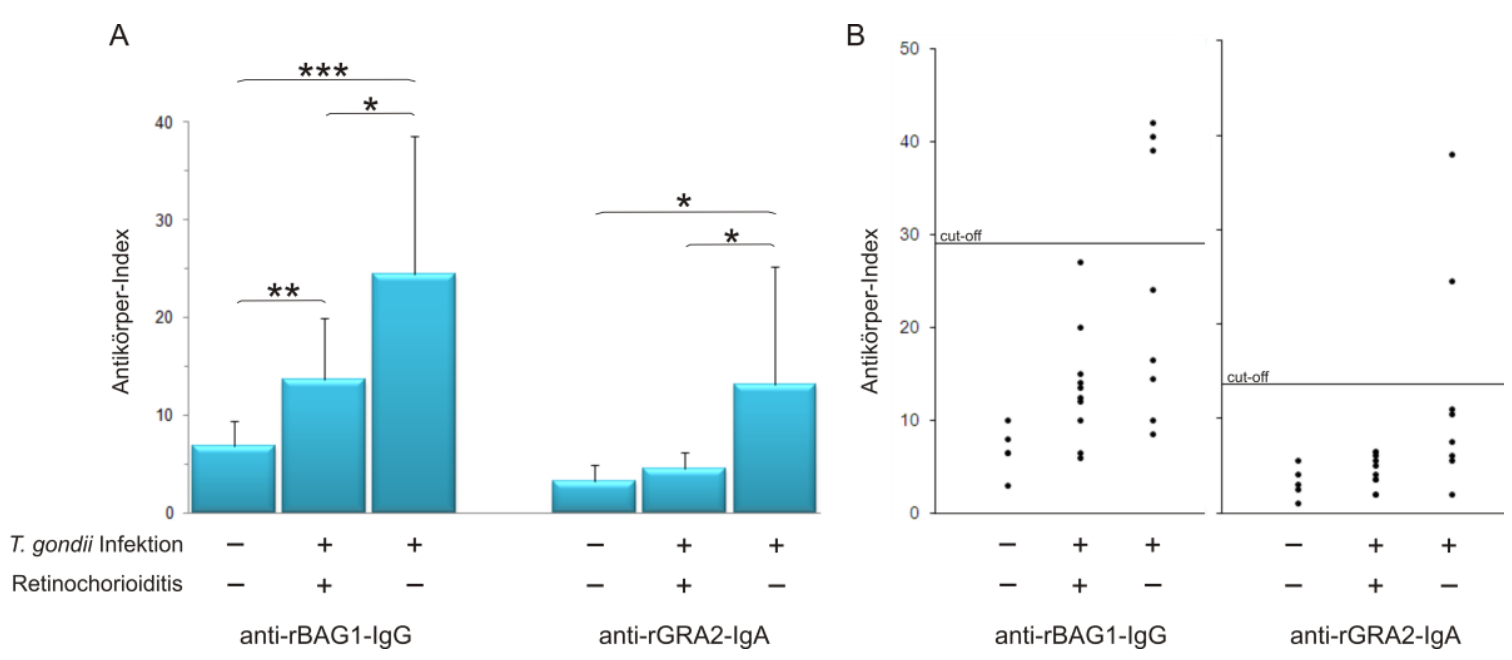

Abb. 3.15: Antikörperreaktionen gegen rekombinante Antigene, die signifikante Unterschiede zwischen Patienten mit und ohne Retinochorioiditis

In einem Lineblot-Assay wurden 10 Seren von Patienten mit und 8 Seren von Patienten ohne okuläre Toxoplasmose auf die Anwesenheit GRA2-spezifischer IgA- und BAG1-spezifischer IgGAntikörper getestet. Als Kontrolle wurden 5 Seren von Patienten ohne eine Toxoplasma-Infektion verwendet. (A) Nach der Auswertung mit Hilfe des ImageJ-Programmes wurden die Mittelwerte und die Standardabweichungen jeder Gruppe für jedes Antigen und Immunoglobulinklasse gebildet. Über den $t$-Test wurde die statistische Signifikanz ermittelt. $\left({ }^{*} \mathrm{P}<0,05 ;{ }^{* *} \mathrm{P}<0,02 ;{ }^{* * *}\right.$ $\mathrm{P}<0,01)$. (B) Darstellung der Antikörper-Index für jedes Einzelserum mit dem jeweiligen Cut-off.

\subsection{Untersuchung der Immunantwort von Nutztieren gegen rekombinante T. gondii-Antigene in einem Lineblot-Assay}

Der Verzehr von Zysten-haltigem Fleisch stellt ein potenzielles Risiko für die Übertragung von T. gondii auf den Menschen dar. Dies kann vor allem in der Schwangerschaft zu schwerwiegenden klinischen Manifestationen beim Kind führen. Die im Fleisch enthaltenen Gewebezysten wandeln sich im Menschen in schnell vermehrende und hoch infektiöse Tachyzoiten um. Die Tachyzoiten können dann über die Planzenta auf den Fötus übergehen und dort zu Schädigungen, u. a. des ZNS, führen.

Da in Deutschland Schweine- und Geflügelfleisch die häufigsten vom Menschen verzehrten Fleischarten sind, sollte hier untersucht werden, ob die rekombinanten Antigene sich auch für den serologischen Nachweis einer Infektion im Tier eignen.

Durch Kooperationen mit der Arbeitsgruppe von Prof. Dr. A. Tenter von der Tierärztlichen Hochschule Hannover (TiHo) und den Arbeitsgruppen von Prof. Dr. R. Straubinger vom Institut für Immunologie und Institut für Lebensmittelhygiene und Prof. Dr. A. Daugschies vom Institut für Parasitologie der Universität Leipzig konnten Seren von experimentell infizierten Schweinen, Hühnern und Puten bezogen werden. Die 
Seren wurden dann in einem Lineblot-Assay in Hinblick auf ihre Antikörperantwort gegen die bereits an Humanseren verwendeten rekombinanten Antigenen getestet.

\subsubsection{Untersuchung der Immunantwort von experimentell mit T. gondii- infizierten Puten}

Die Putenseren entstammten Tieren, die im Alter von vier bis acht Wochen experimentell entweder mit Oozysten oder Tachyzoiten des Toxoplasma ME49Stammes (Typ II) infiziert waren. Die Oozysten wurden dabei oral in einer Konzentration von $5 \times 10^{5}$ als Ein- oder Dreifachdosis in einem Abstand von einem Tag oder in einer Konzentration von $1 \times 10^{7}$ als Einzeldosis verabreicht. Die Tachyzoiten wurden in einer Konzentration von $2 \times 10^{7}$ intramuskulär (i.m.), intravenös (i.v.) oder auf beiden Infektionswegen injiziert. Von den Puten wurden Serumproben vor, wie auch bis 63 Tage nach der Infektion entnommen.

Insgesamt wurden Seren von 18 experimentell infizierten Puten im Lineblot untersucht, wobei jeweils $50 \%$ der Tiere entweder mit Oozysten oder mit Tachyzoiten infiziert waren.

Das Ergebnis der Lineblot-Analyse unter Verwendung der rekombinanten Antigene GRA1, GRA6 $(\mathrm{RH}), \mathrm{ROP} 1$ und SUB1 ist in Abbildung 3.16 dargestellt. Dabei wurden Verlaufseren von sechs mit $2 \times 10^{7}$ Tachyzoiten-infizierten Tieren, sowie sechs mit verschiedenen Mengen von Oozysten infizierten Puten gezeigt. Von jedem Tier wurden vier Serumproben untersucht, die im Abstand von jeweils etwa 14 Tagen entnommen wurden. Als Kontrolle wurde von jeder Pute ein Präimmunserum verwendet.

Der Lineblot-Assay zeigte, dass Puten keine IgG-Immunantwort gegen das rGRA1Antigen aufwiesen. Unter Verwendung der rekombinanten GRA6 (RH)-, ROP1- und SUB1-Antigene konnte gezeigt werden, dass Tachyzoiten infizierte Tiere in den meisten Fällen die stärkste IgG-Immunantwort 13 Tage nach der Infektion zeigten und im weiteren Verlauf diese dann abnahm. Die Immunantwort der mit Oozysten infizierten Puten war, im Vergleich zu den mit Tachyzoiten infizierten Tieren, insgesamt stärker. Bei mit Oozysten infizierten Tieren war eine IgG-Immunantwort im Lineblot etwa 14 Tage nach der Infektion nachzuweisen, wobei bei den meisten Tieren die stärkste Reaktion ca. 29 Tagen nach der Infektion festgestellt werden konnte.

Unterschiede in der IgG-Immunantwort bei Tieren, die intravenös, intramuskulär oder auf beiden Infektionswegen mit Tachyzoiten infiziert wurden, konnten nicht festgestellt werden. Bei den mit verschiedenen Oozysten-Mengen infizierten Puten konnten zwar innerhalb einer Gruppe, jedoch nicht innerhalb der verschiedenen Gruppen Unterschiede festgestellt werden. Die Unterschiede innerhalb einer Gruppe lassen sich 
dadurch erklären, dass Oozysten häufig aneinander lagern und so Varianzen in der applizierten Oozysten-Menge nicht gänzlich auszuschließen waren.

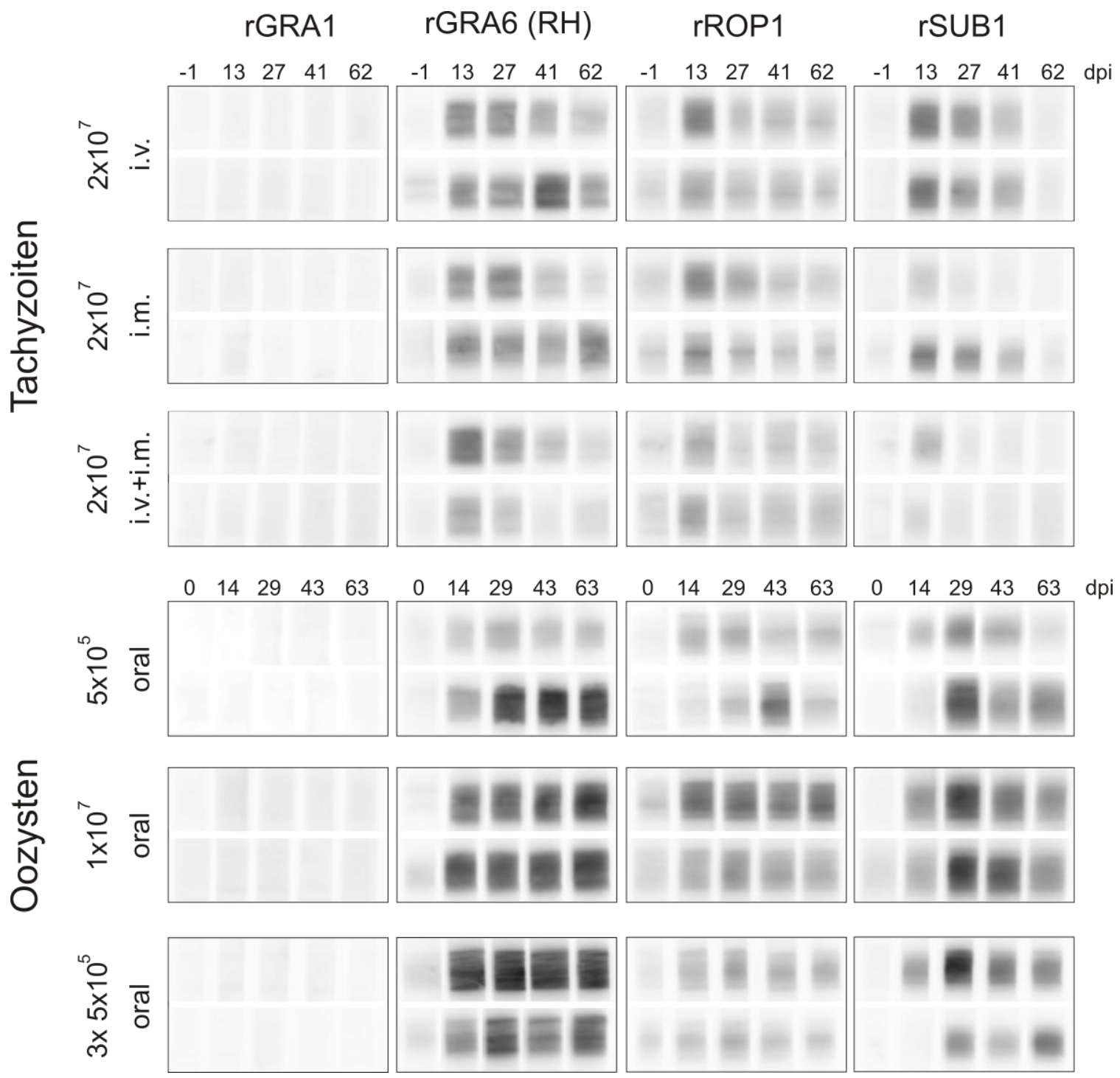

Abb. 3.16: Lineblot-Assay mit Seren von experimentell infizierten Puten

Seren von experimentell mit definierten Mengen an $T$. gondii-Tachyzoiten bzw. -Oozysten infizierten Puten wurden im Lineblot-Assay unter Verwendung der rekombinanten Antigene GRA1, GRA6 (RH), ROP1 und SUB1 untersucht. Die Detektion Antigen-spezifischer IgGAntikörper fand durch Inkubation der Blotstreifen mit 1:100 verdünntem Serum und einem 1:2.000 verdünnten HRP-konjugierten anti-Pute IgG $(H+L)$-Sekundärantikörper statt. Untersucht wurden Verlaufseren zu den angegebenen Tagen nach Infektion (dpi). Die Entwicklungszeit der Lineblots betrug $100 \mathrm{sec}$.

Für eine weitere Überprüfung wurde eine Quantifizierung der Immunantwort nach einer Entwicklungszeit von $100 \mathrm{sec}$ durchgeführt. Anschließend wurden die Mittelwerte der mit Tachyzoiten bzw. Oozysten infizierten Puten zu jedem Zeitpunkt berechnet. In der 
Abbildung 3.17 sind diese für die Antigene rGRA6 $(\mathrm{RH})$, rSUB1, rGRA9 und rSAG1 dargestellt.
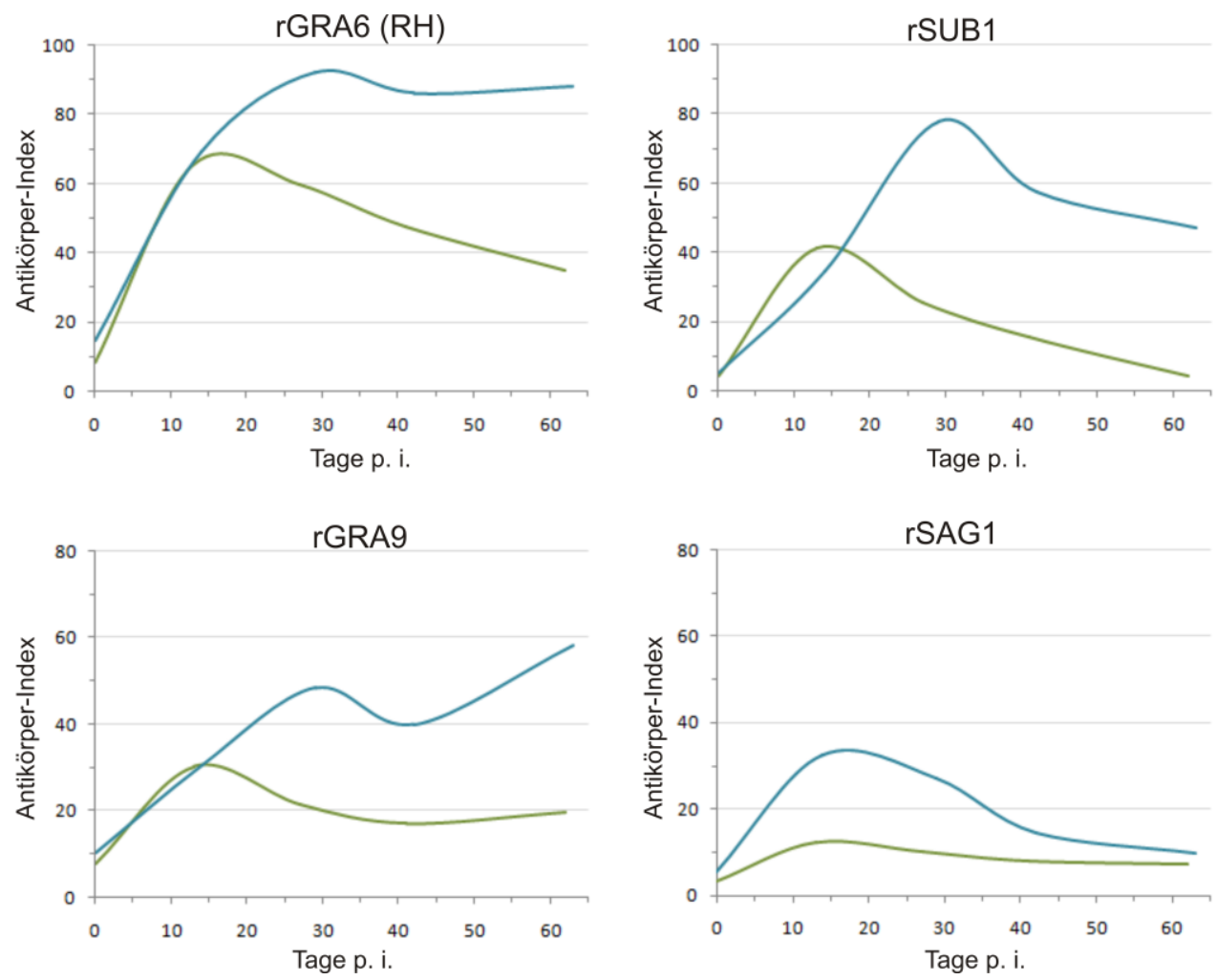

Abb. 3.17: Vergleichende quantitative Auswertung der IgG-Immunantwort von mit Tachyzoiten oder Oozysten infizierten Puten

Von den neun mit T. gondii Tachyzoiten- bzw. Oozysten-infizierten Puten wurden die IgGImmunantwort im Lineblot-Verfahren mit Hilfe des ImageJ-Programmes nach einer Entwicklungszeit von $100 \mathrm{sec}$ quantifiziert und die Mittelwerte für den jeweiligen Zeitpunkt berechnet.

- mit Oozysten infizierte Puten

- mit Tachyzoiten infizierte Puten

Bei der quantitativen Auswertung konnte eine allgemein höhere IgG-Immunantwort der mit Oozysten infizierten Puten bestätigt werden. Unter der Verwendung des rekombinanten SAG1-Antigens konnte gezeigt werden, dass sowohl Oozysten als auch Tachyzoiten infizierte Tiere nach etwa 14 Tagen die stärkste IgG-Immunantwort aufwiesen, während die Bildung von GRA6 (RH)-, GRA9- und SUB1-spezifischen lgGAntikörpern an Tag 28 nach Infektion ihr Maximum erreichten. Die GRA6 $(R H)$ spezifische IgG-Immunantwort der mit Oozysten infizierten Puten zeigte über den gesamten Untersuchungszeitraum einen relativ konstant hohen Antikörper-Index. Im Vergleich dazu sank die SUB1- und SAG1-spezifische IgG-Immunantwort einige Wochen nach der Infektion ab. Die GRA9-spezifische IgG-Immunantwort stieg ca. 40 
Tagen nach Infektion wieder an. Die IgG-Immunantwort gegen die meisten der rekombinanten Antigene zeigte bei den mit Tachyzoiten infizierten Tieren nach einem Anstieg bis zu Tag 14 p. i. in der Regel einen kontinuierlichen Abfall.

\subsubsection{Lineblot-Analyse der Immunantwort bei mit Oozysten infizierten Hühnern}

In Zusammenarbeit mit S. Buschtöns aus der Arbeitsgruppe von Prof. Dr. A. Tenter von der Tierärztlichen Hochschule Hannover ( $\mathrm{TiHo}$ ) wurden Seren von Hühnern untersucht, die im Alter von sieben bis acht Wochen experimentell mit T. gondii Oozysten des DXStammes (Typ II) infizierten worden waren. Die Tiere wurden aufgrund der unterschiedlichen Inokulationsdosen von $10^{1}$ bis $10^{7}$ Oozysten in sieben Gruppen eingeteilt. Jede Gruppe bestand aus vier Tieren und von jedem Tier wurden Seren von Tag 3 bis 86 nach Infektion auf die Anwesenheit von spezifischen IgY-Antikörpern im Lineblot untersucht. Das Immunoglobulin $Y$ der Hühner ähnelt funktionell dem IgG, ist jedoch dafür bekannt, dass dieses weniger Kreuzreaktionen mit Säugetierproteinen aufweist. Als Negativkontrolle wurde von jedem Huhn eine Serumprobe vor der Infektion (0 dpi) entnommen. Um eine mögliche Kontamination mit im Boden lebenden Mikroorganismen zu vermeiden, wurden die Hühner für die Versuchsdurchführung in Käfigen gehalten.

Die Lineblot-Analyse erfolgte in Göttingen unter der Verwendung der rekombinanten Antigene BAG1, MAG1, MIC5, SAG4, SAG1, ROP1, GRA9 und GRA1. Das MAG1 wurde von der Firma Mikrogen (Neuried) zur Verfügung gestellt. Für den Lineblot wurde $1 \mu \mathrm{g}$ des jeweiligen Antigens/Membran verwendet und die jeweilige Immunreaktion mit spezifischen IgY-Antikörpern nachgewiesen.

Zur Darstellung der Lineblot-Analysen wurden für diese Arbeit vier Tiere ausgesucht, die mit einer unterschiedlichen Inokulationsdosis infiziert wurden (Abb. 3.18). Dabei konnte im Lineblot eine vom Alter des Tieres abhängige Zunahme unspezifischer Immunreaktionen beobachten werden. Des Weiteren scheint die humorale Immunantwort von Tieren verschiedener Gruppen unterschiedlich und unabhängig von der Infektionsdosis auf die rekombinanten Antigene zu reagieren. Dieses ist $u$. a. bei dem Nachweis MIC5-spezifischer IgY-Antikörper zu beobachten. Die Immunantwort gegen andere Antigene, wie z. B. das rROP1-Antigen, zeigte eine Abhängigkeit von der Infektionsdosis. Dabei konnte bei einer Zunahme der Infektionsdosis eine kurzzeitige Erhöhung ROP1-spezifischer IgY-Antikörper zu früheren Zeiten p. i. festgestellt werden. 
Wie bei den Puten, zeigte auch das rGRA1-Antigen bei den Hühnern nur geringe immunogene Eigenschaften. Eine positive Immunantwort zeigten vor allem Hühner mit einer hohen Infektionsdosis etwa 7-10 Tage nach der Infektion.

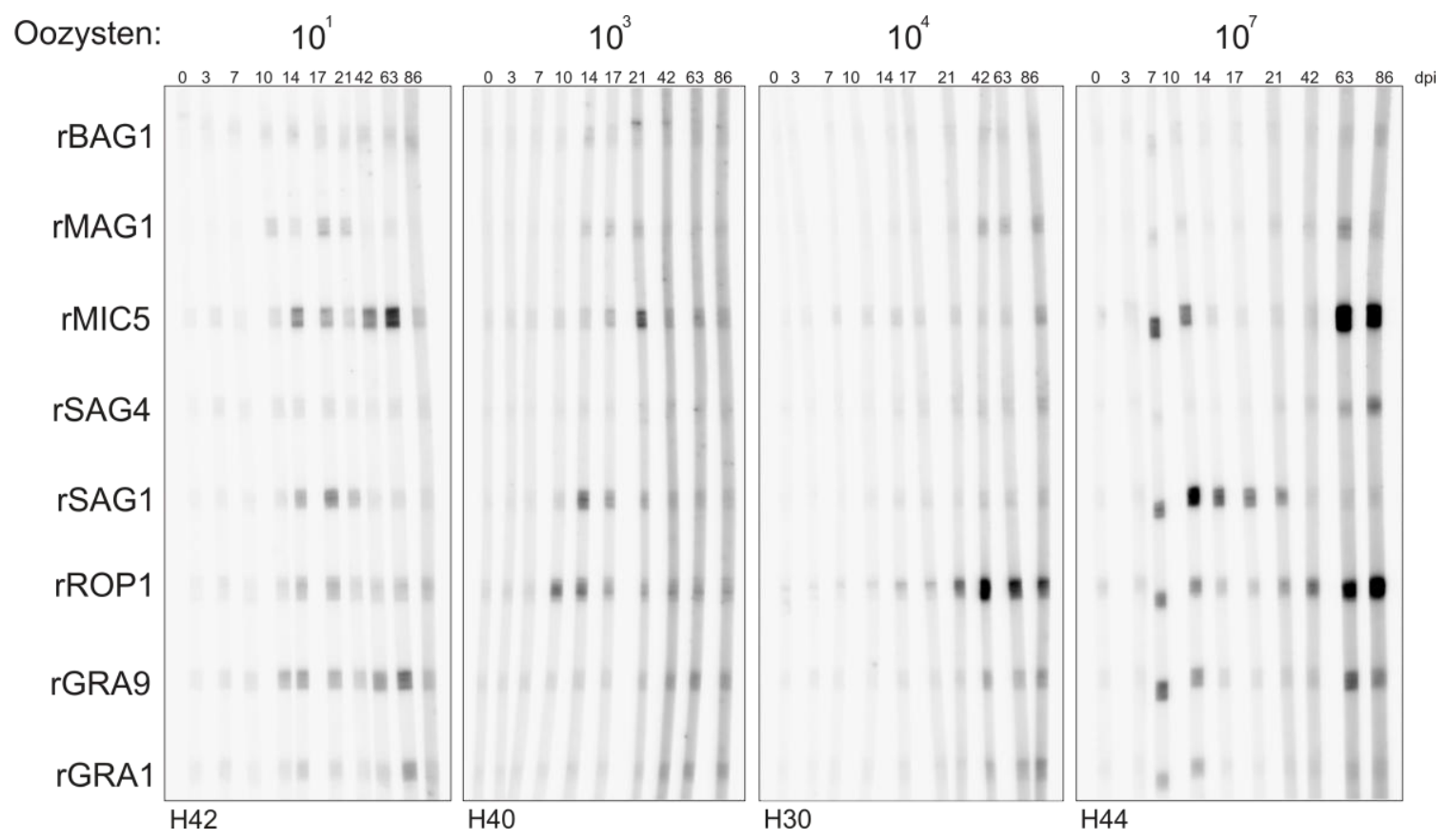

\section{Abb. 3.18: Lineblot-Analyse mit Seren von experimentell infizierten Hühnern}

Experimentell wurden Hühner mit einer Infektionsdosis von $10^{1}$ bis $10^{7}$ Oozysten mit $T$. gondii infiziert. Die IgY-Immunantwort der Hühner wurde im Lineblot-Assay unter Verwendung der acht rekombinanten Antigene untersucht. Dargestellt ist jeweils die IgY-Immunantwort eines Huhns mit einer Infektionsdosis von $10^{1}, 10^{3}, 10^{4}$ bzw. $10^{7}$ Oozysten. Die Detektion Antigen-spezifischer IgY-Antikörper fand durch Inkubation der Blotstreifen mit einem 1:500 verdünnten Serum und einem 1:2.000 verdünnten HRP-konjugierten anti-Huhn $\lg Y(\operatorname{lgG})(H+L)$-Sekundärantikörper statt. Untersucht wurden Verlaufseren zu den angegebenen Tagen nach Infektion (dpi). Die Entwicklungszeit der Lineblots betrug $200 \mathrm{sec}$.

Für eine weitere Untersuchung wurden die Lineblots basierend auf den 8-bit *.tif-Dateien mit Hilfe des ImageJ-Programms nach einer Entwicklungszeit von $200 \mathrm{sec}$ ausgewertet. Bei Verwendung der rekombinanten Antigene MIC5, GRA9 und GRA1 zeigten die Hühner mit einer Infektionsdosis von $10^{7}, 10^{6}$ und $10^{4}$ eine Dosis-abhängige $\lg Y$ Immunantwort (Abb. 3.19). Dabei waren die IgY-Immunantworten der Hühner einer Gruppe ähnlich. Des Weiteren stieg mit Zunahme der Inokulationsdosis der AntikörperIndex, und somit die Menge an IgY-Antikörpern im Serum. Außerdem ist eine Verschiebung der maximalen Immunantwort zu einem früheren Zeitpunkt nach der Infektion zu beobachten. Die Untersuchung von Hühnern mit einer niedrigeren Inokulationsdosis zeigte nur teilweise eine Dosis-abhängige Reaktion. Dabei war die Immunantwort der Hühner einer Gruppe oft unterschiedlich. Eine Infektionsdosis- 
abhängige Immunantwort war auch unter Verwendung der anderen hier eingesetzten Antigene zu beobachten.

Bei dem Nachweis Antigen-spezifischer IgY-Antikörper zeigte sich außerdem, dass viele Tiere zu Beginn einer Infektion eine starke humorale Immunantwort entwickelten, die sich dann kurzzeitig abschwächte, um dann am Tag 63 bis 86 nach Infektion wieder anzusteigen.
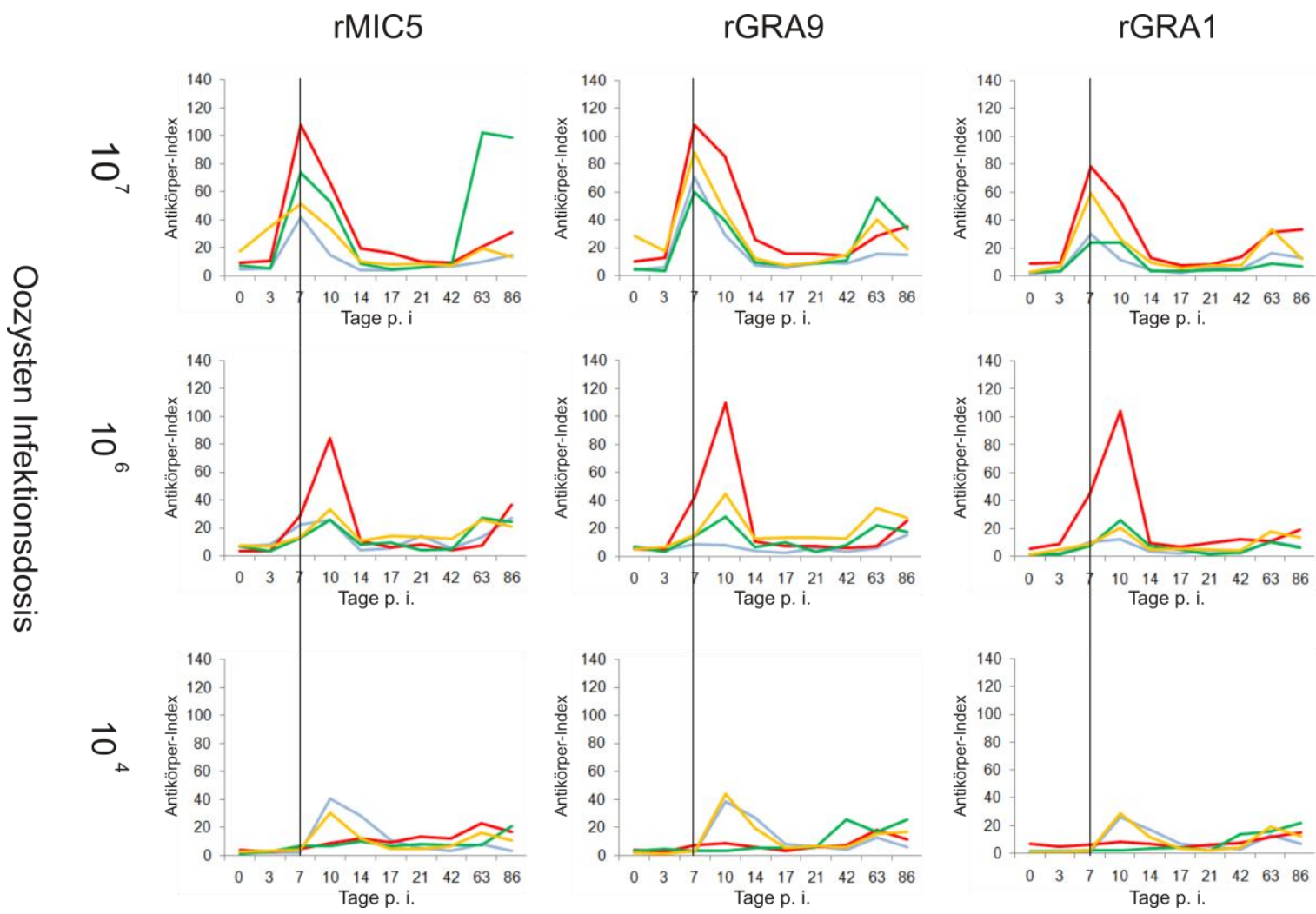

Abb. 3.19: Infektionsdosis-abhängige Immunantwort von Hühnern

Hühner mit einer Infektionsdosis von $10^{4}, 10^{6}$ und $10^{7}$ Oozysten pro Tier wurden im Lineblot auf die Anwesenheit von MIC5-, GRA9- und GRA1-spezifische IgY-Antikörper untersucht. Die Entwicklungszeit betrug $200 \mathrm{sec}$. Anschließend erfolgte die Quantifizierung mit dem ImageJProgramm. Von jeder Gruppe wurden vier Tiere getestet, wobei jede Farbe ein Tier repräsentiert.

Um die spezifischen Immunantworten besser miteinander vergleichen zu können, wurde von der Antikörperantwort jeder Gruppe der Mittelwert zu jedem Untersuchungszeitpunkt berechnet. In einer dreidimensionalen Darstellung wurden die mittlere Antikörper-Index für jedes Antigen und jedem Untersuchungszeitpunkt gruppenabhängig dargestellt (Abb. 3.20). Hühner mit einer Infektionsdosis von $10^{7}$ Oozysten pro Tier besaßen eine insgesamt höhere IgY-Immunantwort als die anderen Gruppen. Bei nur geringen Infektionsdosen $\left(10^{1}\right.$ und $10^{2}$ Oozysten pro Tier) war der Unterschied in der Immunantwort dagegen nur sehr schwach bzw. nicht signifikant ausgeprägt. 

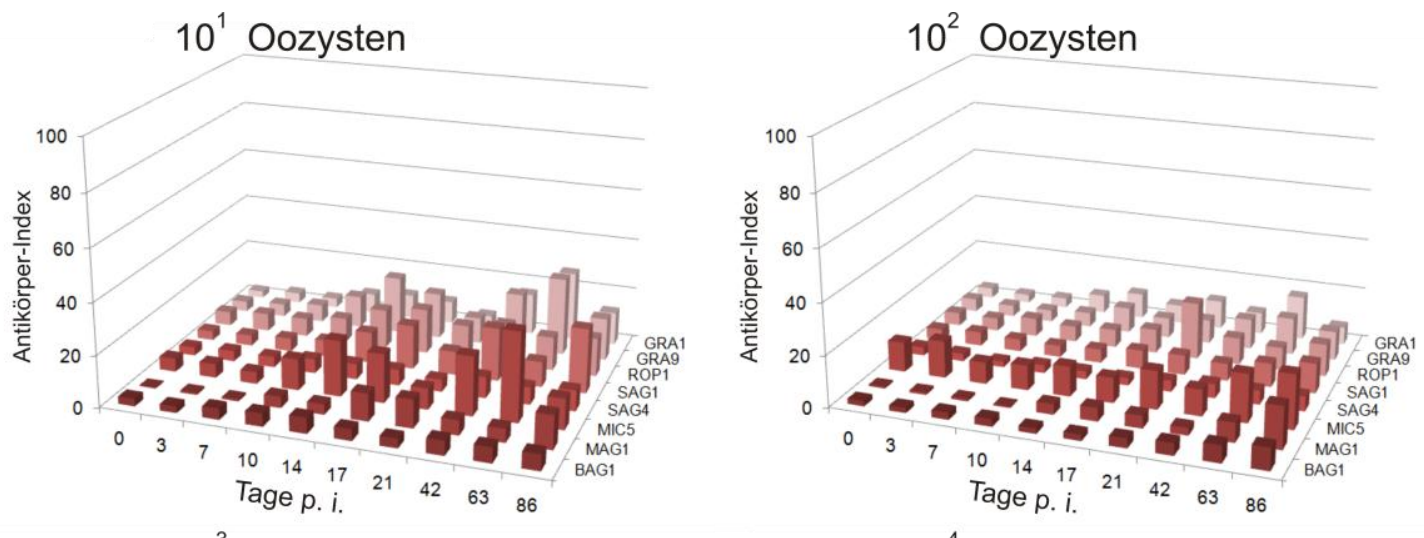

$10^{3}$ Oozysten

$10^{4}$ Oozysten
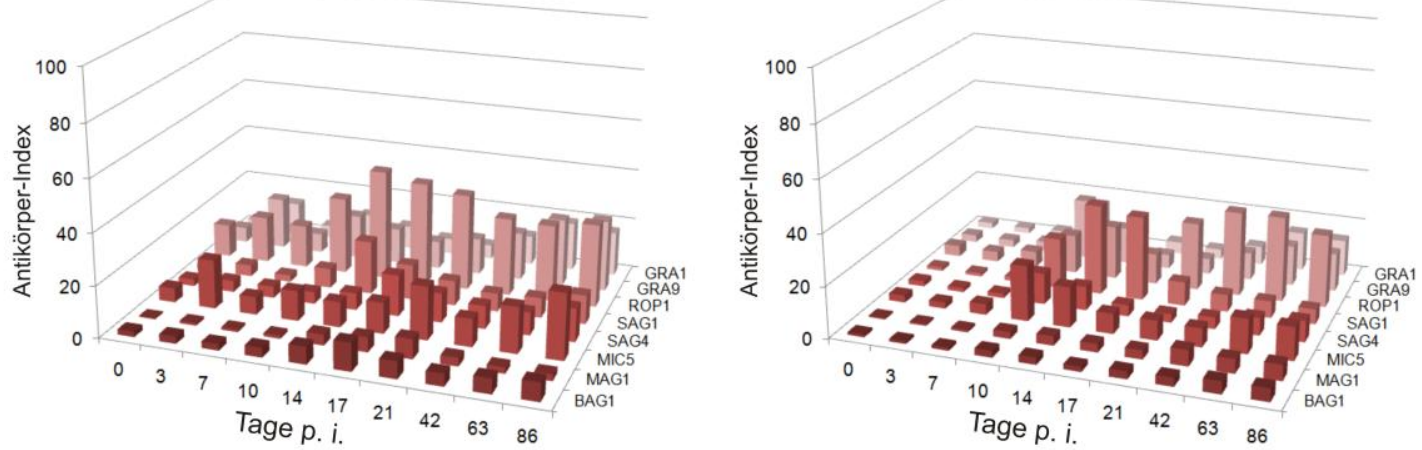

$10^{5}$ Oozysten

$10^{6}$ Oozysten
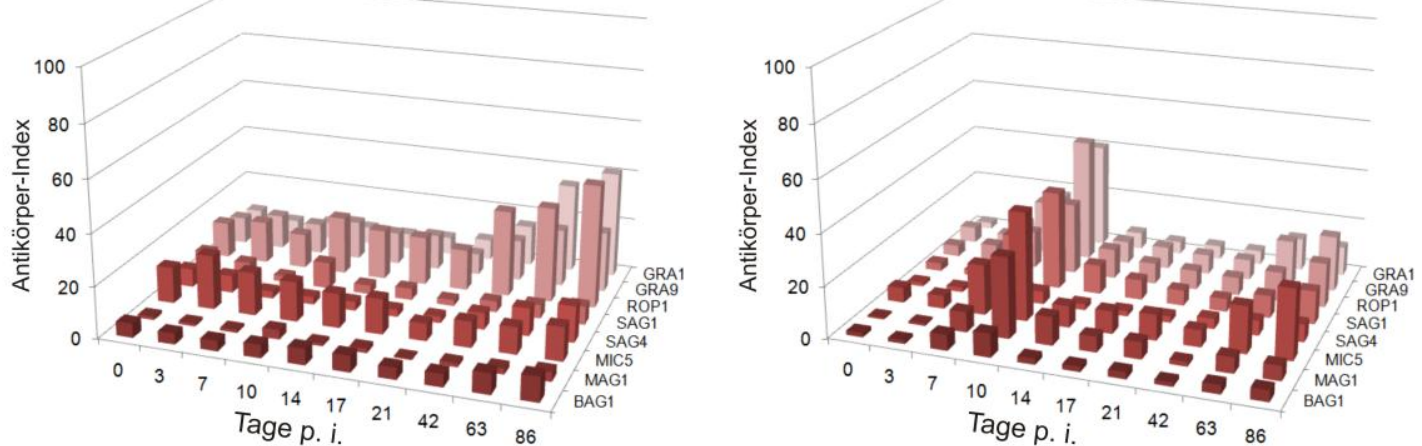

$10^{7}$ Oozysten

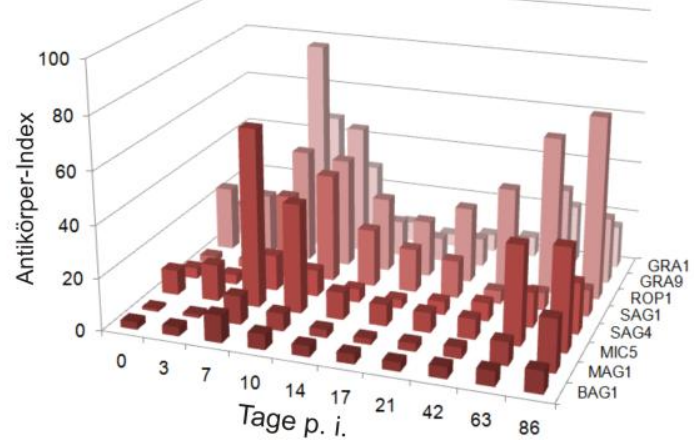

Abb. 3.20: Dreidimensionale Darstellung der humoralen Immunantwort von Hühnern gegen definierte Toxoplasma-Antigene

Die Hühner wurden experimentell mit einer Infektionsdosis von $10^{1}$ bis $10^{7}$ Oozysten pro Tier mit T. gondii infiziert. Nach einer Analyse im Lineblot-Assay unter der Verwendung rekombinanter Antigene wurden die Lineblots nach einer Entwicklungszeit von $200 \mathrm{sec}$ mit Hilfe des ImageJProgramms quantitativ ausgewertet. Von den vier Hühnern einer Gruppe sind jeweils die Mittelwerte zu den angegebenen Zeitpunkten dargestellt. 


\subsubsection{Reproduzierbarkeit der Lineblot-Assay Ergebnisse}

Um die Reproduzierbarkeit des Lineblot-Assays zu beurteilen wurden drei unabhängige Experimente mit Seren von infizierten Hühner durchgeführt. Zum einen wurden die Ergebnisse des in 3.6.2 gezeigten Versuches verwendet. Bei der zweiten Untersuchung wurde ebenfalls $1 \mu \mathrm{g}$ Antigen/Membran aufgetragen, jedoch wurde eine andere Fraktion des jeweiligen Antigens benutzt. Die Serum- und Sekundärantikörperverdünnungen blieben dabei unverändert. In der dritten Untersuchung wurden dieselben Antigenelutionen wie in Versuch 2 verwendet, die Serumverdünnung wurde von 1:500 auf 1:200 herabgesetzt und die Antiserumverdünnung von 1:2.000 auf 1:5.000 heraufgesetzt. Nach einer Entwicklungszeit der Lineblots von $200 \mathrm{sec}$ wurden diese mit Hilfe des ImageJ-Programms ausgewertet. Dabei ist in Abbildung 3.21 gezeigt, dass nur geringe Unterschiede in der Intensität bestehen, die Titerverläufe jedoch unverändert blieben.
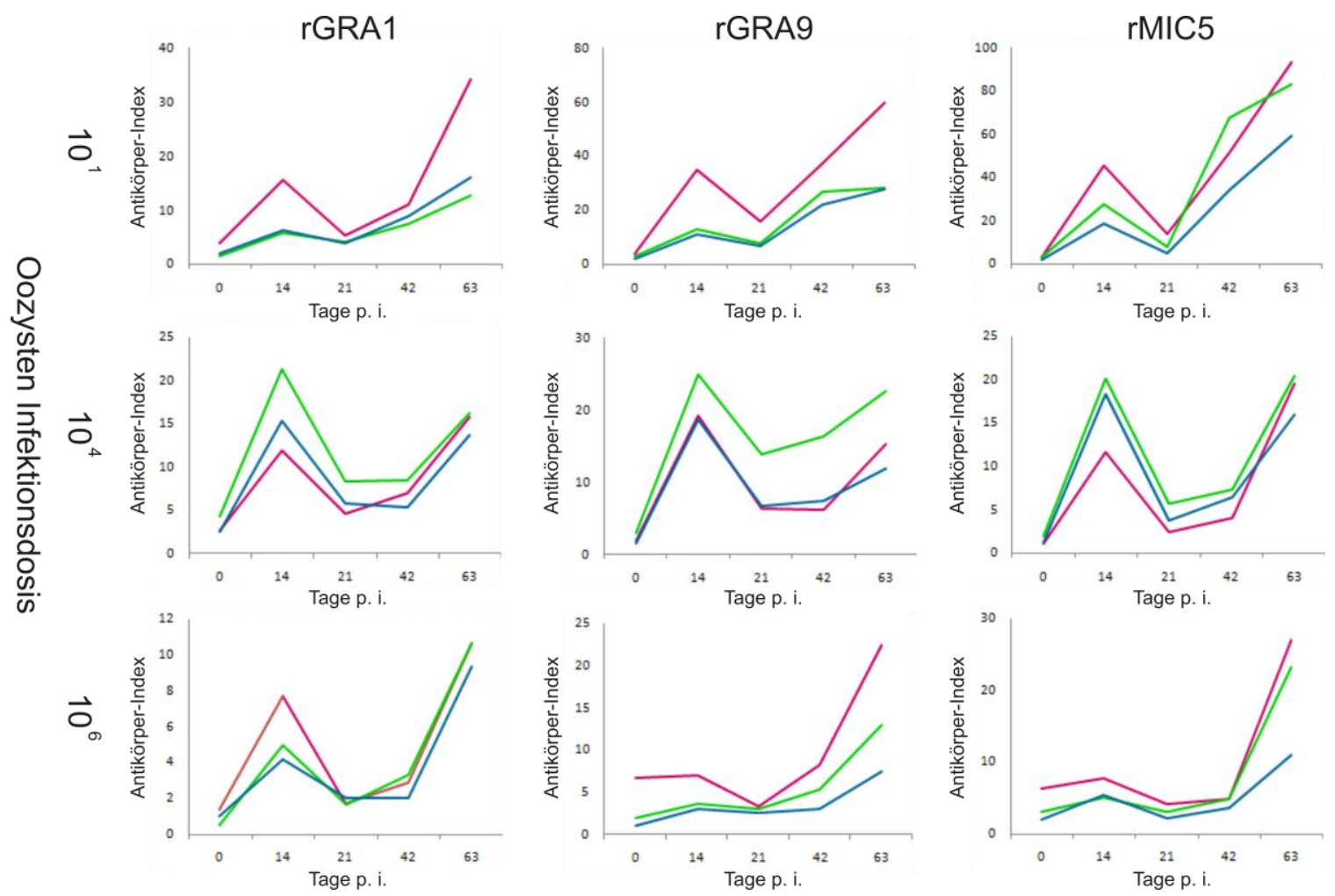

Abb. 3.21: Dreifach-Untersuchung von Hühnerseren im Lineblot

Von jeder Gruppe wurden Verlaufseren von einem Huhn durch drei Untersuchungen im Lineblot auf Reproduzierbarkeit der Ergebnisse getestet. Durch eine Quantifizierung mit dem ImageJProgramm wurden die Antikörper-Indices ermittelt.

- Durchlauf 1: Antigen-Elution (1) / Serum 1:500 / Antiserum 1:2.000

- Durchlauf 2: Antigen-Elution (2) / Serum 1:500 / Antiserum 1:2.000

- Durchlauf 3: Antigen-Elution (2) / Serum 1:200 / Antiserum 1:5.000 


\subsubsection{Untersuchung der Immunantwort von Schweinen im Lineblot}

Die Schweineseren wurden ebenfalls über eine Kooperation mit der Arbeitsgruppe von Prof. Dr. A. Tenter von der Tierärztlichen Hochschule aus Hannover bezogen.

Zur Verfügung gestellt wurden Verlaufseren von drei Schweinen, die oral mit $10^{5}$ Oozysten des Toxoplasma DX (Typ II)-Stammes experimentell infiziert worden waren.

Im Lineblot-Assay wurden mit Hilfe des LAS-4000 Image Readers untersucht, ob und ggf. welche rekombinanten Antigene von IgG-Antikörpern des jeweiligen Schweines erkannt wurden (Abb. 3.22).

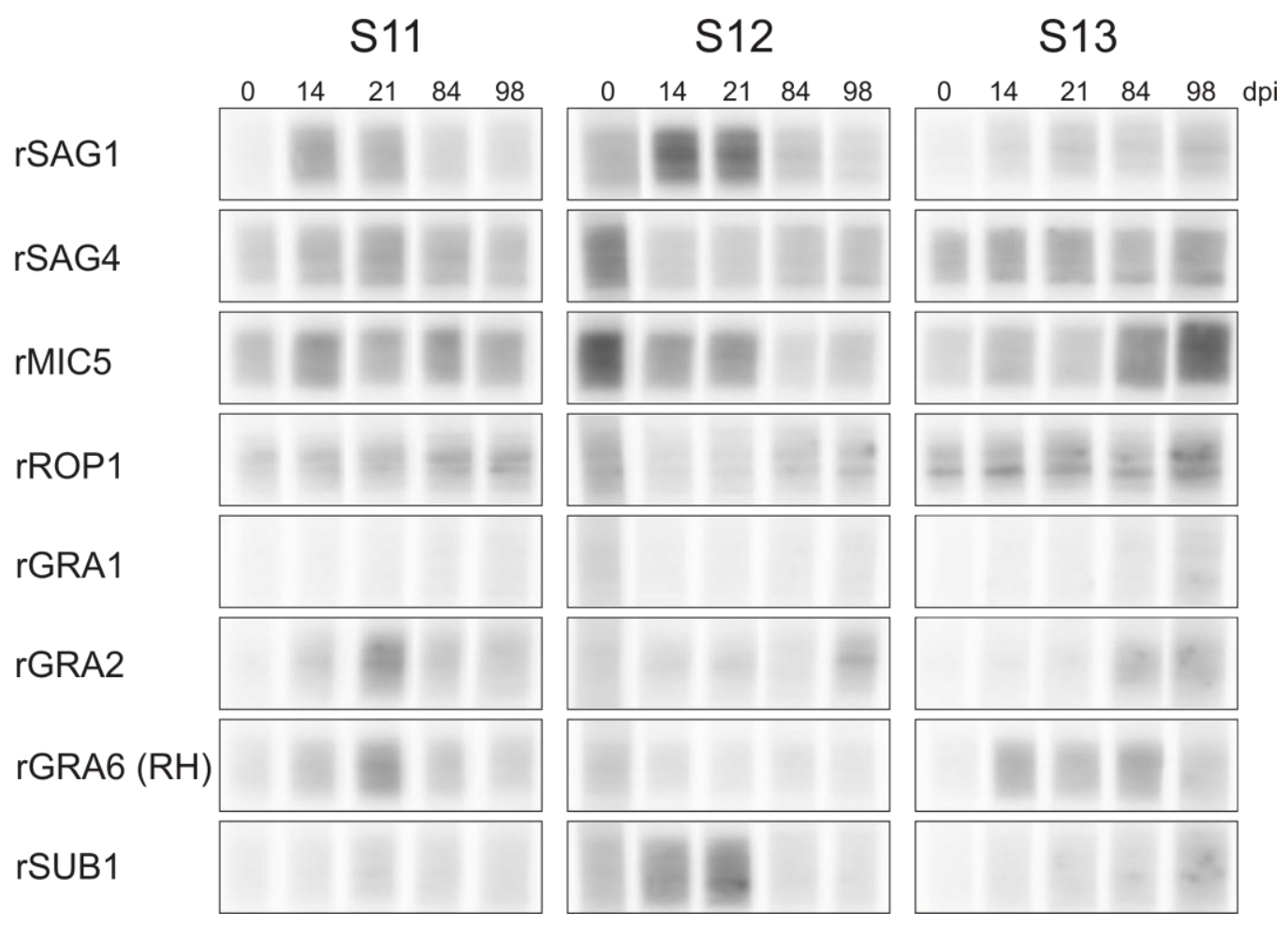

Abb. 3.22: IgG-Immunantwort von Schweinen im Lineblot-Assay

In einem Lineblot unter Verwendung rekombinanter $T$. gondii-Antigene wurden Verlaufseren von Schweinen untersucht, die experimentell mit $10^{5}$ Oozysten des Toxoplasma DX-Stammes infiziert worden waren. Antigen-spezifische lgG-Antikörper wurden durch Inkubation der Blotstreifen mit 1:100 verdünnten Seren und einem 1:10.000 verdünnten HRP-konjugierten Ziege anti-Schwein IgG $(\mathrm{H}+\mathrm{L})$-Sekundärantikörper nachgewiesen. Die Entwicklungszeit der Lineblots betrug $200 \mathrm{sec}$.

Die Analyse der Lineblot-Assays zeigte, dass das Kontrollserum von Schwein 12 (S12) im Vergleich zu den übrigen Seren unspezifische Reaktionen aufwiesen. Dies könnte auf eine unsachgemäße Lagerung der Probe während des Transportes hindeuten, was zu nicht aussagekräftigen Ergebnissen im Lineblot führte. Unter Verwendung der rekombinanten Antigene SAG4, MIC5 und ROP1 war auch in den Kontrollseren (0 dpi) der übrigen Schweine eine Reaktion zu beobachten. Des Weiteren war zu beobachten, 
dass Schweine - ebenso wie Geflügel - bei der Lineblot-Analyse zu den angegebenen Zeitpunkten nach der Infektion keine GRA1-spezifischen IgG-Antikörper aufwiesen. Außerdem ergaben die Lineblot-Analysen erste Hinweise auf eine Antigen-spezifische IgG-Immunantwort, die von Tier zu Tier unterschiedlich zu sein scheint.

Um diese Vermutung zu bestätigen, wurden die Lineblots nach einer Entwicklungszeit von 200 sec quantitativ mit Hilfe des ImageJ-Programms ausgewertet (Abb. 3.23).
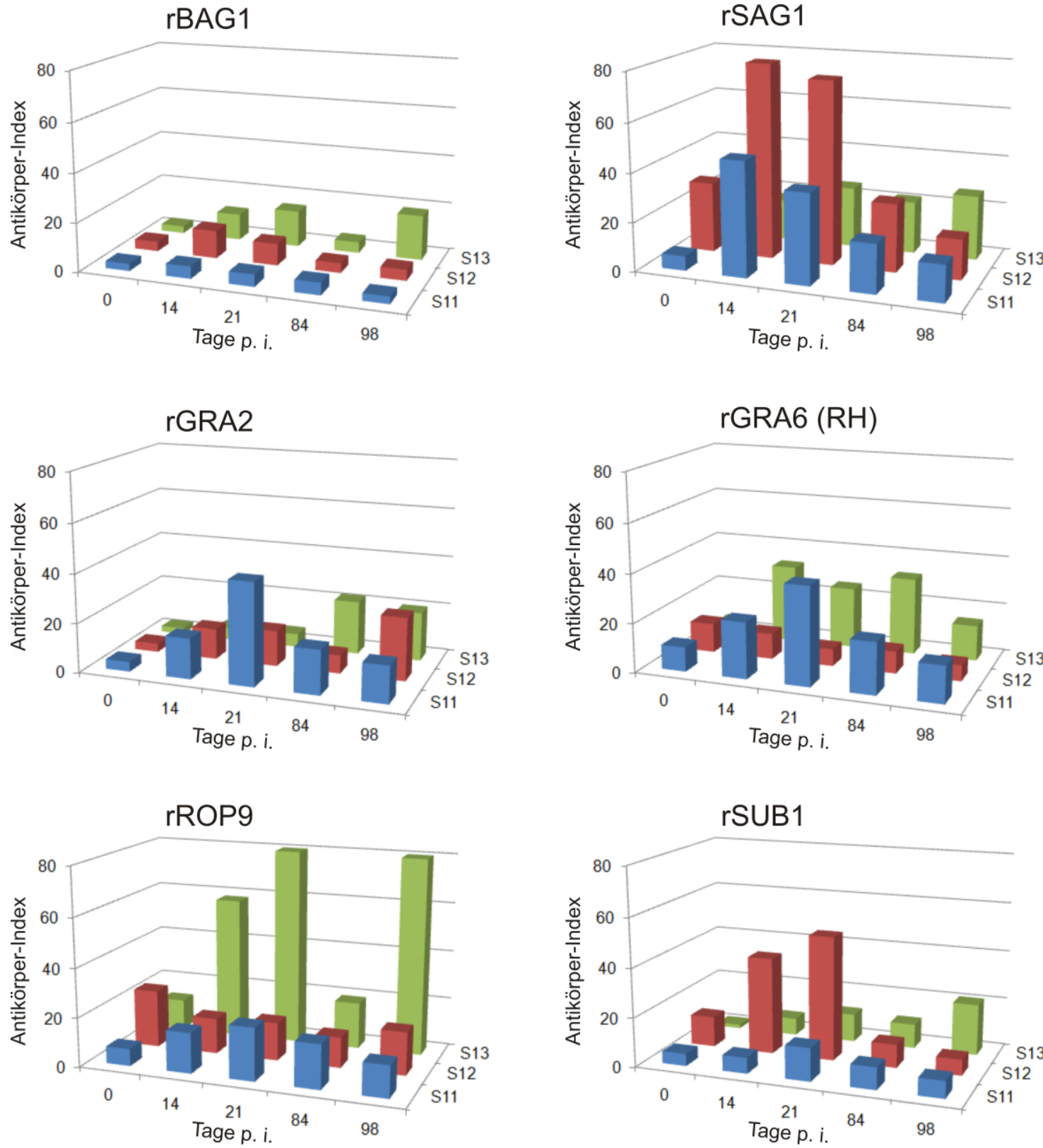

Abb. 3.23: Quantitative Auswertung der Antikörperantwort experimentell infizierter Schweine

Die Antikörperantwort von experimentell $10^{5}$ Oozysten pro Tier infizierten Schweinen wurde im Lineblot-Assay unter Verwendung rekombinanter Antigene mit Hilfe des ImageJ-Programms quantitativ ausgewertet. 
Die quantitative Auswertung der Lineblot-Assays zeigte trotz identischer Infektionsdosis eine unterschiedliche IgG-Immunantwort der Schweine auf die verwendeten Antigene. Besonders deutlich zeigte sich dies bei Verwendung von rROP9 und rGRA6 (RH). Die stärkste Immunantwort wurde in vielen Fällen 14 bis 21 Tage nach der Infektion vermerkt. Unter der Verwendung der rSAG1- und rSUB1-Antigene konnte im weiteren Verlauf in zwei von drei untersuchten Tieren ein eindeutiger Abfall der IgGImmunantwort beobachtet werden. 


\section{Diskussion}

\subsection{Effektivität der pränatalen Therapie}

In der Schwangerschaft kann bei einer Erstinfektion der Frau der Parasit T. gondii auf den Fötus übertragen werden und so zu einer kongenitalen Infektion dessen führen. Dabei sind die Auswirkungen am Fötus abhängig vom Infektionszeitpunkt der Mutter. Ob und ggf. welche Therapie einen günstigen Einfluss auf die Infektion des Kindes oder auf klinische Symptome hat, wird jedoch kontrovers diskutiert.

Im Jahr 2007 veröffentlichte die SYROCOT (Systemic Review On Congenital Toxoplasmosis)-Gruppe eine Studie zur Effektivität der pränatalen Therapie. In dieser Studie wurde nur ein geringer Hinweis für die Verringerung der Transmission von der infizierten Mutter auf den Fötus gefunden, wenn eine antiparasitäre Therapie innerhalb von drei Wochen nach der Serokonversion eingeleitet wurde. Als Vergleich wurden Frauen herangezogen, bei denen eine Therapie erst nach acht oder mehr Wochen nach der Infektion initiiert wurde. Ebenso konnten keine Anzeichen dafür gefunden werden, dass eine pränatale Therapie Einfluss auf das Risiko für die Ausprägung von klinischmanifesten Erkrankungen beim Kind hat. Stattdessen konnten bei einem Wechsel der Therapie von Spiramycin auf die Kombinationstherapie, bestehend aus Pyrimethamin $(P)$, Sulfadiazin $(S)$ und Folinsäure $(F)$, ein erhöhtes Risiko für die Ausprägung von klinischen Symptomen. Als Vergleichsgruppe dienten hier Frauen bei denen nur eine Kombinationstherapie durchführten wurde (Thiebaut et al., 2007).

Um die Effektivität der in Deutschland üblichen pränatalen Therapie zu überprüfen, wurde eine retrospektive Untersuchung an Hand von 685 Frauen durchgeführt, dessen serologische Befunde auf eine Primärinfektion in der Schwangerschaft hindeuteten. Die Therapie erfolgte nach den Richtlinien des Robert-Koch-Institutes (RKI) bis zum Ende der 15. Schwangerschaftswoche (SSW) mit Spiramycin und ab der 16. SSW, unabhängig vom Infektionsstatus des Fötus, mit einer Pyrimethamin-SulfadiazinFolinsäure (PSF) Kombinationstherapie über mindestens vier Wochen.

\subsubsection{Einfluss der Therapie auf die Transmissionsrate}

Die 685 Frauen mit einer schwangerschaftsrelevanten Toxoplasma-Infektion wurden, ausgehend von der SSW bei Infektion, in drei Gruppen eingeteilt. Die Analyse ergab, dass die Transmissionsrate bei fortschreitender Schwangerschaft zunahm. 
Der Grund für die damit einhergehende Zunahme des Infektionsrisikos für den Föten ist wahrscheinlich eine Veränderung der Plazenta mit fortschreitender Schwangerschaft. Die Plazenta ist eine passive Filtermembran, die das mütterliche- und kindliche Blut voneinander trennt, gleichzeitig aber den Fötus mit Nährstoffen versorgt. Um den mit fortschreitender Schwangerschaft vermehrten Nährstoffbedarf des Kindes decken zu können, ist eine Plazentaveränderung notwendig. Dabei wächst diese zu Beginn einer Schwangerschaft zunächst schneller als der Embryo. Ab der zweiten Hälfte der Schwangerschaft wächst jedoch der Fötus schneller. Um diese Diskrepanz kompensieren zu können, passt sich die Plazenta morphologisch und funktionell an (Siegenthaler und Blum, 2006). Dabei werden (i) die Durchblutung des Uterus gesteigert, (ii) die Membranpermeabilität verändert und (iii) Transportsysteme und Poren ausgebildet. Außerdem wird das Zottensystem der Plazenta erweitert und gleichzeitig die Zottenwände immer dünner (Schmidt-Matthiesen und Wallwiener, 2005). Des Weiteren verkürzt sich die Diffusionsstrecke zwischen maternalem- und fetalem Blut (Siegenthaler und Blum, 2006). All diese Faktoren führen vermutlich zu einer erleichterten aktiven Invasion des Parasiten in die Plazenta und somit in die Blutbahn des Föten mit fortschreitender Schwangerschaft. Unsere Ergebnisse zur Transmissionsrate wurden von der SYROCOT-Studie, wie auch vielen anderen Untersuchungen zur kongenitalen Toxoplasmose, beobachtet.

In der von uns durchgeführten Studie lag das Risiko für eine Übertragung des Parasiten von der Mutter auf den Fötus mit 4,8 \% deutlich unter der in der SYROCOT-Gruppe beobachteten durchschnittlichen Transmissionsrate von 29,1\%. Eine durchschnittliche Transmissionsrate von 29 bzw. 30 \% wurde auch in anderen Studien zur kongenitalen Toxoplasmose gefunden (Dunn et al., 1999; Kodjikian, 2010). Wie bei den anderen beiden Veröffentlichungen, stammten auch die in der SYROCOT-Studie einbezogenen Studienpopulationen vorwiegend aus Frankreich, wo in der Schwangerschaft ein Toxoplasmose-Screening einmal im Monat vorgesehen ist. In Italien wurde, je nach Region, in ein- bis dreimonatigen Intervallen auf eine Toxoplasma-Infektion in der Schwangerschaft untersucht. Dabei wurden nur regionale Studien zur kongenitalen Toxoplasmose mit einer geringen Anzahl an Patienten durchgeführt. Die durchschnittliche Transmissionsrate lag hier bei ca. 8-10 \% (Sever et al., 1988; Mombro et al., 1995; Vergani et al., 1998). In Italien, wie auch in Frankreich, wird eine Infektion in der Schwangerschaft nur mit Spiramycin therapiert, es sei denn, die Infektion des Föten ist erwiesen.

In Deutschland gehört die Untersuchung auf eine Toxoplasma-Infektion nicht zu den in der Schwangerschaft durchgeführten und von den gesetzlichen Krankenkassen finanzierten Routineuntersuchungen. Die Kosten hierfür müssen ggf. von der Patientin 
selber getragen werden. Dies führt dazu, dass sich nur wenige Schwangere untersuchen lassen und daher viele Infektionen in der Schwangerschaft - und aufgrund von fehlenden Symptomen - unbemerkt bleiben. Hinzu kommt, dass viele Frauen in Deutschland nur zu Beginn einer Schwangerschaft eine Untersuchung auf eine mögliche Infektion mit T. gondii durchführen lassen, wenn die Transmissionsrate am geringsten ist. Im zweiten und dritten Trimester wird in Deutschland häufig nur auf Verdacht eine Diagnostik durchgeführt. Das Fehlen einer routinemäßigen Untersuchung in der Schwangerschaft ist eine Erklärung zu der von uns beobachteten geringen Transmissionsrate.

Eine andere mögliche Erklärung für die in Deutschland beobachtete geringe Transmissionsrate könnte eine Fehlinterpretation der durchgeführten serologischen Befunde sein. Von den unterschiedlichen Immunoglobulinklassen ist IgG das einzige, welches über die Plazenta von der Mutter auf den Fötus übergeht und somit das ungeborene Kind schützt. Dabei wird IgG aktiv über einen neonatalen Fc-Rezeptor (FcRn) der Syncytiotrophoblasten transportiert (Simister, 2003). Mit ansteigender Transmissionsrate des Parasiten auf bis zu $80 \%$ am Ende der Schwangerschaft, findet gleichzeitig ein vermehrter Transfer von IgG-Antikörpern auf den Föten statt (Garty et al., 1994; Dunn et al., 1999). Daher ist der Nachweis spezifischer IgG-Antikörper im fötalen Blut nicht geeignet, um eine kongenitale Infektion des Kindes nachzuweisen.

Da IgM-, IgA- und IgE-Antikörper die Plazenta nicht passieren können, dient vor allem der Nachweis dieser Antikörper im Blut des Neugeborenen als Nachweis für eine pränatale Infektion. Wallon et al. konnten allerdings zeigten, dass der Nachweis spezifischer IgM- und IgA-Antikörper in Neugeborenen abhängig vom Infektionszeitpunkt der Mutter ist. Dabei führte eine Infektion spät während der Schwangerschaft zu einer höheren Nachweisrate von IgM-Antikörpern. Bei einer Infektion im ersten und zweiten Trimester dagegen sind bei $60 \%$ der Neugeborenen keine spezifischen IgM-Antikörper nachweisbar (Wallon et al., 1999). Gründe hierfür könnten eine nur kurzzeitige Präsenz der IgM-Antikörper oder das Ausbleiben der lgMProduktion durch den Föten in der Schwangerschaft sein. Eine ähnliche Beobachtung konnten Gurevich et al. an Hand von spezifischen IgA-Antikörpern machen. Hierbei führte eine Infektion im ersten Trimester häufig zu einem Ausbleiben der $\lg A$ Immunantwort des Embryos (Gurevich et al., 2003).

Aufgrund des Fehlens dieser Antikörper im Neugeborenen, könnte dies zu falschnegativen Ergebnissen in der prä- als auch in der postnatalen Diagnostik geführt haben. Einfluss dabei hat auch eine pränatale Therapie der Mutter. Eine plazentagängige Therapie, wie die PSF-Kombinationstherapie, könnte zu einer Unterdrückung der Immunantwort des Kindes führen. $\mathrm{Da}$ in der SYROCOT-Studie nur im Falle einer 
gesicherten Infektion des Kindes die Kombinationstherapie durchgeführt wurde und das Spiramycin nicht die Plazenta passiert, könnte dies zu der wesentlich höheren Anzahl an kongenital infizierten Kindern geführt haben. Eine Studie zur pränatalen PSFTherapie an Rhesus-Affen zeigte, dass nach der Einleitung der Therapie der Parasit im Fruchtwasser nach etwa 10-13 Tagen nicht mehr nachweisbar war und auch die Parasitenanzahl nach der Geburt unter der Nachweisgrenze lag (Schoondermark-van de Ven et al., 1995).

Aus ethischen Gründen kann eine therapiefreie Kontrollgruppe in dieser Art von Studien nicht einbezogen werden. Dennoch weisen unsere Ergebnisse darauf hin, dass die in Deutschland routinemäßig durchgeführte PSF-Kombinationstherapie bei einer gesicherten Toxoplasma-Infektion der Mutter in der Schwangerschaft einen günstigen Einfluss auf die Transmissionsrate haben könnte.

\subsubsection{Eine frühzeitig eingeleitete Therapie führt zur Reduzierung von klinischen Symptomen bei einer pränatalen Infektion mit $T$. gondii}

In der von der SYROCOT-Gruppe durchgeführten Studie zur kongenitalen Toxoplasmose konnte keine Minderung von klinischen Symptomen bei einer pränatalen PSF-Therapie festgestellt werden. Stattdessen wurde beobachtet, dass ein Wechsel der Therapie von Spiramycin auf die PSF-Kombinationstherapie häufiger zu klinischen Manifestationen beim Kind zu führen scheint.

Um diese Einschätzung zu überprüfen, wurden die 33 pränatal mit $T$. gondii-infizierten Kinder in der von uns durchgeführten retrospektiven Studie auf klinische Symptome hin untersucht. Dabei konnten bei 30,3 \% der Kinder (10/33) klinische Manifestationen festgestellt werden. Im Vergleich dazu zeigten in der SYROCOT-Studie nur 18,5\% der infizierten Kinder (94/507) klinische Symptome. Eine mögliche Erklärung für das von uns beobachtete höhere Risiko für die Ausprägung von klinischen Symptomen könnte die Größe der Studienpopulation sein. Studien mit einer geringen Patientenzahl ergaben ebenfalls bei $25-36,4 \%$ der pränatal infizierten Kinder eine oder mehrere klinischmanifeste Erkrankungen (Mombro et al., 1995; Dunn et al., 1999; Mazzola et al., 2007). Des Weiteren konnten Dunn et al. zeigen, dass bei Frauen, die zwischen der 24. und 30. SSW serokonvertierten, das Risiko für ein klinisch-auffälliges Kind am höchsten war (Dunn et al., 1999). Da in der SYRCOT-, wie auch bei den anderen aufgeführten Studien, hauptsächlich eine Monotherapie mit Spiramycin durchgeführt wurde, scheint diese keinen schützenden Einfluss auf die Ausprägung einer klinischen Manifestation beim Kind zu haben. 
Die genauere Analyse unserer Studie ergab, dass eine zeitliche Verzögerung von mehr als acht Wochen zwischen Infektion und Beginn der Therapie mit ca. $70 \%(7 / 10)$ signifikant häufiger zur Ausbildung von klinischen Symptomen beim Kind führte. Im Gegensatz dazu wurde bei Initiierung der Therapie innerhalb von vier Wochen nach Infektion bei weniger als $15 \%(3 / 21)$ der infizierten Kinder klinische Symptome beobachtet. Da die Infektion des Föten relativ zeitnah nach der Infektion der Mutter stattfindet (Thalib et al., 2005; Thiebaut et al., 2007) muss davon ausgegangen werden, dass die Therapie bei den erstgenannten zu spät erfolgte und der Parasit im Tachyzoiten-Stadium bereits zu Gewebeschädigungen geführt hatte.

Eine Erklärung für eine ineffektive pränatale Therapie könnte eine unterschiedliche Sensibilität der verschiedenen $T$. gondii-Genotypen auf die verabreichten Medikamente sein. In Europa, und vor allem in Frankreich, sind Infektionen mit dem Genotyp II mit mehr als $90 \%$ vorherrschend (Ajzenberg et al., 2002). Untersuchungen zum antiparasitären Effekt von Pyrimethamin und Sulfadiazin zeigten, dass nur Pyrimethamin die Replikationsrate des Parasiten verringert und in Kombination mit Sulfadiazin ein synergistischer Effekt auftritt. Sulfadiazin als alleinige Therapie zeigte dagegen keine Auswirkungen auf die Parasitenvermehrung (Sheffield und Melton, 1975). In vitro Untersuchungen zeigten jedoch, dass Typ II-Stämme unterschiedlich auf Sulfadiazin reagierten (Meneceur et al., 2008).

Um eine aussagekräftige Studie zur Effektivität der in Deutschland durchgeführten PSFTherapie in der Schwangerschaft durchführen zu können, wäre die Einführung eines Screening-Programmes, wie es in Frankreich durchgeführt wird, wichtig. Dabei könnte ein im monatlichen Abstand durchgeführtes Screening gegebenenfalls eine Infektion frühzeitig erkennen und somit das Zeitintervall bis zur Einleitung der Therapie verkürzen.

\subsection{Serodiagnostik der humanen T. gondii-Infektion mit Hilfe von rekombinanten Antigenen in einem Lineblot-Assay}

Eine Infektion mit dem Parasiten T. gondii verläuft im immunkompetenten Menschen meist asymptomatisch oder führt zu unterschiedlichen Erscheinungen, wie z. B. einer grippeähnlichen Symptomatik (Santoni und Santoni-Williams, 1993; Taila et al., 2011). Aufgrund des Fehlens von typischen klinischen Symptomen ist eine Diagnose oftmals schwierig. Eine serologische Untersuchung ist meist die einzige Möglichkeit eine Infektion sicher festzustellen. 
Heutzutage gibt es viele verschiedene diagnostische Verfahren zum Nachweis Toxoplasma-spezifischer Antikörper. Die verbreitesten Techniken sind dabei automatisierte oder manuelle Enzym-basierende Immunreaktionen (z. B. ELISA und der Enzyme-linked fluorescent immunoassay (ELFA)) und Immunoblot-Methoden.

Vor allem in der Schwangerschaft ist eine zuverlässige Diagnostik unabdingbar und sollte eine Differenzierung zwischen einer akuten und einer chronischen Infektion erlauben. Zur Unterscheidung der Infektionsphasen dienen hierbei die verschiedenen Immunoglobulinklassen. Der Nachweis des Immunoglobulins A $(\lg A)$ im Serum ist ein Zeichen für eine akute Infektion (Gutierrez et al., 1997; Kodym et al., 2007). Des Weiteren sind in der frühen Infektionsphase hohe lgM- und steigende IgG-Titer vorhanden (Kasper et al., 2009; Quan et al., 2009). Obwohl das IgM als Marker für eine akute Infektion gilt, können spezifische IgM-Antikörper monate- bis jahrelang im Serum nachgewiesen werden (Correa et al., 2007). Daher ist der Nachweis von IgMAntikörpern nicht immer ein Hinweis auf eine frische Infektion. Der alleinige Nachweis von spezifischen IgG-Antikörpern dagegen gilt als Zeichen für eine chronische Infektion (Friese und Kachel, 1997).

Der Einsatz von rekombinanten Proteinen in der Diagnostik ermöglicht eine bessere Reproduzierbarkeit der Ergebnisse und ist zudem eine sichere Alternative als das Arbeiten mit dem infektiösen Parasiten.

Um eine akute von einer chronischen Infektion $\mathrm{zu}$ unterscheiden, wurden über Proteomanalysen von Tachyzoiten $u$. a. die Proteine GRA1, GRA7, ROP9, MIC5 und SUB1 als potentielle Marker für eine akute Infektion identifiziert. Diese, sowie fünf weitere - bereits als diagnostisch-relevant erkannte Marker - wurden rekombinant in $E$. coli hergestellt.

Da eine humane Infektion in Europa meist von Toxoplasmen des Genotyps II ausgelöst wird (Ajzenberg et al., 2002), wurden die meisten Antigene aus dem NTE-Stamm (Typ II) kloniert. In einem eigens dafür entwickelten Lineblot-Assay wurden diese dann auf ihre immunogenen Eigenschaften untersucht. Dabei wurde nach Antigen-spezifischen IgG-, IgM- und IgA-Antikörpern in Serumproben infizierter Patienten und nicht-infizierter Kontrollindividuen gesucht. Die verwendeten Humanseren wurden in der Routinediagnostik an den unter 2.6 beschriebenen Testverfahren auf eine mögliche Toxoplasma-Infektion untersucht und in drei Gruppen eingeteilt: (i) Seren von Patienten ohne T. gondii-Infektion, (ii) mit einer akuter Toxoplasmose oder (iii) mit einer chronischen T. gondii-Infektion. 


\subsubsection{Die Auswahl der richtigen Evaluierungsstrategie}

Für die Evaluierung rekombinanter Antigene spielen mehrere Faktoren eine bedeutende Rolle. Zum Einen ist die Auswahl eines geeigneten Antigens, sowie dessen Präparation entscheidend (Kotresha und Noordin, 2010). Außerdem basierte die Serumeinteilung auf den zuvor durchgeführten routinediagnostischen Testverfahren, wobei eine falsche Klassifizierung nicht auszuschließen war und somit das Ergebnis der eigenen Untersuchungen beeinflusste. Zudem zeigte sich, dass die Auswahl der richtigen Evaluierungsstrategie bei einer quantitativen Auswertung ebenso von Bedeutung ist.

Bei der quantitativen Analyse des Lineblot-Assays wurde zunächst eine zeitabhängige Quantifizierung mit Hilfe des Multi Gauge-Programmes durchgeführt. Diese wurde beendet, wenn die Kontrollgruppe - bestehend aus 29 Seren von nicht-infizierten Patienten - den Cut-off-Wert von $10.000 \mathrm{AU} / \mathrm{mm}^{2}$ erreichte. Seren von Patienten mit einer Toxoplasma-Infektion, die zu diesem Zeitpunkt eine Emission von mehr als 20.000 $\mathrm{AU} / \mathrm{mm}^{2}$ aufwiesen, wurden als positiv gewertet. Dies führte zu einer sehr hohen Spezifität von 98-100 \%, jedoch meist nur zu einer geringen Sensitivität. Des Weiteren zeigte sich, dass der Zeitaufwand für die Bestimmung des richtigen Quantifizierungszeitpunktes für jedes Antigen und jede Immunoglobulinklasse, trotz der einfachen Handhabung des Programmes, sehr groß war.

Daher wurde eine zweite Quantifizierung mit fixen Zeitpunkten angewendet und der Cutoff über die Ergebnisse der Kontrollgruppe berechnet. Dabei wurde das bereits verwendete kommerziell erhältliche Multi Gauge- mit dem frei verfügbaren ImageJProgramm verglichen. Der Vergleich der Ergebnisse, die mit den beiden Programmen erzielt wurden, zeigte nur minimale Abweichungen. Dabei ging im Vergleich zu der zeitabhängigen Methode die Spezifität der erzielten Ergebnisse nur gering zurück, während die Sensitivität in vielen Fällen gesteigert werden konnte.

Aufgrund der höheren Sensitivität und des geringeren Zeitaufwandes ist die Evaluierung zu einem definierten Zeitpunkt mit einer Berechnung des Cut-off-Wertes für die diagnostische Anwendung geeigneter. Dabei spielt die Auswahl des Programmes jedoch keine Rolle. Die Verwendung des ImageJ-Programmes ist zwar im Vergleich zu dem Multi Gauge-Programm etwas zeitintensiver, kann aber kostenlos auf jedem Computer installiert und durchgeführt werden. 


\subsubsection{Dichte Granula-Antigene sind nützliche Hilfsmittel für die Diagnose einer Toxoplasma-Infektion}

Die Dichte Granula (dense granules) gehören zu den typischen Organellen von $T$. gondii und sekretieren bei der Invasion in die Wirtszelle Proteine, die als GRA (dense granules antigens) bezeichnet werden. Zusammen mit anderen Proteinen bilden sie intrazellulär um den Parasiten eine parasitophore Vakuole (Coppens et al., 1999), die das Überleben von T. gondii im Wirt sicherstellt. Aufgrund dessen, dass sie vor allem bei der Invasion eine Rolle spielen, stellen die GRA potentielle Marker für eine akute Infektion dar.

Für die Untersuchung von Humanseren wurden das GRA1, GRA2, GRA6 (NTE) und GRA7 rekombinant in E. coli hergestellt, sowie das rGRA6 $(\mathrm{RH})$ - und rGRA9-Antigen in Kooperation von der Arbeitsgruppe von Prof. Dr. W. Däubener vom Institut für Medizinische Mikrobiologie der Universität Düsseldorf bezogen.

Der Nachweis GRA1-spezifischer IgG-Antikörper erzielte bei einer Spezifität von $96 \%$ eine Sensitivität von 88-90 \%. Im Vergleich dazu konnte in einem ELISA der Nachweis von IgG-Antikörpern gegen das rekombinante GRA1 aus E. coli bislang nur eine Sensitivität von 60-68 \% erreichen (Lecordier et al., 2000; Ferrandiz et al., 2004). Des Weiteren wurden GRA1-spezifische IgG-Antikörper vor allem bei chronisch infizierten Patienten nachgewiesen (Ferrandiz et al., 2004; Pietkiewicz et al., 2004). Unsere Ergebnisse im IgG-Lineblot zeigten allerdings, dass eine Differenzierung zwischen einer akuten und einer chronischen Infektion mit Hilfe des rGRA1-Antigens nicht möglich ist.

Daher scheint der Lineblot-Assay mit Nachweis von IgG-Antikörpern gegen rGRA1 eher als „Screening“-Test für die Überprüfung des Vorliegens einer Toxoplasma-Infektion geeignet zu sein und weniger zur Identifizierung des Infektionsstadiums.

Zu einem ähnlichen Ergebnis führte die Evaluierung des rGRA2-Antigens im Lineblot. Nach Nachweis GRA2-spezifischer lgG-Antikörper führte zu einer Spezifität von $93 \%$ mit einer Sensitivität von 70-94 \%. Golkar et al., wie auch Holec-Gąsior et al., konnten zeigen, dass der Nachweis von IgG-Antikörpern gegen GRA2 eher bei akut infizierten Patienten nachweisbar waren (Golkar et al., 2007; Holec-Gasior et al., 2009). Auch in unseren Untersuchungen waren GRA2-spezifische IgG-Antikörper häufiger bei akut infizierten Patienten (94\%) im Vergleich zu chronisch infizierten Patienten (70\%) nachweisbar. Besser geeignet für die Differenzierung zwischen einer akuten und einer chronischen Infektion war jedoch der Nachweis GRA2-spezifischer IgA-Antikörper: Hierdurch konnte eine akute Infektion doppelt so häufig erkannt werden wie eine chronische. Allerdings war die Sensitivität des IgA-Nachweises mit $45 \%$ sehr gering, so dass rGRA2 als alleiniges Antigen für die Serodiagnostik nicht eingesetzt werden kann. 
Durch die Analyse von Humanseren im Lineblot-Assay konnte eine unterschiedliche Immunogenität zwischen dem rekombinanten GRA6-Antigen aus dem Toxoplasma NTE-Stamm (Typ II) und dem aus dem RH-Stamm (Typ I) festgestellt werden. Dabei zeigte das rGRA6 $(\mathrm{RH})$ insgesamt bessere immunogene Eigenschaften und ein gutes Potenzial als Marker für eine akute T. gondii-Infektion. Durch Verwendung dieses Antigens konnten Ergebnisse anderer Arbeitsgruppen bestätigt werden, die Antikörper gegen rGRA6 als Marker für eine akute Infektion nachwiesen (Redlich und Muller, 1998; Hiszczynska-Sawicka et al., 2005; Golkar et al., 2008) bestätigt werden. GRA6spezifische IgM- und IgG-Antikörper wurden auch von uns eher bei Patienten mit einer akuten Infektion nachgewiesen. Dabei zeigte der Nachweis rGRA6 (RH)-spezifischer IgM-Antikörper eine etwa zehn Mal so hohe Sensitivität der Nachweis von IgMAntikörpern gegen das rGRA6 (NTE).

Eine mögliche Ursache für diese Abweichung könnte eine Genotyp-spezifische Reaktion sein. Bei der Analyse der Aminosäuresequenz von GRA6 konnte eine 9\%ige Differenz zwischen den beiden Stämmen festgestellt werden. Dabei zeigte GRA6 $(\mathrm{RH})$ an der Cterminalen Domäne sechs zusätzliche Aminosäuren (Abb. 4.1). Zusätzlich ist an sieben Stellen ein Aminosäure Austausch vorzufinden. GRA6 aus den Genotyp II-Stämmen ME49 und NTE zeigte dagegen eine $100 \%$ ige Übereinstimmung.

\section{TgRH GNGGNEGRGYGGRGEGGAEDDRRPL HPERVNV Tg ME49 GNGGNEGRGEGG- . - . - EDDRRPL HPGSVNE Tg NTE GNGGNEGRGEGG- - - - - EDDRRPL HPGS VNE}

\section{Abb. 4.1: Aminosäuresequenz des T. gondii GRA6}

Gezeigt ist die C-terminale Aminosäuresequenz des T. gondii GRA6 aus den RH (Typ I)-, ME49 (Typ II)- und NTE (Typ II)-Stämmen. Die farbig unterlegten Bereiche zeigen die Unterschiede zwischen Genotyp I und II an.

Kong et al. gehen davon aus, dass jeder Genotyp Antigen-spezifische monoklonale Antikörper durch eine natürliche Infektion hervorruft, die selektiv bestimmte Regionen eines Peptids erkennen (Kong et al., 2003). Ebenso konnten Kato et al. zeigen, dass eine Toxoplasma-Infektion in Mäusen mit dem hoch-virulenten $\mathrm{RH}$ - bzw. dem niedrigvirulenten S272-Stamm zur Bildung unterschiedlicher IgG-Subklassen der Tiere gegen ein rekombinantes SAG1-Antigen führte. Als Begründung führten sie eine Veränderung der T-Zell Aktivierung auf, was zur Produktion von verschiedenen Antikörperklassen führte (Kato et al., 2007). 
Da in Europa eine humane Infektion in mehr als $90 \%$ durch einen Typ II-Stamm ausgelöst wird (Ajzenberg et al., 2002), ist davon auszugehen, dass die meisten untersuchten Seren von Patienten stammten, die mit einem Typ II-Stamm infiziert wurden. Daher sollten diese theoretisch eher mit dem GRA6-Antigen aus dem NTE (Typ II)-Stamm reagieren, welches jedoch nicht bestätigt werden konnte.

Anderseits könnte das Vorhandensein der sechs Aminosäuren an der C-terminalen Domäne des rekombinanten Antigens rGRA6 $(\mathrm{RH})$ zu einer unterschiedlichen Faltung des Proteins bei der Expression führen. Die unterschiedliche Beschaffenheit der Sekundärstruktur des rGRA6-Antigens könnte dann Ursache für eine abweichende Immunantwort sein. Letztendlich sind diese Erklärungsversuche nur hypothetischer Natur. Zur Überprüfung auf eine Genotyp-spezifische Immunreaktion müssten beide Antigene unter gleichen Bedingungen exprimiert, gereinigt und dann erneut mit Humanseren getestet werden.

In einem Line-Assay konnten Pfrepper et al. zeigen, dass IgG-Antikörper gegen das rekombinante GRA7 aus $E$. coli sehr früh in der Infektion nachweisbar waren (Pfrepper et al., 2005). Des Weiteren konnten in einem Immunoblot, wie auch in einem ELISA, GRA7-spezifische IgG-Antikörper als Marker für eine akute Infektion mit einer Sensitivität von bis zu 94 \%, identifiziert werden (Jacobs et al., 1998; Pietkiewicz et al., 2004; Sadeghiani et al., 2009). Diese Ergebnisse konnten wir nicht bestätigen und sehen daher, aufgrund der von uns erzielten geringen Sensitivität, das rGRA7 nicht als ein geeignetes Antigen für die Diagnostik einer T. gondii-Infektion an.

Der Nachweis GRA9-spezifischer IgG-Antikörper zeigte im Vergleich zu rGRA1, GRA2 und rGRA6 $(\mathrm{RH})$ mit $70 \%$ eine etwas geringere Sensitivität und wurde eher von chronisch infizierten Patienten erkannt. Im Gegensatz dazu wurden in einem ELISA gezeigt, dass vor allem akut-infizierte Patienten IgG-Antikörpern gegen das native GRA9 (B10) bildeten (Nockemann et al., 1998). Aus diesem Grund bleibt zunächst unklar, ob rGRA9 als Stadium-spezifischer Marker geeignet sein kann. Der Nachweis GRA9-spezifischer IgG-Antikörper in beiden Infektionsstadien kann zum Einen durch die unterschiedlich eingesetzten Methoden hervorgerufen worden sein. Der Immunoblot, wie auch der ELISA, dienen beide dem Nachweis einer Antigen-spezifischen Immunantwort. Jedoch sind diese beiden Methoden grundsätzlich unterschiedlich. So weisen die verwendeten Oberflächen (z. B. Polyvinylidenfluorid versus Polystyrol) eine unterschiedliche Bindung von Proteinen auf. Zudem unterscheiden sich die Durchführung und die Detektionsart von Antikörpern voneinander. Daher ist ein direkter Vergleich oftmals schwierig. Zum Anderen weisen native Antigene oftmals eine abweichende Proteinfaltung als rekombinant hergestellte Antigene auf, welches ebenfalls zu einer unterschiedlichen Reaktivität führen kann. 
Zusammenfassend zeigen unsere Untersuchungen, dass der Nachweis von GRAspezifischen Antikörpern - unabhängig vom hier verwendeten GRA-Protein - zwar zum Nachweis einer erfolgten Infektion eingesetzt werden kann, nicht aber für die Differenzierung des Krankheitsstadiums (akut versus chronisch) geeignet zu sein scheint. Der Grund für den konstanten Nachweis GRA-spezifischer IgG-Antikörper im Blut könnte möglicherweise durch die kontinuierliche Ruptur Bradyzoiten-haltiger Zysten erklärt werden, durch die anschließend neue Zellen infiziert werden. Als Resultat darauf würde der Wirt (Mensch) permanent spezifische lgG-Antikörper produzieren, um die Immunkontrolle über extrazelluläre Parasiten aufrecht zu erhalten.

\subsubsection{Rekombinante Antigene für den Nachweis einer akuten Infektion}

Als spezifischer Marker für das akute Stadium wird häufig das Tachyzoiten Oberflächenantigen (surface antigen) SAG1 diskutiert. Allerdings besaß das rekombinante SAG1-Antigen aus $E$. coli in unseren Untersuchungen nur eine geringe Sensitivität. SAG1-spezifische $\operatorname{lgM}$ - und $\lg A$-Antikörper wurden sogar eher bei chronisch-infizierten Patienten und weniger häufig bei akut-infizierten Patienten nachgewiesen.

Auch in der Literatur wird die Stadiumspezifität des SAG1-Antigens kontrovers diskutiert. Dabei wurden SAG1-spezifische IgG-Antikörper einerseits bei Patienten mit einer akuten Infektion (Parmley et al., 1992; Pietkiewicz et al., 2004) und andererseits bei einer chronischen Infektion nachgewiesen (Pfrepper et al., 2005; Gatkowska et al., 2006; Gatkowska et al., 2010). Es wurde vermutet, dass die unterschiedlichen immunogenen Eigenschaften auf die Auswahl der Proteinsequenz, wie auch auf die Präparation des rekombinanten Proteins zurückzuführen sei (Kotresha und Noordin, 2010). Aber auch das native SAG1-Antigen aus T. gondii wurde sowohl in der akuten Infektionsphase von IgM- und IgA-Antikörpern (Decoster et al., 1992; Gross et al., 1992) wie auch in der chronischen Phase von IgA-Antikörpern erkannt (Huskinson et al., 1990). Daher ergab die Evaluation des Antigens, dass dieses für den Einsatz im Lineblot-Assays ungeeignet ist.

Durch 2D-Gelelektrophoresen- und Massenspektrometrieanalyse konnte jedoch die native Subtilisin-ähnliche Serinprotease (SUB1) aus T. gondii als Marker für das akute Infektionsstadium identifiziert werden. Das SUB1-Protein wird bei der Invasion des Parasiten in die Wirtszelle von den Mikronemen sekretiert (Miller et al., 2001; Binder et al., 2008). Über einen Glykosyl-phosphatidylinositol (GPI)-Anker wird dieses in die Plasmamembran eingebaut und von Tachyzoiten auf der Zelloberfläche exprimiert 
(Binder et al., 2008). Die Deletion von SUB1 führte in vitro zu einer verminderten Zellanheftung und Invasion in die Wirtszelle und somit zu einer geringeren Virulenz in Mäusen (Lagal et al., 2010).

Aufgrund seiner potenziellen Eigenschaften als spezifischer Marker für eine akute Infektion wurde das Protein von uns rekombinant in E. coli exprimiert. Durch Analyse des Antigenindexes konnte an der C-terminalen Domäne eine mögliche Antikörperbindungsstelle identifiziert werden. Diese wurde daher im Lineblot auf ihre diagnostischen Eigenschaften getestet. Dabei zeigte diese Domäne gute Eigenschaften als Marker für eine akute Infektion. In Abhängigkeit von der Immunoglobulinklasse, konnte für den Nachweis der mit rSUB1-reagierenden Antikörpern eine Spezifität von 94-99 \% im Lineblot erreicht werden. Dabei zeigte sich häufiger eine Reaktion von rSUB1 mit Antikörpern von akut-Infizierten. Die höchste Diskrepanz zwischen einer akuten und einer chronischen Infektion konnte durch den Nachweis SUB1-spezifischer IgM-Antikörper erzielt werden, wobei hier eine positive Reaktion in $88 \%$ für eine akute Infektion sprach. Ebenso zeigte auch der Nachweis SUB1-spezifischer IgG-Antikörper eher eine positive Reaktion mit Seren von Patienten in der akuten Infektionsphase.

Durch den Nachweis ROP1-spezifischer IgA- bzw. IgG-Antikörper zeigte auch dieses Antigen Potenzial zur Identifizierung einer akuten Infektion. Spezifische IgG-Antikörper konnten bei $72 \%$ der akut-Infizierten, aber nur bei $38 \%$ der chronisch-Infizierten festgestellt werden. Holec-Gasior et al. konnten durch den Nachweis rROP1spezifischer lgG-Antikörper sogar in $94,6 \%$ eine akute und nur zu 15,5\% eine chronische Infektion nachweisen (Holec-Gasior et al., 2009). Dieses zeigt, dass der Nachweis ROP1-spezifischer Antikörper großes Potenzial als Marker für eine akute Infektion besitzt.

Viele der hier untersuchten Antigene im Lineblot zeigten aufgrund einer geringen Sensitivität ein nur geringes Potenzial für den Einsatz als diagnostischer Marker oder ermöglichten keine Differenzierung zwischen einer akuten und einer chronischen Infektion.

Der Nachweis von IgG-Antikörpern gegen die rekombinanten GRA1-, GRA2- und GRA6 $(\mathrm{RH})$-Antigene führte zu einer hohen Sensitivität von mehr als $70 \%$ und einem NPVWert von ca. 90 \% (Tab. 3.8). Dabei zeigte jedoch keines dieser Antigene das Potenzial zur Identifizierung einer akuten Infektion.

Werden die rekombinanten Antigene GRA1, GRA2, GRA6 $(\mathrm{RH})$ jedoch mit SUB1 kombiniert, um gegen sie gebildete IgA- und IgG-Antikörper nachzuweisen, führt dies zu einer 100 \%igen Identifizierung einer Infektion (Tab. 4.1). Außerdem kann hierdurch bei 
etwa $50 \%$ der Patienten mit einer Wahrscheinlichkeit von $92 \%$ zwischen einer akuten und einer chronischen Infektion differenziert werden (Tab. 4.2).

Tab. 4.1: Kombination von Antigenen im Lineblot zur Identifizierung einer ToxoplasmaInfektion

\begin{tabular}{lccccc} 
& IgG & Spezifität & Sensitivität & $\begin{array}{c}\text { PPV } \\
\text { (akute Infektion) }\end{array}$ & NPV \\
\hline rGRA1 & + & & $100 \%(1 / 3)$ & & \\
rGRA2 & + & $100 \%{ }^{*}$ & $96 \%(2 / 3)$ & $55 \%$ & $96 \%{ }^{*}$ \\
rGRA6 $(\mathrm{RH})$ & + & & $84 \%(3 / 3)$ & & \\
$\left({ }^{*}\right.$ mindestens 2/3 positive Reaktionen) & & & & &
\end{tabular}

Tab. 4.2: Kombination von Antigenen im Lineblot zur Identifizierung einer akuten Infektion

\begin{tabular}{lcccccc} 
& IgA & IgG & Spezifität & Sensitivität & $\begin{array}{c}\text { PPV } \\
\text { (akute Infektion) }\end{array}$ & NPV** \\
\hline rGRA6 $(\mathrm{RH})$ & + & + & $100 \%$ & $52 \%$ & $88 \%$ & $92 \%$ \\
rGRA2 & + & + & $100 \%$ & $48 \%$ & $77 \%$ & $89 \%$ \\
rSUB1 & & + & $93 \%$ & $80 \%$ & $70 \%$ & $66 \%$ \\
\hline rGRA6 $(\mathrm{RH})$ & + & + & $100 \%$ & $48 \%$ & $92 \%$ & $93 \%$ \\
rSUB1 & & + & & & & \\
$\left({ }^{*}\right.$ *mindestens eine lgG-positive Reaktion) & & & & &
\end{tabular}

\subsection{Die Anwendung des Lineblot-Assays zur Identifizierung einer Retinochorioiditis}

Die Retinochorioiditis gehört zu den häufigsten klinischen Symptomen, die in Verbindung mit einer Toxoplasma-Infektion auftreten (Innes, 2010). Dabei wurde viele Jahre davon ausgegangen, dass die Retinochorioiditis die Folge einer pränatalen Infektion sei (Perkins, 1973; Dutton, 1989; Lebech et al., 1999). Im Jahr 2000 jedoch widerlegten Gilbert und Stanford diese Theorie. Dabei gingen sie davon aus, dass ca. zwei Drittel (66-86 \%) der okulären Toxoplasmose auf eine postnatale Infektion zurückzuführen ist. Sie begründen diese Einschätzung damit, dass zwar einerseits bei einer pränatalen Infektion das Risiko für eine Retinochorioiditis höher ist, aber andererseits eine postnatale Infektion häufiger vorkommt (Gilbert und Stanford, 2000). Des Weiteren wird angenommen, dass eine Retinochorioiditis nicht bei einer 
Primärinfektion mit $T$. gondii stattfindet, sondern erst durch eine Reaktivierung des Parasiten hervorgerufen wird (Guex-Crosier, 2009).

Bei der Ausprägung einer okulären Toxoplasmose spielt außerdem der genetische Hintergrund des Wirtes und des Parasiten, sowie Umweltbedingungen und soziale Faktoren eine bedeutende Rolle (Vallochi et al., 2008).

In dieser Arbeit sollte geklärt werden ob eine klinisch-manifeste Erkrankung, wie die Retinochorioiditis, über die serologische Analyse im Lineblot-Assay mit Hilfe von rekombinanten Antigenen erkannt werden kann. Dazu wurden zehn Seren von Patienten mit und acht Seren von Patienten ohne eine Retinochorioiditis untersucht. Die quantitative Analyse des Lineblots zeigte, dass ein statistisch signifikanter Unterschied zwischen den beiden Gruppen durch den Nachweis BAG1-spezifischer lgG- und GRA2spezifischer IgA-Antikörper bestand (Abb. 3.15). Dabei konnte in beiden Fällen eine niedrigere Immunantwort bei Patienten mit einer okulären Toxoplasmose festgestellt werden konnte.

Diese Beobachtung lässt vermuten, dass eine Assoziation zwischen der humoralen Immunantwort gegen das Bradyzoiten-spezifische Antigen BAG1 bzw. gegen GRA2 und der Entwicklung von okulären Läsionen bestehen könnte.

Diese Theorie ist vereinbar mit den in einem Mausmodell gemachten Beobachtungen. Dabei führte eine durch CD8-positive T-Zellen vermittelte Immunantwort des Wirtes zu einer Verminderung der Läsionen am Auge (Gazzinelli et al., 1994) und das Fehlen dieser zytotoxischen T-Zellen zu einer vermehrten Anzahl an Schädigungen (Lu et al., 2004). Einhergehend damit führte die Aktivierung von B-Zellen zu einer verminderten Proliferation der Tachyzoiten im Auge (Lu et al., 2004).

\subsection{Serodiagnostik von Nutztieren mit Hilfe von rekombinanten Antigenen von T. gondii}

Für die Diagnose einer Toxoplasma-Infektion wird in der Veterinärmedizin meistens ein Enzym-linked Immunosorbent Assay (ELISA), ein modifizierter Agglutinationstest (MAT), ein Latex-Agglutinationstest (LAT) oder der indirekte Hämagglutinationstest (IHAT) eingesetzt. Die Verwendung der in der Humanmedizin lange Zeit als "Goldener Standard“ geltender Sabin-Feldman-Tests, erwies sich an Hühner- und Putenseren als nicht geeignet (Dubey et al., 1993a; Dubey et al., 1993b). Heutzutage gilt der MAT-Test als die sensitivste serologische Methode zur Untersuchung von Hühnerseren (Yan et al., 2010). Der Einsatz des MAT-, wie auch des ELISA-Testes an Schweineseren, zeigte ebenfalls zufriedenstellende Ergebnisse (Gamble et al., 2005; Garcia et al., 2006; 
Garcia et al., 2008). Die Verwendung von rekombinanten Antigenen in einem Immunoblot-Verfahren zur Diagnose einer Toxoplasma-Infektion ist jedoch bisher nicht verbreitet.

Serologische Untersuchungen an experimentell infizierten Puten, Hühnern und Schweinen mit Hilfe von rekombinanten Antigenen in einem Lineblot-Assay ermöglichten die Identifizierung einer T. gondii-Infektion etwa 10 bis 14 Tage nach der Infektion. Dabei zeigten die Hühner zum Teil eine Infektionsdosis-abhängige Immunantwort. Ebenso konnte an Hand von Putenseren gezeigt werden, dass die Immunantwort von mit Tachyzoiten bzw. Oozysten infizierten Tieren abweicht. So zeigten Oozysten-infizierte Puten eine allgemein stärkere Immunantwort. Eine Erklärung für den früheren Antikörperanstieg nach einer Tachyzoiten Infektion von Puten ist wahrscheinlich darauf zurückzuführen, dass Tachyzoiten sofort nach Verabreichung Wirtszellen infizieren können und das Immunsystem des Wirtes dadurch früher reagieren kann. Bei der oralen Gabe der Oozysten müssen diese erst einmal den Magen passieren, bevor sie sich im Darm in Tachyzoiten umwandeln und die Darmepithelzellen infizierten. Daher kommt es wahrscheinlich zu einer verzögerten Antikörperantwort.

Die Untersuchung von Verlaufseren experimentell infizierter Hühner zeigte einen Anstieg von spezifischen IgY-Antikörpern etwa 7 bis 14 Tage nach der oralen Infektion mit Oozysten. Im weiteren Verlauf konnte ein kurzzeitiger Rückgang und ca. 42 bis 63 Tage nach der Infektion ein erneuter Anstieg von spezifischen IgY-Antikörpern registriert werden.

Beal et al. konnten ebenfalls eine solche Immunantwort bei experimentell mit Salmonella enteritica infizierten Hühnern beobachten (Beal et al., 2004). Eine nur temporäre humorale und zelluläre Immunantwort wäre eine Erklärung für dieses Phänomen.

Nach oraler Oozysten Infektion wandeln sich diese im Darm zunächst in Tachyzoiten um und könnte dadurch die humorale Immunantwort induzieren. Nach der anschließenden Differenzierung der Tachyzoiten in das Bradyzoiten-Stadium (Zysten) werden möglicherweise keine weiteren IgY-Antikörper mehr gebildet. Dies könnte nach einer gewissen Zeit wieder zur Reaktivierung der Zysten führen. In Folge dessen dann das Immunsystem der Hühner reaktiviert und neue IgY-Antikörper gebildet werden (Abb. 4.2). 


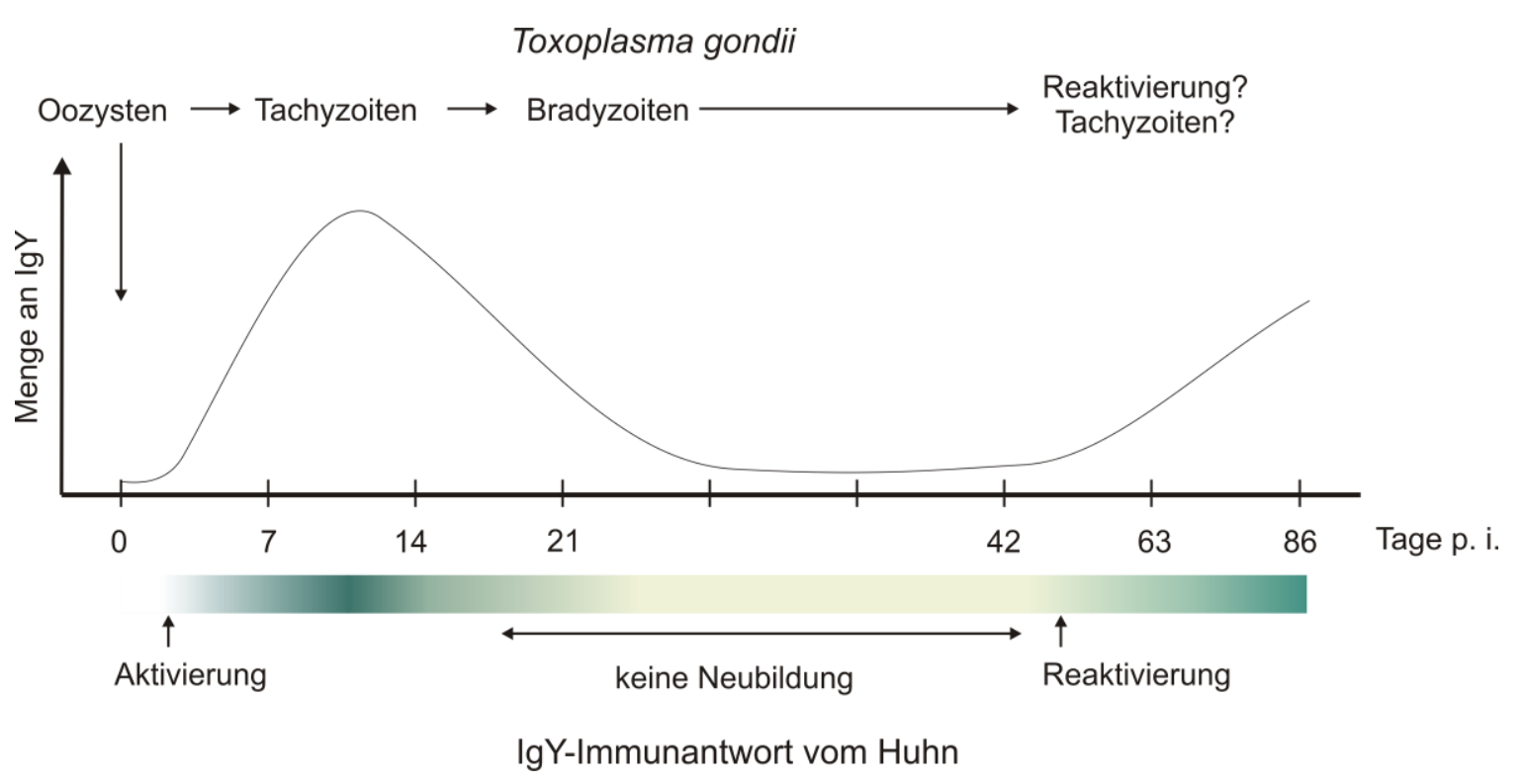

Abb. 4.2: Hypothese zum Anstieg der IgY-Immunantwort des Huhns nach Infektion mit Oozysten

Der beobachtete IgY-Titerverlauf würde bei einer serologischen Untersuchung im Zeitfenster von 21-42 Tagen nach der Infektion eventuell zu falsch-negativen Ergebnissen führen. Je nach dem wann die Infektion stattfindet, könnten im Schlachtalter (Hähnchen ca. im Alter von 32-51 Tagen, Hühner ca. im Alter von 81 Tagen) eventuell keine Antigen-spezifischen IgY-Antikörpern nachgewiesen werden. Daher ist der Nachweis von IgY-Antikörpern im Lineblot-Assay für SeroprävalenzStudien wahrscheinlich nicht geeignet.

Die IgG-Immunantwort der Schweine im Lineblot zeigte, im Vergleich zu den untersuchten Hühner- und Putenseren, eine individuell unterschiedliche Immunreaktion jedes Schweins auf die jeweiligen Antigene. Dieser Befund bestätigt die Beobachtung von Gamble et al. (Gamble et al., 2000). Des Weiteren konnte häufiger eine positive Reaktion der Kontrollseren (0 dpi) beobachtet werden. Eine mögliche Ursache hierfür könnte die Haltung der Schweine auf einem natürlichen Untergrund sein. Dadurch wäre eine natürliche Toxoplasma-Infektion oder eine Koinfektion mit anderen Mikroorganismen, wie z. B. anderen Apikomplexa-Arten (Eimeria, Isospora oder Cryptosporidium), möglich. Letzteres würde zu einer Kreuzreaktion mit den verwendeten rekombinanten Antigenen führen. Aufgrund dessen, dass keine anderen Kontrollseren, z. B. Seren von Tieren mit anderen Apikomplexa-Infektionen, zur Verfügung standen, konnte diese Hypothese nicht überprüft werden.

In der Veterinärmedizin ist der rekombinante Lineblot zur Diagnose einer ToxoplasmaInfektion kein zuverlässiges Testverfahren. Starke Schwankungen in der Immunantwort 
und eventuelle Kreuzreaktionen mit anderen Apikomplexa-Arten könnten nicht ausgeschlossen werden und erschweren somit den Nachweis des Parasiten in einer serologischen Untersuchung.

In der Humanmedizin erwies sich der Einsatz von rekombinanten Antigenen in einem Lineblot-Verfahren jedoch als hilfreich. Mit dieser Methode konnte nicht nur eine Toxoplasma-Infektion mit einer hohen Wahrscheinlichkeit erkannt werden, sondern erlaubte auch die Differenzierung zwischen einer akuten und einer chronischen Infektion. 


\section{Zusammenfassung}

Die Toxoplasmose ist eine Infektionskrankheit, die durch den Parasiten Toxoplasma gondii verursacht wird. Während eine Infektion bei den meisten immunkompetenten Menschen asymptomatisch abläuft, kann bei einer Primärinfektion in der Schwangerschaft der Parasit auf den Föten übergehen und zu einem Abort oder zu schweren Erkrankungen dessen führen.

Eine pränatale Therapie soll eine Übertragung verhindern oder klinische Auswirkungen beim Kind mindern. Um die Effektivität der in Deutschland durchgeführten Therapie beurteilen zu können, wurde im Rahmen dieser Arbeit eine retrospektive Untersuchung von 685 schwangeren Frauen durchgeführt, deren serologische Befunde auf eine Primärinfektion hindeuteten. In Folge dieser Studie konnte gezeigt werden, dass eine innerhalb von vier Wochen nach Infektion eingeleitete antiparasitäre Therapie das Risiko für die Ausprägung von klinisch-manifesten Erkrankungen des Kindes mindert.

Um valide epidemiologische Untersuchungen durchführen zu können ist eine zuverlässige Diagnostik unabdingbar. Hierfür ist von Bedeutung, dass T. gondii ein intrazellulärer Parasit ist, welcher in drei verschiedenen Stadien vorkommt: als Oozysten, Tachy- und Bradyzoiten. Bei einer akuten Infektion sind vorwiegend sich schnell vermehrende Tachyzoiten vorhanden, während bei einer chronischen Infektion Bradyzoiten-enthaltene Zysten dominieren. Es wird davon ausgegangen, dass jedes Parasitenstadium spezifische Antigene exprimiert.

Im Zuge dieser Arbeit sollten daher diagnostische Marker identifiziert werden, die eine Differenzierung zwischen einer akuten und einer chronischen Infektion erlauben. Über 2D-Gelelektrophoresen und Massenspektrometrie konnten dabei u. a. die Proteine GRA1, GRA7, ROP9, MIC5 und SUB1 als Marker für eine akute Infektion ermittelt werden. Diese, sowie sieben weitere Proteine, wurden rekombinant in $E$. coli hergestellt und in einem Lineblot-Verfahren an Humanseren auf ihre diagnostischen Eigenschaften untersucht.

Durch den Nachweis spezifischer IgG-Antikörper gegen rGRA1, rGRA2 und rGRA6 konnte eine Toxoplasma-Infektion in bis zu $100 \%$ erkannt werden. Eine Diskriminierung des Infektionsstadiums war allerdings nicht möglich. Eine akute Infektion ließ sich jedoch durch den Nachweis von rSUB1- und rGRA6-spezifischen IgG- und IgA Antikörper mit einer Wahrscheinlichkeit von bis zu $92 \%$ von einer chronischen Infektion unterscheiden.

Des Weiteren wurden mit Hilfe des Lineblot-Verfahrens untersucht, ob die rekombinanten Antigene auch Potenzial hatten eine der häufigsten klinisch-manifesten 
Erkrankungen - die okuläre Toxoplasmose (Retinochorioiditis) - zu identifizieren. Dabei konnten durch den Nachweis GRA2-spezifischer IgA- und BAG1-spezifischer IgGAntikörper signifikante Unterschiede bei Patienten mit einer Retinochorioiditis im Vergleich zu T. gondii infizierten Patienten ohne okuläre Läsionen festgestellt werden. Um festzustellen, ob der Lineblot-Assay unter der Verwendung rekombinanter Antigene auch in der Veterinärmedizin eingesetzt werden kann, wurden Verlaufseren von Hühnern, Puten und Schweinen untersucht, die experimentell mit Oozysten oder Tachyzoiten infiziert worden waren. Dabei zeigten die Tiere, in Abhängigkeit von dem getesteten Antigen, eine teilweise Infektionsdosis- und Infektionsart-abhängige Antikörper-Kinetik.

In der Zusammenschau können die in dieser Arbeit erzielten Ergebnisse zur Verbesserung der Diagnostik und Therapie der Toxoplasmose - insbesondere in der Schwangerschaft - beitragen. 


\section{Summary}

Toxoplasmosis is an infectious disease caused by the parasite Toxoplasma gondii. Whereas the infection proceeds in most cases asymptomatically in immunocompetent humans, a threat for the foetus occurs when a primary infection takes place in pregnancy. An infection of the foetus can lead to an abort or cause serious symptoms in the newborn.

A prenatal treatment shall prevent transmission of the parasite from the mother to the fetus or reduce clinical symptoms in the child. To estimate the efficacy of the therapy that is used in Germany, we performed a retrospective analysis with 685 pregnant women, who showed serological evidence for a primary infection. As a result we could show that antiparasitic therapy that is initiated within four weeks after infection decrease the risk for clinical symptoms in the child.

For the performance of valid epidemiological investigations, reliable diagnostic markers are indispensable. For this purpose it is important to know that $T$. gondii is an intracellular parasite which exists in three different stages: as oocysts, tachy- and bradyzoites. Within an acute infection replicating tachyzoites dominate, while bradyzoites-containing cysts are presenting in the chronic phase of infection. Each parasite stage is known to express stage-specific antigens.

Hence, one aim of this study was to identify diagnostic markers which allow the differentiation between an acute and chronic infection. By using 2D gelelectrophoresis and mass spectrometry, the proteins GRA1, GRA7, ROP9, MIC5 and SUB1 were identified as markers for an acute infection. These as well as seven other proteins were recombinantly expressed in E. coli and evaluated for their diagnostic qualities in a lineblot assay with human serum samples.

By detection of specific IgG antibodies against rGRA1, rGRA2 and rGRA6, a Toxoplasma infection could be recognized in up to $100 \%$. However, a discrimination of the infection stage was impossible. Instead, an acute infection could be distinguished from a chronic infection with a likelihood of up to $92 \%$ by detection of rSUB1 and rGRA6 specific $\lg G$ and $\lg A$ antibodies.

Furthermore, we also examined with the lineblot technique whether the recombinant antigens might have the potential to identify one of the most prevalent clinical manifestations, ocular toxoplasmosis (retinochorioiditis). Thereby, significant differences were observed by the detection of GRA2-specific IgA- and BAG1-specific IgG antibodies between patients with retinochorioiditis and $T$. gondii-infected patients without ocular lesions. 
Whether to determine the lineblot using the recombinant antigens might also be of value for application in veterinary medicine, we analyzed serum samples of oocysts- or tachyzoites-infected chickens, turkeys and pigs. Thereby, we could show that the animals seem to exhibit antibody kinetics that depend on the infection-dose and the parasite stage that was used for infection.

In conclusion, the results achieved by this study could be contributed as an advance for the diagnostic and therapy of the toxoplasmosis, especially in pregnancy. 


\section{Literaturverzeichnis}

Accorinti, M., Bruscolini, A., Pirraglia, M. P., Liverani, M., Caggiano, C. (2009). Toxoplasmic retinochoroiditis in an Italian referral center. Eur J Ophthalmol 19: 824-30.

Ajzenberg, D., Cogne, N., Paris, L., Bessieres, M. H., Thulliez, P., Filisetti, D., Pelloux, H., Marty, P., Darde, M. L. (2002). Genotype of 86 Toxoplasma gondii isolates associated with human congenital toxoplasmosis, and correlation with clinical findings. J Infect Dis 186: 684-9.

Altcheh, J., Diaz, N. S., Pepe, C. M., Martin, V., Nigro, M., Freilij, H., Angel, S. O. (2006). Kinetic analysis of the humoral immune response against 3 Toxoplasma gondii-recombinant proteins in infants with suspected congenital toxoplasmosis. Diagn Microbiol Infect Dis 56: 161-5.

Ambroise-Thomas, P., Pelloux, H. (1993). Toxoplasmosis - congenital and in immunocompromised patients: a parallel. Parasitol Today 9: 61-3.

Araujo, P. R., Ferreira, A. W. (2010). High diagnostic efficiency of IgM-ELISA with the use of multiple antigen peptides (MAP1) from T. gondii ESA (SAG-1, GRA-1 and GRA-7), in acute toxoplasmosis. Rev Inst Med Trop Sao Paulo 52: 63-8.

Aubert, D., Maine, G. T., Villena, I., Hunt, J. C., Howard, L., Sheu, M., Brojanac, S., Chovan, L. E., Nowlan, S. F., Pinon, J. M. (2000). Recombinant antigens to detect Toxoplasma gondiispecific immunoglobulin $G$ and immunoglobulin $M$ in human sera by enzyme immunoassay. $J$ Clin Microbiol 38: 1144-50.

Augustin, A. J. (2007). Augenheilkunde. 3. Aufl. Springer-Verlag, Berlin - Heidelberg: 286-288.

Baum, J., Papenfuss, A. T., Baum, B., Speed, T. P., Cowman, A. F. (2006). Regulation of apicomplexan actin-based motility. Nat Rev Microbiol 4: 621-8.

Beal, R. K., Powers, C., Wigley, P., Barrow, P. A., Smith, A. L. (2004). Temporal dynamics of the cellular, humoral and cytokine responses in chickens during primary and secondary infection with Salmonella enterica serovar Typhimurium. Avian Pathol 33: 25-33.

Binder, E. M., Lagal, V., Kim, K. (2008). The prodomain of Toxoplasma gondii GPI-anchored subtilase TgSUB1 mediates its targeting to micronemes. Traffic 9: 1485-96.

Black, M. W., Boothroyd, J. C. (2000). Lytic cycle of Toxoplasma gondii. Microbiol Mol Biol Rev 64: 607-23.

Bohne, W., Gross, U., Ferguson, D. J., Heesemann, J. (1995). Cloning and characterization of a bradyzoite-specifically expressed gene (hsp30/bag1) of Toxoplasma gondii, related to genes encoding small heat-shock proteins of plants. Mol Microbiol 16: 1221-30.

Bohne, W., Holpert, M., Gross, U. (1999). Stage differentiation of the protozoan parasite Toxoplasma gondii. Immunobiology 201: 248-54.

Bundesverband der Deutschen Fleischwarenindustrie e. V. (2009). Geschäftsbericht 2008/2009. http://www.bvdf.de/. 
Burg, J. L., Perelman, D., Kasper, L. H., Ware, P. L., Boothroyd, J. C. (1988). Molecular analysis of the gene encoding the major surface antigen of Toxoplasma gondii. $\mathrm{J}$ Immunol 141: 3584-91.

Carruthers, V. B. (1999). Armed and dangerous: Toxoplasma gondii uses an arsenal of secretory proteins to infect host cells. Parasitol Int 48: 1-10.

Carruthers, V. B., Sibley, L. D. (1997). Sequential protein secretion from three distinct organelles of Toxoplasma gondii accompanies invasion of human fibroblasts. Eur J Cell Biol 73: $114-23$.

Carvalho, F. R., Silva, D. A., Cunha-Junior, J. P., Souza, M. A., Oliveira, T. C., Bela, S. R., Faria, G. G., Lopes, C. S., Mineo, J. R. (2008). Reverse enzyme-linked immunosorbent assay using monoclonal antibodies against SAG1-related sequence, SAG2A, and p97 antigens from Toxoplasma gondii to detect specific immunoglobulin $\mathrm{G}(\lg G)$, $\lg \mathrm{M}$, and $\lg A$ antibodies in human sera. Clin Vaccine Immunol 15: 1265-71.

Chen, X. G., Gong, Y., Hua, L., Lun, Z. R., Fung, M. C. (2001). High-level expression and purification of immunogenic recombinant SAG1 (P30) of Toxoplasma gondii in Escherichia coli. Protein Expr Purif 23: 33-7.

Cleary, M. D., Singh, U., Blader, I. J., Brewer, J. L., Boothroyd, J. C. (2002). Toxoplasma gondii asexual development: identification of developmentally regulated genes and distinct patterns of gene expression. Eukaryot Cell 1: 329-40.

Commodaro, A. G., Belfort, R. N., Rizzo, L. V., Muccioli, C., Silveira, C., Burnier Jr, M. N., Belfort Jr, R. (2009). Ocular toxoplasmosis: an update and review of the literature. Mem Inst Oswaldo Cruz 104: 345-50.

Coppens, I., Andries, M., Liu, J. L., Cesbron-Delauw, M. F. (1999). Intracellular trafficking of dense granule proteins in Toxoplasma gondii and experimental evidences for a regulated exocytosis. Eur J Cell Biol 78: 463-72.

Correa, D., Canedo-Solares, I., Ortiz-Alegria, L. B., Caballero-Ortega, H., Rico-Torres, C. P. (2007). Congenital and acquired toxoplasmosis: diversity and role of antibodies in different compartments of the host. Parasite Immunol 29: 651-60.

Couvreur, J., Desmonts, G., Thulliez, P. (1988). Prophylaxis of congenital toxoplasmosis. Effects of spiramycin on placental infection. J Antimicrob Chemother 22 Suppl B: 193-200.

Darde, M. L., Bouteille, B., Pestre-Alexandre, M. (1992). Isoenzyme analysis of 35 Toxoplasma gondii isolates and the biological and epidemiological implications. J Parasitol 78: 786-94.

Decoster, A., Darcy, F., Caron, A., Vinatier, D., Houze de L'Aulnoit, D., Vittu, G., Niel, G., Heyer, F., Lecolier, B., Delcroix, M., et al. (1992). Anti-P30 IgA antibodies as prenatal markers of congenital toxoplasma infection. Clin Exp Immunol 87: 310-5.

Denton, H., Roberts, C. W., Alexander, J., Thong, K. W., Coombs, G. H. (1996). Enzymes of energy metabolism in the bradyzoites and tachyzoites of Toxoplasma gondii. FEMS Microbiol Lett 137: 103-8. 
Di Carlo, P., Casuccio, A., La Chiusa, S., Mazzola, A., Pampinella, D., Romano, A., Schimmenti, M. G., Titone, L., Mancuso, G. (2007). Diagnosis of congenital toxoplasmosis: pre- and post-natal evaluation in Sicilian (Italy) epidemiological area. Preliminary data. Parassitologia 49: 39-41.

Dobrowolski, J. M., Sibley, L. D. (1996). Toxoplasma invasion of mammalian cells is powered by the actin cytoskeleton of the parasite. Cell 84: 933-9.

Dubey, J. P. (2009). Toxoplasmosis in pigs-the last 20 years. Vet Parasitol 164: 89-103.

Dubey, J. P., Hamir, A. N., Shen, S. K., Thulliez, P., Rupprecht, C. E. (1993a). Experimental Toxoplasma gondii infection in raccoons (Procyon lotor). J Parasitol 79: 548-52.

Dubey, J. P., Lindsay, D. S., Speer, C. A. (1998). Structures of Toxoplasma gondii tachyzoites, bradyzoites, and sporozoites and biology and development of tissue cysts. Clin Microbiol Rev 11: 267-99.

Dubey, J. P., Ruff, M. D., Camargo, M. E., Shen, S. K., Wilkins, G. L., Kwok, O. C., Thulliez, P. (1993b). Serologic and parasitologic responses of domestic chickens after oral inoculation with Toxoplasma gondii oocysts. Am J Vet Res 54: 1668-72.

Dubremetz, J. F., Garcia-Reguet, N., Conseil, V., Fourmaux, M. N. (1998). Apical organelles and host-cell invasion by Apicomplexa. Int $J$ Parasitol 28: 1007-13.

Dunn, D., Wallon, M., Peyron, F., Petersen, E., Peckham, C., Gilbert, R. (1999). Mother-tochild transmission of toxoplasmosis: risk estimates for clinical counselling. Lancet 353: 1829-33.

Dutton, G. N. (1989). Toxoplasmic retinochoroiditis-a historical review and current concepts. Ann Acad Med Singapore 18: 214-21.

Ferguson, D. J., Birch-Andersen, A., Siim, J. C., Hutchison, W. M. (1979). An ultrastructural study on the excystation of the sporozoites of Toxoplasma gondii. Acta Pathol Microbiol Scand B 87: 277-83.

Ferguson, D. J., Hutchison, W. M. (1987). An ultrastructural study of the early development and tissue cyst formation of Toxoplasma gondii in the brains of mice. Parasitol Res 73: 483-91.

Ferrandiz, J., Mercier, C., Wallon, M., Picot, S., Cesbron-Delauw, M. F., Peyron, F. (2004). Limited value of assays using detection of immunoglobulin $G$ antibodies to the two recombinant dense granule antigens, GRA1 and GRA6 Nt of Toxoplasma gondii, for distinguishing between acute and chronic infections in pregnant women. Clin Diagn Lab Immunol 11: 1016-21.

Fichera, M. E., Roos, D. S. (1997). A plastid organelle as a drug target in apicomplexan parasites. Nature 390: 407-9.

Filisetti, D., Gorcii, M., Pernot-Marino, E., Villard, O., Candolfi, E. (2003). Diagnosis of congenital toxoplasmosis: comparison of targets for detection of Toxoplasma gondii by PCR. $J$ Clin Microbiol 41: 4826-8.

Freeman, K., Tan, H. K., Prusa, A., Petersen, E., Buffolano, W., Malm, G., Cortina-Borja, M., Gilbert, R. (2008). Predictors of retinochoroiditis in children with congenital toxoplasmosis: European, prospective cohort study. Pediatrics 121: e1215-22. 
Frenkel, J. K., Dubey, J. P., Miller, N. L. (1970). Toxoplasma gondii in cats: fecal stages identified as coccidian oocysts. Science 167: 893-6.

Freyre, A., Dubey, J. P., Smith, D. D., Frenkel, J. K. (1989). Oocyst-induced Toxoplasma gondii infections in cats. J Parasitol 75: 750-5.

Friese, K., Kachel, W. (1997). Infektionserkrankungen der Schwangeren und des Neugeborenen. 2. überarb. und erw. Aufl. Springer Verlag, Berlin: 292-315.

Gamble, H. R., Andrews, C. D., Dubey, J. P., Webert, D. W., Parmley, S. F. (2000). Use of recombinant antigens for detection of Toxoplasma gondii infection in swine. J Parasitol 86: 45962.

Gamble, H. R., Dubey, J. P., Lambillotte, D. N. (2005). Comparison of a commercial ELISA with the modified agglutination test for detection of Toxoplasma infection in the domestic pig. Vet Parasitol 128: 177-81.

Garcia, J. L., Gennari, S. M., Navarro, I. T., Machado, R. Z., Headley, S. A., Vidotto, O., da Silva Guimaraes Junior, J., Bugni, F. M., Igarashi, M. (2008). Evaluation of IFA, MAT, ELISAs and immunoblotting for the detection of anti-Toxoplasma gondii antibodies in paired serum and aqueous humour samples from experimentally infected pigs. Res Vet Sci 84: 237-42.

Garcia, J. L., Navarro, I. T., Vidotto, O., Gennari, S. M., Machado, R. Z., da Luz Pereira, A. B., Sinhorini, I. L. (2006). Toxoplasma gondii: comparison of a rhoptry-ELISA with IFAT and MAT for antibody detection in sera of experimentally infected pigs. Exp Parasitol 113: 100-5.

Garty, B. Z., Ludomirsky, A., Danon, Y. L., Peter, J. B., Douglas, S. D. (1994). Placental transfer of immunoglobulin G subclasses. Clin Diagn Lab Immunol 1: 667-9.

Gatkowska, J., Dziadek, B., Brzostek, A., Dziadek, J., Dzitko, K., Dlugonska, H. (2010). Determination of diagnostic value of Toxoplasma gondii recombinant ROP2 and ROP4 antigens in mouse experimental model. Pol J Microbiol 59: 137-41.

Gatkowska, J., Hiszczynska-Sawicka, E., Kur, J., Holec, L., Dlugonska, H. (2006). Toxoplasma gondii: an evaluation of diagnostic value of recombinant antigens in a murine model. Exp Parasitol 114: 220-7.

Gazzinelli, R. T., Brezin, A., Li, Q., Nussenblatt, R. B., Chan, C. C. (1994). Toxoplasma gondii: acquired ocular toxoplasmosis in the murine model, protective role of TNF-alpha and IFNgamma. Exp Parasitol 78: 217-29.

Gilbert, R. E., Stanford, M. R. (2000). Is ocular toxoplasmosis caused by prenatal or postnatal infection? Br J Ophthalmol 84: 224-6.

Golkar, M., Azadmanesh, K., Khalili, G., Khoshkholgh-Sima, B., Babaie, J., Mercier, C., Brenier-Pinchart, M. P., Fricker-Hidalgo, H., Pelloux, H., Cesbron-Delauw, M. F. (2008). Serodiagnosis of recently acquired Toxoplasma gondii infection in pregnant women using enzyme-linked immunosorbent assays with a recombinant dense granule GRA6 protein. Diagn Microbiol Infect Dis 61: 31-9. 
Golkar, M., Rafati, S., Abdel-Latif, M. S., Brenier-Pinchart, M. P., Fricker-Hidalgo, H., Sima, B. K., Babaie, J., Pelloux, H., Cesbron-Delauw, M. F., Mercier, C. (2007). The dense granule protein GRA2, a new marker for the serodiagnosis of acute Toxoplasma infection: comparison of sera collected in both France and Iran from pregnant women. Diagn Microbiol Infect Dis 58: 41926.

Grigg, M. E., Bonnefoy, S., Hehl, A. B., Suzuki, Y., Boothroyd, J. C. (2001). Success and virulence in Toxoplasma as the result of sexual recombination between two distinct ancestries. Science 294: 161-5.

Gross, U., Bohne, W., Soete, M., Dubremetz, J. F. (1996). Developmental differentiation between tachyzoites and bradyzoites of Toxoplasma gondii. Parasitol Today 12: 30-3.

Gross, U., Roos, T., Appoldt, D., Heesemann, J. (1992). Improved serological diagnosis of Toxoplasma gondii infection by detection of immunoglobulin $\mathrm{A}(\lg \mathrm{A})$ and $\lg \mathrm{M}$ antibodies against P30 by using the immunoblot technique. J Clin Microbio/ 30: 1436-41.

Gross, U., Roos, T., Friese, K. (2001). Toxoplasmose in der Schwangerschaft. Deutsches Ärzteblatt Jg. 98 49: 3293.

Guerardel, Y., Leleu, D., Coppin, A., Lienard, L., Slomianny, C., Strecker, G., Ball, S., Tomavo, S. (2005). Amylopectin biogenesis and characterization in the protozoan parasite Toxoplasma gondii, the intracellular development of which is restricted in the HepG2 cell line. Microbes Infect 7: 41-8.

Guex-Crosier, Y. (2009). Update on the treatment of ocular toxoplasmosis. Int J Med Sci 6: 1402.

Gurevich, P., Elhayany, A., Ben-Hur, H., Moldavsky, M., Szvalb, S., Zandbank, J., Schneider, D. F., Zusman, I. (2003). Secretory component, J chain, and immunoglobulins in human embryos and fetuses of the first trimester of pregnancy: immunohistochemical study. Pediatr Dev Pathol 6: 35-42.

Gutierrez, J., Rodriguez, M., Piedrola, G., del Carmen Maroto, M. (1997). Detection of IgA and low-avidity IgG antibodies for the diagnosis of recent active toxoplasmosis. Clin Microbiol Infect 3: 658-62.

Guy, E. C., Pelloux, H., Lappalainen, M., Aspock, H., Hassl, A., Melby, K. K., HolbergPettersen, M., Petersen, E., Simon, J., Ambroise-Thomas, P. (1996). Interlaboratory comparison of polymerase chain reaction for the detection of Toxoplasma gondii DNA added to samples of amniotic fluid. Eur J Clin Microbiol Infect Dis 15: 836-9.

Hakansson, S., Charron, A. J., Sibley, L. D. (2001). Toxoplasma evacuoles: a two-step process of secretion and fusion forms the parasitophorous vacuole. EMBO $\mathrm{J}$ 20: 3132-44.

Hill, D., Zarlenga, E., Coss, C., Dubey, J. P. (2010). Toxoplasma gondii oocyst protein. United States Patent Patent No. : US 7,741,063 B2.

Hiszczynska-Sawicka, E., Kur, J., Pietkiewicz, H., Holec, L., Gasior, A., Myjak, P. (2005). Efficient production of the Toxoplasma gondii GRA6, p35 and SAG2 recombinant antigens and their applications in the serodiagnosis of toxoplasmosis. Acta Parasitol. 50: 249-54. 
Holec-Gasior, L., Kur, J., Hiszczynska-Sawicka, E. (2009). GRA2 and ROP1 recombinant antigens as potential markers for detection of Toxoplasma gondii-specific immunoglobulin $\mathrm{G}$ in humans with acute toxoplasmosis. Clin Vaccine Immunol 16: 510-4.

Holec, L., Hiszczynska-Sawicka, E., Gasior, A., Brillowska-Dabrowska, A., Kur, J. (2007). Use of MAG1 recombinant antigen for diagnosis of Toxoplasma gondii infection in humans. Clin Vaccine Immunol 14: 220-5.

Homan, W. L., Vercammen, M., De Braekeleer, J., Verschueren, H. (2000). Identification of a 200- to 300-fold repetitive 529 bp DNA fragment in Toxoplasma gondii, and its use for diagnostic and quantitative PCR. Int $J$ Parasitol 30: 69-75.

Howe, D. K., Summers, B. C., Sibley, L. D. (1996). Acute virulence in mice is associated with markers on chromosome VIII in Toxoplasma gondii. Infect Immun 64: 5193-8.

Huskinson, J., Thulliez, P., Remington, J. S. (1990). Toxoplasma antigens recognized by human immunoglobulin A antibodies. J Clin Microbio/ 28: 2632-6.

Hutchison, W. M., Dunachie, J. F., Siim, J. C., Work, K. (1970). Coccidian-like nature of Toxoplasma gondii. Br Med J 1: 142-4.

Innes, E. A. (2010). A brief history and overview of Toxoplasma gondii. Zoonoses Public Health 57: $1-7$

Israelski, D. M., Remington, J. S. (1993). Toxoplasmosis in the non-AIDS immunocompromised host. Curr Clin Top Infect Dis 13: 322-56.

Jackson, M. H., Hutchison, W. M. (1989). The prevalence and source of Toxoplasma infection in the environment. Adv Parasitol 28: 55-105.

Jacobs, D., Dubremetz, J. F., Loyens, A., Bosman, F., Saman, E. (1998). Identification and heterologous expression of a new dense granule protein (GRA7) from Toxoplasma gondii. Mol Biochem Parasitol 91: 237-49.

Jacobs, L., Remington, J. S., Melton, M. L. (1960). The resistance of the encysted form of Toxoplasma gondii. J Parasitol 46: 11-21.

Jameson, B. A., Wolf, H. (1988). The antigenic index: a novel algorithm for predicting antigenic determinants. Comput Appl Biosci 4: 181-6.

Jerome, M. E., Radke, J. R., Bohne, W., Roos, D. S., White, M. W. (1998). Toxoplasma gondii bradyzoites form spontaneously during sporozoite-initiated development. Infect Immun 66: 483844.

Joiner, K. A., Roos, D. S. (2002). Secretory traffic in the eukaryotic parasite Toxoplasma gondii: less is more. $J$ Cell Biol 157: 557-63.

Kasper, D. C., Prusa, A. R., Hayde, M., Gerstl, N., Pollak, A., Herkner, K. R., ReiterReisacher, R. (2009). Evaluation of the Vitros ECiQ immunodiagnostic system for detection of anti-Toxoplasma immunoglobulin $\mathrm{G}$ and immunoglobulin $\mathrm{M}$ antibodies for confirmatory testing for acute Toxoplasma gondii infection in pregnant women. J Clin Microbiol 47: 164-7. 
Kasper, L. H. (1989). Identification of stage-specific antigens of Toxoplasma gondii. Infect Immun 57: 668-72.

Kasper, L. H., Bradley, M. S., Pfefferkorn, E. R. (1984). Identification of stage-specific sporozoite antigens of Toxoplasma gondii by monoclonal antibodies. J Immunol 132: 443-9.

Kato, M., Claveria, F. G., Maki, Y., Sanda, K., Tanaka, T., Omata, Y., Nagasawa, H., Suzuki, N. (2007). Reactivity of synthetic SAG1 (p30) peptide sequences with RH, S273 and Beverley strain-induced anti-Toxoplasma gondii antibodies. Pathobiology 74: 50-6.

Kijlstra, A., Luyendijk, L., Baarsma, G. S., Rothova, A., Schweitzer, C. M., Timmerman, Z., de Vries, J., Breebaart, A. C. (1989). Aqueous humor analysis as a diagnostic tool in toxoplasma uveitis. Int Ophthalmol 13: 383-6.

Kodjikian, L. (2010). Toxoplasmosis and pregnancy. J Fr Ophtalmol 33: 362-7.

Kodym, P., Machala, L., Rohacova, H., Sirocka, B., Maly, M. (2007). Evaluation of a commercial IgE ELISA in comparison with $\lg A$ and $\lg M$ ELISAs, IgG avidity assay and complement fixation for the diagnosis of acute toxoplasmosis. Clin Microbiol Infect 13: 40-7.

Kong, J. T., Grigg, M. E., Uyetake, L., Parmley, S., Boothroyd, J. C. (2003). Serotyping of Toxoplasma gondii infections in humans using synthetic peptides. J Infect Dis 187: 1484-95.

Kotresha, D., Noordin, R. (2010). Recombinant proteins in the diagnosis of toxoplasmosis. APMIS 118: 529-42.

Laemmli, U. K. (1970). Cleavage of structural proteins during the assembly of the head of bacteriophage T4. Nature 227: 680-5.

Lagal, V., Binder, E. M., Huynh, M. H., Kafsack, B. F., Harris, P. K., Diez, R., Chen, D., Cole, R. N., Carruthers, V. B., Kim, K. (2010). Toxoplasma gondii protease TgSUB1 is required for cell surface processing of micronemal adhesive complexes and efficient adhesion of tachyzoites. Cell Microbiol 12: 1792-808.

Lebech, M., Andersen, O., Christensen, N. C., Hertel, J., Nielsen, H. E., Peitersen, B., Rechnitzer, C., Larsen, S. O., Norgaard-Pedersen, B., Petersen, E. (1999). Feasibility of neonatal screening for toxoplasma infection in the absence of prenatal treatment. Danish Congenital Toxoplasmosis Study Group. Lancet 353: 1834-7.

Lecordier, L., Fourmaux, M. P., Mercier, C., Dehecq, E., Masy, E., Cesbron-Delauw, M. F. (2000). Enzyme-linked immunosorbent assays using the recombinant dense granule antigens GRA6 and GRA1 of Toxoplasma gondii for detection of immunoglobulin G antibodies. Clin Diagn Lab Immunol 7: 607-11.

Lekutis, C., Ferguson, D. J., Boothroyd, J. C. (2000). Toxoplasma gondii: identification of a developmentally regulated family of genes related to SAG2. Exp Parasitol 96: 89-96.

Lindsay, D. S., Dubey, J. P., Blagburn, B. L., Toivio-Kinnucan, M. (1991). Examination of tissue cyst formation by Toxoplasma gondii in cell cultures using bradyzoites, tachyzoites, and sporozoites. J Parasitol 77: 126-32. 
Lingelbach, K., Joiner, K. A. (1998). The parasitophorous vacuole membrane surrounding Plasmodium and Toxoplasma: an unusual compartment in infected cells. J Cell Sci 111 ( Pt 11): 1467-75.

Lourenco, E. V., Pereira, S. R., Faca, V. M., Coelho-Castelo, A. A., Mineo, J. R., RoqueBarreira, M. C., Greene, L. J., Panunto-Castelo, A. (2001). Toxoplasma gondii micronemal protein MIC1 is a lactose-binding lectin. Glycobiology 11: 541-7.

Lovett, J. L., Marchesini, N., Moreno, S. N., Sibley, L. D. (2002). Toxoplasma gondii microneme secretion involves intracellular $\mathrm{Ca}(2+)$ release from inositol 1,4,5-triphosphate (IP(3))/ryanodine-sensitive stores. J Biol Chem 277: 25870-6.

Lu, B., Wu, S., Shi, Y., Zhang, R., Zou, L., Gao, S., Lin, M., Zhou, Y. (2006). Toxoplasma gondii: expression pattern and detection of infection using full-length recombinant P35 antigen. Exp Parasitol 113: 83-90.

Lu, F., Huang, S., Kasper, L. H. (2004). CD4+ T cells in the pathogenesis of murine ocular toxoplasmosis. Infect Immun 72: 4966-72.

Ludewig, M., de Buhr, K., Fehlhaber, K. (2007). Toxoplasma gondii - Seroprävalenz in Mastschweinebeständen. Ergebnisse aus einer deutschlandweiten Studie. J. Verbr. Lebensm. 2: 454-56.

Luft, B. J., Hafner, R., Korzun, A. H., Leport, C., Antoniskis, D., Bosler, E. M., Bourland, D. D., 3rd, Uttamchandani, R., Fuhrer, J., Jacobson, J., et al. (1993). Toxoplasmic encephalitis in patients with the acquired immunodeficiency syndrome. Members of the ACTG 077p/ANRS 009 Study Team. N Engl J Med 329: 995-1000.

Luft, B. J., Remington, J. S. (1992). Toxoplasmic encephalitis in AIDS. Clin Infect Dis 15: 21122.

Madigan, M. T., Martinko, J. M., Parker, J., Goebel, W. (2003). Brock Mikrobiologie. Spektrum Akademischer Verlag, Heidelberg - Berlin.

Marechal, E., Cesbron-Delauw, M. F. (2001). The apicoplast: a new member of the plastid family. Trends Plant Sci 6: 200-5.

Martin, S. (2001). Congenital toxoplasmosis. Neonatal Netw 20: 23-30.

Mason, S., Quinnell, R. J., Smith, J. E. (2010). Detection of Toxoplasma gondii in lambs via PCR screening and serological follow-up. Vet Parasitol 169: 258-63.

Mazzola, A., Casuccio, A., Romano, A., Schimmenti, M. G., Titone, L., Di Carlo, P. (2007). Diagnostic problems and postnatal follow-up in congenital toxoplasmosis. Minerva Pediatr 59: 207-13.

Meneceur, P., Bouldouyre, M. A., Aubert, D., Villena, I., Menotti, J., Sauvage, V., Garin, J. F., Derouin, F. (2008). In vitro susceptibility of various genotypic strains of Toxoplasma gondii to pyrimethamine, sulfadiazine, and atovaquone. Antimicrob Agents Chemother 52: 1269-77.

Mercier, C., Dubremetz, J. F., Rauscher, B., Lecordier, L., Sibley, L. D., Cesbron-Delauw, M. F. (2002). Biogenesis of nanotubular network in Toxoplasma parasitophorous vacuole induced by parasite proteins. Mol Biol Cell 13: 2397-409. 
Michel, R., Schupp, K., Raether, W., Bierther, F. W. (1980). Formation of a close junction during invasion of erythrocytes by Toxoplasma gondii in vitro. Int $J$ Parasitol 10: 309-13.

Miller, S. A., Binder, E. M., Blackman, M. J., Carruthers, V. B., Kim, K. (2001). A conserved subtilisin-like protein TgSUB1 in microneme organelles of Toxoplasma gondii. J Biol Chem 276: 45341-8.

Mineo, J. R., McLeod, R., Mack, D., Smith, J., Khan, I. A., Ely, K. H., Kasper, L. H. (1993). Antibodies to Toxoplasma gondii major surface protein (SAG-1, P30) inhibit infection of host cells and are produced in murine intestine after peroral infection. $J$ Immunol 150: 3951-64.

Mombro, M., Perathoner, C., Leone, A., Nicocia, M., Moiraghi Ruggenini, A., Zotti, C., Lievre, M. A., Fabris, C. (1995). Congenital toxoplasmosis: 10-year follow up. Eur J Pediatr 154: 635-9.

Morrissette, N. S., Sibley, L. D. (2002). Disruption of microtubules uncouples budding and nuclear division in Toxoplasma gondii. J Cell Sci 115: 1017-25.

Neves, E. S., Bicudo, L. N., Curi, A. L., Carregal, E., Bueno, W. F., Ferreira, R. G., Amendoeira, M. R., Benchimol, E., Fernandes, O. (2009). Acute acquired toxoplasmosis: clinical-laboratorial aspects and ophthalmologic evaluation in a cohort of immunocompetent patients. Mem Inst Oswaldo Cruz 104: 393-6.

Nicolle, C., Manceaux, L. (1908). Sur un nouveau du gondi. C. R. Hebd. Séances Acad. Sci. 148: 369-72.

Nielsen, H. V., Schmidt, D. R., Petersen, E. (2005). Diagnosis of congenital toxoplasmosis by two-dimensional immunoblot differentiation of mother and child immunoglobulin g profiles. J Clin Microbiol 43: 711-5.

Nigro, M., Gutierrez, A., Hoffer, A. M., Clemente, M., Kaufer, F., Carral, L., Martin, V., Guarnera, E. A., Angel, S. O. (2003). Evaluation of Toxoplasma gondii recombinant proteins for the diagnosis of recently acquired toxoplasmosis by an immunoglobulin $G$ analysis. Diagn Microbiol Infect Dis 47: 609-13.

Nockemann, S., Dlugonska, H., Henrich, B., Kitzerow, A., Daubener, W. (1998). Expression, characterization and serological reactivity of a $41 \mathrm{kDa}$ excreted-secreted antigen (ESA) from Toxoplasma gondii. Mol Biochem Parasitol 97: 109-21.

Parmley, S. F., Sgarlato, G. D., Mark, J., Prince, J. B., Remington, J. S. (1992). Expression, characterization, and serologic reactivity of recombinant surface antigen P22 of Toxoplasma gondii. J Clin Microbio/ 30: 1127-33.

Parmley, S. F., Weiss, L. M., Yang, S. (1995). Cloning of a bradyzoite-specific gene of Toxoplasma gondii encoding a cytoplasmic antigen. Mol Biochem Parasitol 73: 253-7.

Patzelt, J. (2005). Basics Augenheilkunde. Urban \& Fischer, München - Jena: 50-51.

Perkins, E. S. (1973). Ocular toxoplasmosis. Br J Ophthalmol 57: 1-17.

Pettersen, E. K. (1979). Destruction of Toxoplasma gondii by HC1 solution. Acta Pathol Microbiol Scand B 87: 217-20. 
Peyron, F., Garweg, J. G., Wallon, M., Descloux, E., Rolland, M., Barth, J. (2011). Long-term Impact of Treated Congenital Toxoplasmosis on Quality of Life and Visual Performance. Pediatr Infect Dis J. Epub 2011 Jan 27.

Pfefferkorn, E. R. (Ed.). (1990). Cell biology of Toxoplasma gondii. New York: Wyler, D. J.

Pfrepper, K. I., Enders, G., Gohl, M., Krczal, D., Hlobil, H., Wassenberg, D., Soutschek, E. (2005). Seroreactivity to and avidity for recombinant antigens in toxoplasmosis. Clin Diagn Lab Immunol 12: 977-82.

Pietkiewicz, H., Hiszczynska-Sawicka, E., Kur, J., Petersen, E., Nielsen, H. V., Paul, M., Stankiewicz, M., Myjak, P. (2007). Usefulness of Toxoplasma gondii recombinant antigens (GRA1, GRA7 and SAG1) in an immunoglobulin G avidity test for the serodiagnosis of toxoplasmosis. Parasitol Res 100: 333-7.

Pietkiewicz, H., Hiszczynska-Sawicka, E., Kur, J., Petersen, E., Nielsen, H. V., Stankiewicz, M., Andrzejewska, I., Myjak, P. (2004). Usefulness of Toxoplasma gondii-specific recombinant antigens in serodiagnosis of human toxoplasmosis. J Clin Microbiol 42: 1779-81.

Pinon, J. M., Toubas, D., Marx, C., Mougeot, G., Bonnin, A., Bonhomme, A., Villaume, M., Foudrinier, F., Lepan, H. (1990). Detection of specific immunoglobulin E in patients with toxoplasmosis. J Clin Microbiol 28: 1739-43.

Portela, R. W., Bethony, J., Costa, M. I., Gazzinelli, A., Vitor, R. W., Hermeto, F. M., CorreaOliveira, R., Gazzinelli, R. T. (2004). A multihousehold study reveals a positive correlation between age, severity of ocular toxoplasmosis, and levels of glycoinositolphospholipid-specific immunoglobulin A. J Infect Dis 190: 175-83.

Quan, J. H., Hassan, H. A., Cha, G. H., Shin, D. W., Lee, Y. H. (2009). Antigenemia and specific $\operatorname{lgM}$ and IgG antibody responses in rabbits infected with Toxoplasma gondii. Korean $\mathrm{J}$ Parasitol 47: 409-12.

Quentin, C. D., Reiber, H. (1997). Kammerwasseranalytik bei intraokularer Toxoplasmose. Ophthalmology 94: 728-31.

Radke, J. R., Gubbels, M. J., Jerome, M. E., Radke, J. B., Striepen, B., White, M. W. (2004). Identification of a sporozoite-specific member of the Toxoplasma SAG superfamily via genetic complementation. Mol Microbiol 52: 93-105.

Radke, J. R., White, M. W. (1998). A cell cycle model for the tachyzoite of Toxoplasma gondii using the Herpes simplex virus thymidine kinase. Mol Biochem Parasitol 94: 237-47.

Redlich, A., Muller, W. A. (1998). Serodiagnosis of acute toxoplasmosis using a recombinant form of the dense granule antigen GRA6 in an enzyme-linked immunosorbent assay. Parasitol Res 84: 700-6.

Reichmann, G., Dlugonska, H., Fischer, H. G. (2002). Characterization of TgROP9 (p36), a novel rhoptry protein of Toxoplasma gondii tachyzoites identified by $\mathrm{T}$ cell clone. Mol Biochem Parasitol 119: 43-54.

Righetti, P., Gianazza, E., Gelfi, C., Chairi, M. (1990). Gel elektrophoresis of proteins: a practical approach. Oxford University Press 
RKI, (2007). Robert-Koch-Institut (RKI)-Ratgeber Toxoplasmose. Epidemiologisches Bulletin 42/2007:390-394 (http://www.rki.de/cln_049/nn_504566/DE/Content/Infekt/EpidBull/Merkblaetter/ Ratgeber_Mbl_Toxoplasmose.html\#doc208160bodyText9)

Roberts, A., Hedman, K., Luyasu, V., Zufferey, J., Bessieres, M. H., Blatz, R. M., Candolfi, E., Decoster, A., Enders, G., Gross, U., Guy, E., Hayde, M., Ho-Yen, D., Johnson, J., Lecolier, B., Naessens, A., Pelloux, H., Thulliez, P., Petersen, E. (2001). Multicenter evaluation of strategies for serodiagnosis of primary infection with Toxoplasma gondii. Eur J Clin Microbiol Infect Dis 20: 467-74.

Ruf, B., Pohle, H. D. (1995). Therapie und Prophylaxe der Toxoplasmose bei HIV-Infektionen. AIFO 9: 479-90.

Sabin, A. B., Feldman, H. A. (1948). Dyes as Microchemical Indicators of a New Immunity Phenomenon Affecting a Protozoon Parasite (Toxoplasma). Science 108: 660-3.

Sadeghiani, G., Zare, M., Babaie, J., Shokrgozar, M. A., Azadmanesh, K., Fard-Esfahani, P., Golkar, M. (2009). Heterologous production of dense granule GRA7 antigen of Toxoplasma gondii in Escherichia coli. Southeast Asian J Trop Med Public Health 40: 692-700.

Saiki, R. K., Gelfand, D. H., Stoffel, S., Scharf, S. J., Higuchi, R., Horn, G. T., Mullis, K. B., Erlich, H. A. (1988). Primer-directed enzymatic amplification of DNA with a thermostable DNA polymerase. Science 239: 487-91.

Sanger, F., Nicklen, S., Coulson, A. R. (1977). DNA sequencing with chain-terminating inhibitors. Proc Natl Acad Sci U S A 74: 5463-7.

Santoni, J. R., Santoni-Williams, C. J. (1993). Headache and painful lymphadenopathy in extracranial or systemic infection: etiology of new daily persistent headaches. Intern Med $\mathbf{3 2}$ : $530-2$.

Schmidt-Matthiesen, H., Wallwiener, D. (2005). Gynäkologie und Geburtshilfe. 10. Aufl. Schattauer GmbH, Stuttgart: 152-155.

Schoondermark-van de Ven, E., Galama, J., Vree, T., Camps, W., Baars, I., Eskes, T., Meuwissen, J., Melchers, W. (1995). Study of treatment of congenital Toxoplasma gondii infection in rhesus monkeys with pyrimethamine and sulfadiazine. Antimicrob Agents Chemother 39: $137-44$.

Schwab, J. C., Beckers, C. J., Joiner, K. A. (1994). The parasitophorous vacuole membrane surrounding intracellular Toxoplasma gondii functions as a molecular sieve. Proc Natl Acad Sci U $S$ A 91: 509-13.

Seeber, F. (2003). Biosynthetic pathways of plastid-derived organelles as potential drug targets against parasitic apicomplexa. Curr Drug Targets Immune Endocr Metabol Disord 3: 99-109.

Sever, J. L., Ellenberg, J. H., Ley, A. C., Madden, D. L., Fuccillo, D. A., Tzan, N. R., Edmonds, D. M. (1988). Toxoplasmosis: maternal and pediatric findings in 23,000 pregnancies. Pediatrics 82: 181-92.

Sheffield, H. G., Melton, M. L. (1975). Effect of pyrimethamine and sulfadiazine on the fine structure and multiplication of Toxoplasma gondii in cell cultures. J Parasito/ 61: 704-12. 
Sibley, L. D., Boothroyd, J. C. (1992). Construction of a molecular karyotype for Toxoplasma gondii. Mol Biochem Parasitol 51: 291-300.

Siegenthaler, W., Blum, H. E. (2006). Klinische Pathophysiologie. 9. Aufl. Georg Thieme Verlag, Stuttgart: 407-414.

Simister, N. E. (2003). Placental transport of immunoglobulin G. Vaccine 21: 3365-9.

Smith, J. E. (1995). A ubiquitous intracellular parasite: the cellular biology of Toxoplasma gondii. Int J Parasitol 25: 1301-9.

Soete, M., Dubremetz, J. F. (1996). Toxoplasma gondii: kinetics of stage-specific protein expression during tachyzoite-bradyzoite conversion in vitro. Curr Top Microbiol Immunol 219: 76 80 .

Soldati, D., Dubremetz, J. F., Lebrun, M. (2001). Microneme proteins: structural and functional requirements to promote adhesion and invasion by the apicomplexan parasite Toxoplasma gondii. Int J Parasitol 31: 1293-302.

Splendore, A. (1908). Un nuovo protozoa parassita deconigli incontrato nelle lesioni anatomiche d'une malattia che ricorda in molti punti il Kala-azar dell' uoma. Nota preliminare. Rev Soc Sci Sao Paulo 3: 109-12.

Su, C., Evans, D., Cole, R. H., Kissinger, J. C., Ajioka, J. W., Sibley, L. D. (2003). Recent expansion of Toxoplasma through enhanced oral transmission. Science 299: 414-6.

Switaj, K., Master, A., Borkowski, P. K., Skrzypczak, M., Wojciechowicz, J., Zaborowski, P. (2006). Association of ocular toxoplasmosis with type I Toxoplasma gondii strains: direct genotyping from peripheral blood samples. J Clin Microbiol 44: 4262-4.

Taila, A. K., Hingwe, A. S., Johnson, L. E. (2011). Toxoplasmosis in a patient who was immunocompetent: a case report. J Med Case Reports 5: 16.

Tenter, A. M., Heckeroth, A. R., Weiss, L. M. (2000). Toxoplasma gondii: from animals to humans. Int J Parasito/ 30: 1217-58.

Thalib, L., Gras, L., Romand, S., Prusa, A., Bessieres, M. H., Petersen, E., Gilbert, R. E. (2005). Prediction of congenital toxoplasmosis by polymerase chain reaction analysis of amniotic fluid. BJOG 112: 567-74.

Thiebaut, R., Leproust, S., Chene, G., Gilbert, R. (2007). Effectiveness of prenatal treatment for congenital toxoplasmosis: a meta-analysis of individual patients' data. Lancet 369: 115-22.

Tomavo, S., Fortier, B., Soete, M., Ansel, C., Camus, D., Dubremetz, J. F. (1991). Characterization of bradyzoite-specific antigens of Toxoplasma gondii. Infect Immun 59: 3750-3.

Vallochi, A. L., Goldberg, A. C., Falcai, A., Ramasawmy, R., Kalil, J., Silveira, C., Belfort, R., Rizzo, L. V. (2008). Molecular markers of susceptibility to ocular toxoplasmosis, host and guest behaving badly. Clin Ophthalmol 2: 837-48. 
Vergani, P., Ghidini, A., Ceruti, P., Strobelt, N., Spelta, A., Zapparoli, B., Rescaldani, R. (1998). Congenital toxoplasmosis: efficacy of maternal treatment with spiramycin alone. Am J Reprod Immunol 39: 335-40.

Wallon, M., Dunn, D., Slimani, D., Girault, V., Gay-Andrieu, F., Peyron, F. (1999). Diagnosis of congenital toxoplasmosis at birth: what is the value of testing for IgM and IgA? Eur $\mathrm{J}$ Pediatr 158: $645-9$.

Weiss, L. M., Dubey, J. P. (2009). Toxoplasmosis: A history of clinical observations. Int $J$ Parasitol 39: 895-901.

Weiss, L. M., Kim, K. (2000). The development and biology of bradyzoites of Toxoplasma gondii. Front Biosci 5: D391-405.

Wu, K., Chen, X. G., Li, H., Yan, H., Yang, P. L., Lun, Z. R., Zhu, X. Q. (2009). Diagnosis of human toxoplasmosis by using the recombinant truncated surface antigen 1 of Toxoplasma gondii. Diagn Microbiol Infect Dis 64: 261-6.

Yan, C., Yue, C. L., Yuan, Z. G., Lin, R. Q., He, Y., Yin, C. C., Xu, M. J., Song, H. Q., Zhu, X. Q. (2010). Molecular and serological diagnosis of Toxoplasma gondii infection in experimentally infected chickens. Vet Parasitol 173: 179-83. 


\section{Kongressbeiträge}

Hruzik, A., Groß, U., Bohne, W. (2008). Identification of immunogenic parasitic antigens of Toxoplasma gondii. $16^{\text {th }}$ Japanese-German Cooperative Symposium on Protozoan Diseases, Göttingen.

Hruzik, A., Bohne, W., Spekker, K., Däubener, W., Groß, U. (2009). Establishing a lineblot assay with recombinant antigens for diagnosis of Toxoplasma gondii infection. Deutsche Gesellschaft für Hygiene und Mikrobiologie (DGHM), Göttingen.

Hruzik, A., Bohne, W., Spekker, K., Däubener, W., Köthe, M., Straubinger, R., Pleyer, U., Groß, U. (2009). Recombinant antigens of Toxoplasma gondii as diagnostic markers for human infection and potential means for risk assessment of slaughter animals. Nationales Symposium für Zoonosenforschung, Berlin.

Hruzik, A., Pleyer, U., Spekker, K., Däubener, W., Köthe, M., Straubinger, R., Bohne, W., Groß, U. (2009). Recombinant Toxoplasma gondii antigens for diagnosis of human and animal infection. Jahrestagung der Deutschen Gesellschaft für Tropenmedizin und internationalen Gesundheit, München.

Hruzik, A., Asif, A. R., Bohne, W., Spekker, K., Köthe, M., Däubener, W., Groß, U. (2010). Toxoplasma gondii recombinant antigens for diagnostic of human and animal infection. 3. Gemeinsame Tagung der Deutschen Gesellschaft für Hygiene und Mikrobiologie und der Vereinigung für Allgemeine und angewandte Mikrobiologie, Hannover.

Hruzik, A., Asif, A. R., Bohne, W., Spekker, K., Däubener, W., Köthe, M., Buschtöns, S., Tenter, A. M., Groß, U. (2010). Diagnostic tools for Toxoplasma gondii infection: investigation of recombinant antigens. 24. Jahrestagung der Deutschen Gesellschaft für Parasitologie, Düsseldorf.

Hruzik, A.. Spekker, K., Buschtöns, S., Görlich, K., Köthe, M., Straubinger, R., Däubener, W., Tenter, A. M., Groß, U. (2010). Recombinant antigens facilitate determination of Toxoplasma gondii infection in man and animals. Nationales Symposium für Zoonosenforschung, Berlin.

Hruzik, A., Groß, U., Hlobil, H. (2010). Retrospektive Untersuchung zur Effektivität der Toxoplasma-Therapie in der Schwangerschaft. Jahrestagung der Paul-Ehrlich Gesellschaft für Chemotherapie, Bonn.

Hruzik, A., Hlobil, H., Groß, U. (2010). Retrospective analysis for effectiveness of Toxoplasma therapy in pregnancy. $4^{\text {th }}$ International Congress on Congenital Toxoplasmosis (ICOCT), Marseille (Frankreich)

Hruzik, A., Groß, U. (2011). Investigation of Toxoplasma gondii recombinant antigens: choice of evaluation strategy. Statusworkshop 2011, Deutsche Gesellschaft für Hygiene und Mikrobiologie, Fachgruppe Eukaryontische Krankheitserreger, Düsseldorf. 


\section{Veröffentlichungen}

Hruzik, A., Asif, A. R., Groß, U. (2011). Identification of Toxoplasma gondii antigen SUB1 as a marker for the acute infection using an innovative evaluation method. $J$ Clin Microbiol. In press. Epub 2011 Mai 04.

Groß, U., Hruzik, A., Hlobil, H. (2009). Toxoplasmose und Schwangerschaft. Gynäkologe 42: 793-98.

Groß, U., Hruzik, A., Graumann, K., Reiter-Owona, I. (2008). Toxoplasmose in der Schwangerschaft und bei Immunsupprimierten. Chemotherapie Journal 3: 75-83. 


\section{Danksagung}

Mein besonderer Dank gilt Herrn Prof. Dr. Uwe Groß für die Überlassung des Themas, der persönlichen Betreuung und den anregenden Diskussionen während der Anfertigung dieser Arbeit.

Herrn Prof. Dr. Gerhard Braus danke ich für die Übernahme des Koreferates.

Herrn Prof. Dr. Jörg Stülke, Frau Prof. Dr. Stefanie Pöggeler, Frau Prof. Dr. Andrea Polle und Herrn PD Dr. Stefan Irniger möchte ich für die Bereitschaft, Mitglied meiner Prüfungskommission zu werden, danken.

Einen ebenso besonderen Dank gilt den Mitgliedern des Toxonet-Verbundes für die Bereitstellung von Arbeitsmaterialien: Frau Prof. Dr. Astrid M. Tenter, Susanne Buschtöns, Kirsten Görlich, Herrn Prof. Dr. Walter Däubener, Frau Dr. Katrin Spekker, Margret Leineweber, Vanessa Ince, Herrn Dr. Gereon Schares, Pavlo Maksimov, Herrn Prof. Dr. Reinhard Straubinger, Martin Köthe, Herrn Prof. Dr. A. Daugschies, Frau Dr. B. Bangoura, Herrn Prof. Dr. Uwe Pleyer und Sylvia Metzner.

Weiterhin möchte ich mich bei Herrn Dr. Harald Hlobil für die Möglichkeit bedanken, dass an Hand seiner gesammelten Daten, eine epidemiologische Studie zur kongenitalen Toxoplasmose durchgeführt werden konnte.

Ebenso möchte ich mich bei Herrn Dr. Abdul R. Asif und seinen Mitarbeitern für die Durchführung der Massenspektrometrieanalysen bedanken.

Bedanken möchte ich mich ganz herzlich bei meinen Kollegen für deren Hilfsbereitschaft und Diskussionen, sowie für ein angenehmes Arbeitsklima.

Den großmöglichsten Dank gilt meinen Eltern, die mir das Studium erst ermöglicht haben und mir immer zur Seite standen.

Ganz besonders möchte ich mich bei meinem Freund Sven Hotop für seine aufmunternden Worte in den letzten Jahren bedanken. Danke, dass du immer für mich da bist! 


\section{Lebenslauf}

Name: $\quad$ Andrea Hotop, geb. Hruzik

Geburtsdatum: $\quad 21.05 .1982$

Geburtsort: Salzgitter-Bad

Staatsangehörigkeit: deutsch

Schule: $\quad 1988-1992$ Besuch der Grundschule in Salzgitter-Flachstöckheim

1992 - 1994 Besuch der Orientierungsstufe Am Sonnenberg in Salzgitter-Gebhardshagen

1994 - 1995 Besuch des Gymnasiums in Salzgitter-Bad

1995 - 1998 Besuch der Anton-Raky Realschule in Salzgitter-Bad

1998 - 2001 Besuch des Fachgymnasiums für Ernährung und Hauswirtschaft in Salzgitter-Fredenberg

Studium: $\quad 2001-2007 \quad$ Studium der Biologie an der Technischen Universität Carolo-Wilhelmina zu Braunschweig

2004 Diplom-Vorprüfung

2006 Diplom-Hauptprüfung

2006 - 2007 Diplomarbeit am Institut für Mikrobiologie der Universität Braunschweig unter Prof. Dr. D. Jahn mit dem Thema: Charakterisierung der L-Proteinuntereinheit der lichtunabhängigen Protochlorophyllid Oxidoreduktase aus Chlorobium tepidum

Promotion seit 07/2007 Am Institut für Medizinische Mikrobiologie des Universitätsklinikums Göttingen über das Thema: Epidemiologische Untersuchungen zur Toxoplasmose und Identifizierung immunogener parasitärer Antigene 